University of Tennessee Health Science Center

UTHSC Digital Commons

\title{
$5-2011$
}

\section{Biomechanical Comparison of Traditional Laminectomy and Minimally-Invasive Facetectomies}

\author{
Karen Sedacki \\ University of Tennessee Health Science Center
}

Follow this and additional works at: https://dc.uthsc.edu/dissertations

Part of the Analytical, Diagnostic and Therapeutic Techniques and Equipment Commons

\section{Recommended Citation}

Sedacki, Karen , "Biomechanical Comparison of Traditional Laminectomy and Minimally-Invasive Facetectomies" (2011). Theses and Dissertations (ETD). Paper 236. http://dx.doi.org/10.21007/ etd.cghs.2011.0281.

This Thesis is brought to you for free and open access by the College of Graduate Health Sciences at UTHSC Digital Commons. It has been accepted for inclusion in Theses and Dissertations (ETD) by an authorized administrator of UTHSC Digital Commons. For more information, please contact jwelch30@uthsc.edu. 


\title{
Biomechanical Comparison of Traditional Laminectomy and Minimally-Invasive Facetectomies
}

\author{
Abstract \\ The facet joints of the lumbar spine are one of the sources of low-back pain that affects a great portion of \\ the population. Minimally-invasive (MI) procedures have been becoming more popular in the surgical \\ decompression of the spine because they offer shorter recovery time and involve removal of smaller \\ amounts of important structures. With these features, it is believed that MI procedures lead to less \\ clinical instability, and the functionality of the segment is maintained. Another important factor is how the \\ facet angle in the lumbar segments affects the biomechanical instability. In spite of all this interest in MI \\ procedures, there is little biomechanical research to back these claims. Therefore, in this study two MI \\ procedures were compared with the laminectomy, the gold-standard for lumbar decompression. Eight \\ lumbar cadaveric motion segment units were procured, mounted, and tested intact, and then following $\mathrm{MI}$ \\ unilateral facetectomy (UF), MI bilateral facetectomy (BF), and a traditional laminectomy (TL) using three \\ different loading scenarios. The three different loading scenarios utilized in this study were the pure \\ moment (PM), combined loading and moment (CLM), and the coupled-eccentric loading (CEL) protocols. \\ The PM testing protocol is the standard form of biomechanical testing of the spine. The CLM testing \\ protocol introduced compressive and shear forces to increase translation in the sagittal plane. The CEL \\ protocol was used because it combined a sagittal bend with a forced axial rotation. Rotational values \\ were analyzed at the end limit of $8 \mathrm{Nm}$ for flexion and extension and at $6 \mathrm{Nm}$ for left and right lateral \\ bending. Translations under PM and CLM were calculated utilizing a simulation software Visual Nastran. \\ The criterion for instability was used to see if UF, BF, and TL met this criterion as compared to what would \\ be clinically seen radiographically. In addition to these biomechanical data, CT images were analyzed to \\ determine the change in the facet angle, contact area of the facet, and length of the joint removed after \\ the BF. Increased motion was seen in the BF and TL compared to the harvested spine condition in all \\ protocols. A decrease in rotation was seen in the UF condition in all protocols, with the exceptions being \\ in right lateral for PM. None of the PM and CLM data met the criteria for instability. A decrease in facet \\ angle, contact area, and length of the facet after the BF was observed. The TL had the most number of \\ significant biomechanical increases when compared to the harvested condition, making it a less \\ favorable surgical procedure when compared to each of the MI procedures. No studies have used the \\ multiple loading scenarios, have quantified the amount of instability, or have taken account the amount of \\ resection and change in facet angle due to MI procedures. Further investigation of the biomechanical \\ effects of the MI procedures is still needed to gain more insight on how MI procedures affect spine \\ biomechanics.
}

\section{Document Type}

Thesis

\section{Degree Name}

Master of Science (MS)

\section{Program}

Biomedical Engineering and Imaging

\section{Research Advisor}

Denis J. DiAngelo, Ph.D.

\section{Keywords}

Biomechanics, Facetectomy, Laminectomy, Lumbar Spine, Minimally-Invasive 


\section{Subject Categories}

Analytical, Diagnostic and Therapeutic Techniques and Equipment | Medicine and Health Sciences 


\title{
BIOMECHANICAL COMPARISION OF TRADITIONAL LAMINECTOMY AND MINIMALLY-INVASIVE FACETECTOMIES
}

\author{
A Thesis \\ Presented for \\ The Graduate Studies Council \\ The University of Tennessee \\ Health Science Center
}

\begin{abstract}
In Partial Fulfillment
Of the Requirements for the Degree

Master of Science
\end{abstract}

In the Joint Graduate Program in Biomedical Engineering and Imaging

From The University of Tennessee

and

The University of Memphis

By

Karen Sedacki

May 2011 
Copyright $(02011$ by Karen Sedacki. All rights reserved. 


\section{ACKNOWLEDGEMENTS}

First of all I would like to thank my advisor, Dr. Denis DiAngelo, for his support and vital input not only regarding this thesis, but during the entire time in the UT Biomechanics Laboratory. The knowledge and research experience I obtained has been inestimable to me. I have felt that I have progressed so much. Secondly, I would like to thank my committee members, Dr. Brian Kelly and Dr. Gladius Lewis, for their invaluable input.

Special thanks go out to Dr. Mauricio Campos. He has helped me with the understanding of the clinical impact, aided during testing, given moral support through data analysis, and sat with me on weekends analyzing CT images. His friendship made all the hours in lab bearable. He performed a majority of the surgeries and was one of the driving forces behind this thesis. For his surgical help during the bilateral facetectomies and help with the clinical significance section of this thesis, I am in gratitude to Dr. Daniel Lu. I also would like to thank Dr. Hamid Shah for his help with CT measurements and Dr. Raul Cardenas for his aid in preparing the testing results manuscript in Appendix A.

Next, I would like to thank all the members of the UT Biomechanics Laboratory: Kyle Fraysur, for the contributions of the pure moment and combined loading and moment code; Dr. Yuan Li, for the creation of a simulation of the pure moment and combined loading and moment data; Jessica Stubbs, for aid during testing; and Braham Dhillon, and Daniel Wido, for their friendship and support during this whole endeavor.

Last, but not least, I would like to thank my family and friends for all their support. My parents have instilled the importance of hard work, and my brothers, Andrew, Juston, and Alan. I have always considered my best friends. As for my friends, I do not think I will ever grasp how many blessings they have been to me. 


\begin{abstract}
The facet joints of the lumbar spine are one of the sources of low-back pain that affects a great portion of the population. Minimally-invasive (MI) procedures have been becoming more popular in the surgical decompression of the spine because they offer shorter recovery time and involve removal of smaller amounts of important structures. With these features, it is believed that MI procedures lead to less clinical instability, and the functionality of the segment is maintained. Another important factor is how the facet angle in the lumbar segments affects the biomechanical instability. In spite of all this interest in MI procedures, there is little biomechanical research to back these claims. Therefore, in this study two MI procedures were compared with the laminectomy, the gold-standard for lumbar decompression.
\end{abstract}

Eight lumbar cadaveric motion segment units were procured, mounted, and tested intact, and then following MI unilateral facetectomy (UF), MI bilateral facetectomy (BF), and a traditional laminectomy (TL) using three different loading scenarios. The three different loading scenarios utilized in this study were the pure moment (PM), combined loading and moment (CLM), and the coupled-eccentric loading (CEL) protocols. The PM testing protocol is the standard form of biomechanical testing of the spine. The CLM testing protocol introduced compressive and shear forces to increase translation in the sagittal plane. The CEL protocol was used because it combined a sagittal bend with a forced axial rotation. Rotational values were analyzed at the end limit of $8 \mathrm{Nm}$ for flexion and extension and at $6 \mathrm{Nm}$ for left and right lateral bending. Translations under PM and CLM were calculated utilizing a simulation software Visual Nastran. The criterion for instability was used to see if UF, BF, and TL met this criterion as compared to what would be clinically seen radiographically. In addition to these biomechanical data, CT images were analyzed to determine the change in the facet angle, contact area of the facet, and length of the joint removed after the BF.

Increased motion was seen in the BF and TL compared to the harvested spine condition in all protocols. A decrease in rotation was seen in the UF condition in all protocols, with the exceptions being in right lateral for PM. None of the PM and CLM data met the criteria for instability. A decrease in facet angle, contact area, and length of the facet after the BF was observed.

The TL had the most number of significant biomechanical increases when compared to the harvested condition, making it a less favorable surgical procedure when compared to each of the MI procedures. No studies have used the multiple loading scenarios, have quantified the amount of instability, or have taken account the amount of resection and change in facet angle due to MI procedures. Further investigation of the biomechanical effects of the MI procedures is still needed to gain more insight on how MI procedures affect spine biomechanics. 


\section{TABLE OF CONTENTS}

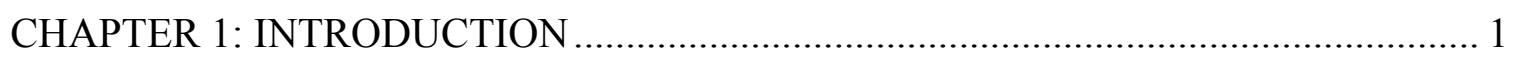

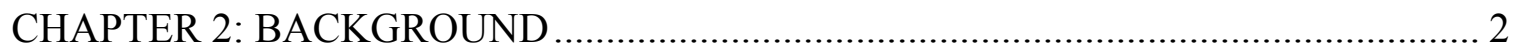

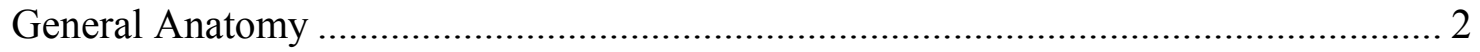

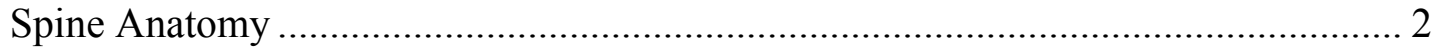

Motion Segment Unit Anatomy ………………………................................... 2

Anterior Column Anatomy …………………………………………………... 2

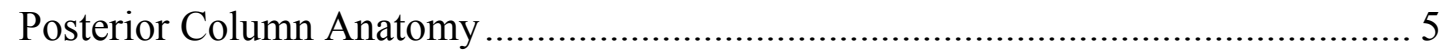

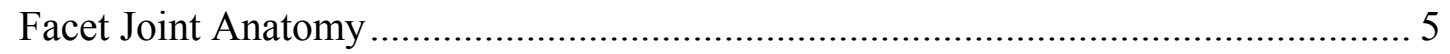

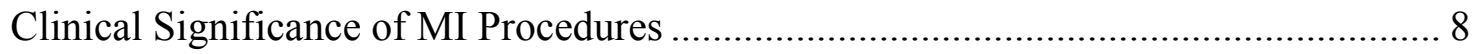

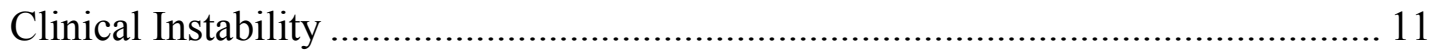

Clinical Indications for Experimental Spine Conditions ............................................ 14

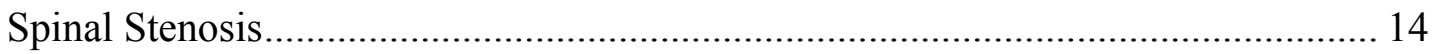

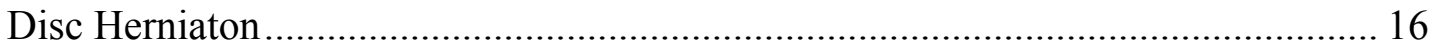

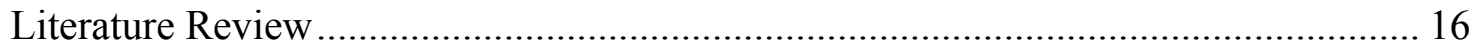

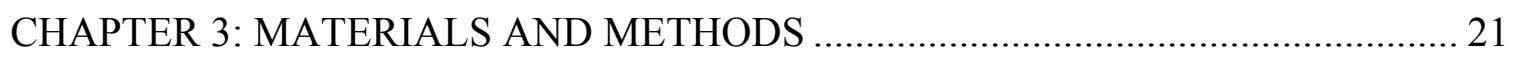

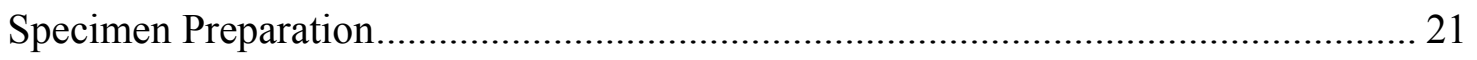

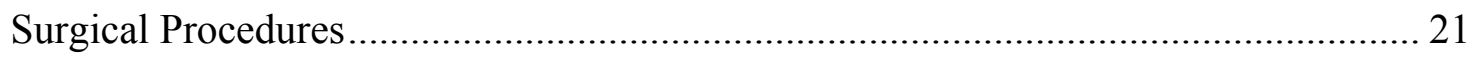

Minimally-Invasive Partial Facetectomy........................................................... 24

Minimally-Invasive Bilateral Medial Facetectomy ……………………………....... 24

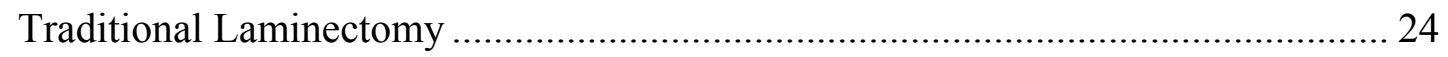

UT Biomechanics Laboratory Robotic Testing Platform ............................................. 24

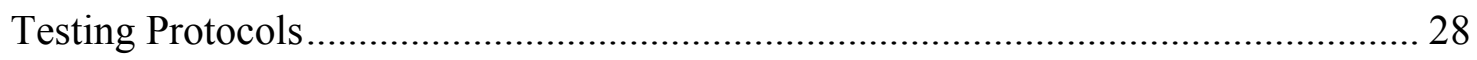

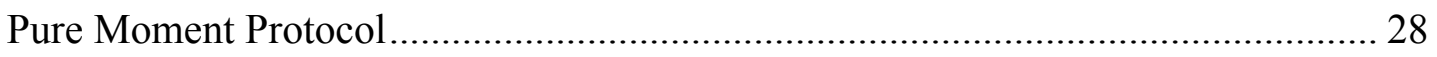

Combined Loading and Moment Protocol ............................................................. 28

Coupled Eccentric Loading Protocol..................................................................... 30

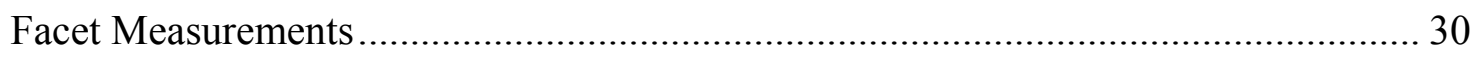

Calculation of Translation along Disc Plane for PM and CLM Protocols.................... 33

Data Management and Statistical Analysis .......................................................... 33

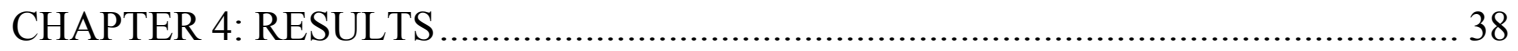

Pure Moment Protocol .................................................................................... 38

Combined Loading and Moment Protocol .................................................................. 38 
Simulation of Pure Moment and Combined Loading and Moment Protocols..... 38

Coupled Eccentric Loading Protocol ....................................................................... 41

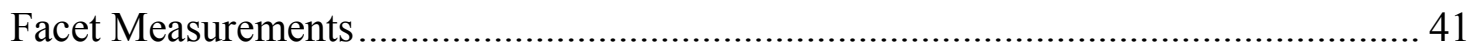

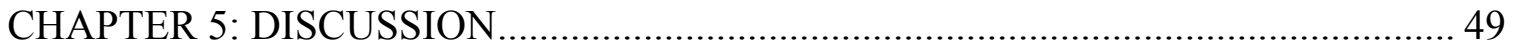

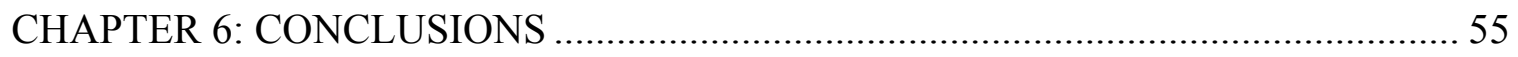

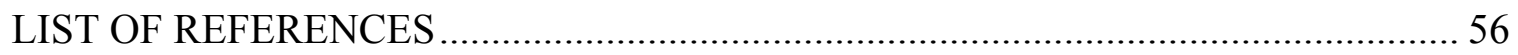

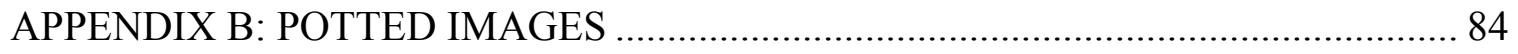

APPENDIX C: PM AND CLM TESTING PROTOCOLS TABULATED DATA......... 88

APPENDIX D: TABULATED SIMULATION DATA FROM PM AND CLM

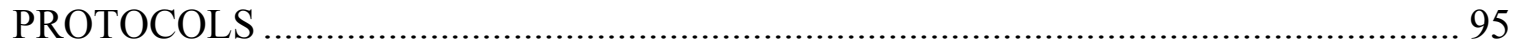

APPENDIX E: TABULATED DATA FROM CEL PROTOCOL ................................ 97

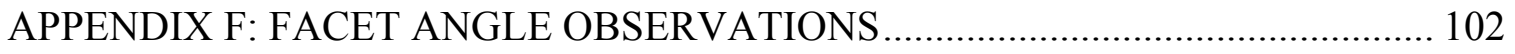

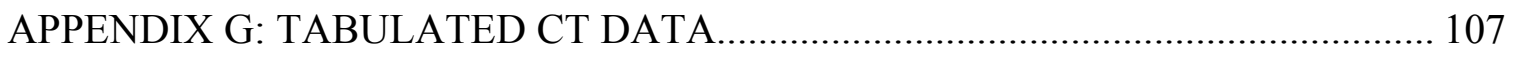

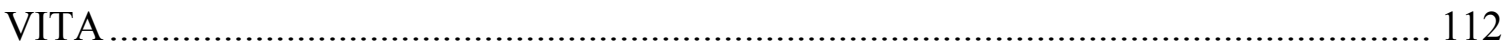




\section{LIST OF TABLES}

Table 2-1. Clinical Instability Checklist for the Lumbar Spine (L1-L5) ...................... 15

Table 2-2. Previous Studies of the Facet Influence on Biomechanics of the Spine...... 19

Table 4-1. Summary of Statistical Results under Specified Loading Protocols ........... 44

Table 5-1. Facet Angle Observations and Comparison to Previous Studies.................. 53

Table 5-2. Facet Area Observations and Comparison to Previous Studies.................... 53

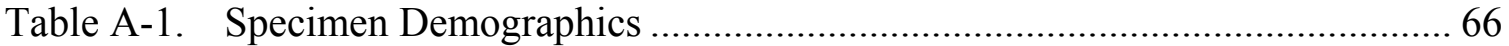

Table A-2. Tabulated Results from Protocols and the Simulation................................. 73

Table A-3. Previous Studies of the Influence of the Facets on Biomechanics .............. 80

Table C-1. Harvested Tabulated Data from PM Protocol............................................ 89

Table C-2. UF Tabulated Data from PM Protocol..................................................... 90

Table C-3. BF Tabulated Data from PM Protocol .......................................................... 91

Table C-4. Laminectomy Tabulated Data from PM Protocol ....................................... 92

Table C-5. Harvested and UF Tabulated Data from CLM Protocol.............................. 93

Table C-6. BF and Laminectomy Tabulated Data from CLM Protocol ......................... 94

Table D-1. Simulation Tabulated Data from PM and CLM Protocols ........................... 95

Table D-2. Translation Data of PM and CLM, Excluding Specimen 0701888............ 96

Table E-1. Harvested Tabulated CEL Data ............................................................. 98

Table E-2. Tabulated UF Data from CEL Protocol................................................... 99

Table E-3. Tabulated BF Data from CEL Protocol................................................... 100

Table E-4. Tabulated Laminectomy Data from CEL Protocol...................................... 101

Table G-1. Tabulated CT Angle Observations …………........................................ 108

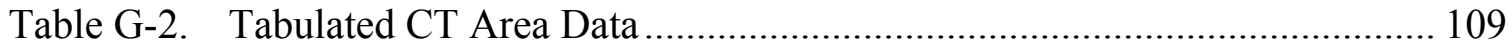

Table G-3. Tabulated CT Length Data .................................................................... 110

Table G-4. Calculated Preservation Percentages …………….................................... 111 


\section{LIST OF FIGURES}

Figure 2-1. A Depiction of the Human Spine............................................................ 3

Figure 2-2. Degrees of Freedom of a FSU ………................................................. 4

Figure 2-3. Bony Structures of a Lumbar Vertebra........................................................ 6

Figure 2-4. A Depiction of the Ligaments of the Lumbar Spine...................................... 7

Figure 2-5. Facet Angles of the Thoracolumbar Spine ................................................. 9

Figure 2-6. Areas of Nerve Root Irritation and Anatomy ............................................ 10

Figure 2-7. Flexion, Neutral (Standing), and Extension Radiographs ........................... 12

Figure 2-8. Determination of Translation Using Radiographs ........................................ 13

Figure 2-9. Diagram of Pure Moment Testing ............................................................ 17

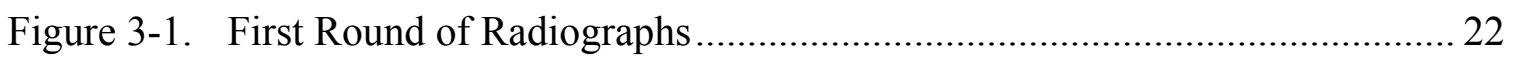

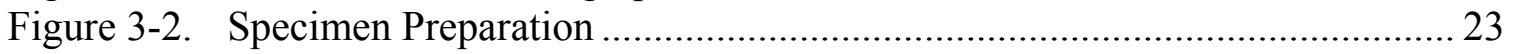

Figure 3-3. Image Analysis of Radiograph ............................................................ 23

Figure 3-4. Schematic of the Lumbar Spine and the Three Surgical Procedures........... 25

Figure 3-5. An Image of the Surgical Setup (MERI, Memphis, TN) ............................ 26

Figure 3-6. Gimbal Assembly and CEL Setup ............................................................ 27

Figure 3-7. PM and CLM Free-Body Diagrams............................................................ 29

Figure 3-8. Schematic of Motion in Coupled Eccentric Loading Protocol ..................... 31

Figure 3-9. Angle Measurements Gathered from CT Images ....................................... 32

Figure 3-10. Osirix Window for Determination of Measurement Slice............................ 34

Figure 3-11. Measurements Gathered from CT Images .................................................... 35

Figure 3-12. Simulation of PM and CLM Protocols in Flexion ....................................... 36

Figure 4-1. Rotational Differences for PM and CLM Protocols ..................................... 39

Figure 4-2. Comparing Sagittal Rotations between CLM and PM Protocols ................ 40

Figure 4-3. Translations for CLM and PM (without 0701888) .................................... 42

Figure 4-4. Rotational Results of the CEL Protocol...................................................... 43

Figure 4-5. Mean Facet Angulation................................................................... 45

Figure 4-6. Mean Facet Joint Area .......................................................................... 45

Figure 4-7. Mean Facet Preservation Length ............................................................. 46

Figure 4-8. Mean Percent of Preservation Length.......................................................... 47

Figure 5-1. Harvested Rotational Comparison with Previous Studies ............................ 50

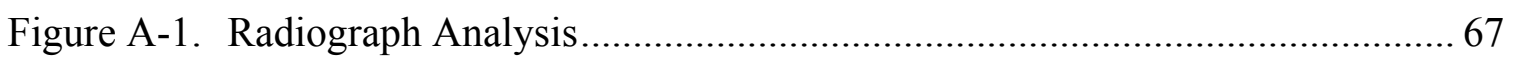

Figure A-2. UT Biomechanical Testing Laboratory Robot............................................. 68

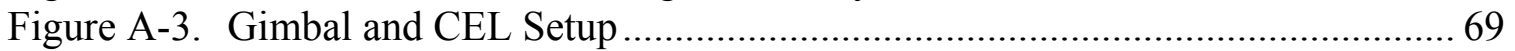

Figure A-4. Simulation of PM and CLM Protocols ..................................................... 71

Figure A-5. Pure Moment and Combined Loading Protocol Rotations ............................ 74

Figure A-6. Comparison of Sagittal Rotations between CLM and PM ......................... 75

Figure A-7. Coupled Eccentric Loading Protocol Rotational Results ............................. 76

Figure A-8. Translation Data from PM and CLM Protocols .......................................... 77 


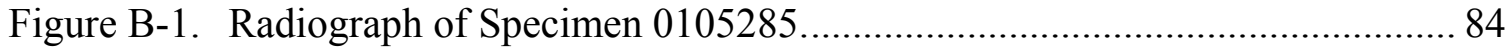

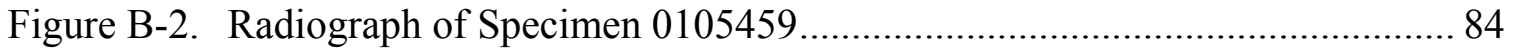

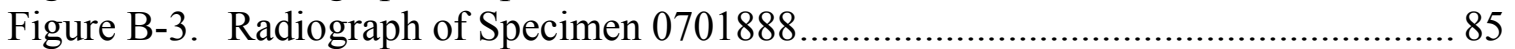

Figure B-4. Radiograph of Specimen 07087036..................................................... 85

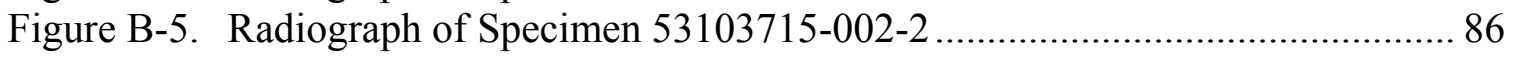

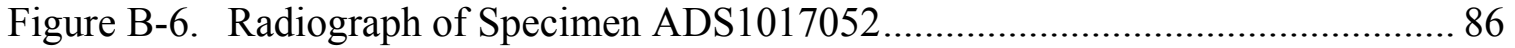

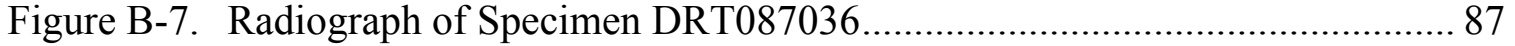

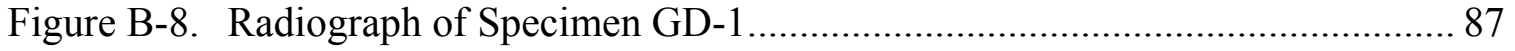

Figure F-1. Harvested Facet Angle Measurements (KS)....................................... 103

Figure F-2. Harvested Facet Angle Measurements (MC)........................................ 104

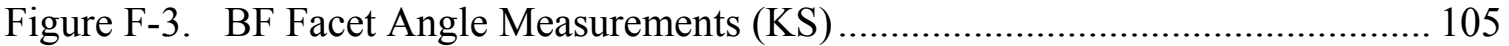

Figure F-4. BF Facet Angle Measurements (MC) .............................................. 106 


\section{CHAPTER 1: INTRODUCTION}

Minimally-invasive (MI) procedures are gaining popularity with advantages suggested by clinical trials to be shorter duration of post-operative disability, lower postoperative narcotic use, shorter operative stay, less blood loss, smaller incision, and higher patient satisfaction [1-8]. The goal of minimally-invasive procedures is to achieve the same goals of conventional surgery (exposure of the nerve root), while reducing the amount of trauma to the surrounding tissues. With more surgeons adopting this method of surgical treatment for their patients, there is debate whether these procedures produce segmental instability as much as has been seen in the traditional decompressive procedure, the laminectomy.

The concept and quantification of instability has been under much debate.It is essential to have a better biomechanical and in vivo understanding to better treat those cases where the line between a stable spine and unstable spine is not clearly defined, for the surgeon as well as the patient. Clinical studies have shown there is less instability radiographically when compared to the traditional laminectomy, but no statistically significant reduction [9]. There is also debate whether the orientation of the facets may play a key role in instability and pathology [10-14]. Biomechanically, the aims of minimally-invasive procedures are that the decreased amount of tissue removal will reduce the impact on the normal motion segment's stability and function, and reduce the amount of adjacent level segment degeneration. The biomechanical evaluation of the role of facetectomies and traditional laminectomies have been studied before [15-24], but there have been few biomechanical studies on MI facetectomies [25].

The objective of this research was to analyze the biomechanical rotation differences between the MI and traditional approaches under three different loading protocols. Determine the amount of resection through a measurement of the surface area of the joint, length of the joint, and the facet angle to see the relation to the biomechanical changes in the spinal conditions, and quantify the amount of clinical instability from a computer simulation model. From this data, the surgically altered specimens were compared to the harvested control condition and the least stable procedure was identified, which may require instrumentation in a clinical setting. A manuscript of the biomechanical study is located in Appendix A. 


\section{CHAPTER 2: BACKGROUND}

This chapter is divided into four different portions. The first portion describes the general anatomy, with additional focus on the facets. The second portion describes the clinical significance of this study with respect to instability and its importance. The third section is a critical review of the biomechanical literature pertaining to the investigations of facet removal.

\section{General Anatomy}

\section{Spine Anatomy}

The human spine is comprised of twenty-four vertebrae and one sacral-coccygeal complex. The four major sections of the spine consist of seven cervical vertebrae, twelve thoracic vertebrae, five lumbar vertebrae, and one sacral-coccygeal process, which is composed of five sacral and four coccygeal fused vertebrae. The cervical and lumbar sections are lordotic with an inward curvature, whereas the thoracic and sacral-coccygeal complexes are kyphotic with an outward curvature (Figure 2-1). The major functions of the spine are to support the body, to maintain an erect posture, and to protect the spinal cord and nerves. The focus for this study will be on the lumbar region. In order to gain a better understanding of the biomechanics of the spine or any joint of the human body, it is best to simplify the model, in this case into a motion segment unit or functional spinal unit (MSU, FSU).

\section{Motion Segment Unit Anatomy}

A MSU consists of the two intervertebral bodies and the intervertebral disc and the major ligaments in between. This biomechanical model of the full spine consists of three joints - the two zyphogeal joints and the disc joint between the two intervertebral bodies. These three joints provide the MSU with six degrees of freedom of movement, with three rotational and three translational (Figure 2-2). For this study, it is important to have a full understanding of the anatomy, especially of the facets or zyphogeal joints. The anatomy section is broken down into the anterior and posterior sections of the MSU.

\section{Anterior Column Anatomy}

The vertebrae of the thoracic, cervical, and lumbar spinal sections have similar anterior anatomy. The only exceptions are that the thoracic vertebrae have an articular surface on the side of the body and the cervical vertebrae have foramen in the transverse processes. Lumbar vertebrae are much larger to support the body weight. Anterior portions of the vertebrae consist of the vertebral body and anterior longitudinal ligament 

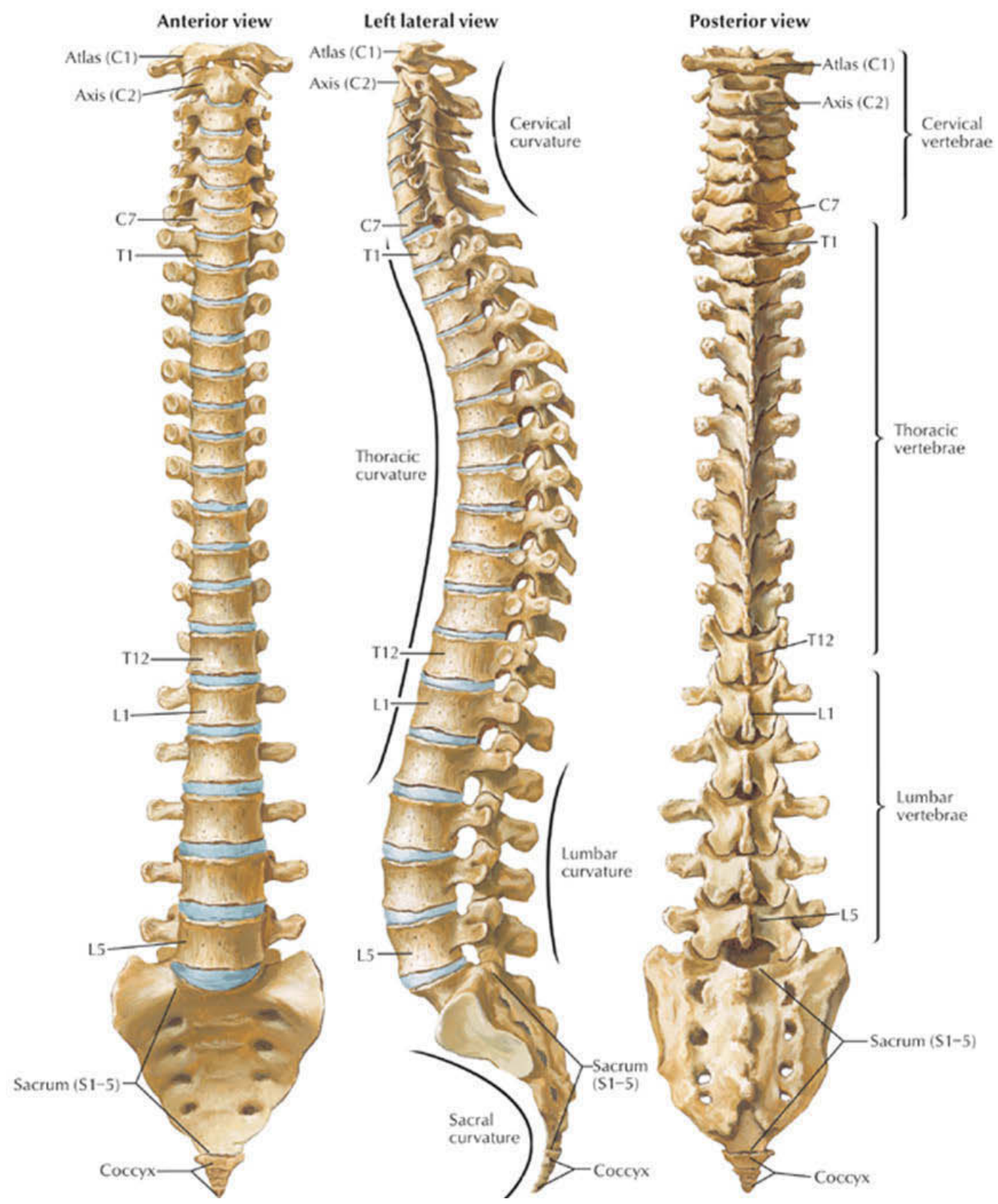

Figure 2-1. A Depiction of the Human Spine. Reprinted with permission. Netter, F.H. and Hansen, J.T., Atlas of human anatomy. 3rd ed. 2003. Teterboro, N.J.: Icon Learning Systems. p. 146 [26]. 


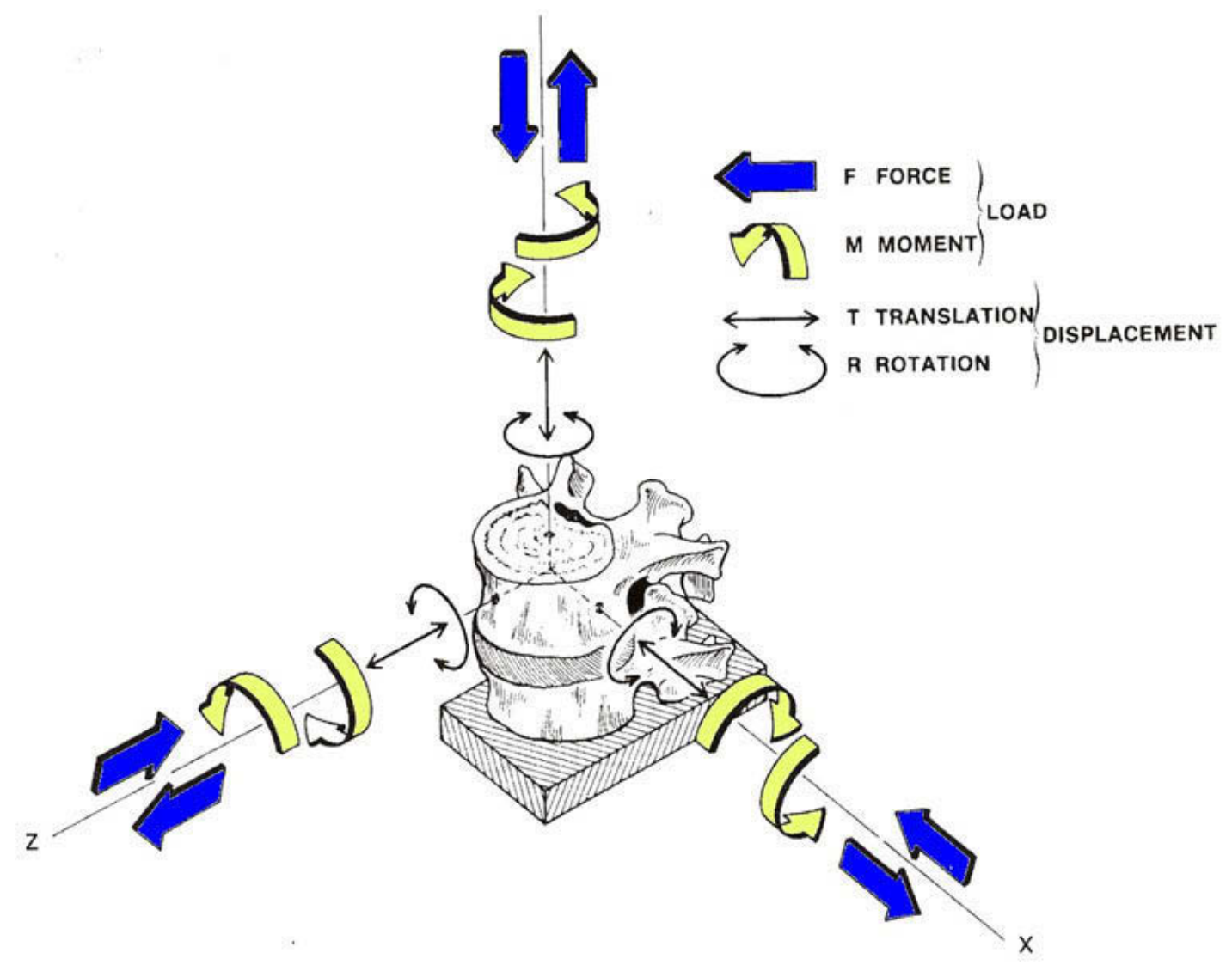

Figure 2-2. Degrees of Freedom of a FSU. Adapted with permission. White, A.A. and Panjabi, M.M., Clinical biomechanics of the spine. 2nd ed. 1990. Philadelphia:

Lippincott. p. 54 [27]. 
(ALL). The ALL is subjected to the most strain in extension. High collagen content of the ligaments of the spine limits excessive motion. Each vertebral body consists of cortical bone that is less than half a millimeter thick encompassing the inner cancellous bone [28]. The thickness of the cortical bone varies from anterior to posterior and the cortical bone is more consistent of a lamellar rather than osteonal structure [29]. The cortical shell is thicker in the anterior portion of the vertebral body, especially in the "corners" to withstand the high loads that occur from bending. Also, the cortical shell is more porous in the center of body where the nucleus pulposus (fibrogelatinous center of the intervertebral disc) which allows diffusion of nutrients from the bone to the disc.

The natural curvature of the spine allows it to have increased flexibility and shock-absorbing capacity due to the intervertebral disc between each vertebral body. Intervertebral discs produce the lordotic curves of the cervical and lumbar spine due to their varying thicknesses. The intervertebral disc is comprised of cartilaginous endplates, nucleus pulposus, and annulus fibers.

The nucleus pulposus constitutes $30-50 \%$ of the disc and is located slightly posterior in the lumbar spine [27]. The nucleus is composed of hydrophilic glycosaminoglycans and type II collagen fibers. Osmotic swelling of the nucleus pulposus is what allows it to withstand compressive loads, and to provide nutrients to the rest of the disc, since the disc does not have a blood supply. The annulus fibrous is multilamellar, with each lamella comprising of organized aligning collagen fibers [30]. The cartilaginous endplates are the interfaces between the disc and the vertebral bodies.

\section{Posterior Column Anatomy}

The posterior longitudinal ligament (PLL) runs behind the vertebral bodies. Laminae connect the pedicles to the spinous process to form the neural canal. The space between the pedicles and the laminae, which is known as the foramen, is where spinal nerve roots branch out from the spinal canal to the rest of the body. Figure 2-3 displays the general bony structure of a vertebra. The transverse processes are also connected at the pedicle and jut out transversely to the vertebral body. In a MSU, the transverse ligament runs between the transverse processes on each side of the MSU. Attached to spinous processes are the inter- and intra-spinous ligaments. The ligamentum flavum (LF) runs anterior to the lamina in the neural canal. It is the only ligament that is composed of a large majority of elastin, which allows it to shorten in extension and elongate in flexion [31]. Figure 2-4 displays all the ligaments for a FSU.

\section{Facet Joint Anatomy}

The zygapophyseal joint or facet joint of an MSU is comprised of the superior and inferior articular processes of the facets with capsular ligaments in between. Capsular ligaments have been found to give greater resistance to flexion than to the supraspinous, interspinous ligaments, and the ligamentum flavum [32]. The shape of the laminae and 


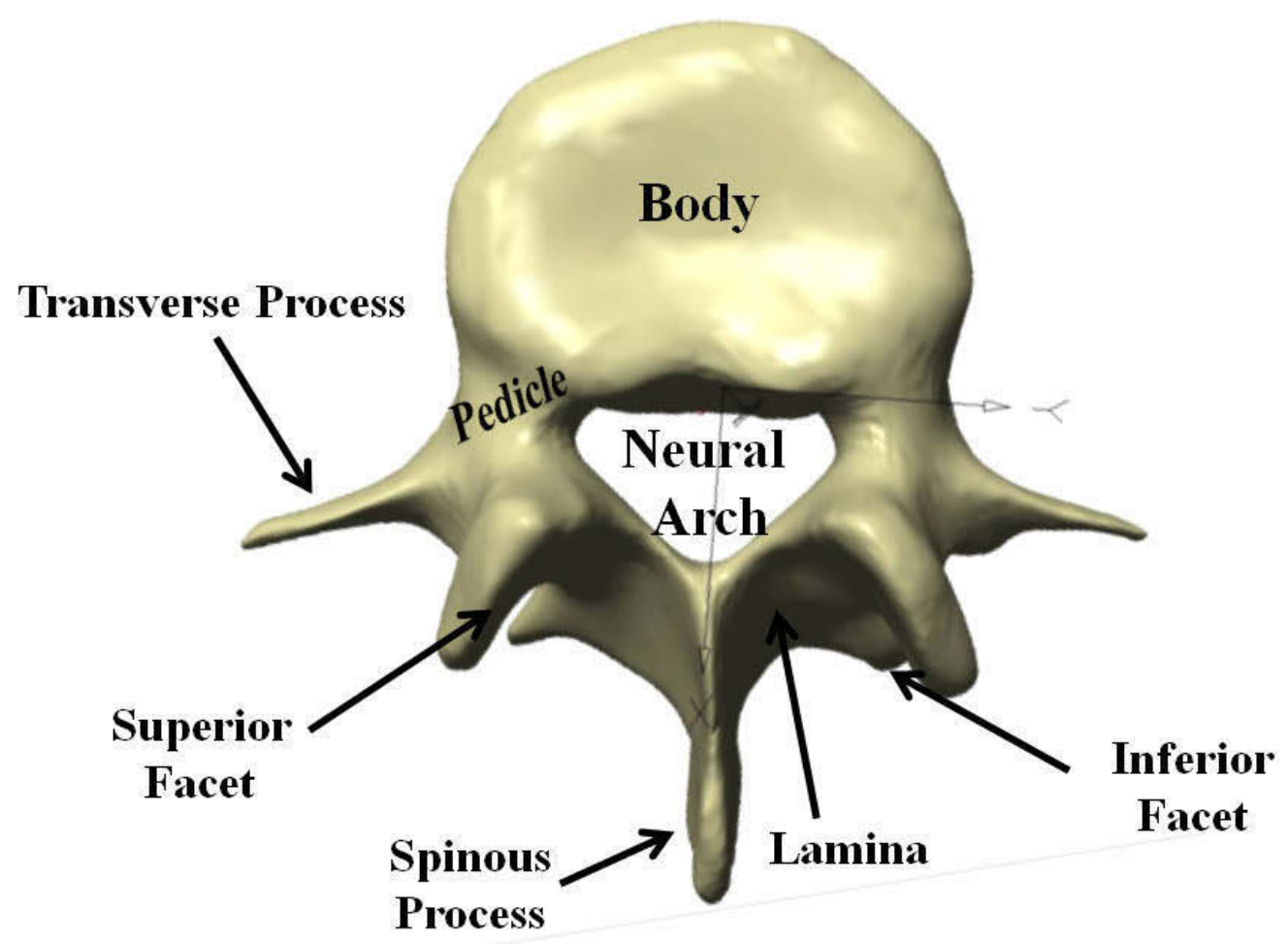

Figure 2-3. Bony Structures of a Lumbar Vertebra. 


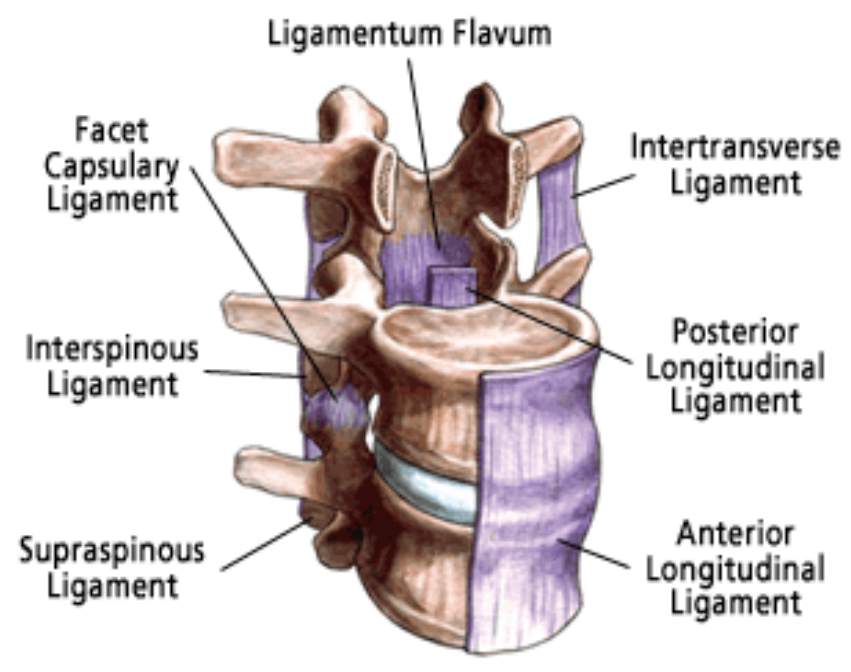

Figure 2-4. A Depiction of the Ligaments of the Lumbar Spine. Reprinted with permission. Orthopedics International-Spine Spinal Anatomy-Overview. 2010.

[Accessed: 2010 June 15]; http://www.oispine.com/subject.php?pn=spinal-anatomy-018 [33]. 
facets has been thought to affect the ability of the spine to resist shear forces, especially in patients with pathology [10-14]. Angles less than 40 degrees are thought to create instability in patients with the pathology of spondylolisthesis [10]. Angulation of the facets in the lumbar spine increases from L1 to L5 (Figure 2-5). The more laterally placed the facets, the greater resistance to shear force. The facets of the lower lumbar levels are subjected to more shear than the upper regions. More sagittally-oriented facets of L1 play an important role in axial rotation. Yang and King hypothesized that the facet joints are a major source of low-back pain and found that the facets also carry 3-25\% of the compressive load, the rest being carried by the disc. When there is damage to the facet joint, remodeling occurs in the ligamentous capsule and bony part of the facet, which may stabilize the joint or lead to nerve compression. Depending on the where the remodeling occurs, nerve root compression can occur in different locations in the spine. Figure 2-6 displays the different areas of nerve root compression as well as a depiction of the anatomy of the nerve roots. For decompressive procedures for the surgical treatment of the pathologies of disc herniation and spinal stenosis, the removal of facets to create room for the neural elements is essential. Furthermore, it is controversial when fusion and instrumentation intervention is needed after removal of posterior elements to prevent instability.

\section{Clinical Significance of MI Procedures}

Minimally-invasive surgical techniques have made inroads into modern surgical intervention. Most notably, certain laparoscopic approaches have shown significant improvement over open techniques in some general surgery cases [34]. Similar MI techniques have been developed in other areas of surgery, such as obstetrics and gynecology, cardiac surgery, thoracic surgery, and urology [35-38]. New MI systems are being adopted by surgeons with the potential clinical benefit of a less invasive procedure [39-44].

One fundamental difference between the new techniques and older types of "minimally invasive" spine surgery (such as chymopapain or intradiscal electrothermal therapy) is that the new surgical procedures are the same whether they are open or minimally invasive [5, 45-47]. For instance, pedicle screws can be placed percutaneously or via open standard incision; but in both cases, posterior segmental instrumentation is achieved using pedicle screws. Furthermore, even open techniques have evolved as well, with the traditional laminectomy decompression procedure becoming less aggressive from a Christmas tree laminectomy (complete laminectomy, bilateral facetectomies, and bilateral foraminotomies) to a facet sparing laminectomy [48].

Performing a microdiscectomy via an endoscopic approach is essentially the same as performing a microdiscectomy via an open technique; in both cases, a microdiscectomy is performed [43]. However, the older "minimally invasive" systems, such as chymopapain, attempted to shrink the disc in the hopes of relieving pressure against the nerve root. This was an attempt at an alternative technique to microdiscectomy, not an actual microdiscectomy. Thus, because the modern MI 


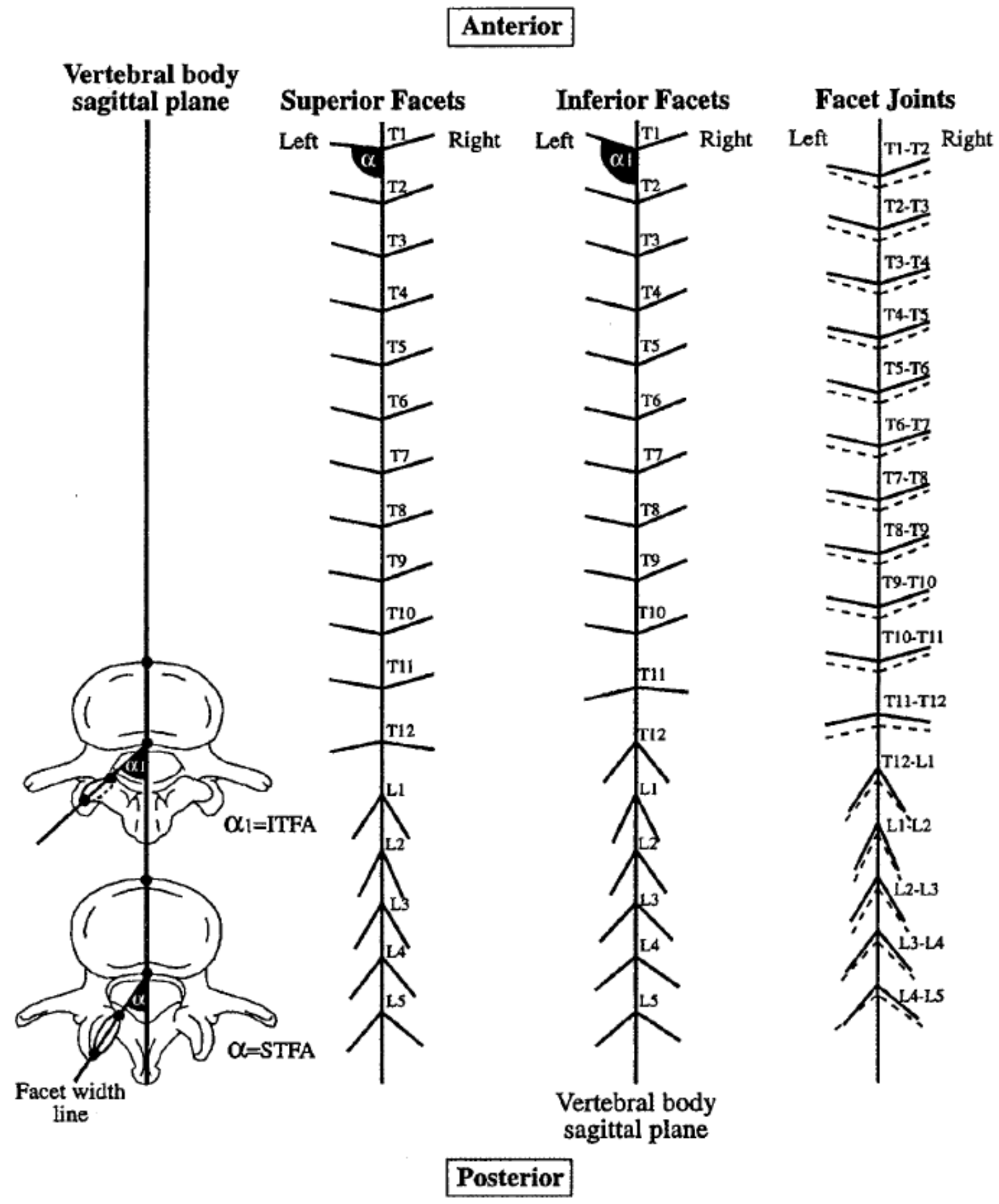

Figure 2-5. Facet Angles of the Thoracolumbar Spine. Reprinted with permission. Masharawi, Y., Rothschild, B., Dar, G., Peleg, S., Robinson, D., Been, E., et al. Facet orientation in the thoracolumbar spine: three-dimensional anatomic and biomechanical analysis. Spine. 2004. 29(16): p. 1758 [49]. 

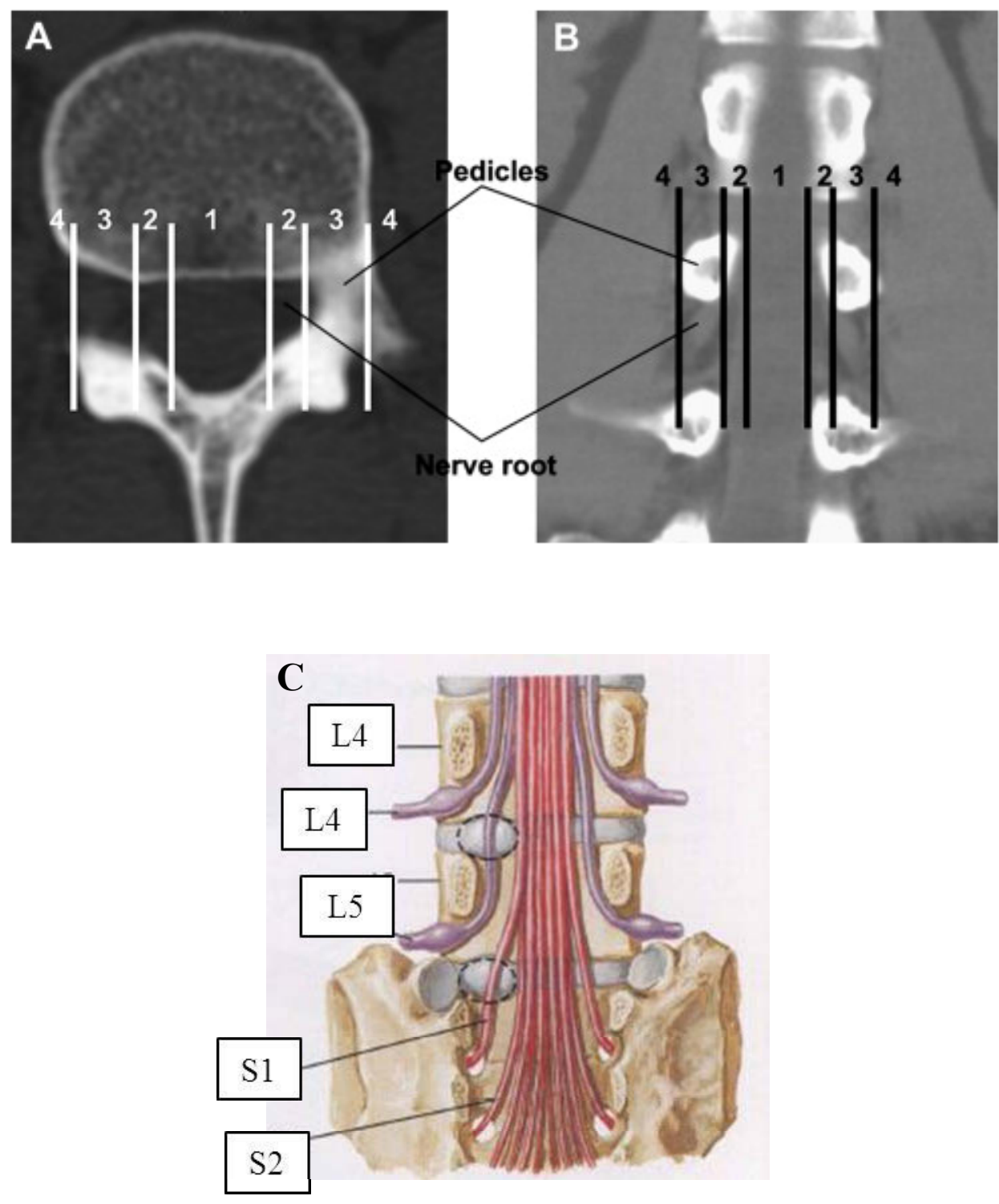

Figure 2-6. Areas of Nerve Root Irritation and Anatomy. The top panel A displays the areas where nerve root impingement can occur. 1. Central, 2. Lateral Recess, 3. Foramen, 4. Extraforaminal. Panel B shows the area of irritation in relation to the pedicles. Panel C is a depiction of the anatomical location of the nerve roots in the lower lumbar spine. Panels A and B reprinted with permission. Genevay, S. and Atlas, S.J. Lumbar spinal stenosis. Best Pract Res Clin Rheumatol. 2010. 24(2): p. 253-65 [50]. Panel C adapted with permission. Netter, F.H. and Hansen, J.T. Atlas of human anatomy. 3rd ed. 2003. Teterboro, N.J.: Icon Learning Systems. p. 154 [26]. 
procedures are essentially the same operation as the open procedures, there is promise that such MI procedures could improve patient outcomes.

The premise behind MI surgical (MIS) procedures is that reduction of soft tissue trauma will reduce impact on the normal FSU stability and function. Range of motion (ROM) preservation, less adjacent level degeneration, and less pain are the benefits expected from MIS procedures. Clinical trials have suggested the advantages of MI microdisectomy and microdecompression procedures include shorter duration of postoperative disability, lower post-operative narcotic use, shorter operative stay, less intraoperative blood loss, smaller incision, and higher patient satisfaction [1-8].

MIS procedures are believed to reduce the amount of trauma to a normal FSU, thus decreasing the possibility of spinal instability. However, in all surgical treatments that require the removal of posterior elements of the lumbar spine, especially the facets, there is a possibility of segmental instability. With MI decompression procedures the goal is minimal removal of posterior elements to expose the nerve root. Even with the removal of many posterior structures, the gold-standard laminectomy has seen favorable clinical outcomes [51,52]. Segmental instability is believed to be the major source of low back pain and sciatica $[27,53]$.

Segmental instability can manifest in the form of mechanical back pain, where a patient with pain upon spinal loading (e.g. sitting, standing, and ambulating). In cases of spondylolisthesis, the loss of disc height combined with the encroachment of neural foramen due to the movement of spinal segments, lead to impingement of the nerve roots and symptoms of radiculopathy. Radiographic assessment of segmental instability is usually performed by lateral flexion-extension x-rays (Figures 2-7 and 2-8).

Spondylolisthesis which is the displacement of one vertebral body over another is characterized by a translation greater than $3 \mathrm{~mm}$ on a radiographic image $[9,10,13]$. Iguchi et al found that sagittal translation is a more critical symptom of lumbar instability than angulation $\left(>10^{\circ}\right)[9]$. While there are dynamic or weight-bearing CT and MRI scans available, they are not currently in widespread use. Assessment of abnormal FSU motion on dynamic radiographs is performed by measuring the displacement at the posterior edge of the vertebral body of one level compared to another; and whether this displacement increases upon flexion or extension.

\section{Clinical Instability}

The concept and quantification of instability has been under much debate. It is essential to have a better biomechanical and in vivo understanding to better treat those cases where the line between stability and instability is not clearly defined for the surgeon as well as for the patient. White and Panjabi defined clinical instability as "the loss of the ability of the spine under physiologic loads to maintain its pattern of displacement so that there is no initial or additional neurological deficit, no major deformity, and no incapacitating pain" [27, p. 342]. Also, they created the first checklist for diagnosis of the 

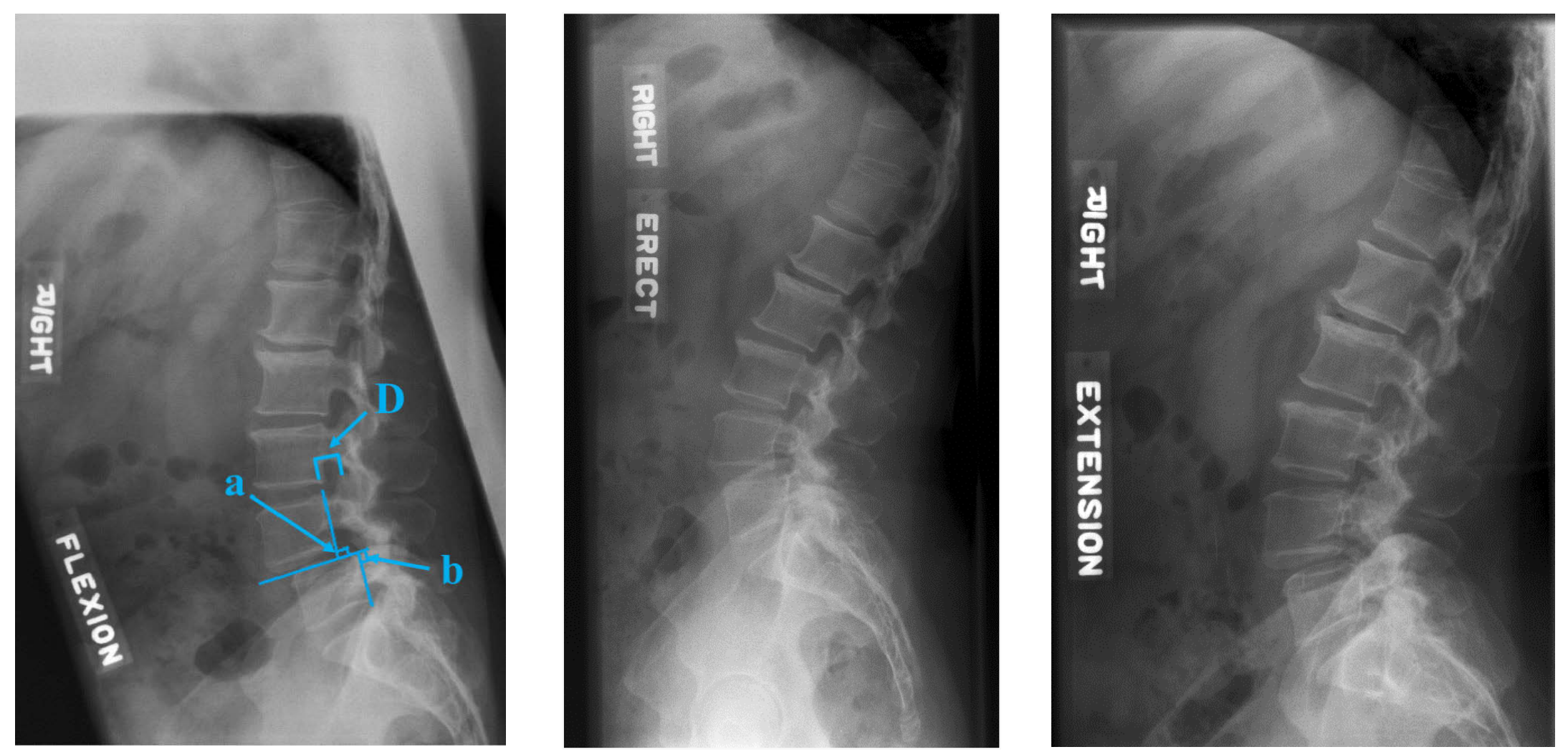

Figure 2-7. Flexion, Neutral (Standing), and Extension Radiographs. If the amount of anterolisthesis (denoted as D) in the flexion radiograph is $>8 \%$ of the total length of the vertebral body, then that segment is determined to be unstable. On an erect radiograph, the sagittal translation must be $>4.5 \mathrm{~mm}$ before applying a scaling factor for magnification errors. In the far right radiograph (extension) must be $>9 \%$ for extension to be considered unstable. Sources: White, A.A. and Panjabi, M.M. Clinical biomechanics of the spine. 2nd ed. 1990. Philadelphia: Lippincott. p. 352 [27]. Iguchi, T., Wakami, T., Kurihara, A., Kasahara, K., Yoshiya, S. and Nishida, K. Lumbar multilevel degenerative spondylolisthesis: radiological evaluation and factors related to anterolisthesis and retrolisthesis. $\mathrm{J}$ Spinal Disord Tech. 2002. 15(2): p. 94 [13]. 
A

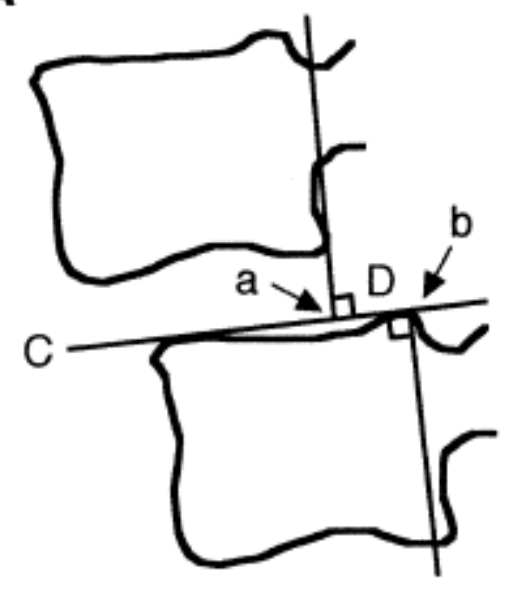

B

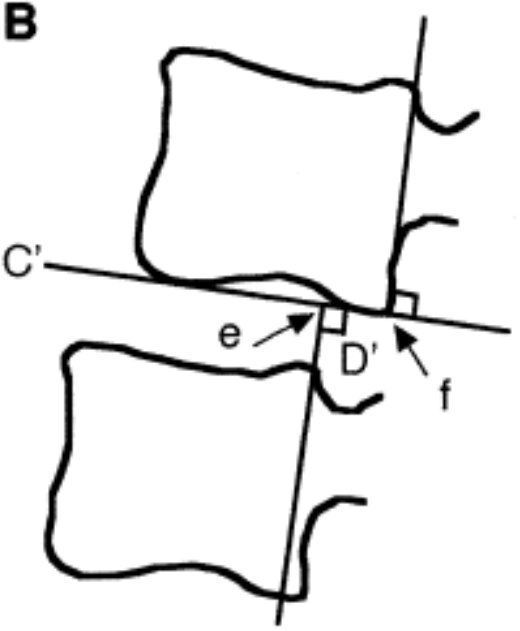

Figure 2-8. Determination of Translation Using Radiographs. A. Depicts the measurement of anterolisthesis. The amount of slip is the intersections of the lines along the posterior edges of the superior and inferior body ( $a$ and $b$ ) perpendicular to the line along the endplate of the inferior body (C). B. Depicts the amount of retrolisthesis, employing a similar method as with flexion but intersecting the posterior edge lines with a line along the endplate of the superior body. Reprinted with permission. Iguchi, T., Wakami, T., Kurihara, A., Kasahara, K., Yoshiya, S. and Nishida, K. Lumbar multilevel degenerative spondylolisthesis: radiological evaluation and factors related to anterolisthesis and retrolisthesis. J Spinal Disord Tech. 2002. 15(2): p. 94 [13]. 
clinical instability of the lumbar spine. Posner et al and Disch et al have improved upon this checklist from the results of their biomechanical and radiographic studies. An amalgamation of these checklists is provided in Table 2-1 [27, 53, 54].

The criticality of which clinical symptom is more important, sagittal translation or segmental angulation, has been debated [9]. In the clinical setting, segmental translation is measured using lateral radiographs of flexion and extension. The three major landmarks used in radiographs are the anterior and the posterior edge of the upper endplate of the inferior body and the inferior posterior edge of the superior body [27]. Segmental angulation is measured as the difference of the intervertebral angles from extension to flexion. Furthermore, there have been few studies that have linked the angulation of the facets with instability; this issue will be discussed later. The surgical removal of posterior elements, such as the facet joints, ligamentum flavum (LF), capsular ligaments, posterior longitudinal ligament (PLL), and lamina may bring about instability as well as accelerate disc degeneration.

The instability caused by disruption of the posterior elements can lead to nonphysiological motion. This can lead to fracture of the facets, trauma of neural elements, disc disruption, or spondylolisthesis [19, 55-57]. Four general causes of post-surgical spondylolisthesis are laminectomy with partial or complete facetectomy for spinal stenosis, discectomy and partial facetectomy, recurrent disc herniation after discectomy, or fusion at an adjacent level or coextensive with a previous fusion as part of a pseudoarthrosis [56]. Spondylolisthesis is characterized by subluxation of one vertebral body over another by $10 \%$ of the A-P vertebral length [58]. In this study, MI procedures will be performed on single-level motion segment units to recreate procedures used in clinical practice that are known to potentially render the spine unstable leading to postsurgical olithesis (spondylolisthesis).

\section{Clinical Indications for Experimental Spine Conditions}

In this study, four different spinal conditions were compared. The spine conditions were the intact, a MI unilateral facetectomy, a MI bilateral facetectomy, and a traditional laminectomy. Clinically, each decompressive procedure is selected based on a patient's individual ailments to create enough room so that no structure is impinging upon the nerve root or neural canal. A MI unilateral facetectomy procedure is used to decompress the spine in a patient who has unilateral foraminal spinal stenosis or a disc herniation. A MI bilateral facetectomy is used to treat spinal stenosis and disc herniation. Laminectomies are used to decompress the spine for the treatment of spinal stenosis, disc herniation, or the presence of a tumor in the neural canal.

\section{Spinal Stenosis}

In patients over the age of 65 , spinal stenosis has been identified as the most frequent reason for spinal surgery [59]. Spinal stenosis is characterized as the narrowing 
Table 2-1. Clinical Instability Checklist for the Lumbar Spine (L1-L5).

\begin{tabular}{lc}
\hline Element & Point Value* \\
\hline Cauda Equina Damage & 3 \\
Radiographic Criteria & 2 \\
Flexion/Extension X-Rays & \\
$\quad$ Relative Flexion Sagittal Plane Translation $>10 \%$ & 2 \\
$\quad$ or Extension Sagittal Plane Translation $>9 \%$ & 2 \\
Relative Sagittal Plane Angulation $<9^{\circ}$ & 2 \\
Anterior Elements Destroyed or Unable to Function & 2 \\
Posterior Elements Destroyed or Unable to Function & 2 \\
Dangerous Loading Anticipated & 1 \\
\hline
\end{tabular}

Note: *Total of 5 or more $=$ unstable

Sources: White, A.A. and Panjabi, M.M. Clinical biomechanics of the spine. 2nd ed. 1990. Philadelphia: Lippincott. p 352 [27]. Posner, I., White, A.A., 3rd, Edwards, W.T. and Hayes, W.C. A biomechanical analysis of the clinical stability of the lumbar and lumbosacral spine. Spine. 1982. 7(4): p. 374-89 [53]. Disch, A.C., Schmoelz, W., Matziolis, G., Schneider, S.V., Knop, C. and Putzier, M. Higher risk of adjacent segment degeneration after floating fusions: long-term outcome after low lumbar spine fusions. J Spinal Disord Tech. 2008. 21(2): p. 79-85 [54]. 
of the neural canal. It predominately affects the three lower lumbar levels [60]. There are two types of spinal stenosis: congenital and acquired or degenerative, with the most common being degenerative. This slow process of degeneration is believed to start in the disc by initiation of cell death and loss of water in the disc, leading to progressive disc bulging and collapse. This result accelerates the degeneration of the cartilage; hypertrophy and thickening of the ligamentum flavum ensue, followed by the formation of osteophytes. This increases the amount of stress on the facet joints. The neural canal is narrowed by the hypertrophy of the LF, ventral disc bulging, and osteophyte formation [61-64]. This encroachment of the neural elements causes radiculopathy, pain, weakness, and numbness.

\section{Disc Herniaton}

Lumbar disc herniation is a pathology that affects accounts for $16 \%$ of all specific diagnoses for back pain [65]. In 2004, five billion dollars in the United States alone was spent on inpatient laminectomy and discectomy surgeries for lumbar disc herniations [66]. Disc herniations are defined as the displacement of the disc material, whether it be the annulus or nucleus, outside the margin of the disc space [67]. Disc herniations appear central posterior, paracentral posterior, and posterolateral annulus [68]. Surgical treatment procedures are routinely elective, after failure of non-operative therapies.

\section{Literature Review}

Even though there have been numerous studies on the influence of the facet joints on the biomechanics of a MSU $[15-18,20,21,25,53,69,70]$, to date there have been no studies that investigate the relationship between the amount of facet removal and the facet angle change from the influence of MI procedures [15-18, 20, 21, 25, 53, 69]. Also, only two previous studies have looked at the influence of facet removal on vertebral body displacement in the sagittal plane $[53,71]$. However, none of these studies have utilized testing protocols that simulate the many complex loading scenarios that occur during daily living activities.

The standard technique used in spinal biomechanical testing of is the pure moment testing method $[72,73]$. Thus, it has been used for investigating spinal fixation [20], non-fusion devices [74-76], spinal trauma [76-78], spinal injuries [79], and spinal instability $[18,20]$. For example, Abumi et al utilized this method to investigate instability due to graded facetectomies and Kato et al used the pure moment to study instability after total facetectomies and the effect osteoplastic laminectomies. In this form of testing, forces are minimized to produce a rotation induced by moment alone (Figure 2-9).

However, pure moment testing is not physiologic, as the native spine undergoes coupled-rotations in everyday activities [79]. Besides the pure moment form of testing, 


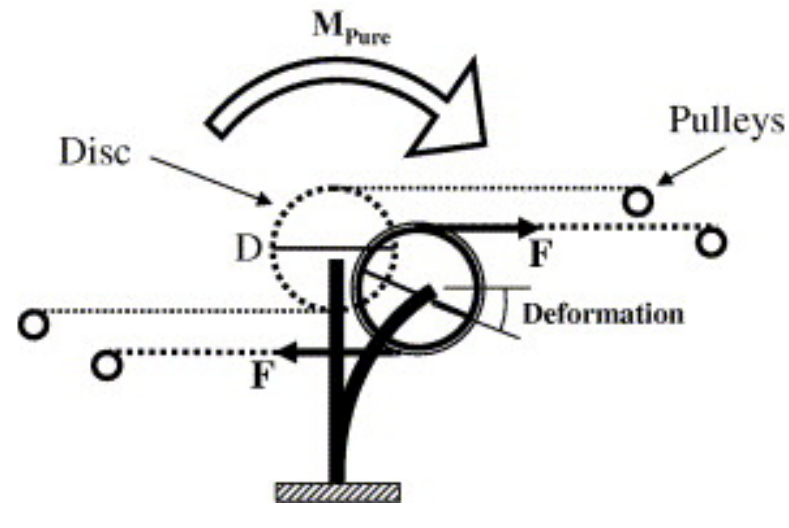

Figure 2-9. Diagram of Pure Moment Testing. Reprinted with permission. Panjabi, M.M. Hybrid multidirectional test method to evaluate spinal adjacent-level effects. Clin Biomech 2007. 22(3): p. 257-65 [76]. 
previous biomechanical investigations of the role of the facets have used compressive loading $[16,25,70]$, eccentric loading $[15,16,25]$, and simultaneous shear and compressive loading [53]. Of all the previous biomechanical studies that have investigated the effect of facet removal by graded, medial, or total removal--only Hamasaki et al has examined the biomechanical implications of minimally-invasive procedures. All studies observed increases in motion with sequential or total removal of facets $[15,16,18,20,25,53]$, and Posner et al found that there was an increase in displacement with increased removal [53].

Previous in vitro studies investigating the role of the facet joints on the biomechanical properties of the lumbar spine have been limited to simple loading scenarios (such as pure moment testing methods), and have not analyzed the changes to the facet area or facet alignment following surgical resection. Oxland et al studied the effect of injuries to the PLL, intervertebral disc, and the facet joint on rotational coupling using L5-S1 specimen under a pure moment testing protocol. They analyzed the amount of axial coupling that occurred with flexion/extension and lateral bending and the amount of lateral bending that occurred with axial rotation [79]. Abumi et al also used a pure moment protocol to study the effects of graded facetectomies on MSU motion. Both Oxland et al and Abumi et al found no significant difference in the amount of lateral bending that occurred after open bilateral facetectomies. Pintar et al investigated the injuries of UF, BF, excision of the PLL, LF, inter- and supraspinous ligaments (BFL), and partial discectomy (BFLD) through the use of a compression-flexion loading protocol (anterior eccentric load), and found a difference between all injury conditions and the intact condition in the amount of deflection due to the compression. Kato et al observed an increase in range of motion for flexion-extension and axial rotation after a laminectomy was performed, which is in agreement with this study [18].

Also, there have been finite element models of the repercussions of facet removal, whether it was a simulation of MIS procedures, graded, or total removal of the facet joint [71, 80-82]. A summary of all previous studies, with a general description and brief summary of their results is given in Table 2-2.

Due to the small number of biomechanical investigations of MIS on the facets, the objectives of this study were to investigate MIS decompression procedures and compare them to the traditional laminectomy procedure by examining the biomechanical effects of these surgical treatments through the use of three different testing protocols, determining whether or not these procedures meet the criteria for clinical instability, and use of CT analysis to quantify the amount of removal of the facets and measure the change in facet angle. The surgical procedures studied are the minimally invasive (MI) unilateral facetectomy (UF), the MI bilateral facetectomy through a unilateral approach (BF), and the traditional laminectomy. 
Table 2-2. Previous Studies of the Facet Influence on Biomechanics of the Spine.

\begin{tabular}{|c|c|c|c|c|}
\hline Investigators & Removal/ Surgical Procedures & Levels & Testing Method & Results* \\
\hline \multicolumn{5}{|l|}{$\begin{array}{l}\text { Biomechanical } \\
\text { Studies }\end{array}$} \\
\hline Abumi et al [20] & $\begin{array}{l}\text { 1. PLL, Supra- and Interspinous } \\
\text { Ligaments } \\
\text { 2. Left UF (Medial) } \\
\text { 3. BF (Medial) } \\
\text { 4. UF (Total) } \\
\text { 5. BF (Total) }\end{array}$ & $\begin{array}{l}3 \text { L2-L3 } \\
7 \text { L3-L4 } \\
2 \text { L4-L5 }\end{array}$ & $\begin{array}{l}200 \text { N Preload, Pure } \\
\text { Moment }\end{array}$ & $\begin{array}{l}\mathrm{ROM} \uparrow \text { in Flexion after } \\
\mathrm{UF} \text { (medial), Medial } \\
\text { Facetectomy: ROM } \rightarrow \mathrm{NC} \text {, } \\
\text { TF -Unstable }\end{array}$ \\
\hline Haher et al [70] & $\begin{array}{l}\text { 1. Facet Joints } \\
2 \text { Anterior Annulus } \\
\text { 3. Lateral Annulus }\end{array}$ & $10 \mathrm{~T} 11-\mathrm{S} 2$ & $\begin{array}{l}1000 \mathrm{~N} \text { Compression at } \\
20 \mathrm{~N} / \mathrm{min}\end{array}$ & $\begin{array}{l}20 \% \downarrow \text { in Stiffness after } \\
\text { UF }\end{array}$ \\
\hline Hamasaki et al [25] & $\begin{array}{l}\text { 1. Left Fenestration } \\
\text { 2. Bilateral Decompression via } \\
\text { Unilateral Approach } \\
\text { 3. Medial Facetectomy } \\
\text { 4. Total Facetectomy }\end{array}$ & $\begin{array}{l}4 \text { L2-L3 } \\
4 \text { L4-L5 }\end{array}$ & $\begin{array}{l}\text { Cyclic Conditioning, } \\
750 \text { N Compression, } \\
750 \text { N Eccentric Load }\end{array}$ & $\begin{array}{l}\downarrow \text { in Global Stiffness with } \\
\text { More Removal }\end{array}$ \\
\hline Okawa et al [16] & $\begin{array}{l}\text { 1. Partial Laminotomy (YL) } \\
\text { 2. Wide Fenestration (WF) } \\
\text { 3. UF (Total) } \\
\text { 4. BF (Total) }\end{array}$ & 10 L3-L4 & $\begin{array}{l}729 \text { N Compression, } \\
\text { Eccentric Load }\end{array}$ & $\begin{array}{l}\text { Stiffness } \downarrow \text { in Extension } \\
\text { after WF and in Lateral } \\
\text { after UTF }\end{array}$ \\
\hline Pintar et al [15] & $\begin{array}{l}\text { 1. UF (Left or Right) } \\
\text { 2. BF } \\
\text { 3. PLL } \\
\text { 4. LF, Inter- and Supraspinous (BFL) } \\
\text { 5. Partial Discectomy(BFLD) }\end{array}$ & $\begin{array}{l}4 \text { L2-L3 } \\
4 \text { L4-L5 }\end{array}$ & $\begin{array}{l}\text { Compression-Flexion } \\
\text { Loading, Movement of } \\
\text { Spinal Components } \\
\text { Recorded }\end{array}$ & $\begin{array}{l}\uparrow \text { Force Deflection from } \\
\text { BF to BFL, } \uparrow \text { in Facet } \\
\text { Joint Motion with } \uparrow \\
\text { Removal }\end{array}$ \\
\hline Posner et al [53] & $\begin{array}{l}\text { Posterior Ligaments } \rightarrow \text { Facet } \\
\text { Joints } \rightarrow \text { Disc } \rightarrow \text { ALL and } 1 / 2 \text { Specimens } \\
\text { in Opposite Order until Failure }\end{array}$ & $\begin{array}{l}6 \text { L1-L2 } \\
6 \text { L3-L4 } \\
6 \text { L5-S1 }\end{array}$ & $\begin{array}{l}\text { Preload, Flexion and } \\
\text { Extension Forces as } \% \\
\text { of Body Weight }\end{array}$ & $\begin{array}{l}\uparrow \text { Displacement with } \\
\text { Removal }\end{array}$ \\
\hline
\end{tabular}


Table 2-2. (continued).

\begin{tabular}{|c|c|c|c|c|}
\hline Investigators & Removal/ Surgical Procedures & Levels & Testing Method & Results* \\
\hline \multicolumn{5}{|l|}{$\begin{array}{l}\text { Computational } \\
\text { Models }\end{array}$} \\
\hline Bresnahan et al [80] & $\begin{array}{l}\text { 1. MIS Right Medial Facetectomy } \\
\text { 2. Laminotomy } \\
\text { 3. Laminectomy }\end{array}$ & $\begin{array}{c}\text { Full } \\
\text { Lumbar }\end{array}$ & $\begin{array}{l}800 \text { N Preload, Follower } \\
\text { Load, Non-Linear FE }\end{array}$ & $\begin{array}{l}\uparrow \text { Motion for Flexion- } \\
\text { Extension, Axial Rotation }\end{array}$ \\
\hline Lee et al [82] & $\begin{array}{l}\text { Unilateral and Bilateral Facetectomies } \\
\text { in Stages of } 25 \%, 50 \%, 75 \% \text {, and } 100 \%\end{array}$ & $\mathrm{~L} 2-3$ & $\begin{array}{l}400 \mathrm{~N} \text { Preload, Pure } \\
\text { Moment }(7.5 \mathrm{Nm})\end{array}$ & $\begin{array}{l}\uparrow \text { Motion in Extension for } \\
\text { UF and Resection on } \\
\text { Contralateral Side }\end{array}$ \\
\hline $\begin{array}{l}\text { Sharma, Langrana, } \\
\text { and Rodriguez [71] }\end{array}$ & $\begin{array}{l}\text { Removal of Posterior Ligaments, } \\
\text { Facets, Disc }\end{array}$ & L3-4 & $\begin{array}{l}\text { Pure Moment, Flexion } \\
\text { and Extension with } \\
\text { Shear, Translation, Non- } \\
\text { Linear FE }\end{array}$ & $\begin{array}{l}\uparrow \text { Displacement with } \\
\text { Removal- in Agreement } \\
\text { with Posner et al }\end{array}$ \\
\hline Zander et al [81] & $\begin{array}{l}\text { Hemi-UF, Hemi-BF, Laminectomy, } \\
\text { Two-Level Laminectomy }\end{array}$ & L2-S1 & $\begin{array}{l}\text { Pure Moment, Erect and } \\
\text { Flexion Physiological } \\
\text { Loading, Non-Linear FE }\end{array}$ & $\begin{array}{l}\text { Stability } \downarrow \text { after } \\
\text { Laminectomy for Flexion, } \\
\text { after 2-Level } \\
\text { Laminectomy for Standing }\end{array}$ \\
\hline
\end{tabular}

Note: *An increase is denoted as $\uparrow$. A decrease is represented by $\downarrow$. No change is represented by NC. 


\section{CHAPTER 3: MATERIALS AND METHODS}

This section is divided into five parts. In the first part, the specimen preparation and the testing apparatus are described. The second part contains a description of the surgical procedures. In the third part, the testing protocols, and the fourth portion describes the methods used for the facet measurements after the surgical procedures. The data management and statistical analysis methods applied are in the fifth part.

\section{Specimen Preparation}

A fluoroscopic C-arm (GE9800, GE Healthcare, Chalfont St. Giles, United Kingdom) was used to screen eight cadaveric specimens at the Medical Education Research Institute (MERI, Memphis, TN) to be free of visible pathology and osteophytes ( 2 Females and 6 Males having a mean age $52.9 \pm 16.7$ years old). Using the open source program, ImageJ (nih.gov), the natural lordotic angle of each specimen was measured with respect to the superior endplate of L1 (Figure 3-1). These specimens were segmented into 4 L1-2, 2 L2-3, and 2 L4-5 MSUs by disarticulating the MSU from the cranial and caudal adjacent vertebrae. After the excess tissue and the soft tissue of the superior and inferior endplates were scraped away, wood screws were driven into the endplates and exposed portions of the facets to ensure a secure adhesion of the lowmelting point bismuth alloy (McMaster-Carr, mcmaster.com) to the specimen. The specimens were mounted in the neutral alignment(with the superior endplate of L1 horizontal) into custom-built cylindrical molds using a technique previously used in the laboratory [83]. Images of the mounting process are in Figure 3-2. After being mounted, the specimen were frozen at $-20^{\circ} \mathrm{C}$, and then thawed for a second round of radiographs. A second round of radiographs was taken with calipers set to $10 \mathrm{~mm}$ to calibrate the radiograph and the coordinates of the disc center were found (Figure 3-3 and Appendix B), which were later used to transform the tool tip of the robotic testing platform.

\section{Surgical Procedures}

All specimens underwent the three testing protocols for every spine condition, which will be described later. The order of the tests was organized to minimize the time the tissue was thawed and exposed to the air during testing. For example, flexion and extension testing were completed in the same day.

Overall, four surgical conditions were studied, these being

1. Harvested (Intact)

2. Minimally-Invasive Unilateral Partial Facetectomy (UF) Minimally-Invasive

3. Bilateral Facetectomy Via a Unilateral Approach (BF)

4. Traditional Laminectomy (Lami) 


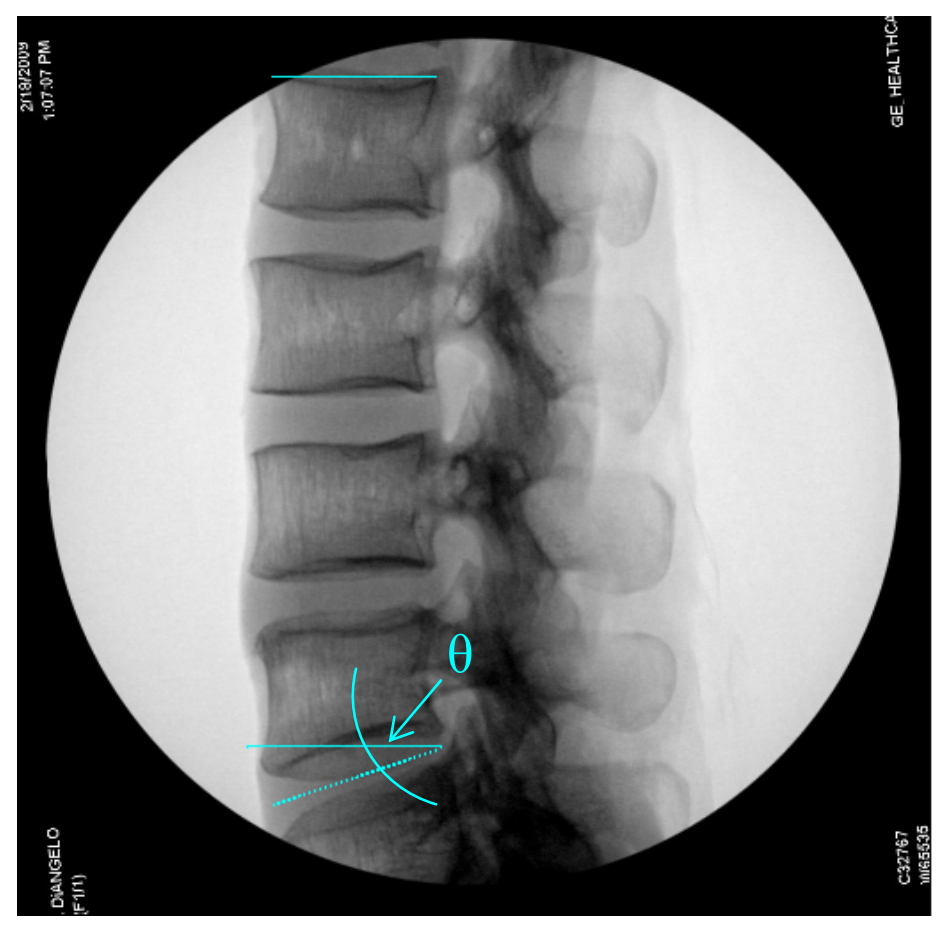

Figure 3-1. First Round of Radiographs. Radiographs were used to ensure the tissue quality and for lordotic angle measurements $(\theta)$ using ImageJ software. 

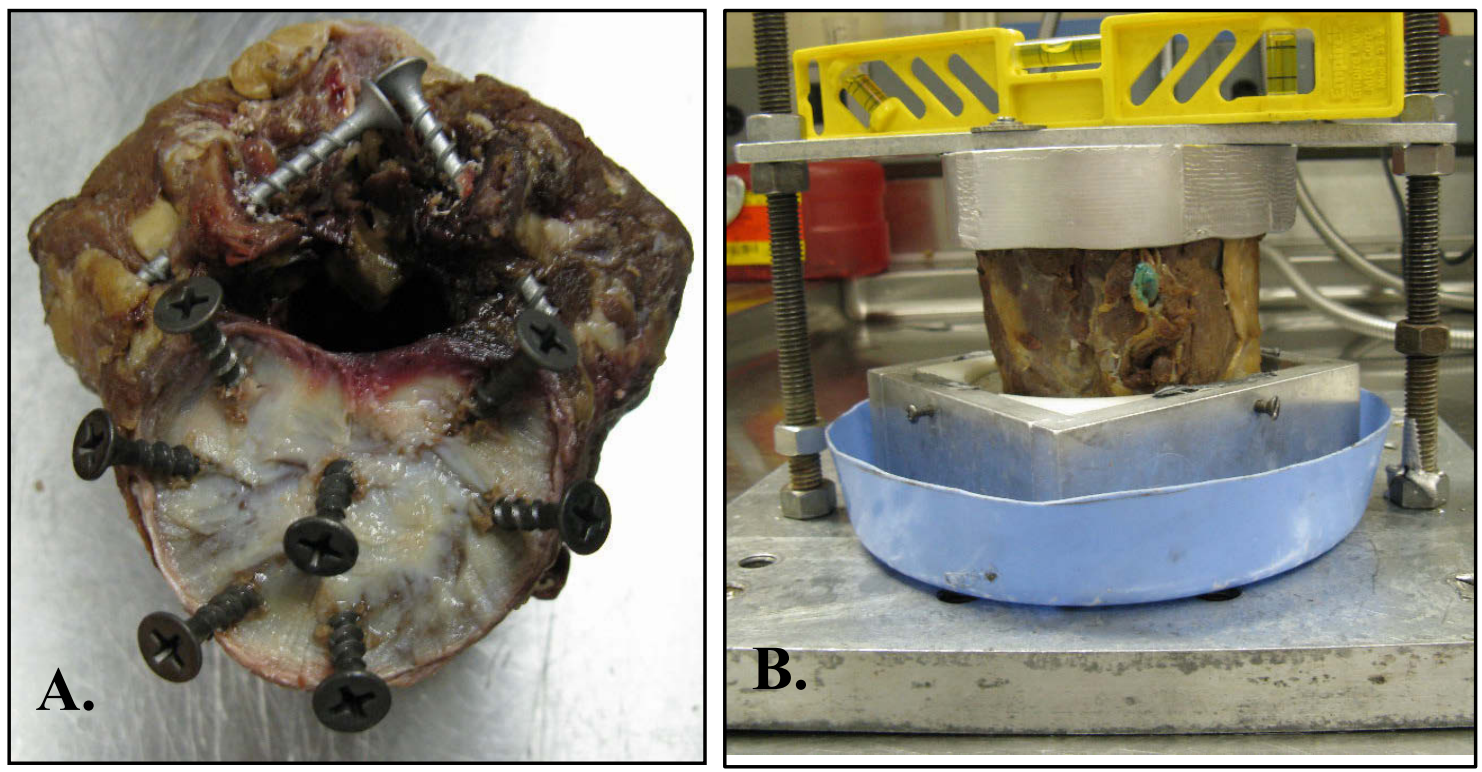

Figure 3-2. Specimen Preparation. A. Preparation included special care to scrape the superior and inferior endplates of disc material. B. Specimens were mounted in a lowmelting point bismuth alloy in their natural alignment.

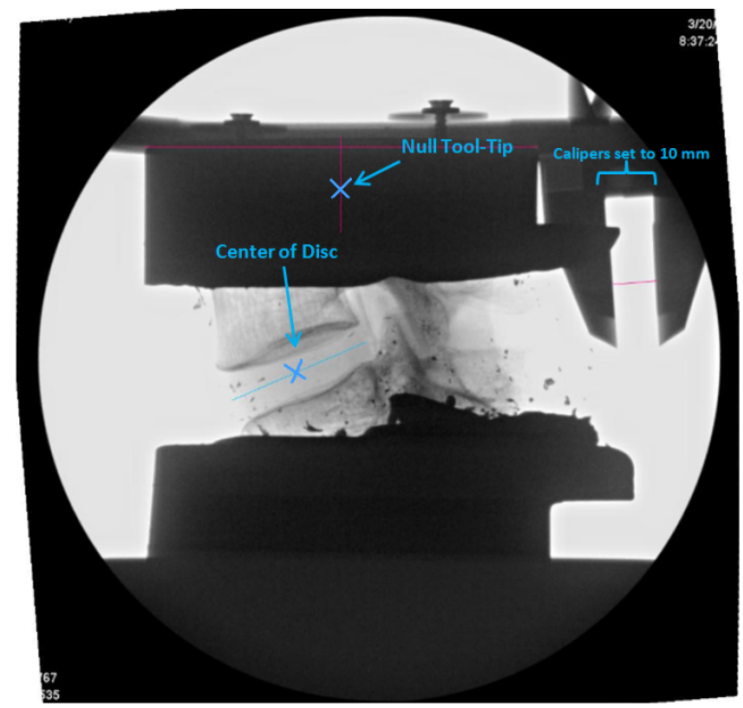

Figure 3-3. Image Analysis of Radiograph. Using ImageJ to calibrate and analyze distances on the image, the original tooltip of the robot was found to be $9.72 \mathrm{~mm}$ below the top of the center of the pot for this specimen. The coordinate of the center of the disc were found with respect to this point [84]. 
A schematic of these surgical procedures are shown in Figure 3-4. The amount of resection varied from specimen to specimen.

\section{Minimally-Invasive Partial Facetectomy}

Using a surgical microscope, the MetrxSystem ${ }^{\mathrm{TM}}$ (Medtronic,Inc., Minneapolis, MN), and a Midas Rex drill (Medtronic, Inc., Minneapolis, MN) a left-side approach was used to burr the superior and inferior articular processes and inferior lamina until the nerve root was exposed. This procedure was performed at MERI by Dr. Mauricio Campos. An image of this surgical procedure setup is shown in Figure 3-5.

\section{Minimally-Invasive Bilateral Medial Facetectomy}

The surgical microscope, Metrx kit, and surgical drill were used again for the minimally-invasive bilateral medial facetectomy. Using the unilateral approach, the superior and inferior articular processes and inferior lamina were burred until the nerve root was exposed. Care was taken to also remove the ligamentum flavum. The hypertrophied ligamentum flavum has been found to be the cause of nerve root and cauda equina compression [85]. This procedure was performed at MERI by neurosurgeons, Dr. Mauricio Campos and Dr. Daniel Lu.

\section{Traditional Laminectomy}

This laminectomy was performed at UT Biomechanics Laboratory by Dr. Mauricio Campos. In this case, rongeurs and curettes were used to remove the lamina, including the spinous process of the superior body, supraspinous ligament, and the interspinous ligament of the MSU.

\section{UT Biomechanics Laboratory Robotic Testing Platform}

The UT Biomechanics Laboratory's custom-built robotic testing platform (UT Spine Robot) used for testing has four programmable degrees of freedom (DOF): two translational and two rotational [86]. These DOFs were necessary to replicate the proposed vertebral motion for this study. Images of the device and its corresponding programmable DOFs for the gimbal setup are shown in Figure 3-6. By removing the gimbal and incorporating a rotary table coupled motions were created, which was the setup used in the coupled eccentric loading protocol. This setup had three DOFs, two translational and one rotational (Figure 3-6). The apparatus was capable of rotating a spinal segment and simultaneously reading force and moment data from any single prescribed point location in space (i.e. the tool-tip location). Force and moment data were recorded using a six-axis load cell (JR3 Inc., Woodland, CA). 


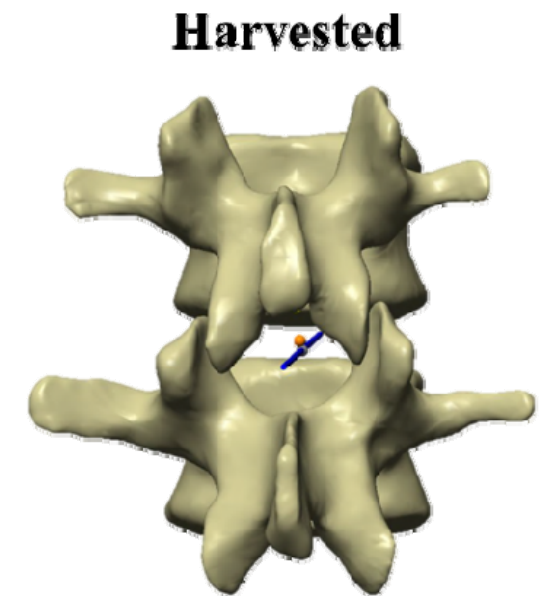

Tube Adjusted Over

Contralateral

Facet Complex

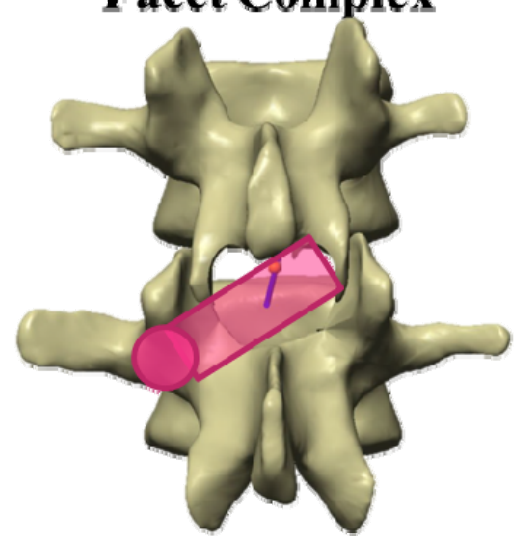

Metrx System Adjusted Over Facet Complex

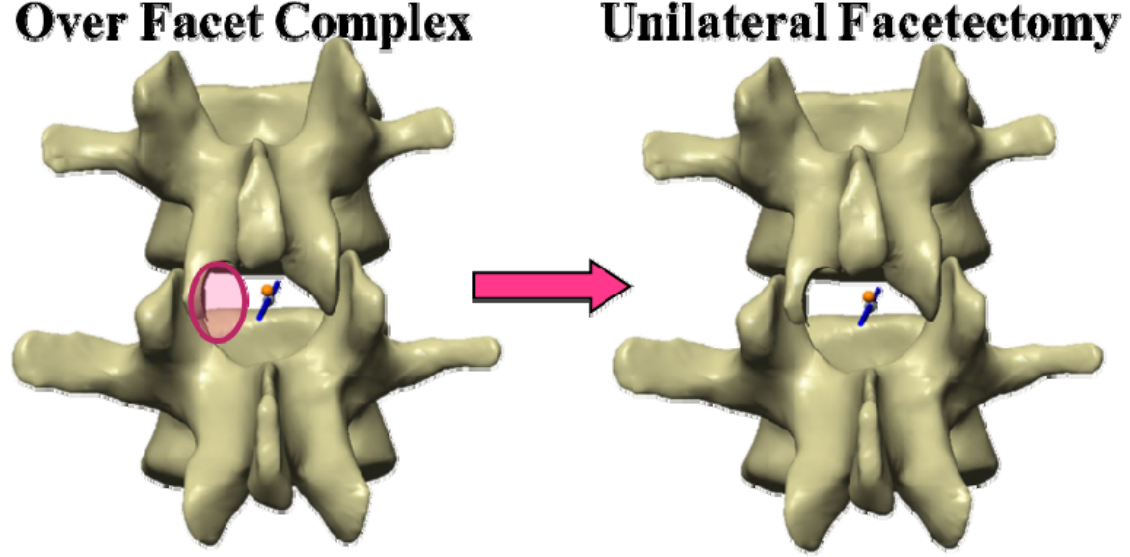

Minimally-Invasive Bilateral Facetectomy

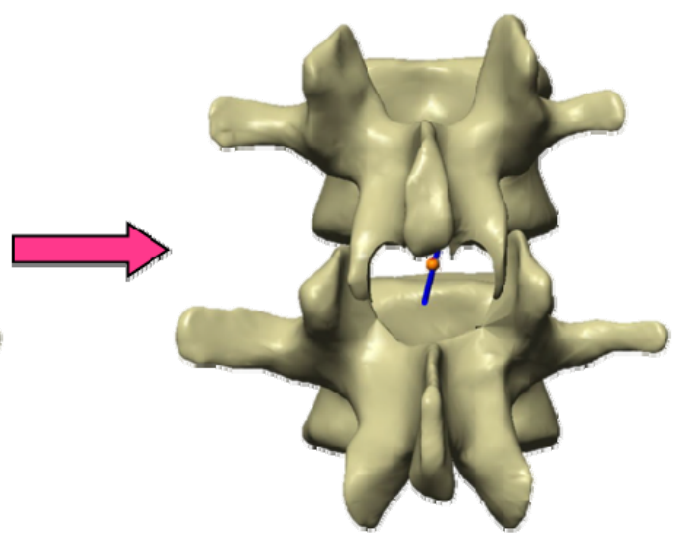

Traditional Laminectomy

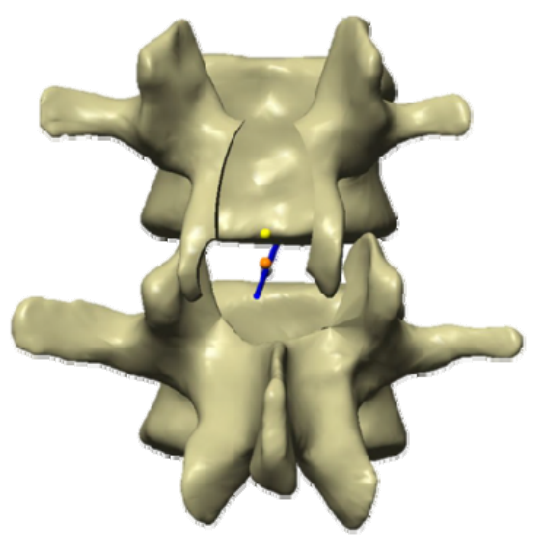

Figure 3-4. Schematic of the Lumbar Spine and the Three Surgical Procedures. 


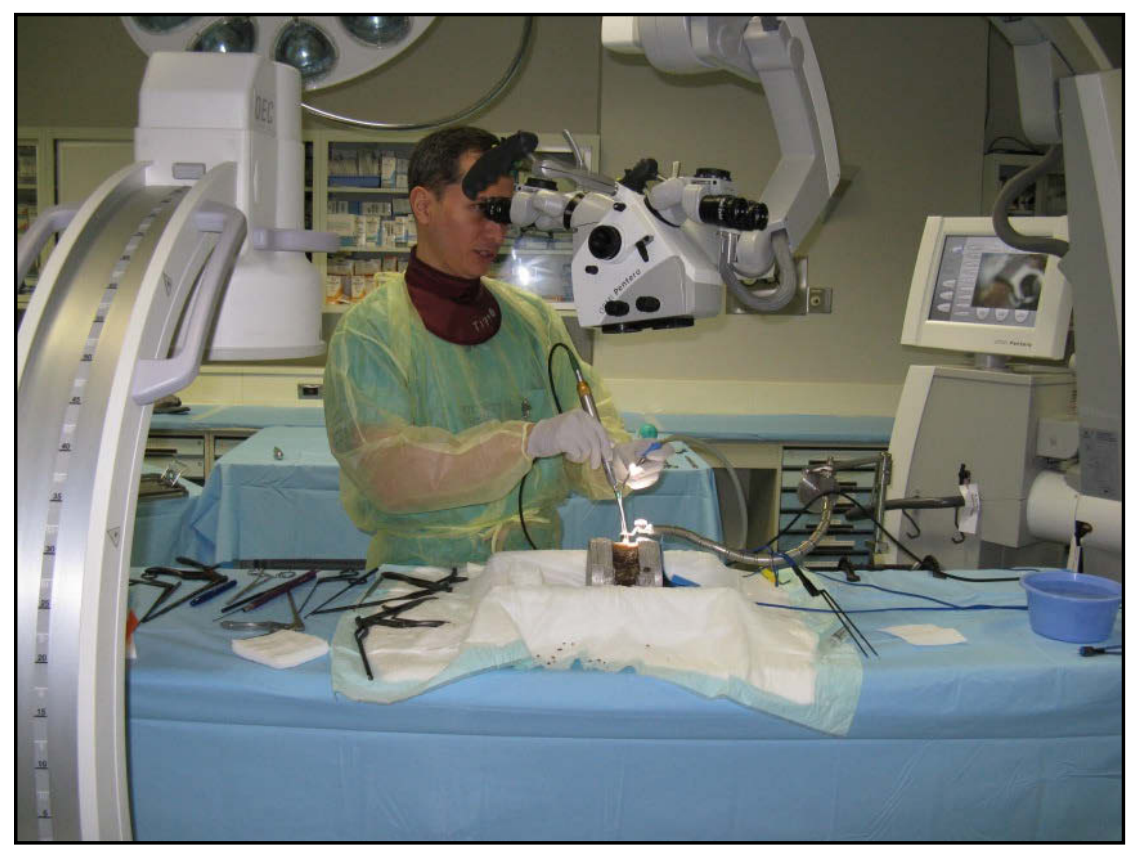

Figure 3-5. An Image of the Surgical Setup (MERI, Memphis, TN). 

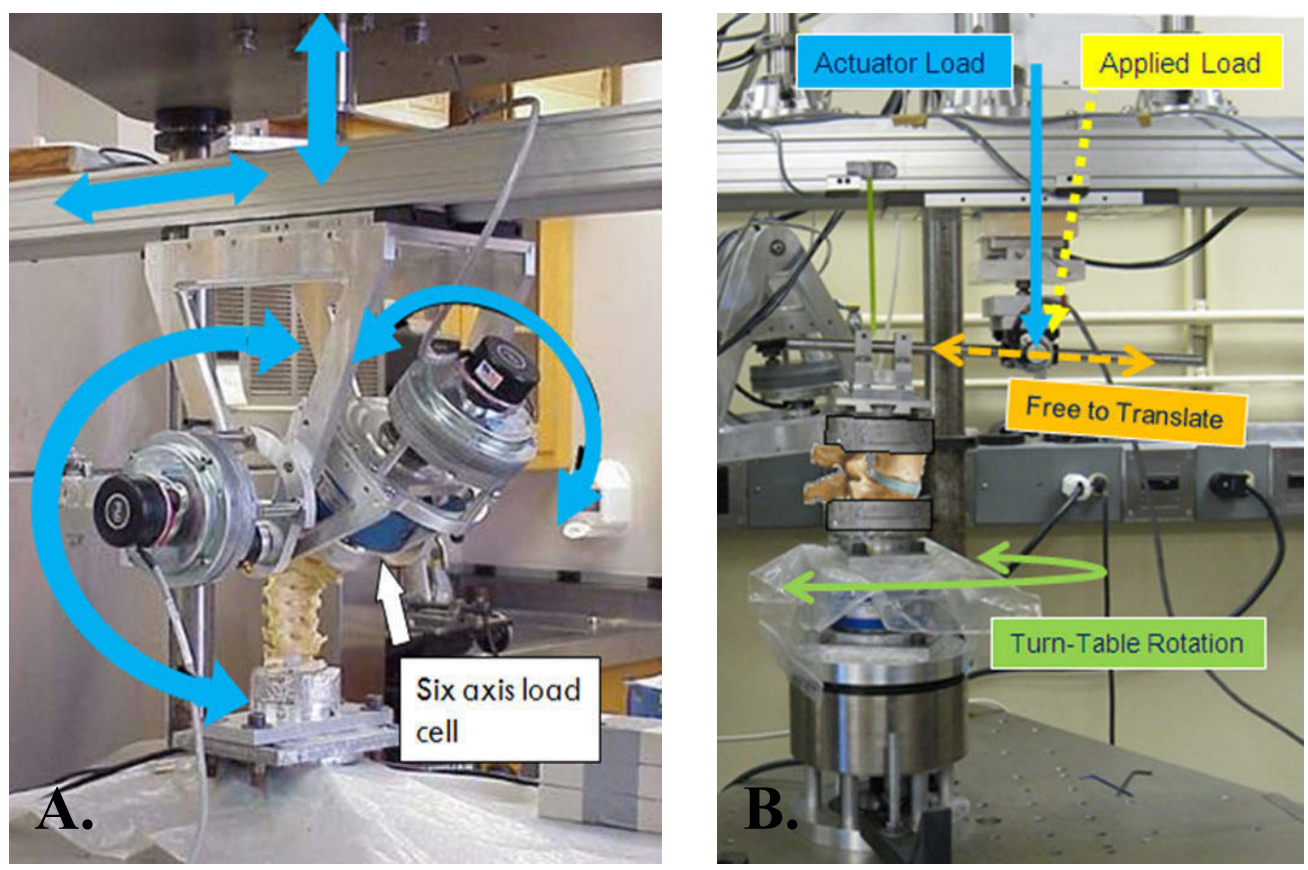

Figure 3-6. Gimbal Assembly and CEL Setup. Image A shows the gimbal assembly with four degrees of freedom and plastic spine model in extension. Image B shows the offset lever arm protocol setup. A $150 \mathrm{~mm}$ lever arm was used as well as a six-axis load cell to record the force and moment values at the base of the specimen. A rotary voltage transducer recorded the sagittal rotation. 


\section{Testing Protocols}

The native spine undergoes many complex movements and different loading scenarios throughout normal daily living activities. Three different protocols were developed and used to attempt to simulate these motion and loading conditions, namely the pure moment (PM), the combined loading and moment (CLM), and the coupledeccentric loading (CEL) protocols.

\section{Pure Moment Protocol}

For the PM protocol, the specimen was loaded into the UT Spine Robot using a custom-built mounting plate. This protocol is a pure moment protocol in that every $0.25^{\circ}$ of specimen rotation the forces in the $\mathrm{z}$ direction and then in the $\mathrm{x}$ direction were minimized (close to zero, within a tolerance $\pm 3 \mathrm{~N}$ ), resulting in a moment from pure rotation in the sagittal plane. The test was run until a target end limit of $8 \mathrm{Nm}$ for flexion and extension, $6 \mathrm{Nm}$ for left and right lateral bending, or if $15^{\circ}$ of rotation was reached. Left and right lateral bending were passively coupled with axial rotation using a rotary turntable. However, the laminectomized condition did not have the passive axial rotation recorded during left and right lateral bending due to an adjustment in the protocol setup. The change in the setup required the incorporation of a multi-axis vice to accommodate the large change in specimen alignment. The multi-axis vice was secured to the passive rotary table and limited motion from occurring due to its weight. The first location of the tool-tip transformations of the load cell was to the coordinates of the center of the disc, and this was the first center of rotation (COR). The COR was changed as the specimen rotated and the actuators translated in the $\mathrm{x}$ and $\mathrm{z}$ directions to minimize the forces along those axes.

\section{Combined Loading and Moment Protocol}

To introduce a shear load and A-P displacement, the combined loading and moment protocol was used. The protocol was similar to the PM in that for every 0.25 degrees of rotation, the $\mathrm{z}$ and $\mathrm{x}$ actuators were moved to get a target force respectively. In this protocol, however, a vertically directed target compressive force of $264 \mathrm{~N}$ (i.e., a load perpendicular to the floor) was used. The target amounts of force in the $\mathrm{x}$ and $\mathrm{z}$ direction were dependent on the amount of rotation of the specimen. For instance, at an angle $\theta$, the target force in the $\mathrm{x}$-direction was $264 \sin \theta \mathrm{N}$ and the target force in the zdirection was $264 \cos \theta$ N. A depiction of the PM and CLM protocols can be found in Figure 3-7. The tool-tip was placed at the center of the disc, and due to high initial sagittal moments, the tool-tip was moved in the A-P direction until the sagittal moment was zero. The test was completed when a target end limit of $8 \mathrm{Nm}$ or $15^{\circ}$ of rotation was reached for flexion and extension modes of bending. 

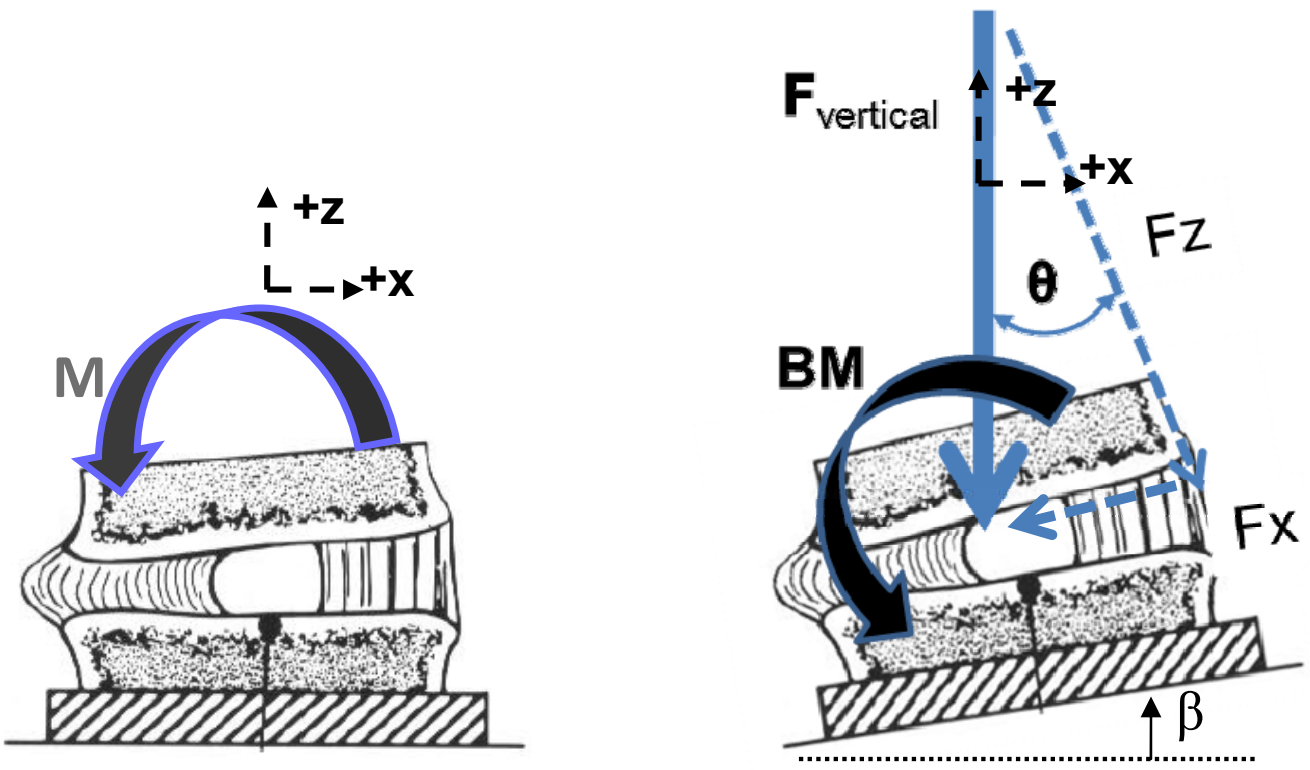

$F x=F_{\text {shear }}=264 \sin \theta \mathrm{N}$ $F z=F_{\text {compression }}=264 \cos \theta \mathrm{N}$

Figure 3-7. PM and CLM Free-Body Diagrams. On the left is the force diagram of the pure moment testing protocol. The right has a diagram of the combined loading and moment protocol with the specimen mounted at its lordotic angle, $\beta$. A compressive load always perpendicular to $\mathrm{x}$-axis induced a shear load. 


\section{Coupled Eccentric Loading Protocol}

The natural lumbar spine undergoes many complex coupled motions, especially during lateral bending. To try to simulate this motion, the z-actuator applied compressive force to a $150 \mathrm{~mm}$ lever arm attached to the superior pot of the specimen causing the specimen to bend; while simultaneously an axial rotation was applied using a rotary turntable. However, before the specimen completed these motions continuously, the end limit points were found. To find these points the specimen was first placed in the neutral position and then flexed (or subjected to whichever mode of bending) to a load limit of 6 $\mathrm{Nm}$, then the specimen was left axially rotated to an end limit of $6 \mathrm{Nm}$. The data were analyzed at a resultant of $8 \mathrm{Nm}$ for flexion and extension and $6 \mathrm{Nm}$ for left and right lateral bending. Axial rotation in the anatomic direction coupled to left and right lateral bending was recorded at the resultant $6 \mathrm{Nm}$ end limit, as well.

This position defined the coupled left axial point (CLA). The same procedure was repeated for the coupled right axial point (CRA). During the process of saving data, there was continuous saving of the forces and moments when the motions were cycled five times from neutral to the CLA then neutral to CRA. Figure 3-8 depicts the motions during the CEL protocol. The sequence of saving points is highlighted in blue in Figure $3-8$.

\section{Facet Measurements}

There has been much debate whether the morphology of the facet joints can contribute to spinal disease, such as degenerative disc disease, or disc herniation [11, 12]. Additionally, it is unclear on how the facet angle may affect a segment's stability, especially in patient with spondylolisthesis. Facet angles less than 40 degrees have been thought to cause instability in patients with spondylolisthesis because of their inability to resist shear [10].Thus, in addition to the biomechanical testing, CT images were taken of the specimen in the intact and BF conditions to see if the amount of facet and change in facet angle correlate with the instability of the specimen. The CT images were taken using Hitachi CB MercuRay ${ }^{\mathrm{TM}}$ Maxillofacial Imaging System (Hitachi Medical Systems America, Inc., Twinsburg, Ohio) and were analyzed using Osirix imaging program(osirix-viewer.com). We are unaware of any studies that have correlated the amount of facet removal with instability.

Using a transverse slice with distinct view of the facet complex chosen by a neurosurgeon, two observers examined the orientation of the facets by drawing a line between the two margins of the superior articular facets. Next, a line was drawn that joined the two facet lines at the midpoint of the joint (Figure 3-9), according to Cassidy et al. The greater the facet angle the more laterally located the facets, increasing the A-P stability. The mean of the measurements and the interobserver errors were recorded. The interobserver error was calculated using the following equation 


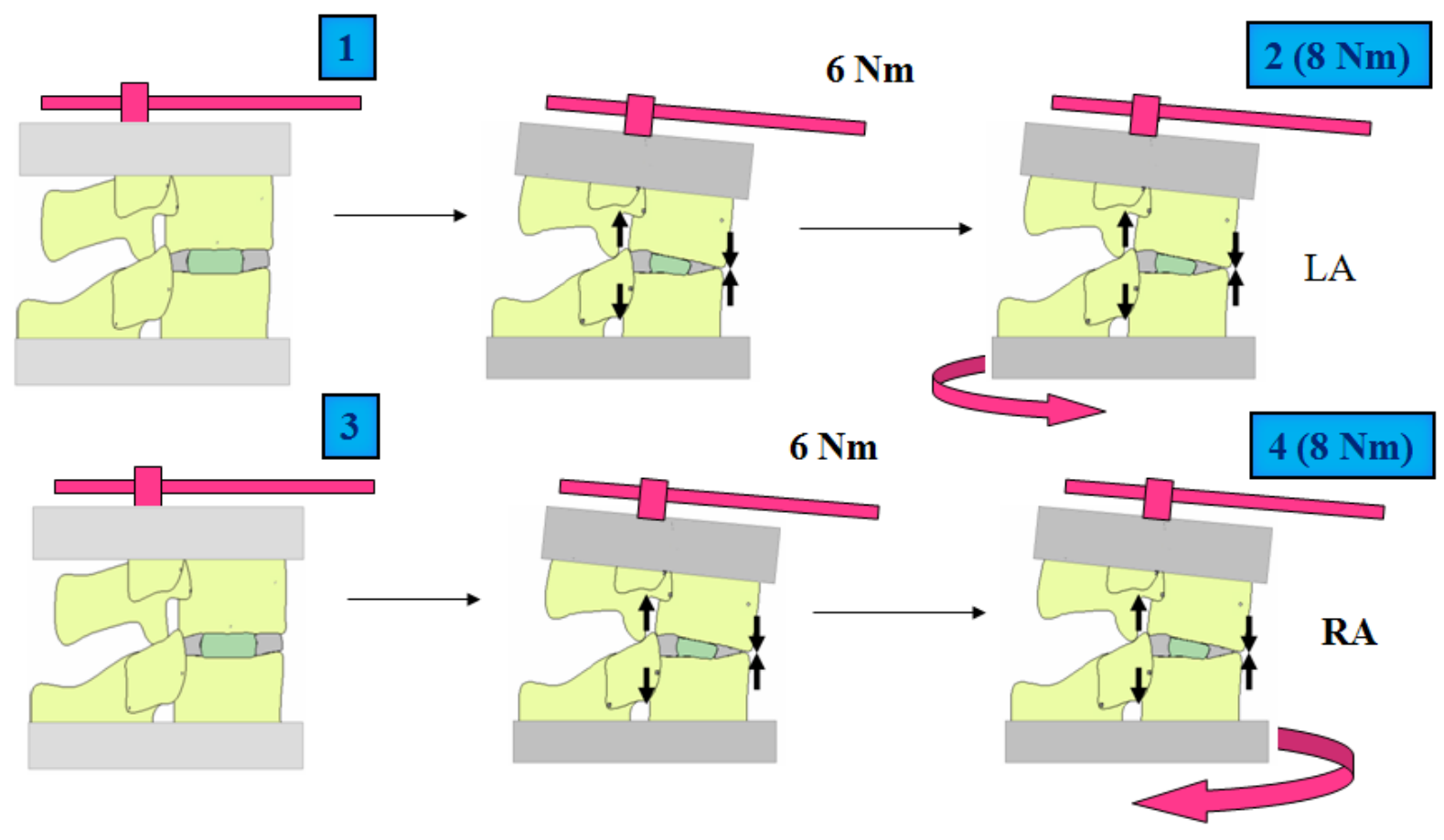

Figure 3-8. Schematic of Motion in Coupled Eccentric Loading Protocol. The end limits were found in the following order: neutral $\rightarrow 6 \mathrm{Nm}$ of bending $\rightarrow 8 \mathrm{Nm}(6 \mathrm{Nm}$ sagittal $+6 \mathrm{Nm} \mathrm{LA}) \rightarrow$ neutral $\rightarrow 6 \mathrm{Nm}$ bending $\rightarrow 8 \mathrm{Nm}(6 \mathrm{Nm}$ sagittal $+6 \mathrm{Nm} \mathrm{RA})$. The saving of continuous motion was comprised of points 1-4 (blue). Anatomic axial rotation was recorded for left and right lateral bending at the $6 \mathrm{Nm}$ resultant end limit. 

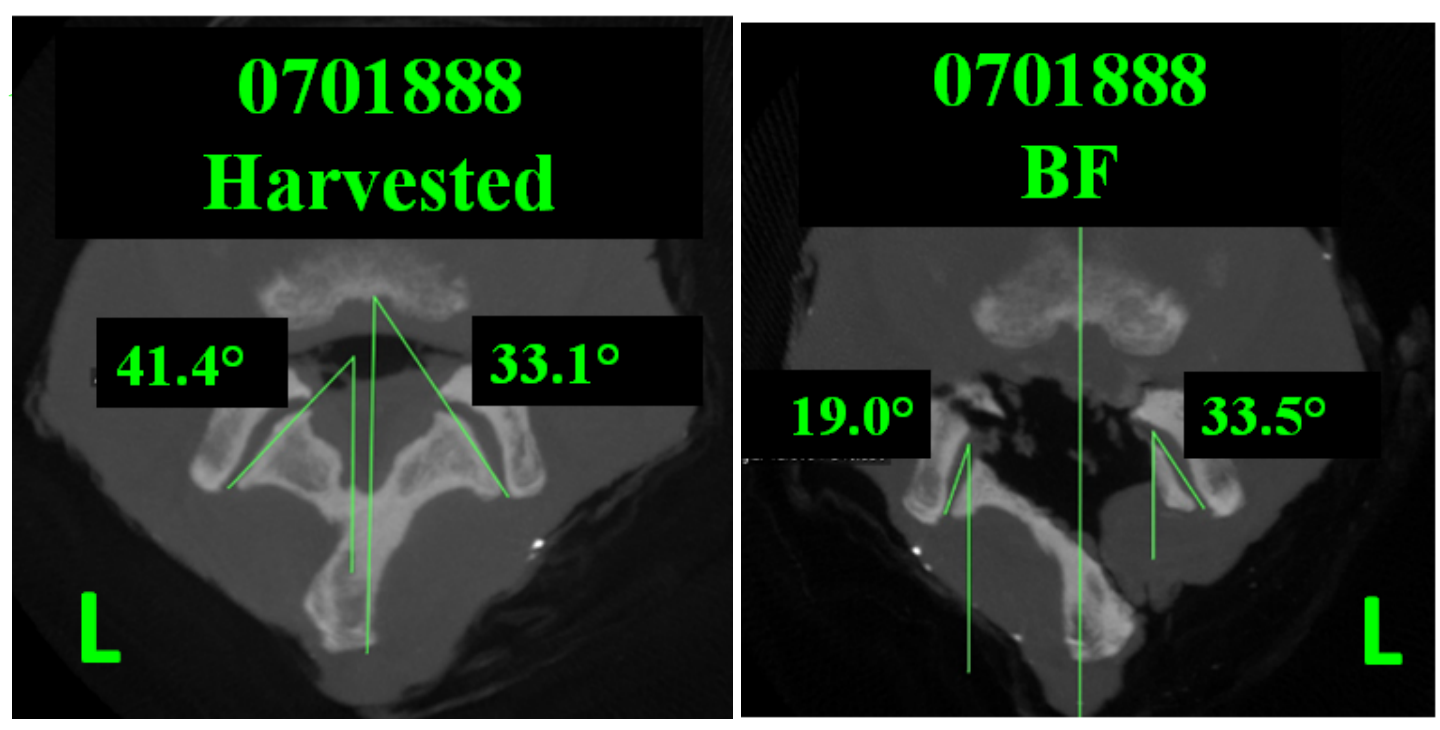

Figure 3-9. Angle Measurements Gathered from CT Images. The left and right images display the facet angle measurement for the harvested and bilateral facetectomy in the transverse plane. 


$$
\sqrt{\frac{\sum\left(x_{1}-x_{2}\right)^{2}}{2 n}}
$$

where $x_{1}$ represents the measurement of the first observer, $x_{2}$ is the measurement of the second observer, and $n$ represents the total pairs of observations. For this study, the observers recorded the facet angle and facet area (32 pairs--one for each condition and each facet for the eight specimens).

The amount of resection of the facets directly affects the overall instability of the segment [87]. The more facet removed, the more likely the MSU will undergo A-P translation and rotation. The facet area of the inferior articulating process of the superior body was measured by utilizing the area measurement function in Osirix after obtaining a slice within the center of the joint plane (Figure 3-10). An initial guess of the facet boundaries was made in the right panel of Figure 3-10, then the boundaries were confirmed by moving the axes over the traced area in the views of the other two respective planes and adjusted accordingly. Matsumura et al also created a method for calculation of percentage of joint preservation by measuring the length of the joint, the method depicted in Figure 3-11 [88]. The area of the facet, the length measurement of Matsumura et al, and the calculation of percentage of joint preservation of the intact and BF conditions and interobserver error were recorded (Figure 3-11).

\section{Calculation of Translation along Disc Plane for PM and CLM Protocols}

Dr. Yuan Li, with the aid of commercially available dynamic simulation software, MSC.visualNastran ${ }^{\text {TM }}$ (MSC. Software Corp., Santa Ana, CA), used the movement of the tool tip in the $\mathrm{x}$ and $\mathrm{z}$ directions recorded during testing, as well as the amount of rotation, to determine the amount of anteroposterior (A-P) translation. This package allows the determination of the kinematic relationship of a model through a series of common mechanical joint systems. In this model, the following components were included: three spheres, the first representing the tool-tip of the testing robot, the second the posterior point on the posterior edge of upper vertebra, and the third recording point to track the translation due to the movement of the posterior point projected on the disc angle plane. The amount of translation of the posterior point of each specimen for each condition along the disc axis was determined (in $\mathrm{mm}$ ) and was compared to the criteria for instability. An image of the simulation is located in Figure 3-12.

\section{Data Management and Statistical Analysis}

All rotational data were analyzed at an $8 \mathrm{Nm}$ end limit for flexion and extension and $6 \mathrm{Nm}$ for left and right lateral bending for each testing protocol. Using SigmaStat 3.5 (Systat Software Inc., San Jose, CA), a non-parametric one-way repeated-measure ANOVA on ranks (Friedman's test) was used to test significance of the experimental and translation results with a $\mathrm{p}<0.05$. If a statistical difference was detected, a StudentNeuman Keuls comparison test was then applied. The facet angle, area measurements, 


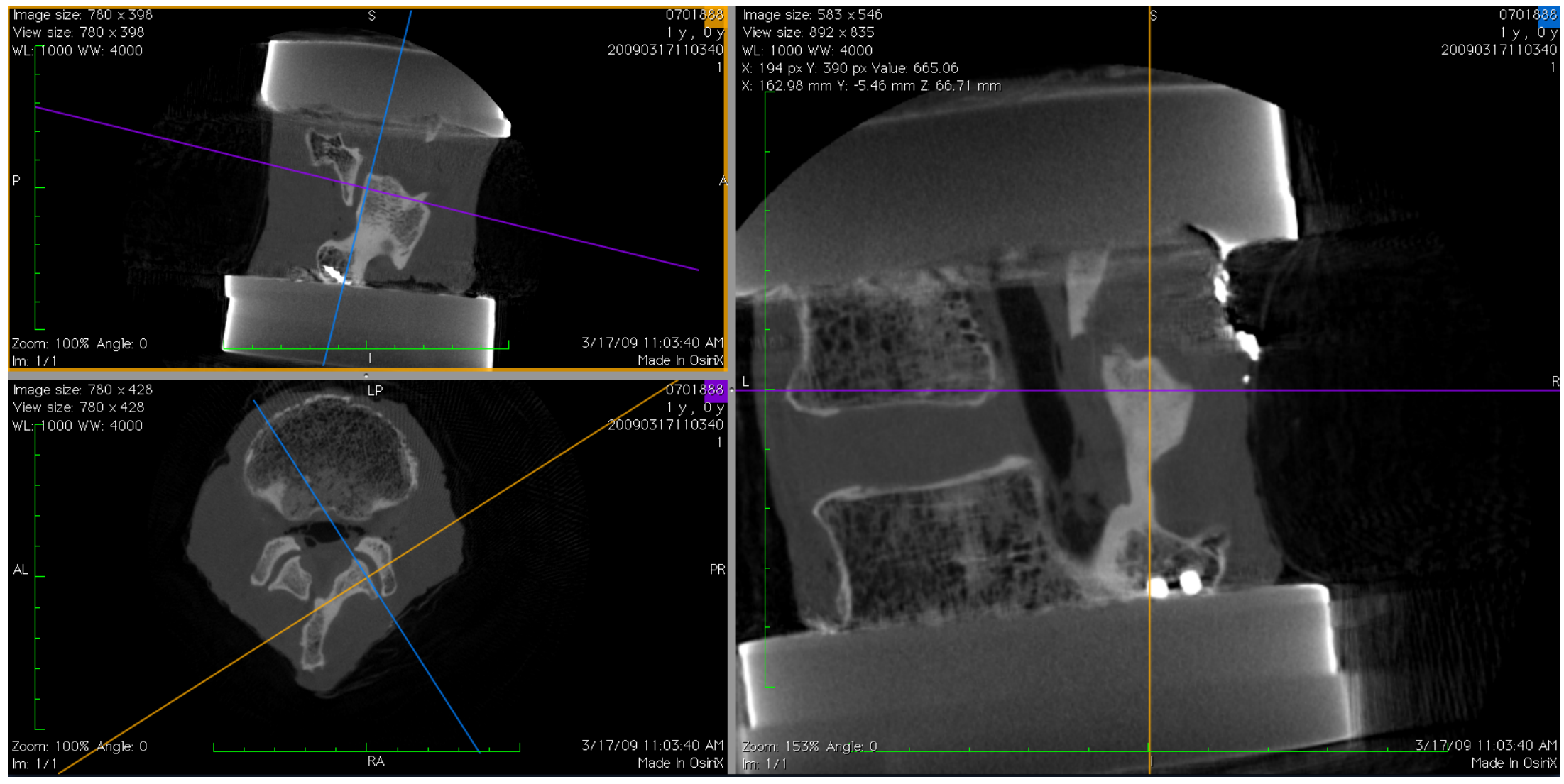

Figure 3-10. Osirix Window for Determination of Measurement Slice. The top left panel depicts the plane selected within the joint. The bottom left panel shows the chosen reference line in the transverse direction (mid-depth of the joint). The right panel is the slice that has a distinct view of the facet surface. 

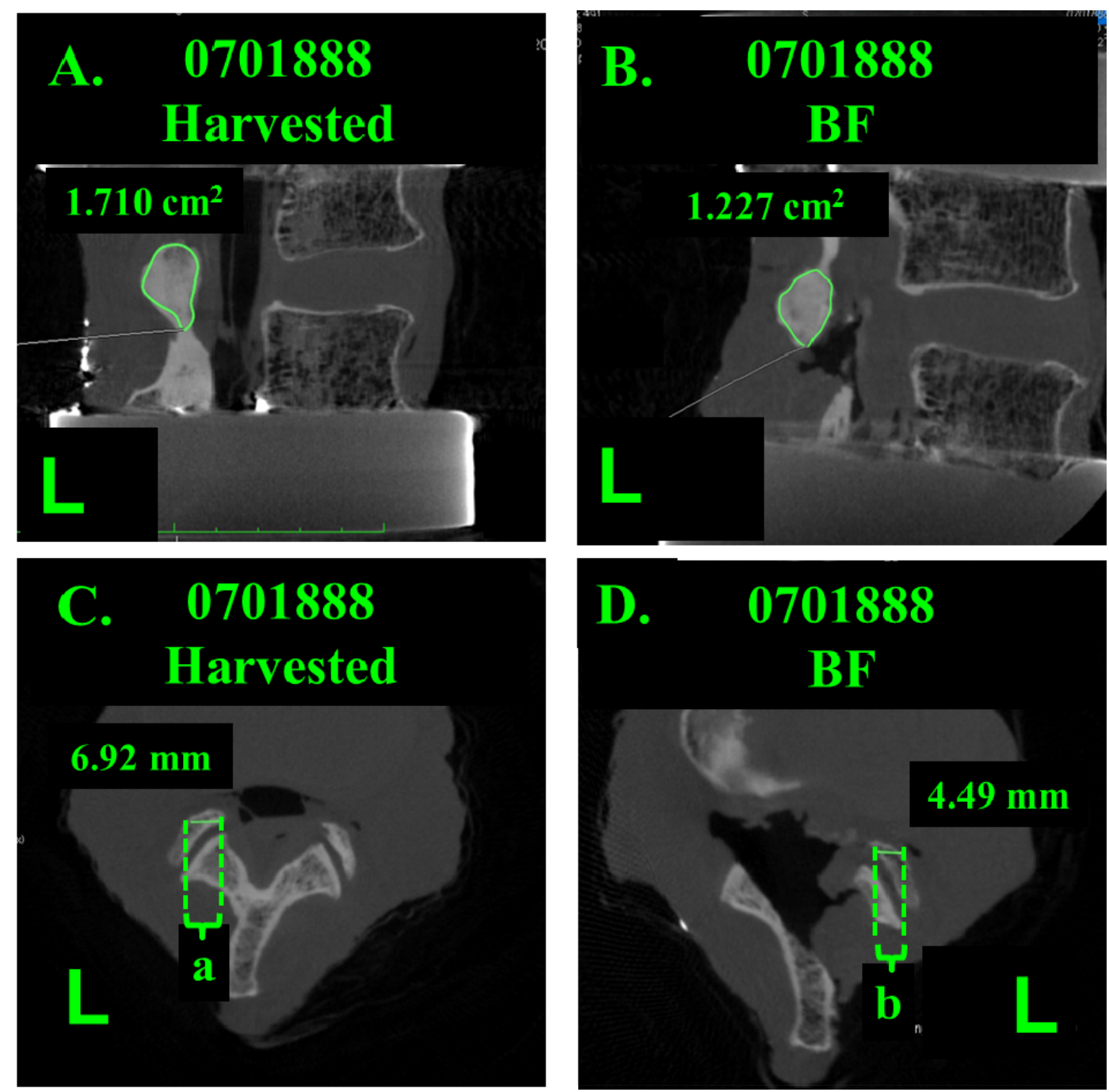

Figure 3-11. Measurements Gathered from CT Images. Images A and B display the measured area of the facet using the built-in area function in Osirix for the harvested and bilateral facetectomy. Images $C$ and $D$ display the length of the facet joint measurement according to Matsumura et al. The joint preservation percentage was calculated as $\mathrm{b} / \mathrm{a} \mathrm{x}$ $100[88]$. 


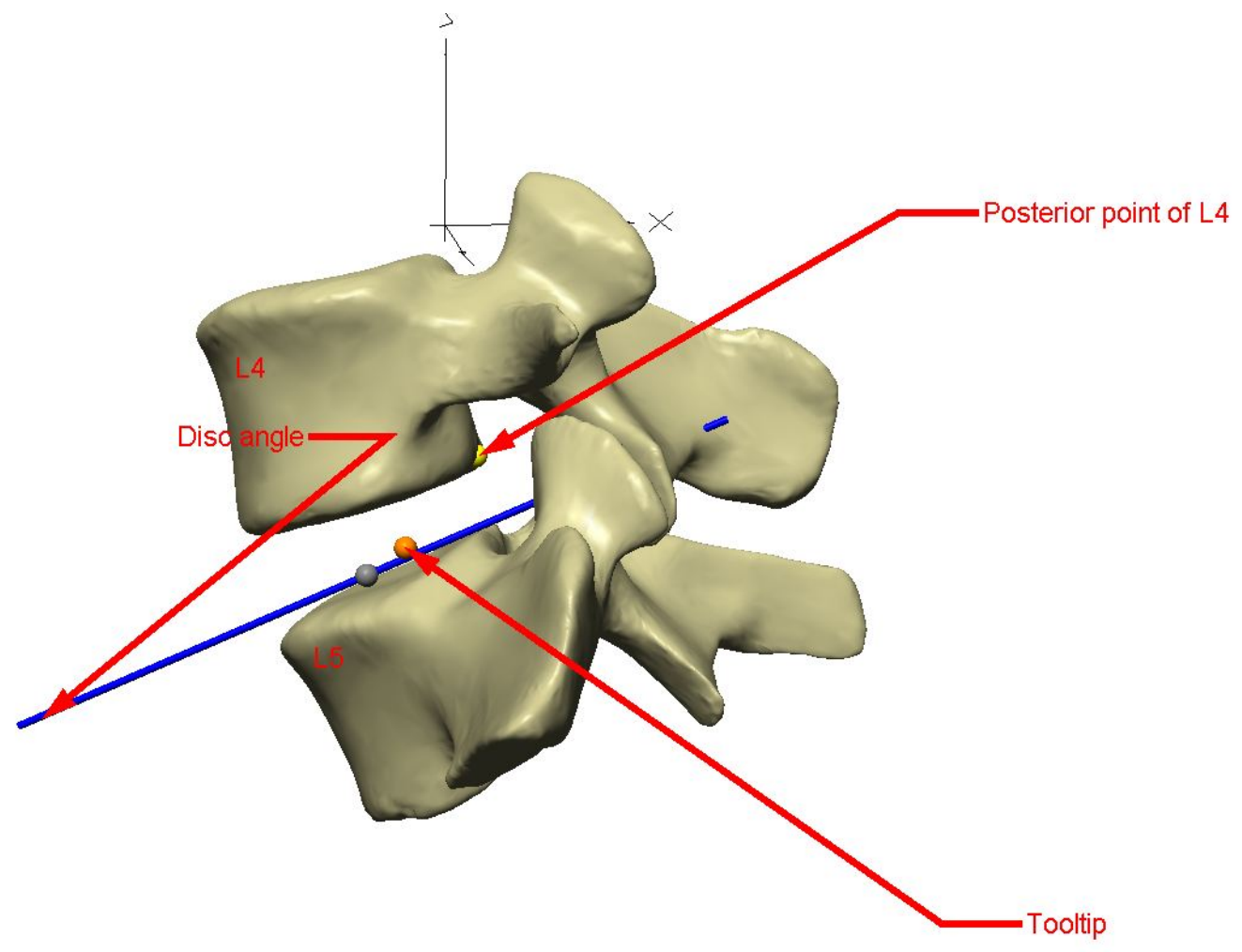

Figure 3-12. Simulation of PM and CLM Protocols in Flexion. The yellow point is the posterior point of the inferior endplate of the upper vertebrae. The translation of this point is what clinicians use to determine instability. The orange point is the tool-tip coordinates, and the blue line is the disc angle axis from which the translations were recorded. 
percentage of preservation, and comparison between the simulation translation data of PM and CLM protocols were analyzed using a Wilcoxon Signed Rank test (nonparametric paired t-test) at $\mathrm{p}<0.05$. All CT measurements were analyzed using a Wilcoxon-Signed Rank test to test for statistical differences between observers. 


\section{CHAPTER 4: RESULTS}

\section{Pure Moment Protocol}

Figure 4-1 displays the mean rotational data from the PM and CLM protocols. The rotation is plotted on the $y$-axis and the mode of bending is on the $\mathrm{x}$-axis. In all modes of bending there was a statistical difference between the harvested and the UF condition. There was a decrease in motion from the intact to UF in all modes of bending, except right lateral. There were differences seen between the UF and the BF conditions, except in right lateral bending. With respect to the laminectomized condition, there were differences seen between the laminectomized condition and the UF condition in flexion, extension, and left lateral bending. Also, there were differences seen between the intact and the laminectomized condition in right lateral.

\section{Combined Loading and Moment Protocol}

Figures 4-1 and 4-2 display the flexion and extension mean rotational data of the combined loading and moment and pure moment protocols to enable easy comparison between the two. The CLM protocol displayed differences between the intact and the UF condition in flexion, and differences between the BF and UF conditions. Also, when the laminectomized condition was added differences were seen between the UF and laminectomy. In extension for the CLM protocol, there were no differences seen between the intact and the UF condition, but with the BF condition, differences between the harvested and $\mathrm{BF}$ and between the UF and BF were seen. The laminectomized condition was found to be statistically different from the intact and the UF conditions. When comparing the outcomes of the PM and the CLM protocols for each spine condition, there were differences seen in the harvested condition in flexion, and in the harvested, $\mathrm{BF}$, and laminectomized condtions in extension. PM and CLM tabulated data can be found in Appendix C.

\section{Simulation of Pure Moment and Combined Loading and Moment Protocols}

The first reports of post-operative instability after decompression were made by Hazlett and Kinnard [19], White and Wiltse [89], and Shenkin and Hash [90]. White and Panjabi and Posner created a checklist for instability based on a point system using radiographic and injury criteria $[27,53]$. In this study there was no radiographic data, but measurements of translation along the disc axis were determined via a simulation model.

A $30 \%$ scaling factor was used to account for imaging magnification and applied to the radiograph definition [27]. The rescaled definitions of instability by Disch et al, and White and Panjabi for absolute values range from 2.3 and $3.5 \mathrm{~mm}[27,54]$. The value of $10 \%$ of the vertebral A-P length was used, as it is one of the clinical requirements for the diagnosis of spondylolisthesis [58]. A graph of the results, without the translations of 


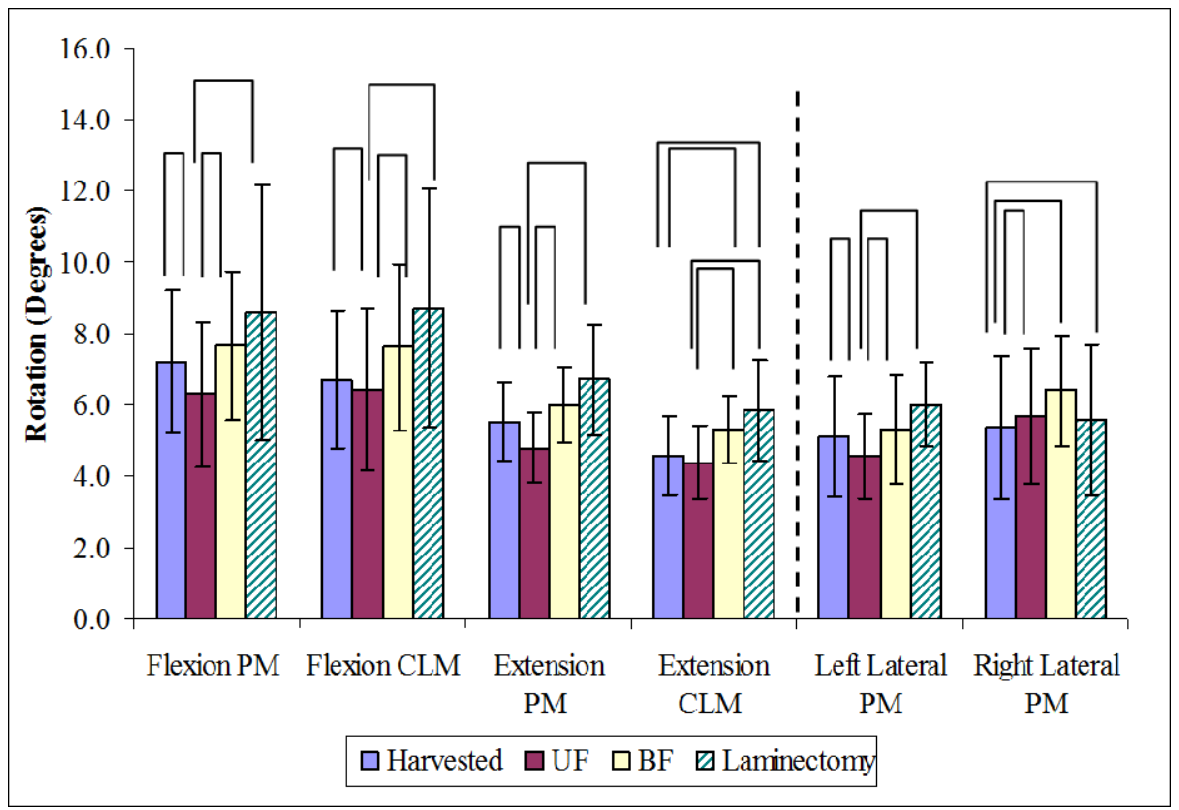

Figure 4-1. Rotational Differences for PM and CLM Protocols. A RM ANOVA on ranks was used to compare the conditions within the modes of bending. Significant differences are represented by brackets and the standard deviations are represented with bars. End limits of $8 \mathrm{Nm}$ for flexion and extension and $6 \mathrm{Nm}$ for left and right lateral bending were used. 


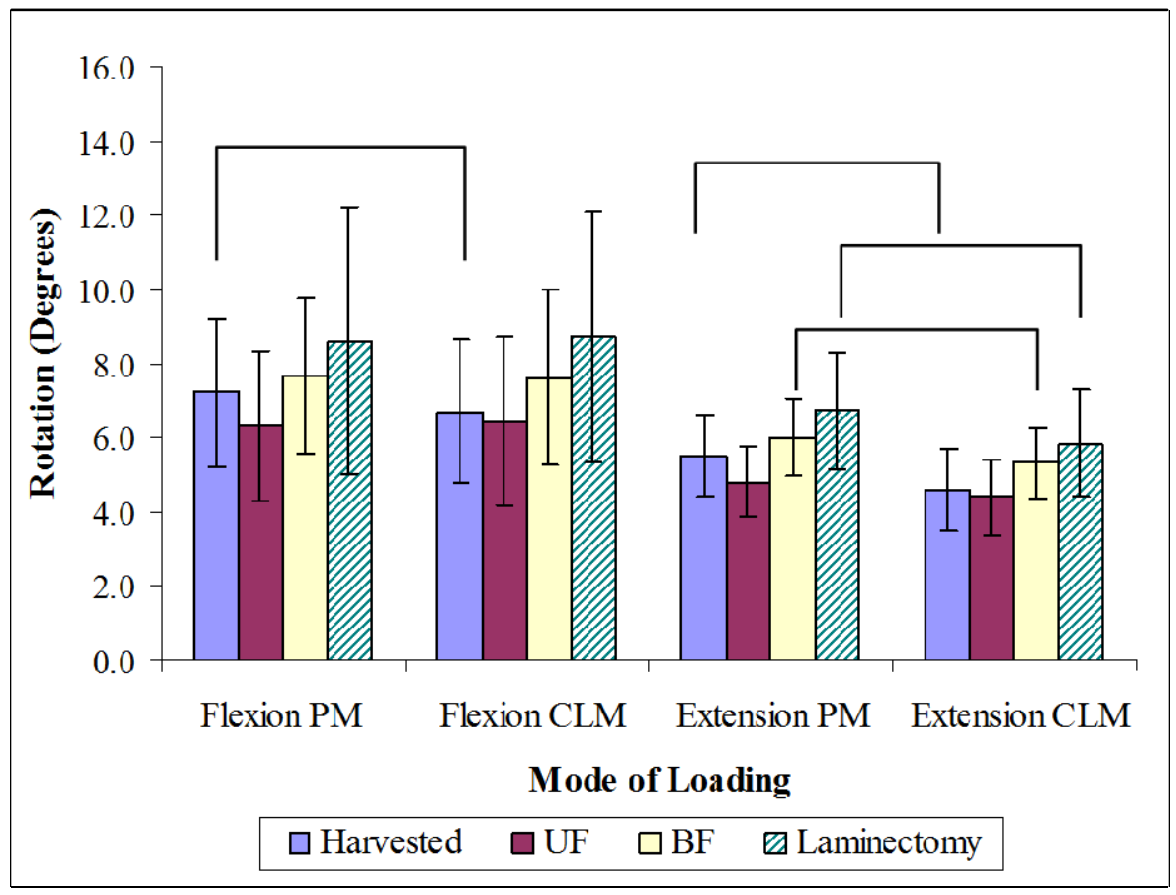

Figure 4-2. Comparing Sagittal Rotations between CLM and PM Protocols. A Signed-Rank test was performed to view statistical differences between the two protocols at the $8 \mathrm{Nm}$ end limit, shown in brackets. Standard deviations are represented as bars and all data was analyzed at an $8 \mathrm{Nm}$ end limit. 
the specimen 0701888 which had values of a possible outlier, is shown in Figure 4-3. None of the mean values met the clinical instability criteria. There were no differences seen in the translation results from the PM protocol; however, there were differences within the CLM testing protocol. There was a slight decrease in translation from the harvested in the UF and BF conditions. A sharp increase in translation was seen in the laminectomized condition, but not statistically significant. The only difference seen between the two protocols in translation was in the laminectomized condition. Appendix D contains the tabulated simulation data.

\section{Coupled Eccentric Loading Protocol}

The CEL rotational data can be found in Figure 4-4 and Appendix E. Comparing the harvested and the UF spine conditions, there are differences seen in extension with left axial. With the BF condition, there were differences seen from the harvested and the $\mathrm{BF}$ and between the UF and BF conditions in extension with left axial and left axial with left lateral. Axial rotation accentuated the significant differences that occurred between the laminectomized and the other three conditions in flexion with right axial, extension with left axial, extension with right axial, left axial with left lateral, and right axial with right lateral. A summary of all the data from the three testing protocols can be found in Table 4-1.

\section{Facet Measurements}

Facet angles less than 40 degrees are considered to have pathological implications [10]. Since the MSUs were of varying levels and there were too few to compare within each level, the specimens were pooled together in the same procedure as the rotational data and statistically compared. The Wilcoxon-Signed Rank test found a difference between the intact and the facetectomy spine conditions for both the left and right sides $(\mathrm{p}=0.039$ and $\mathrm{p}=0.039$, respectively) for the facet angle observations. The interobserver error for the facet angle was calculated to be $1.3^{\circ}$. Also, the facet area for each joint was statistically different, with a p-value of 0.039 for the left side and 0.008 for right side when comparing the $\mathrm{BF}$ to the respective harvested facet areas. The interobserver error of the area of resection measurements was calculated to be $0.147 \mathrm{~cm}^{2}$. The length of the facet also displayed differences between the surgically altered and harvested conditions, $\mathrm{p}=0.016$ for the left facet and $\mathrm{p}=0.016$ for the right facet with an interobserver error of $0.55 \mathrm{~mm}$. Figures 4-5, 4-6, and 4-7 display the facet angle observations, the area observations, and the length of joint preservation for each facet joint of the varying levels. The calculated mean percent of preservation length compared to values from Matsumura is shown in Figure 4-8. Matsumura et al observed less removal on the contralateral side of the surgical approach, whereas this study observed more removal on the contralateral to the surgical approach [88]. No statistical differences were found between observers for all measurements.

The largest facet angle change was in the L2-3 specimen and was 9.0 degrees on 


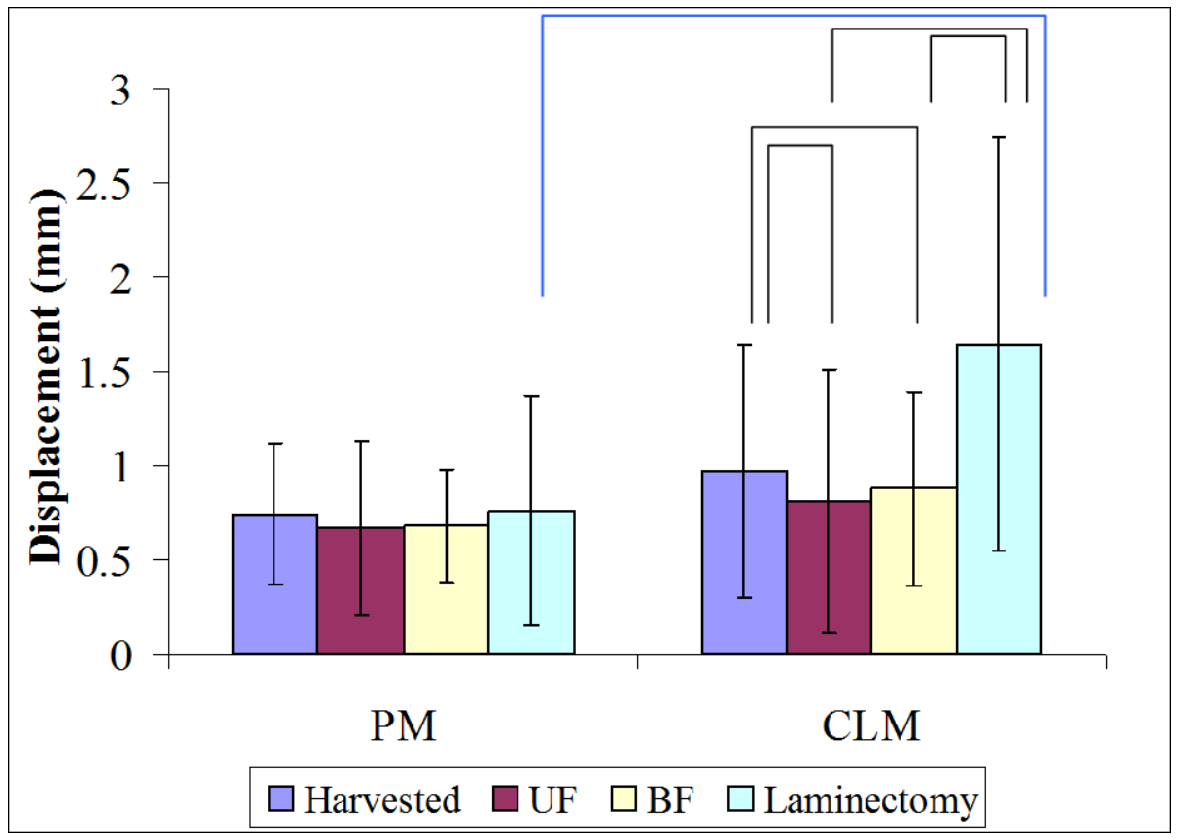

Figure 4-3. Translations for CLM and PM (without 0701888). A Wilcoxon Signed Rank test was performed to view statistical differences between the two protocols shown in blue. A non-parametric RM ANOVA was used to determine surgical differences within each protocol. 


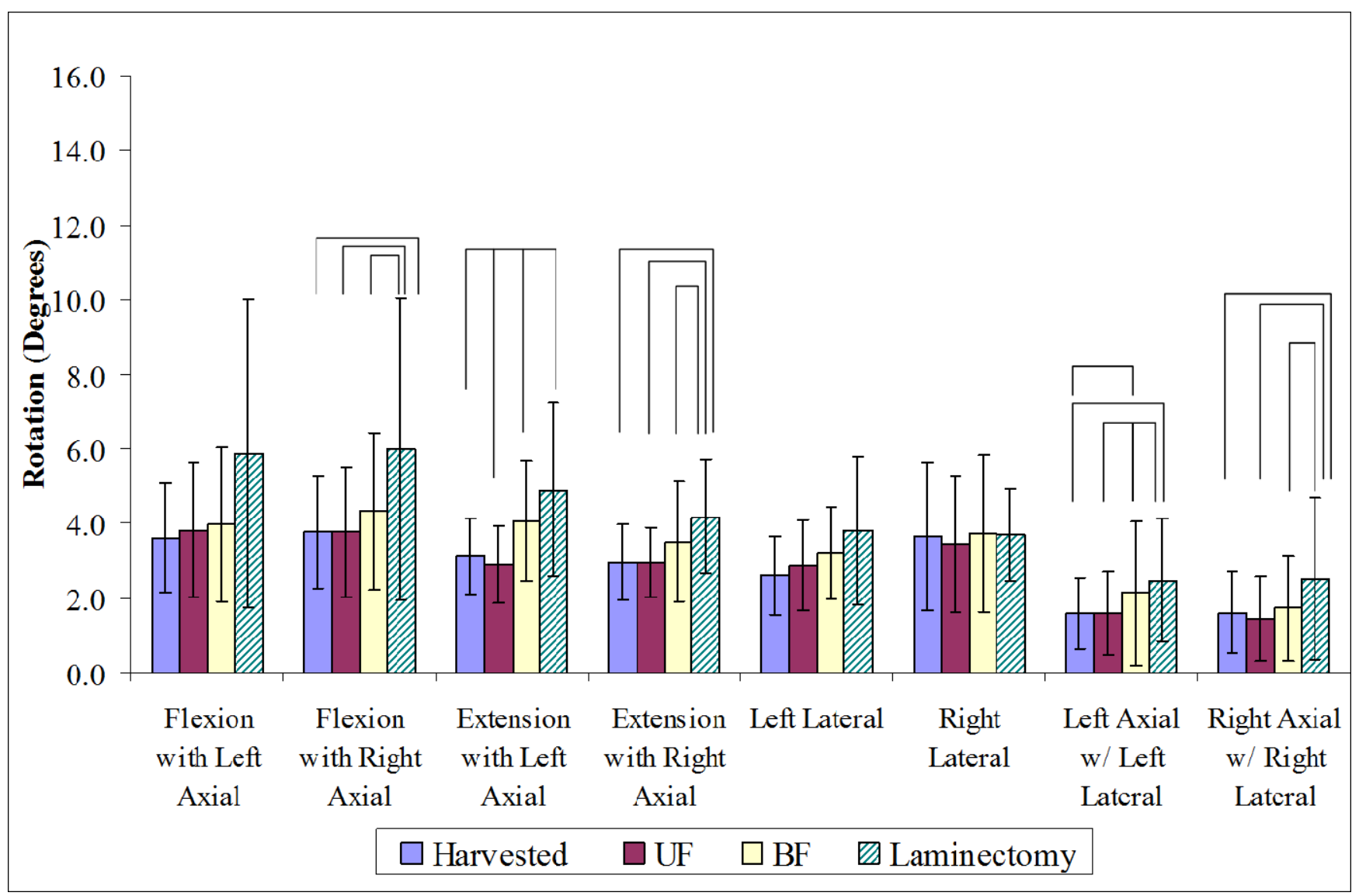

Figure 4-4. Rotational Results of the CEL Protocol. A RM ANOVA on Ranks with SNK multi-comparison test ( $p<0.05)$ was performed to view statistical differences between the spine conditions based on the rotations. The differences seen are shown with brackets. Axial rotation during left and right lateral bending is also shown. Resultant end limits for flexion and extension were 8Nm and $6 \mathrm{Nm}$ for left and right lateral bending. 
Table 4-1. Summary of Statistical Results under Specified Loading Protocols.

\begin{tabular}{|c|c|c|c|c|c|c|c|c|}
\hline \multirow[b]{2}{*}{ Measurement } & \multirow[b]{2}{*}{ Protocol } & \multirow[b]{2}{*}{ Mode of Bending } & \multicolumn{6}{|c|}{ Spine Conditions Compared* } \\
\hline & & & Harv vs. UF & Harv vs. BF & Harv vs. Lami & UF vs. BF & UF vs. Lami & BF vs. Lami \\
\hline \multicolumn{9}{|l|}{ Rotation } \\
\hline & \multirow[t]{4}{*}{$\mathrm{PM}$} & Flexion & $\downarrow$ & $\mathrm{NC}$ & $\mathrm{NC}$ & $\uparrow$ & $\uparrow$ & NC \\
\hline & & Extension & $\downarrow$ & $\mathrm{NC}$ & $\mathrm{NC}$ & $\uparrow$ & $\uparrow$ & $\mathrm{NC}$ \\
\hline & & Left Lateral & $\downarrow$ & $\mathrm{NC}$ & $\mathrm{NC}$ & $\uparrow$ & $\uparrow$ & $\mathrm{NC}$ \\
\hline & & Right Lateral & $\uparrow$ & $\uparrow$ & $\uparrow$ & $\mathrm{NC}$ & $\mathrm{NC}$ & $\mathrm{NC}$ \\
\hline & \multirow[t]{2}{*}{ CLM } & Flexion & $\downarrow$ & $\mathrm{NC}$ & $\mathrm{NC}$ & $\uparrow$ & $\uparrow$ & $\mathrm{NC}$ \\
\hline & & Extension & $\mathrm{NC}$ & $\uparrow$ & $\uparrow$ & $\uparrow$ & $\uparrow$ & $\mathrm{NC}$ \\
\hline & \multirow[t]{8}{*}{ CEL } & Flexion (+ LA) & $\mathrm{NC}$ & $\mathrm{NC}$ & $\mathrm{NC}$ & $\mathrm{NC}$ & $\mathrm{NC}$ & $\mathrm{NC}$ \\
\hline & & Flexion (+ RA) & $\mathrm{NC}$ & $\mathrm{NC}$ & $\uparrow$ & $\mathrm{NC}$ & $\uparrow$ & $\uparrow$ \\
\hline & & Extension (+ LA) & $\downarrow$ & $\uparrow$ & $\uparrow$ & $\uparrow$ & $\uparrow$ & $\uparrow$ \\
\hline & & Extension (+ RA) & $\mathrm{NC}$ & $\mathrm{NC}$ & $\uparrow$ & $\mathrm{NC}$ & $\uparrow$ & $\uparrow$ \\
\hline & & Left Lateral (+LA) & $\mathrm{NC}$ & $\mathrm{NC}$ & $\mathrm{NC}$ & $\mathrm{NC}$ & $\mathrm{NC}$ & $\mathrm{NC}$ \\
\hline & & Right Lateral (+RA) & $\mathrm{NC}$ & $\mathrm{NC}$ & $\mathrm{NC}$ & $\mathrm{NC}$ & $\mathrm{NC}$ & $\mathrm{NC}$ \\
\hline & & Left Axial (+ LL) & $\mathrm{NC}$ & $\uparrow$ & $\uparrow$ & $\uparrow$ & $\uparrow$ & $\uparrow$ \\
\hline & & Right Axial (+ RL) & $\mathrm{NC}$ & $\mathrm{NC}$ & $\uparrow$ & $\mathrm{NC}$ & $\uparrow$ & $\uparrow$ \\
\hline \multicolumn{9}{|l|}{ Translation } \\
\hline & PM & Flexion & $\mathrm{NC}$ & $\mathrm{NC}$ & $\mathrm{NC}$ & $\mathrm{NC}$ & $\mathrm{NC}$ & $\mathrm{NC}$ \\
\hline & CLM & Flexion & $\downarrow$ & $\downarrow$ & $\mathrm{NC}$ & NC & $\uparrow$ & $\uparrow$ \\
\hline 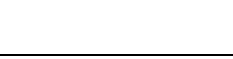 & \multicolumn{2}{|c|}{ Number of Statistical Changes } & 7 & 5 & 7 & 7 & 11 & 6 \\
\hline
\end{tabular}




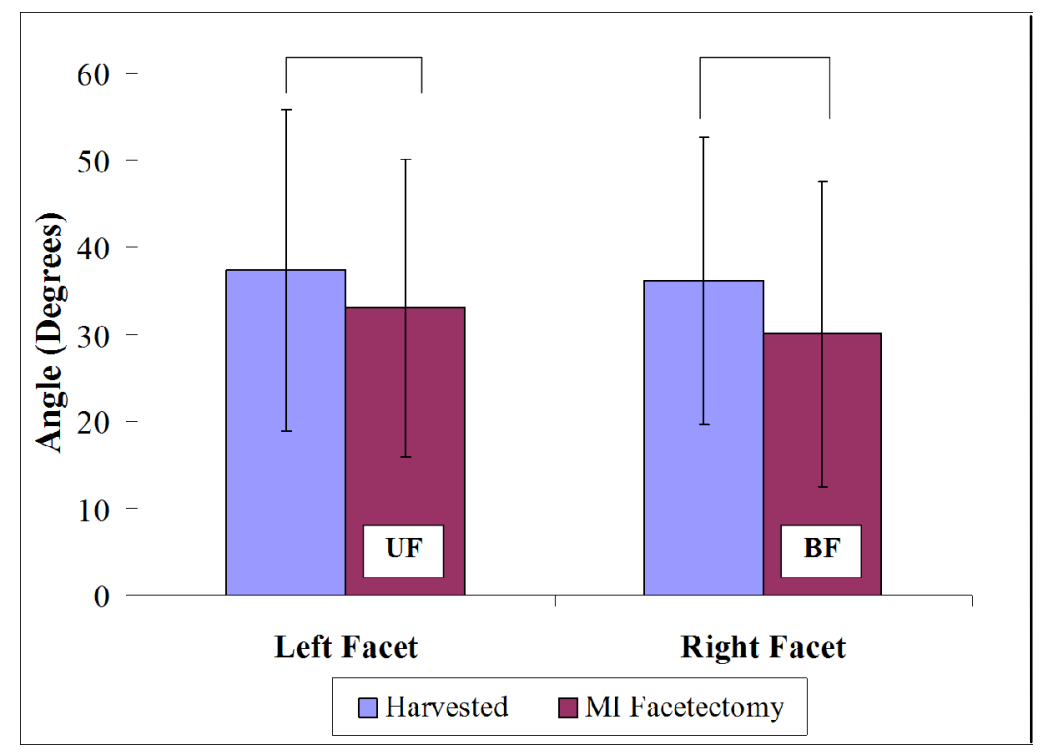

Figure 4-5. Mean Facet Angulation. Angulation was recorded in the transverse plane. Differences displayed using a Wilcoxon Signed Rank test with $\mathrm{p}<0.05$.

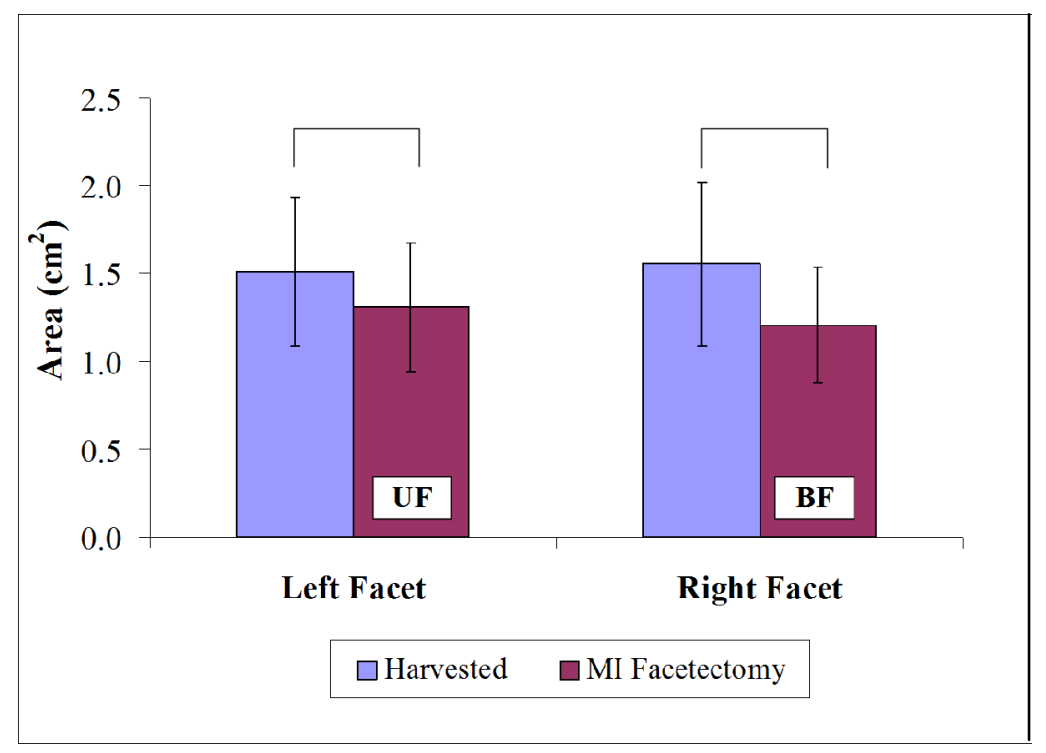

Figure 4-6. Mean Facet Joint Area. A Wilcoxon Signed Rank Test was performed with a $p<0.05$ to show difference between the intact and MI Facetectomy. UF procedure performed on the left facet and the BF procedure performed on the right facet. 


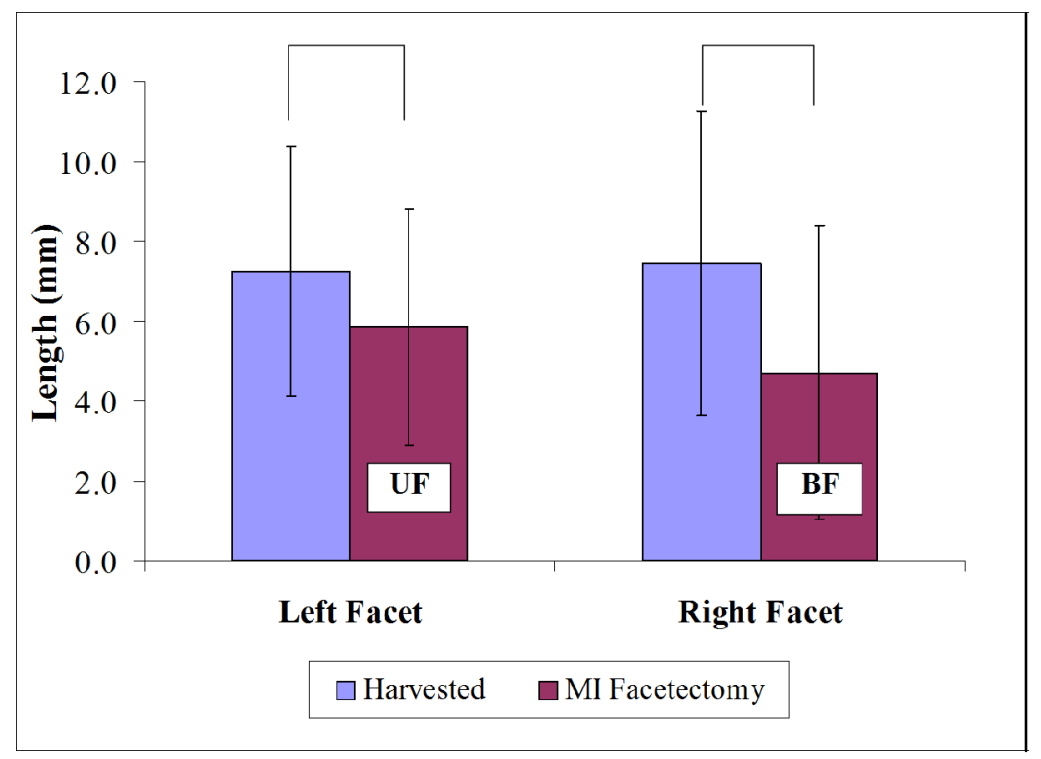

Figure 4-7. Mean Facet Preservation Length. UF procedure performed on the left facet and the BF procedure performed on the right facet. Differences displayed using a Wilcoxon Signed Rank test with $\mathrm{p}<0.05$. 


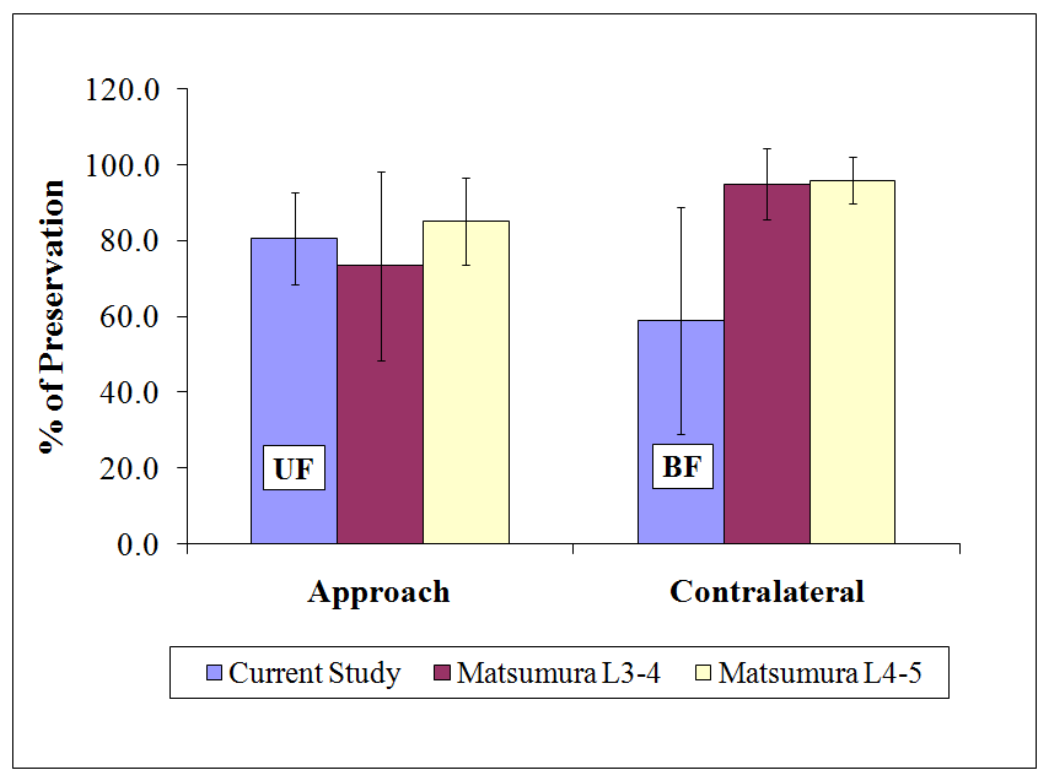

Figure 4-8. Mean Percent of Preservation Length. UF procedure performed on the left facet and the BF procedure performed on the right facet. Calculation performed according to Matsumura et al. Source: Matsumura, A., Namikawa, T., Terai, H., Tsujio, T., Suzuki, A., Dozono, S., et al. The influence of approach side on facet preservation in microscopic bilateral decompression via a unilateral approach for degenerative lumbar scoliosis. Clinical article. J Neurosurg Spine. 2010. 13(6): p. 758-65 [88]. 
the right facet complex (6.0 degrees for L1-2 and 3.4 degrees for L4-5). On the left side, the angle changes were 1.2 degrees for L1-2, 8.5 degrees for L2-3, and 6.3 degrees for L4-5. The CT observations can be found in Appendices F and G. 


\section{CHAPTER 5: DISCUSSION}

Historically traditional open surgical techniques have evolved toward minimallyinvasive surgical (MIS) procedures, and are gaining popularity because of the benefits they provide: decreased recovery time and decreased amount of removal of important anatomical structures. Reduction of soft tissue trauma will decrease the impact on the normal FSU stability and function. ROM preservation, less adjacent level degeneration, and less pain are the expected benefits of MIS procedures. However, there is little biomechanical evidence that MIS procedures do not cause clinical instability [25]. Furthermore, it is controversial when fusion and instrumentation intervention is needed after decompression procedures, especially one that removes much of the posterior elements.

The objectives of this study were to compare minimally-invasive surgical decompression procedures to the traditional laminectomy procedure via the following methods 1) evaluation of the biomechanical stability of these interventions through three different testing protocols (PM, CLM, and CEL), 2) comparison of translational results to clinical instability criteria, and 3) investigation of the change in morphology of the facets after a minimally-invasive bilateral medial facetectomy. The results of the surgically altered conditions were compared to the harvested control condition, and the least stable procedure was identified. The surgical procedures tested were the minimally invasive (MI) unilateral facetectomy (UF), the MI bilateral facetectomy via a unilateral approach $(\mathrm{BF})$, and the standard laminectomy.

Figure 5-1 displays how the intact rotational values from the PM and CLM testing protocols were similar as compared to values from previous biomechanical studies by Schultz et al and Panjabi et al (400 N pre-load and pure moment 7.5 Nm), giving validity to the protocols $[91,92]$. When comparing the PM and CLM findings the overall amount of rotation was significantly less for the CLM relative to the PM for flexion (harvested) and extension (harvested, BF, and Lami) loading. However, even though the total ROM was less for the CLM, more significant differences between the spine conditions occurred for the CLM (one more). Another way of saying this is that the CLM protocol was more sensitive to detecting differences between spine conditions even though the overall ROM was less. When comparing the spine conditions within the same testing protocol, both the PM and CLM protocols detected the same three differences during flexion. During extension, the CLM detected four significant differences that identified the weaker spine conditions (BF and Lami) to be significantly different from the two more stable ones. Conversely, the PM condition detected differences between the UF condition and the other three spine conditions.

The UF condition yielded less motion when compared to the intact condition for flexion in the CLM protocol and for all modes of bending in the PM protocol, except right lateral. Left and right lateral bending in the PM protocol displayed the dependence of the surgical side. A plausible hypothesis for this observation is that the operated, leftsided approach of the UF may have caused the joint to catch the roughened surfaces after 


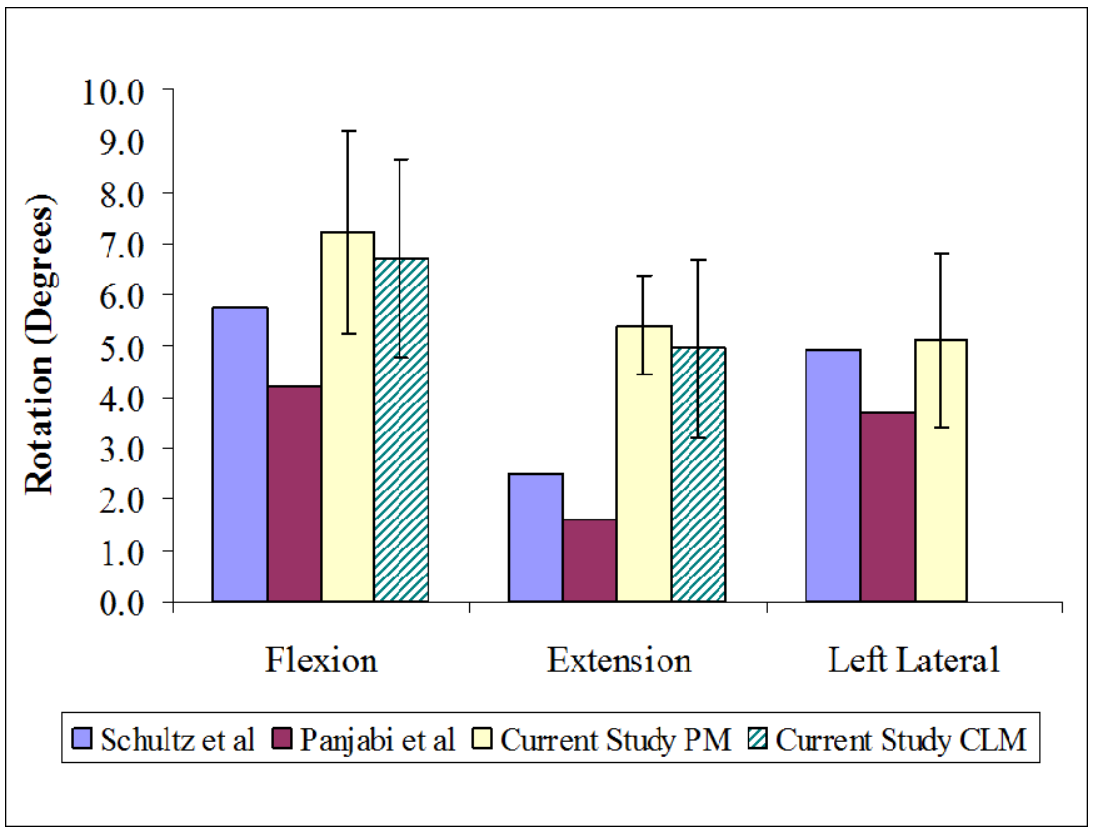

Figure 5-1. Harvested Rotational Comparison with Previous Studies. Schultz et al and Panjabi et al rotational values obtained under a $400 \mathrm{~N}$ pre-load and pure moment 7.5 Nm load scenario. Sources: Panjabi, M.M., Krag, M.H. and Chung, T.Q. Effects of disc injury on mechanical behavior of the human spine. Spine. 1984. 9(7): p. 707-13 [91]. Schultz, A.B., Wareick, D. N., Berkson, M.H. Mechanical properties of human lumbar spine motion segments: responses in flexion, extension, lateral bending and torsion. $\mathrm{J}$ Biomech Eng. 1979. 101: p. 46-52 [92]. 
bone removal on the left side, but in right lateral bending the left-side facet joint opened more, hence showing an increase in rotation.

As one would expect, in extension, when the facets are fully engaged, any disruption of the joint would lead to differences from the intact condition. The rotational results of the CEL protocol displayed differences among all conditions in extension with left axial rotation. Facet morphology plays an important role in axial rotation; moreover, left axial rotation coupled with left lateral bending saw no difference between the UF and harvested condition, but more removal led to significantly more motion amongst all other conditions. Significantly more motion between the destabilized laminectomized condition and all other conditions occurred in flexion with right axial, extension with right axial, and right axial rotation during right lateral bending.

The PM protocol does not induce a compressive load and the CEL protocol has a moderate compressive load when compared to the CLM. When comparing the CEL to the PM and CLM protocols, the inclusion of axial rotation had less significant rotational differences between the harvested and the UF and BF conditions, but more significant differences occurred once the most destabilized--laminectomized condition was introduced. The CEL protocol also displayed increases in motion between the MI BF and traditional laminectomy conditions. Although no translational data can be extracted from the CEL protocol, the study of the influence of facet removal on active axial rotation is important.

In this study, the translation of the posterior edge of the superior body in the simulation did not find evidence to support instability, even with the traditional laminectomy. Even when divided into the translation for each MSU level, no segments reached the criteria for instability scaled from the clinical radiographic translation criteria $[27,53,54]$. If a larger compressive force was introduced for the CLM protocol, it would have led to more shear, inducing more translation along the disc axis.

The facets play an important role in the resistance of A-P shear, especially in flexion and extension. This shear force can induce translation, and can render the level unstable. Shear-flexion ratios at symptomatic levels in patients with degenerative lumbar instability have been found to be related [93]. There have been few biomechanical studies that have measured the effect of facet removal on the translational stability of the MSU $[53,71]$. Posner et al measured displacement after PLL, facet removal, disc removal, and ALL injury until failure, which observed increased displacement with removal. The nonlinear FE model by Sharma et al showed increases in displacement with removal of the same structures in agreement with Posner et al $[53,71]$. These two studies are much different from the current one, but the generalization that more motion with more removal should hold true.

Using different measurements to quantify the amount of removal due to surgery or to understand pathology is important. There has been much debate whether the morphology of the facet joints can contribute to spinal disease, such as degenerative disc disease, or disc herniation $[11,12]$. Additionally, it is unclear on how the facet angle may 
affect a segment's stability, especially in the patient with spondylolisthesis. Facet angles less than 40 degrees have been thought to cause instability in patients with spondylolisthesis because of their inability to resist shear [10]. There were significant decreases found between the intact and facetectomy cases for both the left and right facets for the angle, area, and length preservation measurements. The results of the current study are comparable to the results by Masharawi et al (Table 5-1).

One of major limitations of this study is the small sample size. Otsuka et al measured the facet area in vivo using tracings on a tablet digitizer, estimated the area with polygons, and took a mean of both the left, right, inferior, and superior facets. Table 5-2 displays the results of the current study compared to two previous studies. The results for the L3-4 and L4-5 segments of the Otsuka et al study were $158.2 \pm 4.1 \mathrm{~mm}^{2}$ and 189.8 $\pm 7.2 \mathrm{~mm}^{2}(\mathrm{n}=90)$ and were comparable to the values of the current study $(153.2 \pm 43.13$ $\mathrm{mm}^{2}$ ). The results of Panjabi et al also were a comparable to the current study, and had more upper level lumbar segments for a better comparison.

No correlation could be made to the significant differences seen in the facet measurements with the biomechanical data. The L4-5 segments were the closest to the criteria for clinical instability, with an average translation of $1.98 \mathrm{~mm}$. Perhaps, if greater compressive and shear load was applied in the CLM protocol to induce more translation this data would be in agreement with the facet measurement results biomechanically. This would be important for L4-5 segments, due more laterally oriented facets and natural lordotic angle that induces more shear force.

The laminectomy was found to be the weakest or most destabilized condition amongst the three protocols, displaying increases in half of the rotational values in the various modes of bending compared to the harvested condition. Hence, this condition may require instrumentation. Conversely, significant increases in rotation may not mean the segment is clinically unstable, especially since the other half of the rotational difference between the laminectomy and the harvested condition were not significantly different. Also, there have been clinically favorable outcomes cited [51, 52].

The limitations of this study are the small sample size per segmental level, the inability to measure the translational motion along the disc axis for the CEL protocol, and movement of the specimen out of the testing apparatus for surgery or change of the testing setup. The ideal testing method for this study would have been leaving the specimen in the testing frame while performing the surgical procedures. However, this is not very practical in that these procedures required the use of a surgical microscope and $\mathrm{C}$-arm and would have been difficult to manage. Lastly, during normal activities the muscles play an important role of reducing and distributing the amount of load on the spine. In this study, no muscle involvement was included.

Further investigation of instability due to induced shear load on a spinal unit is needed. Although this study made an attempt to study the influence of the change in facet morphology with the biomechanical study of a coupled-eccentric loading protocol, it was merely a scratch on the surface. Furthermore, the dissection of these specimens would 
Table 5-1. Facet Angle Observations and Comparison to Previous Studies.

\begin{tabular}{cccccccc}
\hline & \multicolumn{2}{c}{ Left Inferior Transverse Facet Angle } & & \multicolumn{2}{c}{ Right Inferior Transverse Facet Angle } \\
\cline { 2 - 4 } \cline { 6 - 7 } Level & Current Study & Masharawi et al* & Panjabi et al & & Current Study & Masharawi et al* & Panjabi et al $\S$ \\
\hline L1 & 25.3 & $24.54( \pm 16.17)$ & 66.1 & & 26 & $26.39( \pm 17.38)$ \\
L2 & 34.9 & $28.77( \pm 28.77)$ & 47.9 & & 31.9 & $33.87( \pm 19.27)$ \\
L4 & 63.9 & $50.19( \pm 17.08)$ & 25.1 & & 60.6 & $54.15( \pm 14.53)$ \\
\hline
\end{tabular}

Note: *Masharawi et al n=240 [49], § Panjabi et al n=12 [94], Current study L1-L2 (n=4), L2-L3 (n=2), L4-L5 (n=2).

Sources: Masharawi, Y., Rothschild, B., Dar, G., Peleg, S., Robinson, D., Been, E., et al. Facet orientation in the thoracolumbar spine: three-dimensional anatomic and biomechanical analysis. Spine. 2004. 29(16): p. 1755-63 [49]. Panjabi, M.M., Oxland, T., Takata, K., Goel, V., Duranceau, J. and Krag, M. Articular facets of the human spine. Quantitative three-dimensional anatomy. Spine. 1993. 18(10): p. 1298-310 [94].

Table 5-2. Facet Area Observations and Comparison to Previous Studies.

\begin{tabular}{cccc}
\hline & \multicolumn{3}{c}{ Inferior Facet Area } \\
\cline { 2 - 4 } Level & Current Study $(\mathrm{n}=8)^{*}$ & Otsuka $(\mathrm{n}=90)$ & Panjabi $(\mathrm{n}=12)$ \\
\hline L1 & 131 & - & 127 \\
L2 & 144 & - & 152 \\
L3 & - & 150 & 164 \\
L4 & 206 & 182 & 175 \\
Mean & 153 & 166 & 154.5 \\
\hline
\end{tabular}

Notes: *This is the mean area of both the left and right facet. The current study has 4 L1-2, 2 L2-3, and 2 L4-5 segments.

Sources: Otsuka, Y., An, H.S., Ochia, R.S., Andersson, G.B., Espinoza Orias, A.A. and Inoue, N. In vivo measurement of lumbar facet joint area in asymptomatic and chronic low back pain subjects. Spine. 2010. 35(8): p. 924-8 [95]. Panjabi, M.M., Oxland, T., Takata, K., Goel, V., Duranceau, J. and Krag, M. Articular facets of the human spine. Quantitative three-dimensional anatomy. Spine. 1993. 18(10): p. 1298-310 [94]. 
have validated the measurements from the CT data, as well as gain a better insight how much real removal of tissue occurred. Also, future studies of how the surgical approach affects the MSU function can also be done to determine whether removal of the bone needs to remain perpendicular to the facet joint or at an angle. Further studies must be done to investigate the influence of the facet structures both in its native form and following surgical intervention. 


\section{CHAPTER 6: CONCLUSIONS}

The biomechanical evaluations of the lumbar facets and facetectomies have been studied before, but no previous research has utilized multiple loading scenarios, taken into account the amount of resection or the facet angle, or attempted to quantify the amount of instability that occurs through the surgical procedures of minimally-invasive unilateral facetectomies, bilateral facetectomies, and laminectomies.

The CLM protocol saw decreased motion in the harvested condition for the intact condition when compared to the PM. The CLM showed one more significant difference despite the decreased ROM compared to PM, suggesting that it is a more sensitive protocol to finding differences in the surgically altered specimen. The CEL protocol highlighted more differences when the most destabilized condition, the laminectomy was introduced. No instability was found in the simulation of the protocols of PM and CLM, but the CLM protocol showed more statistical differences in translation along the disc axis when compared to the pure moment protocol. Significant differences in facet angle, contact area, and length of joint measurements were found. A summary of the results and tabulated changes of all the testing protocols was shown in Table 4-1. The least amount of significant changes between the harvested spine condition occurred with the bilateral facetectomy with five changes, followed by the unilateral facetectomy and laminectomy with seven changes. The UF procedure saw a decrease in motion, which may have a more stabilizing effect on a motion level. The laminectomy displayed an increase in motion, making it the weakest surgical procedure, which may require instrumentation.

With the increasing popularity of minimally-invasive procedures, further investigation of how they biomechanically affect the spine is warranted. Recommendations for further work are using more L4-L5 MSUs, adding more compressive and shear load, and the investigation of minimally-invasive procedures on cervical and thoracic MSUs using the CEL and CLM protocols. 


\section{LIST OF REFERENCES}

1. Hermantin, F.U., Peters, T., Quartararo, L. and Kambin, P. A prospective, randomized study comparing the results of open discectomy with those of videoassisted arthroscopic microdiscectomy. J Bone Joint Surg Am. 1999. 81(7): p. 958-65.

2. Huang, T.J., Hsu, R.W., Li, Y.Y. and Cheng, C.C. Less systemic cytokine response in patients following microendoscopic versus open lumbar discectomy. $\mathrm{J}$ Orthop Res. 2005. 23(2): p. 406-11.

3. Righesso, O., Falavigna, A. and Avanzi, O. Comparison of open discectomy with microendoscopic discectomy in lumbar disc herniations: results of a randomized controlled trial. Neurosurgery. 2007. 61(3): p. 545-9; discussion 549.

4. McCulloch, J.A. Microdecompression and uninstrumented single-level fusion for spinal canal stenosis with degenerative spondylolisthesis. Spine. 1998. 23(20): p. 2243-52.

5. Palmer, S. Use of a tubular retractor system in microscopic lumbar discectomy: 1 year prospective results in 135 patients. Neurosurg Focus. 2002. 13(2): p. E5.

6. Haufe, S.M. and Mork, A.R. Effects of unilateral endoscopic facetectomy on spinal stability. J Spinal Disord Tech. 2007. 20(2): p. 146-8.

7. Weiner, B.K., Walker, M., Brower, R.S. and McCulloch, J.A. Microdecompression for lumbar spinal canal stenosis. Spine. 1999. 24(21): p. 2268-72.

8. Palmer, S., Turner, R. and Palmer, R. Bilateral decompressive surgery in lumbar spinal stenosis associated with spondylolisthesis: unilateral approach and use of a microscope and tubular retractor system. Neurosurg Focus. 2002. 13(1): p. E4.

9. Iguchi, T., Kanemura, A., Kasahara, K., Sato, K., Kurihara, A., Yoshiya, S., et al. Lumbar instability and clinical symptoms: which is the more critical factor for symptoms: sagittal translation or segment angulation? J Spinal Disord Tech. 2004. 17(4): p. 284-90.

10. Sato, K., Wakamatsu, E., Yoshizumi, A., Watanabe, N. and Irei, O. The configuration of the laminas and facet joints in degenerative spondylolisthesis. A clinicoradiologic study. Spine. 1989. 14(11): p. 1265-71.

11. Boden, S.D., Riew, K.D., Yamaguchi, K., Branch, T.P., Schellinger, D. and Wiesel, S.W. Orientation of the lumbar facet joints: association with degenerative disc disease. J Bone Joint Surg Am. 1996. 78(3): p. 403-11. 
12. Cassidy, J.D., Loback, D., Yong-Hing, K. and Tchang, S. Lumbar facet joint asymmetry. Intervertebral disc herniation. Spine. 1992. 17(5): p. 570-4.

13. Iguchi, T., Wakami, T., Kurihara, A., Kasahara, K., Yoshiya, S. and Nishida, K. Lumbar multilevel degenerative spondylolisthesis: radiological evaluation and factors related to anterolisthesis and retrolisthesis. J Spinal Disord Tech. 2002. 15(2): p. 93-9.

14. Karacan, I., Aydin, T., Sahin, Z., Cidem, M., Koyuncu, H., Aktas, I., et al. Facet angles in lumbar disc herniation: their relation to anthropometric features. Spine. 2004. 29(10): p. 1132-6.

15. Pintar, F.A., Cusick, J.F., Yoganandan, N., Reinartz, J. and Mahesh, M. The biomechanics of lumbar facetectomy under compression-flexion. Spine. 1992. 17(7): p. 804-10.

16. Okawa, A., Shinomiya, K., Takakuda, K. and Nakai, O. A cadaveric study on the stability of lumbar segment after partial laminotomy and facetectomy with intact posterior ligaments. J Spinal Disord. 1996. 9(6): p. 518-26.

17. Lorenz, M., Patwardhan, A. and Vanderby, R., Jr. Load-bearing characteristics of lumbar facets in normal and surgically altered spinal segments. Spine. 1983. 8(2): p. 122-30.

18. Kato, Y., Panjabi, M.M. and Nibu, K. Biomechanical study of lumbar spinal stability after osteoplastic laminectomy. J Spinal Disord. 1998. 11(2): p. 146-50.

19. Hazlett, J.W. and Kinnard, P. Lumbar apophyseal process excision and spinal instability. Spine. 1982. 7(2): p. 171-6.

20. Abumi, K., Panjabi, M.M., Kramer, K.M., Duranceau, J., Oxland, T. and Crisco, J.J. Biomechanical evaluation of lumbar spinal stability after graded facetectomies. Spine. 1990. 15(11): p. 1142-7.

21. Tai, C.L., Hsieh, P.H., Chen, W.P., Chen, L.H., Chen, W.J. and Lai, P.L. Biomechanical comparison of lumbar spine instability between laminectomy and bilateral laminotomy for spinal stenosis syndrome - an experimental study in porcine model. BMC Musculoskelet Disord. 2008. 9: p. 84.

22. Lee, M.J., Bransford, R.J., Bellabarba, C., Chapman, J.R., Cohen, A.M., Harrington, R.M., et al. The effect of bilateral laminotomy versus laminectomy on the motion and stiffness of the human lumbar spine: a biomechanical comparison. Spine. 2010. 35(19): p. 1789-93.

23. Chang, T.S., Chang, J.H., Wang, C.S., Chen, H.Y. and Cheng, C.W. Evaluation of unilateral cage-instrumented fixation for lumbar spine. J Orthop Surg Res. 2010. 5: p. 86. 
24. Cardoso, M.J., Dmitriev, A.E., Helgeson, M., Lehman, R.A., Kuklo, T.R. and Rosner, M.K. Does superior-segment facet violation or laminectomy destabilize the adjacent level in lumbar transpedicular fixation? An in vitro human cadaveric assessment. Spine. 2008. 33(26): p. 2868-73.

25. Hamasaki, T., Tanaka, N., Kim, J., Okada, M., Ochi, M. and Hutton, W.C. Biomechanical assessment of minimally invasive decompression for lumbar spinal canal stenosis: a cadaver study. J Spinal Disord Tech. 2009. 22(7): p. 486-91.

26. Netter, F.H. and Hansen, J.T. Atlas of human anatomy. 3rd ed. 2003. Teterboro, N.J.: Icon Learning Systems.

27. White, A.A. and Panjabi, M.M. Clinical biomechanics of the spine. 2nd ed. 1990. Philadelphia: Lippincott.

28. Grosland, N.M. and Goel, V.K. Vertebral endplate morphology follows bone remodeling principles. Spine. 2007. 32(23): p. E667-73.

29. Fazzalari, N.L., Parkinson, I.H., Fogg, Q.A. and Sutton-Smith, P. Antero-postero differences in cortical thickness and cortical porosity of T12 to L5 vertebral bodies. Joint Bone Spine. 2006. 73(3): p. 293-7.

30. Cassidy, J.J., Hiltner, A. and Baer, E. Hierarchical structure of the intervertebral disc. Connect Tissue Res. 1989. 23(1): p. 75-88.

31. Nordin, M. and Frankel, V.H. Basic biomechanics of the musculoskeletal system. 2nd ed. 1989. Philadelphia: Lea \& Febiger.

32. Adams, M.A., Hutton, W.C. and Stott, J.R. The resistance to flexion of the lumbar intervertebral joint. Spine. 1980. 5(3): p. 245-53.

33. Orthopedics International- Spine Spinal Anatomy-Overview. 2010 [Accessed: 2010 June 15]; http://www.oispine.com/subject.php?pn=spinal-anatomy-018.

34. Barkun, J.S., Barkun, A.N., Sampalis, J.S., Fried, G., Taylor, B., Wexler, M.J., et al. Randomised controlled trial of laparoscopic versus mini cholecystectomy. The McGill Gallstone Treatment Group. Lancet. 1992. 340(8828): p. 1116-9.

35. Adamyan, L.V. Minimally invasive surgery in gynecologic practice. Int J Gynaecol Obstet. 2003. 82(3): p. 347-55.

36. Gulbins, H., Pritisanac, A. and Hannekum, A. Minimally invasive heart valve surgery: already established in clinical routine? Expert Rev Cardiovasc Ther. 2004. 2(6): p. 837-43.

37. Heinz-Peer, G. Functional reconstruction and minimally invasive techniques. Curr Opin Urol. 2002. 12(3): p. 205-8. 
38. Samphire, J., Nafteux, P. and Luketich, J. Minimally invasive techniques for resection of benign esophageal tumors. Semin Thorac Cardiovasc Surg. 2003. 15(1): p. 35-43.

39. Assaker, R. Minimal access spinal technologies: state-of-the-art, indications, and techniques. Joint Bone Spine. 2004. 71(6): p. 459-69.

40. Fourney, D.R., Schomer, D.F., Nader, R., Chlan-Fourney, J., Suki, D., Ahrar, K., et al. Percutaneous vertebroplasty and kyphoplasty for painful vertebral body fractures in cancer patients. J Neurosurg. 2003. 98(1 Suppl): p. 21-30.

41. Jaikumar, S., Kim, D.H. and Kam, A.C. History of minimally invasive spine surgery. Neurosurgery. 2002. 51(5 Suppl): p. S1-14.

42. Khoo, L.T. and Fessler, R.G. Microendoscopic decompressive laminotomy for the treatment of lumbar stenosis. Neurosurgery. 2002. 51(5 Suppl): p. S146-54.

43. Nakagawa, H., Kamimura, M., Uchiyama, S., Takahara, K., Itsubo, T. and Miyasaka, T. Microendoscopic discectomy (MED) for lumbar disc prolapse. $\mathrm{J}$ Clin Neurosci. 2003. 10(2): p. 231-5.

44. Perez-Cruet, M.J., Foley, K.T., Isaacs, R.E., Rice-Wyllie, L., Wellington, R., Smith, M.M., et al. Microendoscopic lumbar discectomy: technical note. Neurosurgery. 2002. 51(5 Suppl): p. S129-36.

45. Saal, J.A. and Saal, J.S. Intradiscal electrothermal treatment for chronic discogenic low back pain: a prospective outcome study with minimum 1-year follow-up. Spine. 2000. 25(20): p. 2622-7.

46. Simmons, J.W., Nordby, E.J. and Hadjipavlou, A.G. Chemonucleolysis: the state of the art. Eur Spine J. 2001. 10(3): p. 192-202.

47. Song, J. and Park, Y. Ligament-sparing lumbar microdiscectomy: technical note. Surg Neurol. 2000. 53(6): p. 592-6; discussion 596-7.

48. Detwiler, P.W., Spetzler, C.B., Taylor, S.B., Crawford, N.R., Porter, R.W. and Sonntag, V.K. Biomechanical comparison of facet-sparing laminectomy and christmas tree laminectomy. J Neurosurg. 2003. 99(2 Suppl): p. 214-20.

49. Masharawi, Y., Rothschild, B., Dar, G., Peleg, S., Robinson, D., Been, E., et al Facet orientation in the thoracolumbar spine: three-dimensional anatomic and biomechanical analysis. Spine. 2004. 29(16): p. 1755-63.

50. Genevay, S. and Atlas, S.J. Lumbar spinal stenosis. Best Pract Res Clin Rheumatol. 2010. 24(2): p. 253-65. 
51. Iguchi, T., Kurihara, A., Nakayama, J., Sato, K., Kurosaka, M. and Yamasaki, K. Minimum 10-year outcome of decompressive laminectomy for degenerative lumbar spinal stenosis. Spine. 2000. 25(14): p. 1754-9.

52. Katz, J.N., Lipson, S.J., Chang, L.C., Levine, S.A., Fossel, A.H. and Liang, M.H. Seven- to 10-year outcome of decompressive surgery for degenerative lumbar spinal stenosis. Spine. 1996. 21(1): p. 92-8.

53. Posner, I., White, A.A., 3rd, Edwards, W.T. and Hayes, W.C. A biomechanical analysis of the clinical stability of the lumbar and lumbosacral spine. Spine. 1982. 7(4): p. 374-89.

54. Disch, A.C., Schmoelz, W., Matziolis, G., Schneider, S.V., Knop, C. and Putzier, M. Higher risk of adjacent segment degeneration after floating fusions: long-term outcome after low lumbar spine fusions. J Spinal Disord Tech. 2008. 21(2): p. 7985.

55. Hopp, E. and Tsou, P.M. Postdecompression lumbar instability. Clin Orthop Relat Res. 1988. 227: p. 143-51.

56. Winn, H.R. and Youmans, J.R.Youmans neurological surgery. 5th ed. 2004. Philadelphia: W.B. Saunders.

57. Johnsson, K.E., Redlund-Johnell, I., Uden, A. and Willner, S. Preoperative and postoperative instability in lumbar spinal stenosis. Spine. 1989. 14(6): p. 591-3.

58. Ishida, Y., Ohmori, K., Inoue, H. and Suzuki, K. Delayed vertebral slip and adjacent disc degeneration with an isthmic defect of the fifth lumbar vertebra. $\mathrm{J}$ Bone Joint Surg Br. 1999. 81(2): p. 240-4.

59. Weinstein, J.N., Lurie, J.D., Olson, P.R., Bronner, K.K. and Fisher, E.S. United States' trends and regional variations in lumbar spine surgery: 1992-2003. Spine. 2006. 31(23): p. 2707-14.

60. Amundsen, T., Weber, H., Lilleas, F., Nordal, H.J., Abdelnoor, M. and Magnaes, B. Lumbar spinal stenosis. Clinical and radiologic features. Spine. 1995. 20(10): p. $1178-86$.

61. Buckwalter, J.A. Aging and degeneration of the human intervertebral disc. Spine. 1995. 20(11): p. 1307-14.

62. Verbiest, H. Pathomorphologic aspects of developmental lumbar stenosis. Orthop Clin North Am. 1975. 6(1): p. 177-96.

63. Yong-Hing, K., Reilly, J. and Kirkaldy-Willis, W. The ligamentum flavum. Spine. 1976. 1: p. 226-34. 
64. Djurasovic, M., Glassman, S.D., Carreon, L.Y. and Dimar, J.R., 2nd. Contemporary management of symptomatic lumbar spinal stenosis. Orthop Clin North Am. 2010. 41(2): p. 183-91.

65. Martin, B.I., Deyo, R.A., Mirza, S.K., Turner, J.A., Comstock, B.A., Hollingworth, W., et al. Expenditures and health status among adults with back and neck problems. JAMA. 2008. 299(6): p. 656-64.

66. Deyo, R. Back surgery—who needs it? New Engl J Med. 2007. 356: p. 2239-43.

67. Fardon, D.F. and Milette, P.C. Nomenclature and classification of lumbar disc pathology. Recommendations of the combined task forces of the North American Spine Society, American Society of Spine Radiology, and American Society of Neuroradiology. Spine. 2001. 26(5): p. E93-113.

68. Ninomiya, M. and Muro, T. Pathoanatomy of lumbar disc herniation as demonstrated by computed tomography/discography. Spine. 1992. 17(11): p. 1316-22.

69. Yang, K.H. and King, A.I. Mechanism of facet load transmission as a hypothesis for low-back pain. Spine. 1984. 9(6): p. 557-65.

70. Haher, T.R., O'Brien, M., Dryer, J.W., Nucci, R., Zipnick, R. and Leone, D.J. The role of the lumbar facet joints in spinal stability. Identification of alternative paths of loading. Spine. 1994. 19(23): p. 2667-70 discussion 2671.

71. Sharma, M., Langrana, N.A. and Rodriguez, J. Role of ligaments and facets in lumbar spinal stability. Spine. 1995. 20(8): p. 887-900.

72. Goel, V.K., Panjabi, M.M., Patwardhan, A.G., Dooris, A.P. and Serhan, H. Test protocols for evaluation of spinal implants. J Bone Joint Surg Am. 2006. 88 (2 Suppl): p. 103-9.

73. Goel, V.K., Wilder, D.G., Pope, M.H. and Edwards, W.T. Biomechanical testing of the spine. Load-controlled versus displacement-controlled analysis. Spine. 1995. 20(21): p. 2354-7.

74. Hitchon, P.W., Eichholz, K., Barry, C., Rubenbauer, P., Ingalhalikar, A., Nakamura, S., et al. Biomechanical studies of an artificial disc implant in the human cadaveric spine. J Neurosurg Spine. 2005. 2(3): p. 339-43.

75. Kotani, Y., Cunningham, B.W., Abumi, K., Dmitriev, A.E., Ito, M., Hu, N., et al. Multidirectional flexibility analysis of cervical artificial disc reconstruction: in vitro human cadaveric spine model. J Neurosurg Spine. 2005. 2(2): p. 188-94.

76. Panjabi, M.M. Hybrid multidirectional test method to evaluate spinal adjacentlevel effects. Clin Biomech. 2007. 22(3): p. 257-65. 
77. Oxland, T.R., Panjabi, M.M. and Lin, R.M. Axes of motion of thoracolumbar burst fractures. J Spinal Disord. 1994. 7(2): p. 130-8.

78. Lu, W.W., Luk, K.D., Holmes, A.D., Cheung, K.M. and Leong, J.C. Pure shear properties of lumbar spinal joints and the effect of tissue sectioning on load sharing. Spine. 2005. 30(8): p. E204-9.

79. Oxland, T.R., Crisco, J.J., 3rd, Panjabi, M.M. and Yamamoto, I. The effect of injury on rotational coupling at the lumbosacral joint. A biomechanical investigation. Spine. 1992. 17(1): p. 74-80.

80. Bresnahan, L., Ogden, A.T., Natarajan, R.N. and Fessler, R.G. A biomechanical evaluation of graded posterior element removal for treatment of lumbar stenosis: comparison of a minimally invasive approach with two standard laminectomy techniques. Spine. 2009. 34(1): p. 17-23.

81. Zander, T., Rohlmann, A., Klockner, C. and Bergmann, G. Influence of graded facetectomy and laminectomy on spinal biomechanics. Eur Spine J. 2003. 12(4): p. 427-34.

82. Lee, K.K., Teo, E.C., Qiu, T.X. and Yang, K. Effect of facetectomy on lumbar spinal stability under sagittal plane loadings. Spine. 2004. 29(15): p. 1624-31.

83. Zufelt, N. A kinematic-based testing protocol to study the mechanics of the human lumbar spine, in Biomedical Engineering and Imaging. 2008. UTHSC, Master's Thesis: Memphis. p. 102.

84. Bonin, H. In vitro analysis of the instantaneous center of rotation in a human cervical spine model using a spine robot, in Biomedical Engineering and Imaging. 2006. UTHSC, Master's Thesis: Memphis. p. 224.

85. Okuda, T., Baba, I., Fujimoto, Y., Tanaka, N., Sumida, T., Manabe, H., et al. The pathology of ligamentum flavum in degenerative lumbar disease. Spine. 2004. 29(15): p. 1689-97.

86. Kelly, B. A multiaxis programmable spine robot for the study of multibody spinal biomechanics using real-time hybrid force and displacement control strategies, in Biomedical Engineering and Imaging. 2005. UTHSC, Doctoral Dissertation: Memphis. p. 154.

87. Celik, S.E., Celik, S., Kara, A., Ince, I. and Goksu, K. Lumbar facet joint angle and its importance on joint violation in lumbar microdiscectomy. Neurosurgery. 2008. 62(1): p. 168-72; discussion 172-3.

88. Matsumura, A., Namikawa, T., Terai, H., Tsujio, T., Suzuki, A., Dozono, S., et al. The influence of approach side on facet preservation in microscopic bilateral decompression via a unilateral approach for degenerative lumbar scoliosis. Clinical article. J Neurosurg Spine. 2010. 13(6): p. 758-65. 
89. White, A.A. and Wiltse, L.L. Spondylolisthesis after extensive lumbar laminectomy. AAOS 43rd Annual Meeting. 1976. New Orleans, Louisiana.

90. Shenkin, H. and Hash, C.J. Spondylolisthesis after multiple bilateral laminectomy and facetectomies for lumbar spondylosis. J of Neurosurgery. 1979. 50(1): p.45-7.

91. Panjabi, M.M., Krag, M.H. and Chung, T.Q. Effects of disc injury on mechanical behavior of the human spine. Spine. 1984. 9(7): p. 707-13.

92. Schultz, A.B., Wareick, D. N., Berkson, M.H. Mechanical properties of human lumbar spine motion segments: responses in flexion, extension, lateral bending and torsion. J Biomech Eng. 1979. 101: p. 46-52.

93. Stokes, I.A. and Frymoyer, J.W. Segmental motion and instability. Spine. 1987. 12(7): p. 688-91.

94. Panjabi, M.M., Oxland, T., Takata, K., Goel, V., Duranceau, J. and Krag, M. Articular facets of the human spine. Quantitative three-dimensional anatomy. Spine. 1993. 18(10): p. 1298-310.

95. Otsuka, Y., An, H.S., Ochia, R.S., Andersson, G.B., Espinoza Orias, A.A. and Inoue, $\mathrm{N}$. In vivo measurement of lumbar facet joint area in asymptomatic and chronic low back pain subjects. Spine. 2010. 35(8): p. 924-8. 


\title{
APPENDIX A: BIOMECHANICAL EFFECTS OF SEQUENTIAL FACET RESECTION ON LUMBAR SPINE MECHANICS*
}

\begin{abstract}
Lumbar facetectomy is one of the most commonly performed spinal surgeries [1]. Whether it's performed for foraminal stenosis or other pathologies, there is always the concern of iatrogenic spine destabilization [2]. Minimally invasive techniques (MIS) have been developed to preserve the joint and ligamentous structures in the area of interest. Despite these advancements, controversy of whether or not one has destabilized the spine after performing a lumbar facetectomy remains. The objective of this study was to investigate the effects of sequential facet resection by comparing the biomechanical stability of four different spine conditions: harvested, after an MIS partial unilateral facetectomy (UF), after an MIS bilateral facetectomy via unilateral approach (BF) and after a traditional laminectomy (TL).
\end{abstract}

Eight fresh human cadaveric lumbar spinal segments (four L1-2, two L2-3 and two L4-5) were tested with three different protocols using a multi-axis robotic testing platform. They included the pure moment method (PM) and two novel testing techniques: a combined load and moment protocol (CLM) and a coupled eccentric loading protocol (CEL). The CLM protocol introduces to the PM an anterior-posterior (A-P) displacement to the flexion-extension (F-E) modes of testing through application of shear and compressive loads, while the CEL protocol introduces the coupling of F-E or lateral bending (LB) with active left and right axial rotation (AR). The purpose of these protocols was to simulate a more physiological mode of testing in vitro. All rotational data were analyzed at an $8 \mathrm{Nm}$ end limit for F-E and $6 \mathrm{Nm}$ for $\mathrm{LB}$ and $\mathrm{AR}$. A nonparametric one-way repeated-measure ANOVA on ranks (Friedman's test) was employed to analyze the rotational data $(\mathrm{p}<0.05)$. If a statistical difference was detected, a StudentNeuman Keuls comparison test was then applied.

For both PM and CLM, the UF caused a reduction in motion during flexion and extension. Further facet resection, namely BF and TL, resulted in a significant increase in rotation during flexion and extension compared to the UF condition. During LB tests (using the PM protocol), the UF caused a reduction in rotation for movement towards the surgical side (left) and an increase in rotation during LB away from the surgical side (right). Further facet resection through BF or TL resulted in significant increases in lateral rotation. The inclusion of active axial rotation coupled with F-E or LB in the CEL protocol accentuated the differences of the most destabilizing condition, the laminectomy.

Unilateral facetectomy was associated with an increase in stability highlighting the efficacy of this surgical procedure. However, the overall biomechanical stability of

Note: *Authors: Karen Sedacki, Maurico Campos, Brian P. Kelly, Raul J. Cardenas, Daniel Lu, and Denis J. DiAngelo 
the spine significantly decreased following subsequent BF and TL surgical resections, indicating the possible need for surgical stabilization.

\section{Introduction}

Lumbar facetectomy is one of the most commonly performed spinal surgeries [1]. When performed, the unique dynamic relationship between the facets and the intervertebral discs is altered and, by consequence so is their role in supporting and sharing loads on the lumbar spine. These structural changes after conventional spine surgery have always been a cause of concern with spinal surgeons. Despite a wealth of data addressing this issue, controversy of whether or not spinal instability was iatrogenically induced after a facetectomy remains [2,3]. In addition, it is noteworthy to mention that most of the biomechanical studies performed on this topic have only used the pure moment (PM) protocol to test the specimens. Although there has been a biomechanical study where only minimal bone resection was performed on the specimens [4], no study attempts to replicate the clinical situation a surgeon faces in the operating room when performing this procedure in a minimally invasive (MIS) manner, i.e.- the limited exposure of the anatomy the MetRx retracting system affords. The goal of this study was to use three testing techniques to attempt and replicate a more physiologically accurate scenario to investigate the effects of sequential MIS facet resections on the biomechanical stability of the spine. In addition, an attempt to reach clinical parameters of instability as defined by White and Panjabi was made by using measurements of translation along the disc axis using a simulation model.

\section{Materials and Methods}

Six fresh human lumbar cadaveric spines were procured (see Table A-1 for demographics). The tissue was radiographically assessed for quality by the operating surgeon and dissected into eight motion segment units (MSU) (four L1-2, two L2-3 and two L4-5). A protocol was developed to retain the natural upright lordosis of the motion segment unit when mounted. Once selected, MSUs were dissected and mounted in a lowmelting point cerrobend bismuth-alloy (Small Parts, Miami Lakes, FL). A second series of radiographs were taken of the mounted MSUs with calipers to calibrate the radiographs in the freeware Image $\mathrm{J}(\mathrm{NIH}$, nih.gov). The coordinates of the disc center (Figure A-1) were identified, and were later used to transform the tool tip of the testing platform shown in (Figure A-2).

A multi-axis robotic testing platform was used for testing specimens in this study. It has four programmable degrees of freedom (DOF) in the gimbal setup, two translational and two rotational (Figure A-3). These DOF were necessary to replicate the proposed vertebral motion for this study. In the coupled-eccentric loading setup, it has two degrees of freedom, one translational and one rotational provided an active axial turntable (Yaskawa America Inc., Waukegan, IL) as shown in Figure A-3. The UT Biomechanics Laboratory Robot is capable of rotating, reading force and moment data 
Table A-1. Specimen Demographics.

\begin{tabular}{cccc}
\hline Specimen & Age & Gender & Level \\
\hline 105285 & 76 & $\mathrm{~F}$ & $\mathrm{~L} 2-3$ \\
105459 & 49 & $\mathrm{M}$ & $\mathrm{L} 1-2$ \\
710888 & 59 & $\mathrm{M}$ & $\mathrm{L} 2-3$ \\
708736 & 37 & $\mathrm{M}$ & $\mathrm{L} 1-2$ \\
$53103715-002-2$ & 69 & $\mathrm{M}$ & $\mathrm{L} 4-5$ \\
ADS1017052 & 24 & $\mathrm{M}$ & $\mathrm{L} 4-5$ \\
DRT087036 & 51 & $\mathrm{~F}$ & $\mathrm{~L} 1-2$ \\
GD-1 & 58 & $\mathrm{M}$ & $\mathrm{L} 1-2$ \\
Mean & 52.875 & & \\
Standard Deviation & 16.745468 & & \\
\hline
\end{tabular}




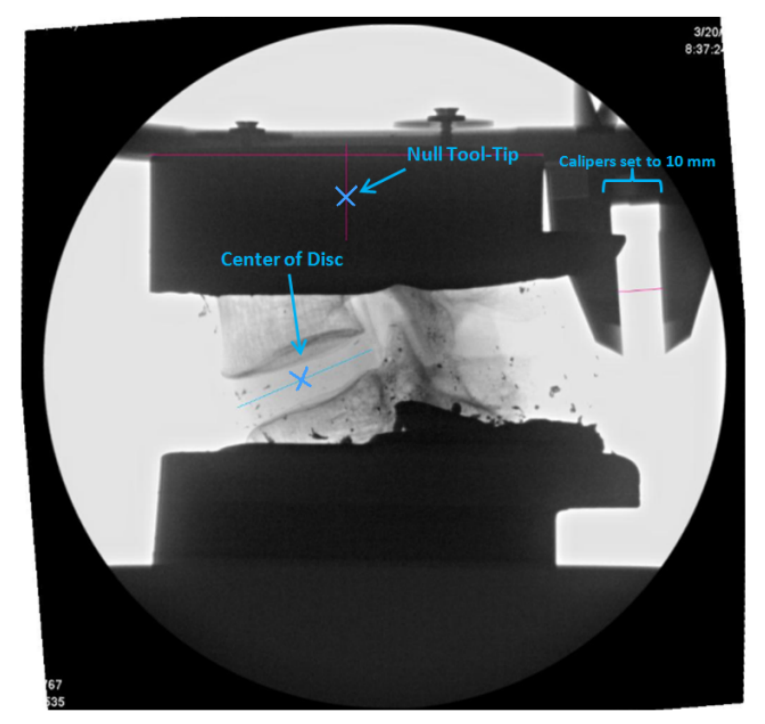

Figure A-1. Radiograph Analysis. Using ImageJ to calibrate and analyze the image, the original tooltip of the robot was found $9.72 \mathrm{~mm}$ below the top of the center of the pot. The coordinate of the center of the disc were found with respect to this point. 


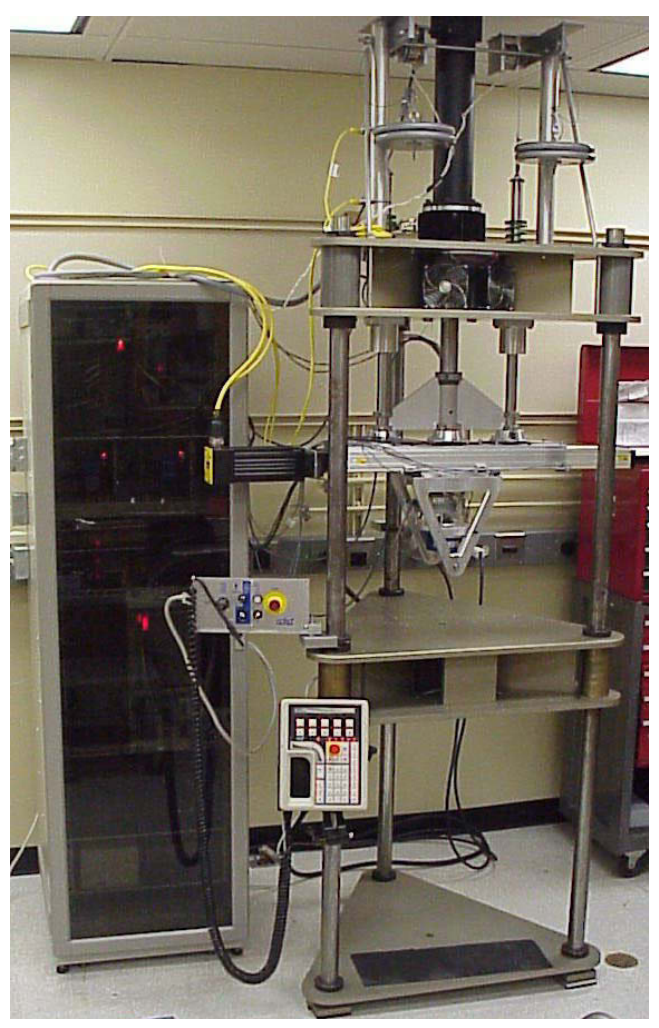

Figure A-2. UT Biomechanical Testing Laboratory Robot. This custom-built apparatus can utilize force feedback, displacement feedback, or a hybrid of the two. 

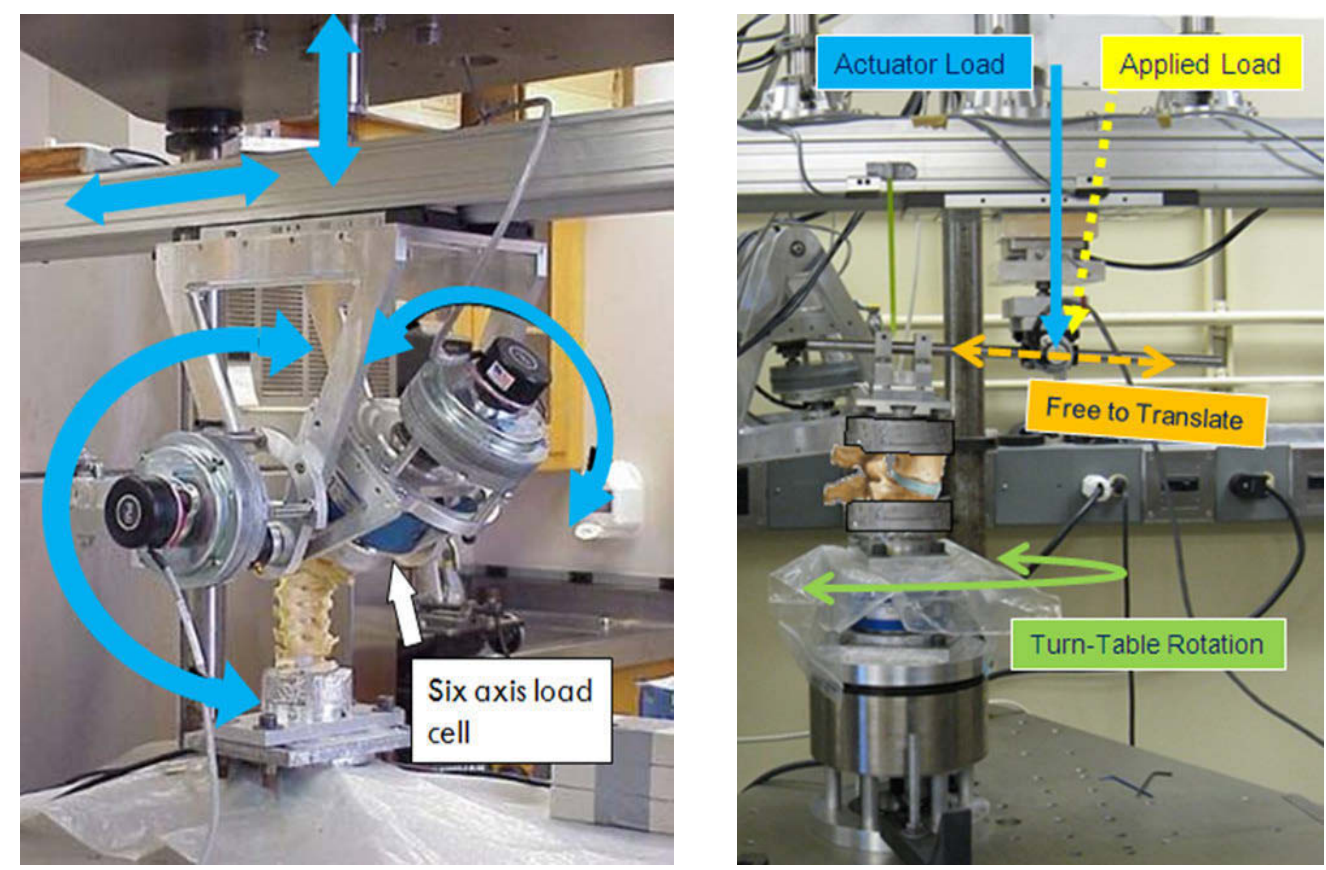

Figure A-3. Gimbal and CEL Setup. The gimbal setup has four degrees of freedom to perform sagittal rotation (left). A $150 \mathrm{~mm}$ lever arm was used and a six-axis load cell recorded the force and moment values located underneath the specimen (right). A rotary voltage transducer recorded the sagittal rotation. 
from any prescribed location (tool-tip location). Force and moment data were recorded using a six-axis load cell (JR3 Inc., Woodland, CA).

The specimens were tested with three different protocols as harvested, after a partial MIS unilateral facetectomy (UF), after a bilateral MIS facetectomy via unilateral approach (BF) and after a traditional laminectomy (TL). The protocols used were the pure moment method (PM) and two novel testing techniques: a combined load and moment protocol (CLM) and a coupled eccentric loading protocol (CEL). The CLM protocol introduces to the PM an A-P displacement to the flexion-extension (F-E) modes of testing through application of shear and compressive loads, and the CEL protocol introduces the coupling of F-E or lateral bending (LB) with left and right axial rotation (AR). The purpose of these protocols was to simulate a more physiological mode of testing in vitro. All specimens underwent these three protocols for every spine condition.

Minimally invasive techniques, along with the retraction system were used to perform the procedures in efforts to reproduce the exposure obtained in vivo. All procedures were performed using a surgical microscope, the MetRx System ${ }^{\mathrm{TM}}$, and the Midas Rex high-speed drill system designed for MIS procedures. For the unilateral facetectomy, the superior and inferior articular processes and lamina were burred until the nerve root was exposed through a left-sided approach. Using the unilateral approach, the tube retractors were re-directed as previously described by Guiot et al [5]. After this, the lamina was drilled until the contralateral superior and inferior articular processes were seen and the nerve root was exposed.

Since the two translational and one rotational data recorded during the PM and CLM data is sufficient to describe motion in the sagittal plane, a simulation model of the motion in the sagittal plane was created with MSC.visualNastran. This model provided the kinematic relationship through a series of common mechanical joint systems. In this model, the following components were included, three spheres representing the tool-tip of the testing robot, posterior point on the posterior edge of upper vertebra, and one recording point to track the translation due to the movement of the posterior point projected on the disc angle plane. The amount of translation of the posterior point of each specimen for each condition along the disc axis was determined (in $\mathrm{mm}$ ). An image of the simulation is located in Figure A-4. A 30 \% scaling factor was applied to the radiograph definition [6]. For a vertebral slip to be classified as spondylolisthesis, there must be subluxation of $10 \%$ of the A-P vertebral length [7]. The rescaled definitions of instability by Disch et al, and White and Panjabi for absolute values range from 2.3 and $3.5 \mathrm{~mm}$ [6, 8].

All rotational data were analyzed at an $8 \mathrm{Nm}$ end limits for flexion and extension and $6 \mathrm{Nm}$ for left and right lateral bending for the PM and CLM testing protocols. The CEL protocol was analyzed at a resultant of $8 \mathrm{Nm}$ for flexion and extension and $6 \mathrm{Nm}$ for left and right lateral bending. Using SigmaStat 3.5 (Systat Software Inc., San Jose, CA), a non-parametric one-way repeated-measure ANOVA on ranks (Friedman's test) was used to analyze the rotational and the translational A-P shear data $(\mathrm{p}<0.05)$ on all conditions. If there was a statistical difference was detected, a Student-Neuman Keuls comparison test 


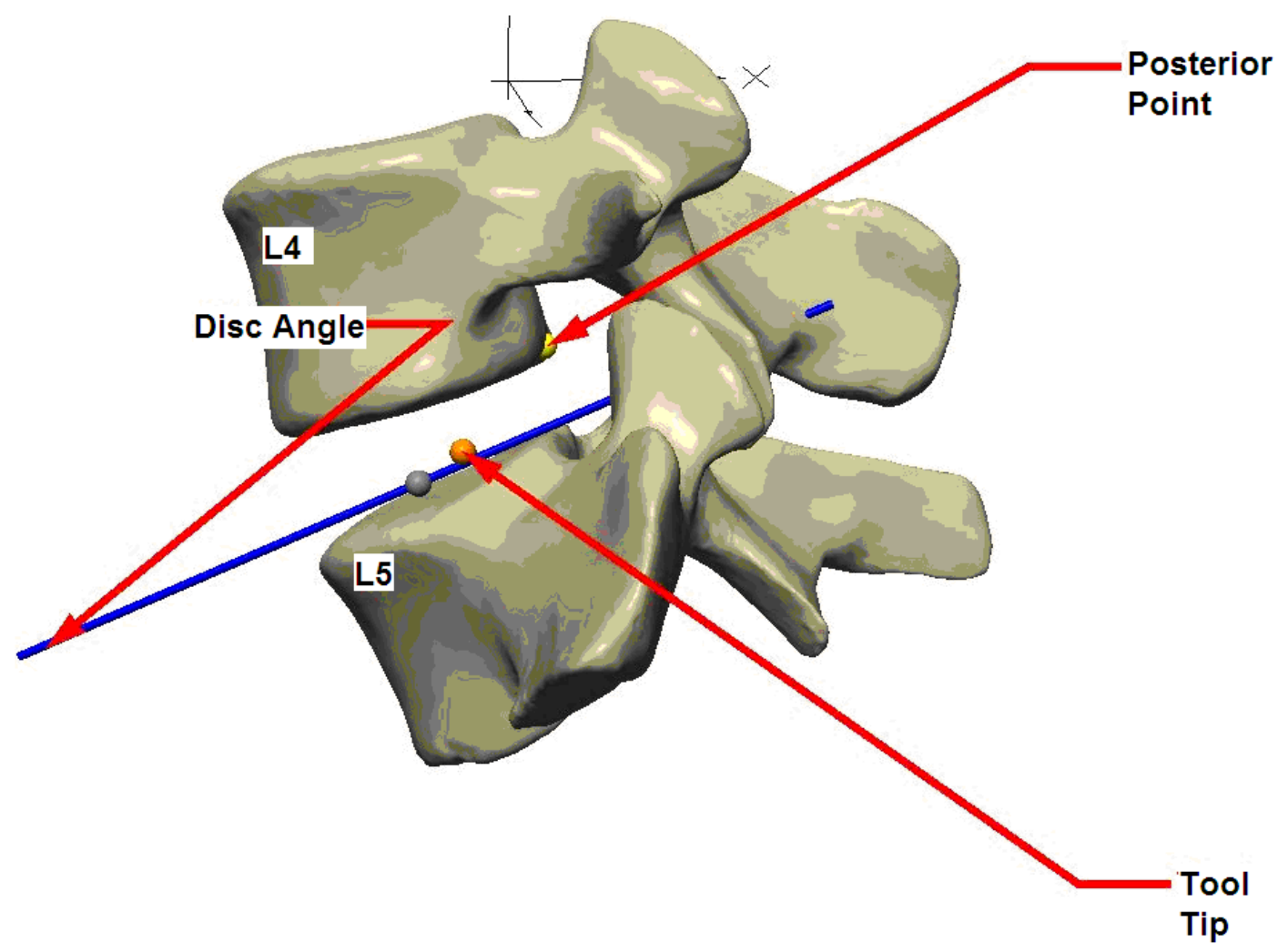

Figure A-4. Simulation of PM and CLM Protocols. The yellow point is the posterior point of the inferior endplate of the upper vertebrae. The translation of this point is what clinicians use to determine instability. The orange point is the tool-tip coordinates, and the blue line is the disc angle axis from which the translations were recorded. 
was then applied. Also, a Wilcoxon Signed Rank test was used to find difference between the PM and CLM protocols. The facet angle and area measurements were analyzed using a Wilcoxon Signed Rank test (non-parametric paired t-test, $p<0.05$ ) comparing the intact the bilateral facetectomy condition.

\section{Results}

The rotational values for all the tested conditions are summarized in Table A-2. For both PM and CLM, the UF caused a reduction in motion for flexion and extension. Further facet resection, namely BF and TL resulted in a significant increase in rotation during flexion and extension compared to the UF condition. During LB (on the PM method), the UF caused a reduction in rotation for movement towards the surgical side (left) and an increase in rotation away from the surgical side (right). Further facet resection, namely BF and TL, resulted in significant increases in rotation (Figure A-5). Figure A-6 displays the differences between the protocols for each of the spine conditions. In the harvested condition, there was a decrease in rotation from the PM and CLM in both flexion and extension. However, in the other three conditions, the differences occurred in extension (BF and laminectomy).

The inclusion of active axial rotation coupled with F-E or LB in the CEL protocol accentuated the differences of the most destabilizing condition, the laminectomy (Figure A-7). The differences between the laminectomy and the other three spine condition occurred in flexion with right axial, extension with left axial, extension with right axial, left axial with left lateral, and right axial with right lateral. There were differences amongst all the conditions in extension with left axial rotation.

No significant differences were detected in the A-P shear translational data between the conditions in the PM protocol (Figure A-8). In the CLM protocol, there were more differences seen. The significant differences were between the intact and UF, intact and $\mathrm{BF}, \mathrm{BF}$ and laminectomized condition, and a significant increase in motion between the UF and laminectomized condition.

\section{Discussion}

Even though there have been numerous studies on the influence of the facet joints on the biomechanics of a MSU, to date there are very few studies that investigate the amount of facet removal after minimally-invasive procedures (MIS) as it correlates to biomechanical stability [4]. Moreover, there is little data with testing protocols other than with a PM protocol [9-16].

Hamasaki et al [4] investigated the biomechanical changes after MIS facetectomy. However, when they used the term "minimally invasive," it was only to describe that the amount of bone and facet joint removed to decompress the specimens as being "minimal." They did not employ the retractor system usually employed for these cases as 
Table A-2. Tabulated Results from Protocols and the Simulation.

\begin{tabular}{|c|c|c|c|c|c|}
\hline \multirow[b]{2}{*}{ Protocol } & \multirow[b]{2}{*}{ Mode of Bending } & \multicolumn{4}{|c|}{ Rotations (Degrees) } \\
\hline & & Harvested & UF & $\mathrm{BF}$ & Lami \\
\hline \multicolumn{6}{|l|}{$\mathbf{P M}$} \\
\hline & Flexion & $7.21 \pm 1.98$ & $6.30 \pm 2.04$ & $7.68 \pm 2.08$ & $8.59 \pm 3.59$ \\
\hline & Extension & $5.52 \pm 1.09$ & $4.80 \pm 0.97$ & $5.99 \pm 1.05$ & $6.71 \pm 1.54$ \\
\hline & Left Lateral & $5.12 \pm 1.69$ & $4.56 \pm 1.20$ & $5.31 \pm 1.51$ & $6.00 \pm 1.19$ \\
\hline & Right Lateral & $5.36 \pm 2.00$ & $5.69 \pm 1.90$ & $6.41 \pm 1.56$ & $5.56 \pm 2.10$ \\
\hline \multicolumn{6}{|l|}{ CLM } \\
\hline & Flexion & $6.71 \pm 1.93$ & $6.42 \pm 2.28$ & $7.61 \pm 2.36$ & $8.71 \pm 3.36$ \\
\hline & Extension & $4.59 \pm 1.09$ & $4.39 \pm 1.03$ & $5.30 \pm 0.95$ & $5.83 \pm 1.44$ \\
\hline \multicolumn{6}{|l|}{ CEL } \\
\hline & Flexion $(+\mathrm{LA})$ & $3.6 \pm 1.5$ & $3.8 \pm 1.8$ & $4.0 \pm 2.1$ & $5.9 \pm 4.1$ \\
\hline & Flexion (+RA) & $3.8 \pm 1.5$ & $3.8 \pm 1.8$ & $4.3 \pm 2.1$ & $6.0 \pm 4.1$ \\
\hline & Extension (+LA) & $3.1 \pm 1.0$ & $2.9 \pm 1.0$ & $4.1 \pm 1.6$ & $4.9 \pm 2.3$ \\
\hline & Extension (+RA) & $3.0 \pm 1.0$ & $3.0 \pm 0.9$ & $3.5 \pm 1.6$ & $4.2 \pm 1.5$ \\
\hline & Left Lateral (+LA) & $2.6 \pm 1.0$ & $2.9 \pm 1.2$ & $3.2 \pm 1.2$ & $3.8 \pm 2.0$ \\
\hline & $\begin{array}{l}\text { Right Lateral } \\
(+\mathrm{RA})\end{array}$ & $3.6 \pm 2.0$ & $3.5 \pm 1.8$ & $3.7 \pm 2.1$ & $3.7 \pm 1.3$ \\
\hline & Left Axial (+LL) & $1.59 \pm 0.95$ & $1.57 \pm 1.12$ & $2.14 \pm 1.92$ & $2.47 \pm 1.64$ \\
\hline & Right Axial (+RL) & $1.61 \pm 1.08$ & $1.45 \pm 1.14$ & $1.73 \pm 1.42$ & $2.52 \pm 2.16$ \\
\hline \multicolumn{6}{|c|}{$\begin{array}{l}\text { Translation along } \\
\text { Disc Axis }(\mathbf{m m})\end{array}$} \\
\hline & PM & $0.74 \pm 0.37$ & $0.67 \pm 0.46$ & $0.68 \pm 0.30$ & $0.76 \pm 0.61$ \\
\hline & CLM & $0.97 \pm 0.67$ & $0.81 \pm 0.70$ & $0.88 \pm 0.51$ & $1.64 \pm 1.10$ \\
\hline
\end{tabular}




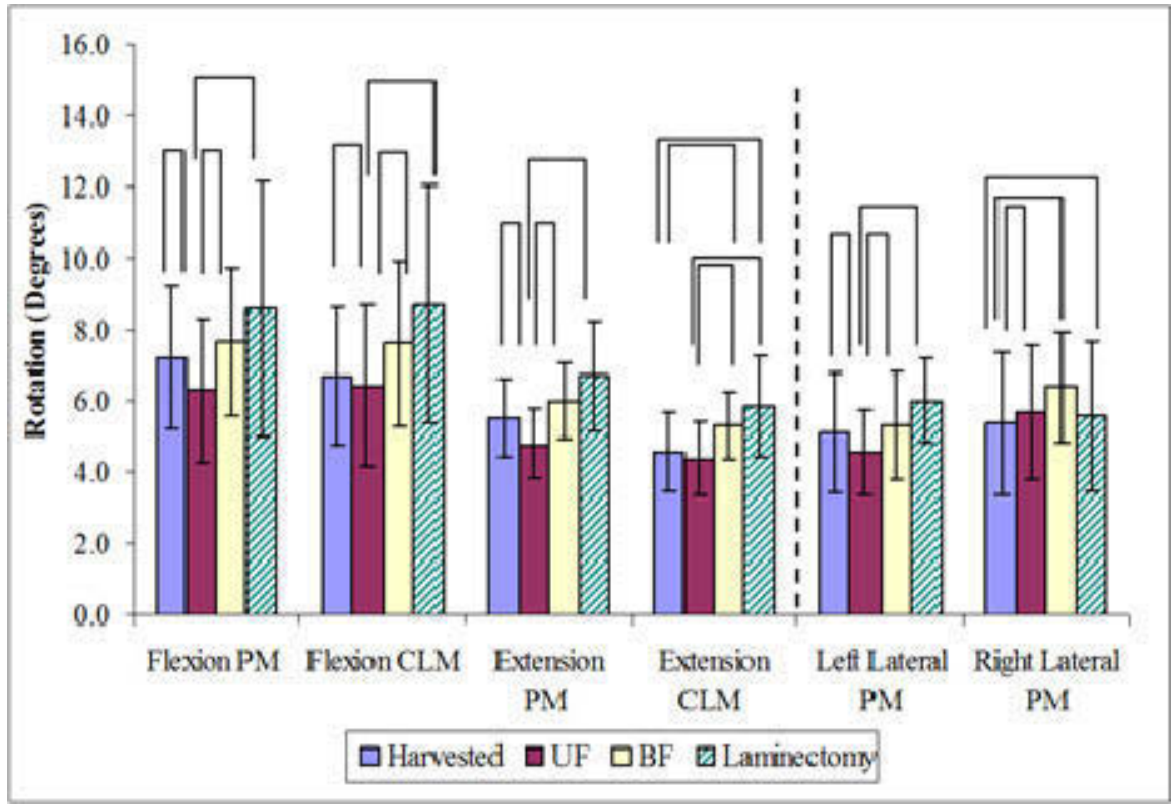

Figure A-5. Pure Moment and Combined Loading Protocol Rotations. Left and right lateral bending was only tested in the PM protocol and is separated by a dashed line. Significant differences among conditions are represented by brackets and the standard deviations are represented by bars. The UF conditions displayed a decrease in motion for all modes of bending, except right lateral. Flexion and extension end limits were $8 \mathrm{Nm}$ and $6 \mathrm{Nm}$ for left and right lateral bending. 


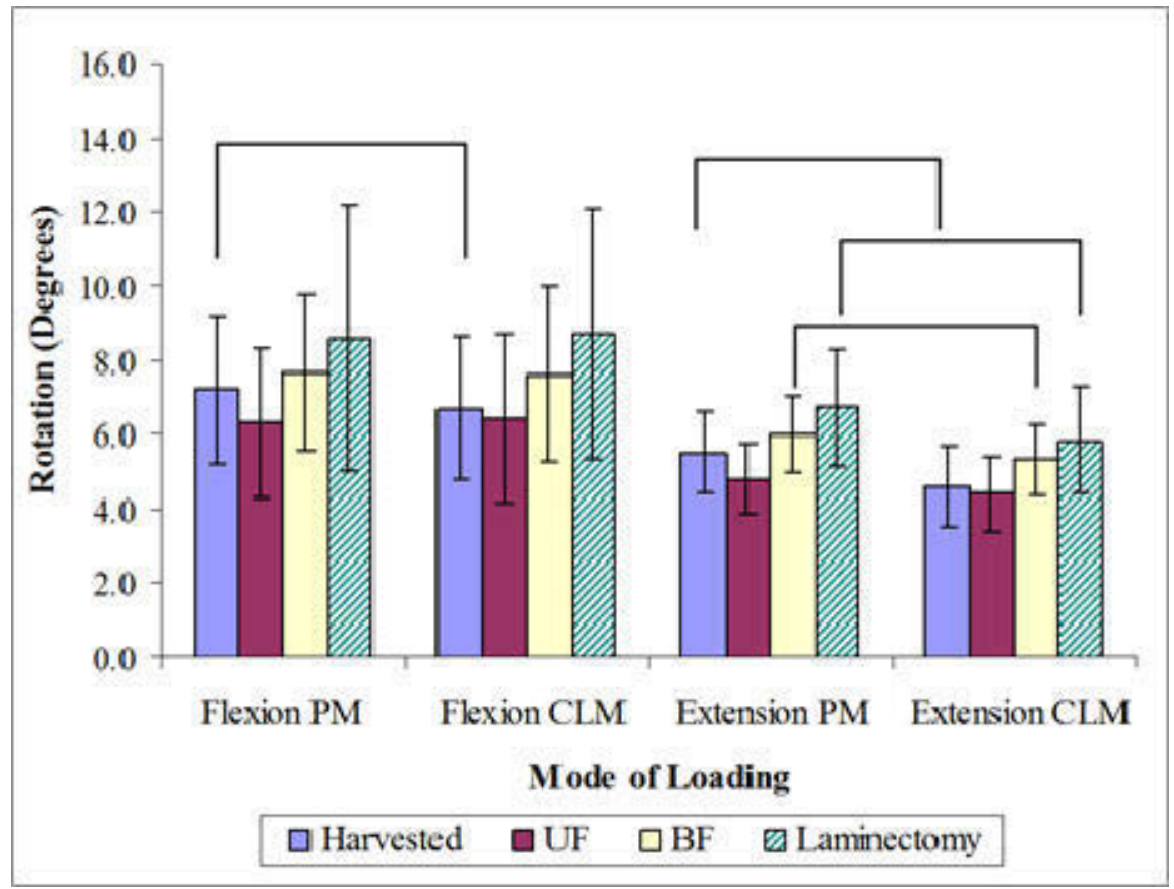

Figure A-6. Comparison of Sagittal Rotations between CLM and PM. A SignedRank test was performed to view statistical differences between the two protocols, shown in brackets. All data was analyzed at an $8 \mathrm{Nm}$ end limit. 


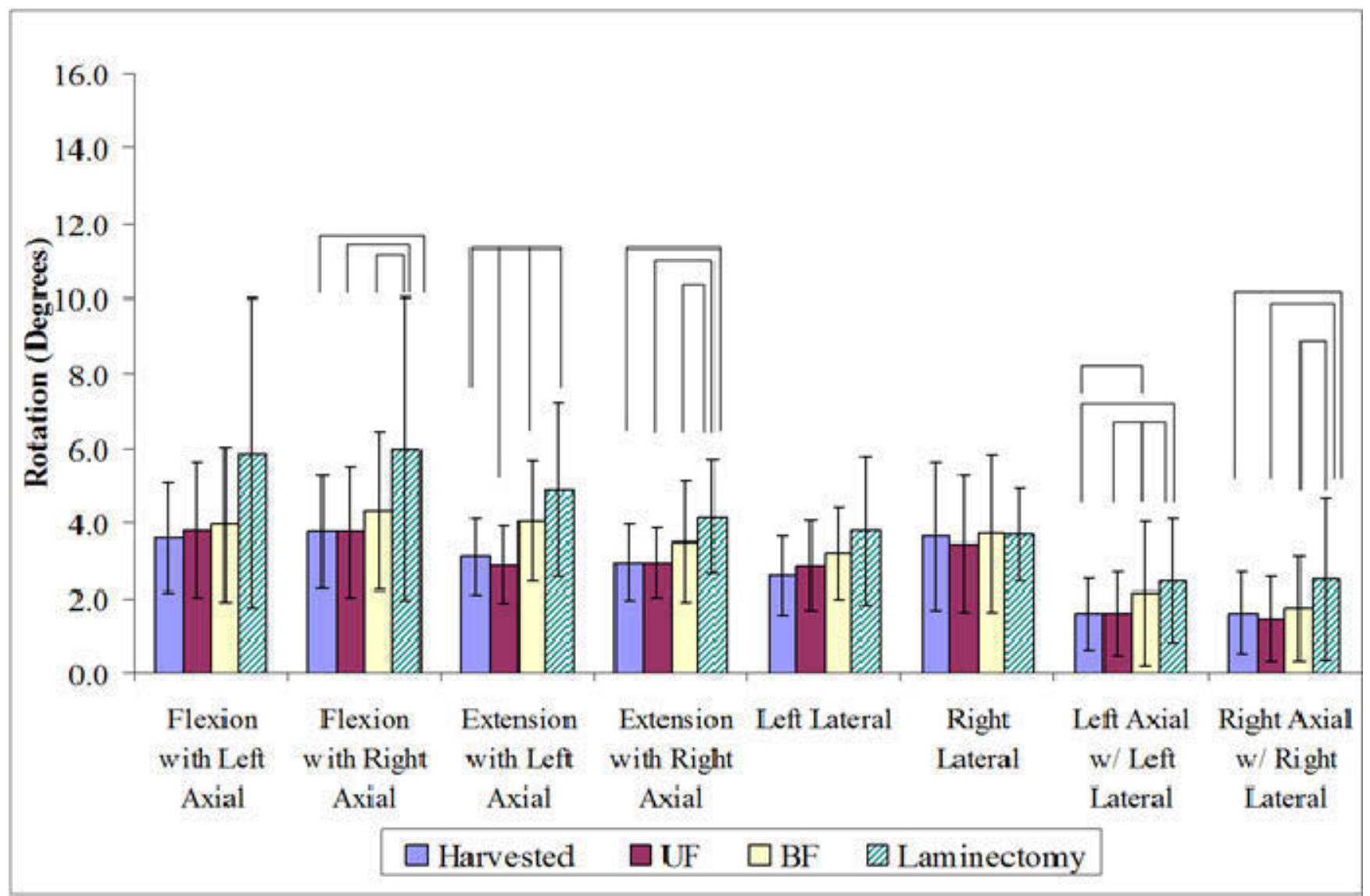

Figure A-7. Coupled Eccentric Loading Protocol Rotational Results. Significant differences are represented by brackets and standard deviations are denoted with bars. The most significant differences occurred in extension coupled with left axial rotation. Flexion and extension data were analyzed at a resultant of $8 \mathrm{Nm}$ and left and right lateral bending were analyzed at a $6 \mathrm{Nm}$ resultant value. 


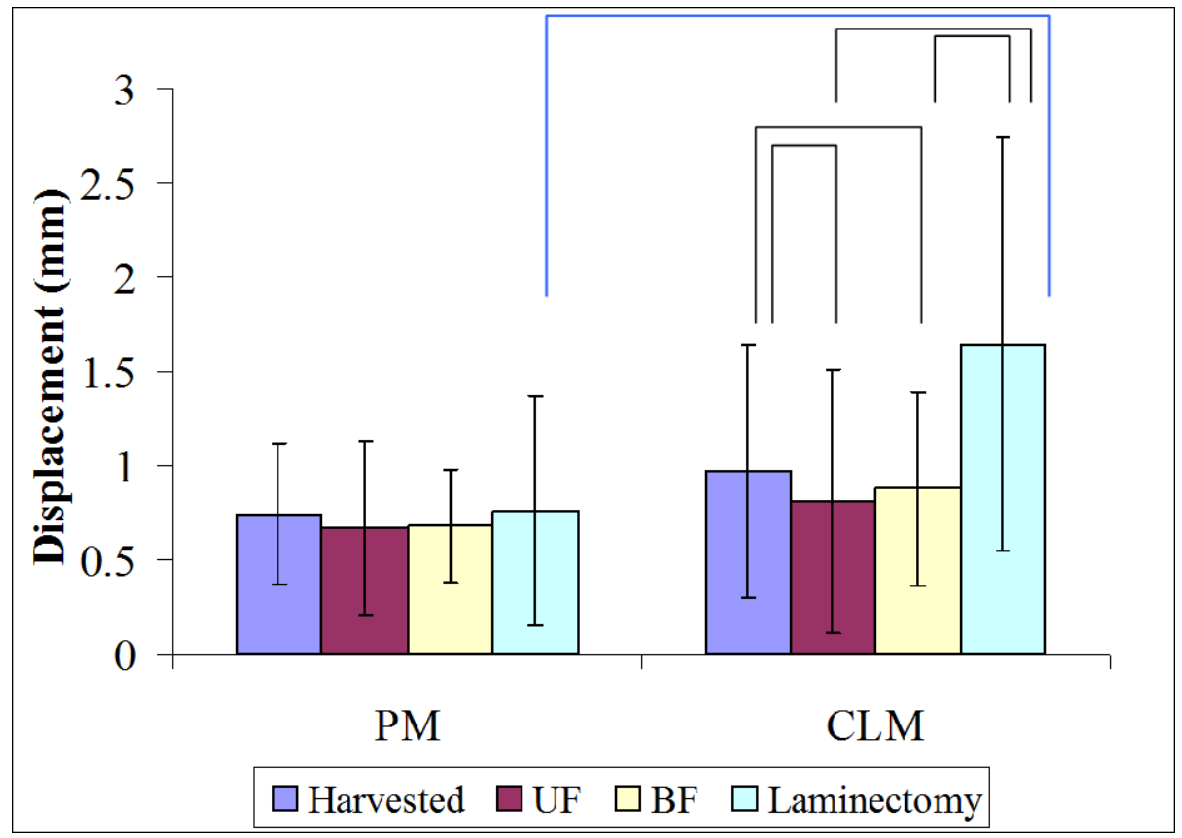

Figure A-8. Translation Data from PM and CLM Protocols. This graph does not include data from specimen 0701888. Significant differences among conditions are represented with black brackets and the blue bracket signifies the difference between protocols. The more significant differences occurred utilizing the CLM protocol. 
we did in this study. After testing the MSUs with a pure compressive load and a flexion/extension eccentric compressive load, they concluded that the MIS bilateral decompression via a unilateral approach poses little risk for causing instability, but an "open" medial facetectomy did decrease stability. In another cadaveric model study, albeit not an MIS one, Abumi et al studied the effect of graded facetectomies using the PM protocol. They, unlike Hamasaki et al did not find a significant change in an open medial facetectomy. Thus, although there is some variability in the biomechanical data, these studies generally conclude that instability correlates directly with the amount of facet resected. For the MIS procedures in our study, we introduced the MIS retractor system and surgical technique [5] to reproduce the limited intra-operative view these retractors impose on the surgeon, making the conditions closer to the clinical scenario encountered when performing these operations. Because of these "intraoperative" visual constraints, we performed the facetectomy until the nerve root was visible, as we would routinely do it in a clinical situation.

When analyzing the PM data in our study, the UF condition showed a statistically significant decrease in motion when compared to the intact in flexion, extension and left lateral bending. We hypothesize that the observed decrease in motion during testing for the UF condition could have been a result of utilizing MIS techniques. This could have, because of the particular field of vision afforded by the MetRx retraction system, caused the surgeon to expose the bony surfaces of the left facet to one another upon left-sided partial facetectomy in such a way that resistance to motion on all modes of bending, except for the right lateral (contralateral to the surgical side), was observed. However, as the amount of posterior element removal progressed beyond this condition, so did the rotations.

As the design and operation of biomechanical testing platforms improve, investigators are often trying to more accurately approximate in vivo situations. In an attempt to do this, the present study examined the MSUs using two protocols designed inhouse for this purpose. In regards to the data gathered using the CLM protocol, a similar decrease in flexion and extension was seen after UF, but further resection of the posterior elements (BF and TL) did cause an increase in motion. Comparing the PM and CLM protocols, there was a reduction in rotation seen in the harvested condition with the added shear and compression of the CLM. However, the inclusion of active axial rotation coupled with F-E or LB in the CEL protocol emphasized the differences between most destabilized condition (laminectomy) in the modes of bending in flexion with right axial, extension with left axial, extension with right axial, left axial with left lateral, and right axial with right lateral.

During the A-P shear translation segment of this study, the translation of the posterior edge of the superior body did not support a situation akin to clinical instability as defined by White and Panjabi on any of the tested conditions. When divided into the translation for each MSU level, none of the segments reached the criteria for instability scaled from the clinical radiographic translation criterion $[6,8,11]$. The largest values of translation were seen with the CLM protocol in the laminectomy condition. In concordance with this observation, patient outcome data also fails to show clinically 
significant instability caused by these procedures [17]. In a study by Garrido et al [18], using a conventional facetectomy with a tissue sparing approach, only one case of instability requiring fusion was noted out of 41 patients. Another study by Hazlett and Kinard found no cases of spinal instability in a group of 28 patients who underwent unilateral facetectomy with and without discectomy [3]. Table A-3 displays a summary of all previous studies, with a general description and brief summary of their results.

\section{Conclusions}

The unilateral facetectomy condition was not associated with a decrease in stability in all of the utilized protocols. These results support the MIS approach to decompressing the lumbar spine. In the A-P shear translation portion of this study, the inability of the established PM protocol to show any significant difference in motion between all the conditions should prompt us to question the ability to correlate this testing protocol with a clinically relevant situation. Further experiments using these modes of testing are necessary for further data accumulation and validation. 
Table A-3. Previous Studies of the Influence of the Facets on Biomechanics.

\begin{tabular}{|c|c|c|c|c|}
\hline Investigators & $\begin{array}{l}\text { Removal/ Surgical } \\
\text { Procedures }\end{array}$ & Levels & Testing Method & Results* \\
\hline Abumi et al [16] & $\begin{array}{l}\text { 1. PLL, Supra- and } \\
\text { Interspinous Ligaments } \\
\text { 2. Left UF (Medial) } \\
\text { 3. BF (Medial) } \\
\text { 4. UF (Total) } \\
\text { 5. BF (Total) }\end{array}$ & $\begin{array}{l}3 \text { L2-L3 } \\
7 \text { L3-L4 } \\
2 \text { L4-L5 }\end{array}$ & $\begin{array}{l}200 \text { N Preload, Pure } \\
\text { Moment }\end{array}$ & $\begin{array}{l}\text { ROM } \uparrow \text { in Flexion after } \\
\text { UF (medial), Medial } \\
\text { Facetectomy: ROM } \rightarrow \\
\text { NC, TF -Unstable }\end{array}$ \\
\hline Hamasaki et al [4] & $\begin{array}{l}\text { 1. Left Fenestration } \\
\text { 2. Bilateral } \\
\text { Decompression via } \\
\text { Unilateral Approach } \\
\text { 3. Medial Facetectomy } \\
\text { 4. Total Facetectomy }\end{array}$ & $\begin{array}{l}4 \text { L2-L3 } \\
4 \text { L4-L5 }\end{array}$ & $\begin{array}{l}\text { Cyclic Conditioning, } \\
750 \text { N Compression, } \\
750 \text { N Eccentric Load }\end{array}$ & $\begin{array}{l}\downarrow \text { in Global Stiffness with } \\
\text { More Removal }\end{array}$ \\
\hline $\begin{array}{l}\text { Kato, Panjabi, and } \\
\text { Nibu [15] }\end{array}$ & $\begin{array}{l}\text { 1. Total Facetectomy } \\
\text { 2. Osteoplastic } \\
\text { Laminectomy }\end{array}$ & 6 L3-L4 & Pure Moment & $\begin{array}{l}\mathrm{ROM} \uparrow \text { in Flexion- } \\
\text { Extension and Axial } \\
\text { Rotation }\end{array}$ \\
\hline Okawa et al [13] & $\begin{array}{l}\text { 1. Partial Laminotomy } \\
\text { (YL) } \\
\text { 2. Wide Fenestration } \\
\text { (WF) } \\
\text { 3. UF (Total) } \\
\text { 4. BF (Total) }\end{array}$ & 10 L3-L4 & $\begin{array}{l}729 \text { N Compression, } \\
\text { Eccentric Load }\end{array}$ & $\begin{array}{l}\text { Stiffness } \downarrow \text { in Extension } \\
\text { after WF and in Lateral } \\
\text { after UTF }\end{array}$ \\
\hline Pintar et al [12] & $\begin{array}{l}\text { 1. UF (Left or Right) } \\
\text { 2. BF } \\
\text { 3. PLL } \\
\text { 4. LF, Inter- and } \\
\text { Supraspinous (BFL) } \\
\text { 5. Partial } \\
\text { Discectomy(BFLD) }\end{array}$ & $\begin{array}{l}4 \text { L2-L3 } \\
4 \text { L4-L5 }\end{array}$ & $\begin{array}{l}\text { Compression-Flexion } \\
\text { Loading, Movement of } \\
\text { Spinal Components } \\
\text { Recorded }\end{array}$ & $\begin{array}{l}\uparrow \text { Force Deflection from } \\
\text { BF to BFL, } \\
\uparrow \text { in Facet Joint Motion } \\
\text { with } \uparrow \text { Removal }\end{array}$ \\
\hline
\end{tabular}


Table A-3. (continued).

\begin{tabular}{|c|c|c|c|c|}
\hline Investigators & $\begin{array}{l}\text { Removal/ Surgical } \\
\text { Procedures }\end{array}$ & Levels & Testing Method & Results* \\
\hline Posner et al [11] & $\begin{array}{l}\text { Posterior Ligaments } \rightarrow \\
\text { Facet Joints } \rightarrow \text { Disc } \rightarrow \\
\text { ALL and } 1 / 2 \text { Specimens } \\
\text { in Opposite Order until } \\
\text { Failure }\end{array}$ & $\begin{array}{l}6 \text { L1-L2 } \\
6 \text { L3-L4 } \\
6 \text { L5-S1 }\end{array}$ & $\begin{array}{l}\text { Preload, Flexion and } \\
\text { Extension Forces as \% } \\
\text { of Body Weight }\end{array}$ & $\begin{array}{l}\uparrow \text { Displacement with } \\
\text { Removal }\end{array}$ \\
\hline
\end{tabular}

Note: *An increase is denoted as $\uparrow$. A decrease is represented by $\downarrow$. No change is represented by NC. 


\section{References}

1. A.A.o.N. Surgeons (Editor). National Neurosurgical Procedural Statistics, in 2006 Survey. 2008. Rolling Meadows, IL: American Association of Neurological Surgeons.

2. Caputy, A.J., Spence, C.A., Bejjani, G.K. and Luessenhop, A.J. The role of spinal fusion in surgery for lumbar spinal stenosis: a review. Neurosurg Focus. 1997. 3(2): p. e3; discussion $1 \mathrm{p}$ following e4.

3. Hazlett, J.W. and Kinnard, P. Lumbar apophyseal process excision and spinal instability. Spine. 1982. 7(2): p. 171-6.

4. Hamasaki, T., Tanaka, N., Kim, J., Okada, M., Ochi, M. and Hutton, W.C. Biomechanical assessment of minimally invasive decompression for lumbar spinal canal stenosis: a cadaver study. J Spinal Disord Tech. 2009. 22(7): p. 486-91.

5. Guiot, B.H., Khoo, L.T. and Fessler, R.G. A minimally invasive technique for decompression of the lumbar spine. Spine. 2002. 27(4): p. 432-8.

6. White, A.A. and Panjabi, M.M. Clinical biomechanics of the spine. 2nd ed. 1990. Philadelphia: Lippincott.

7. Ishida, Y., Ohmori, K., Inoue, H. and Suzuki, K. Delayed vertebral slip and adjacent disc degeneration with an isthmic defect of the fifth lumbar vertebra. $\mathrm{J}$ Bone Joint Surg Br. 1999. 81(2): p. 240-4.

8. Disch, A.C., Schmoelz, W., Matziolis, G., Schneider, S.V., Knop, C. and Putzier, M. Higher risk of adjacent segment degeneration after floating fusions: long-term outcome after low lumbar spine fusions. J Spinal Disord Tech. 2008. 21(2): p. 7985.

9. Yang, K.H. and King, A.I. Mechanism of facet load transmission as a hypothesis for low-back pain. Spine. 1984. 9(6): p. 557-65.

10. Tai, C.L., Hsieh, P.H., Chen, W.P., Chen, L.H., Chen, W.J. and Lai, P.L. Biomechanical comparison of lumbar spine instability between laminectomy and bilateral laminotomy for spinal stenosis syndrome - an experimental study in porcine model. BMC Musculoskelet Disord. 2008. 9: p. 84.

11. Posner, I., White, A.A., 3rd, Edwards, W.T. and Hayes, W.C. A biomechanical analysis of the clinical stability of the lumbar and lumbosacral spine. Spine. 1982. 7(4): p. 374-89.

12. Pintar, F.A., Cusick, J.F., Yoganandan, N., Reinartz, J. and Mahesh, M. The biomechanics of lumbar facetectomy under compression-flexion. Spine. 1992. 17(7): p. 804-10. 
13. Okawa, A., Shinomiya, K., Takakuda, K. and Nakai, O. A cadaveric study on the stability of lumbar segment after partial laminotomy and facetectomy with intact posterior ligaments. J Spinal Disord. 1996. 9(6): p. 518-26.

14. Lorenz, M., Patwardhan, A. and Vanderby, R., Jr. Load-bearing characteristics of lumbar facets in normal and surgically altered spinal segments. Spine. 1983. 8(2): p. 122-30.

15. Kato, Y., Panjabi, M.M. and Nibu, K. Biomechanical study of lumbar spinal stability after osteoplastic laminectomy. J Spinal Disord. 1998. 11(2): p. 146-50.

16. Abumi, K., Panjabi, M.M., Kramer, K.M., Duranceau, J., Oxland, T. and Crisco, J.J. Biomechanical evaluation of lumbar spinal stability after graded facetectomies. Spine. 1990. 15(11): p. 1142-7.

17. Katz, J.N., Lipson, S.J., Chang, L.C., Levine, S.A., Fossel, A.H. and Liang, M.H. Seven- to 10-year outcome of decompressive surgery for degenerative lumbar spinal stenosis. Spine. 1996. 21(1): p. 92-8.

18. Garrido, E. and Connaughton, P.N. Unilateral facetectomy approach for lateral lumbar disc herniation. J Neurosurg. 1991. 74(5): p. 754-6. 
APPENDIX B: POTTED IMAGES

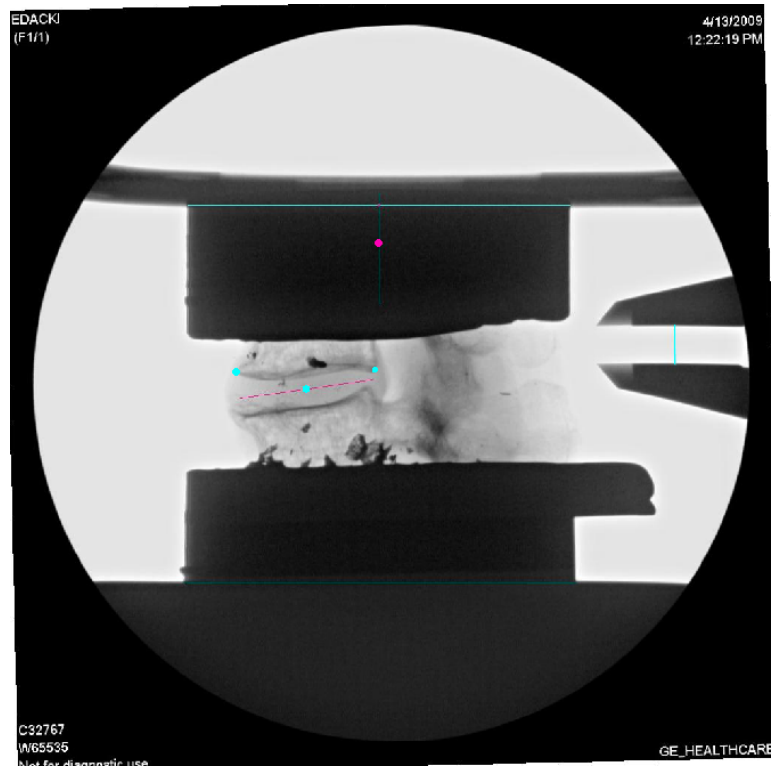

Figure B-1. Radiograph of Specimen 0105285.

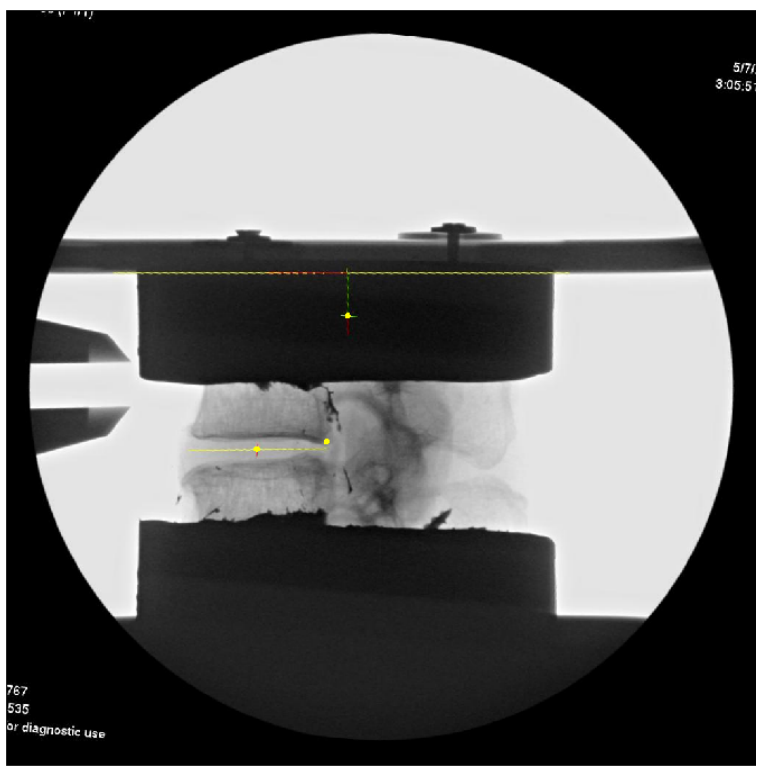

Figure B-2. Radiograph of Specimen 0105459. 


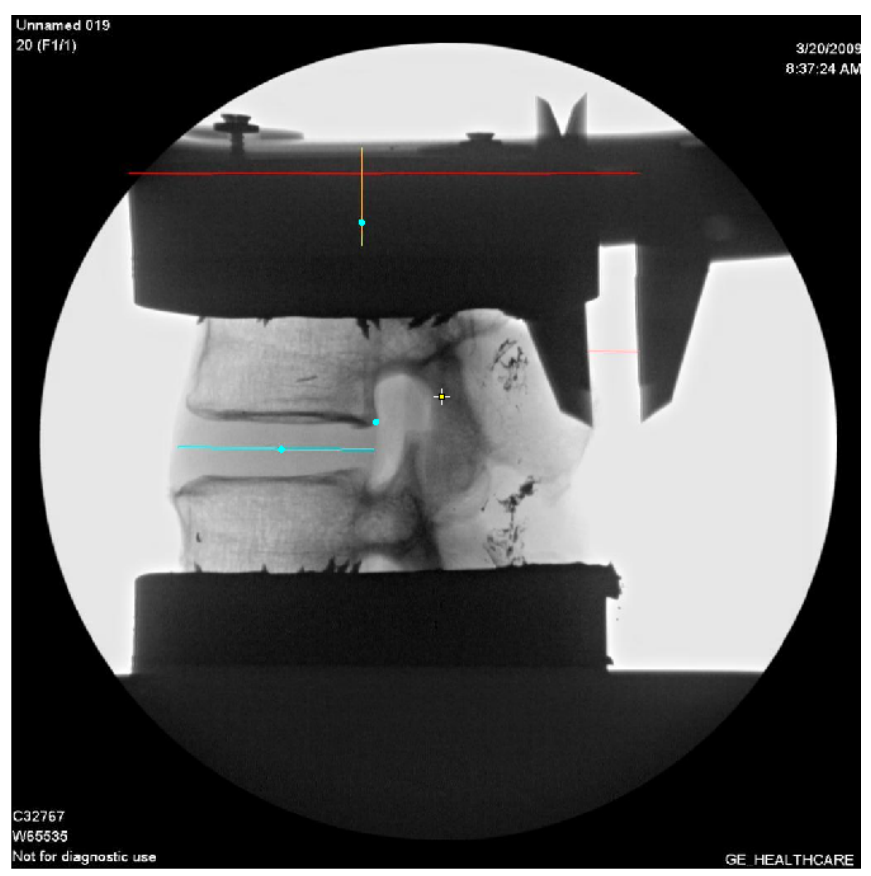

Figure B-3. Radiograph of Specimen 0701888.

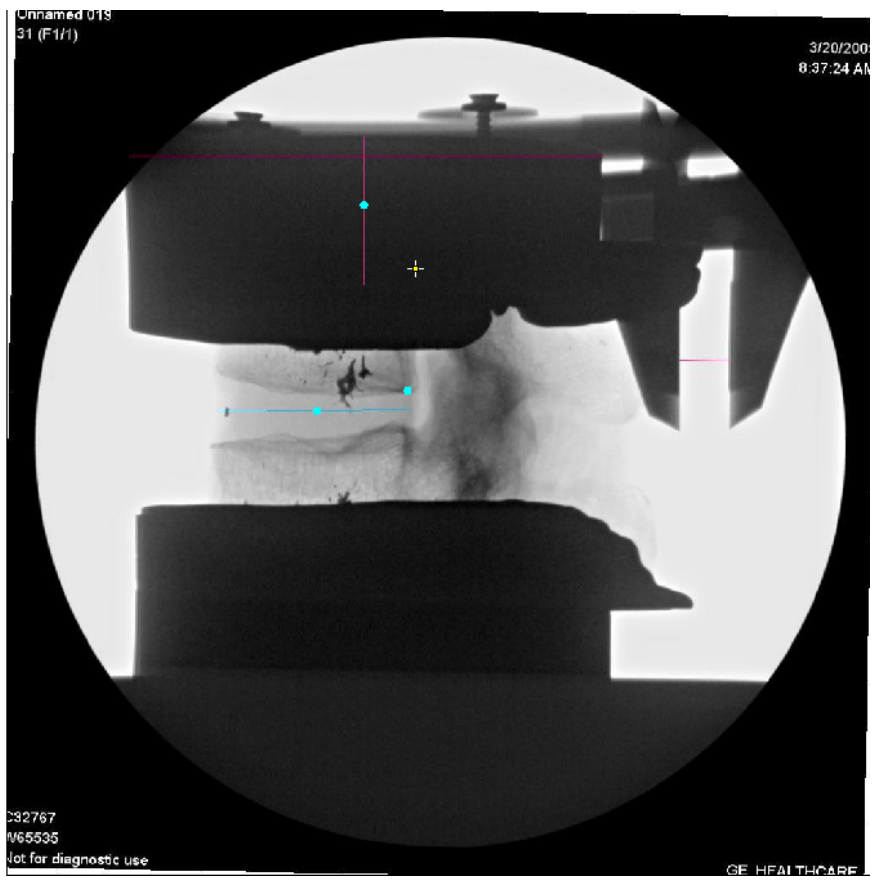

Figure B-4. Radiograph of Specimen 07087036. 


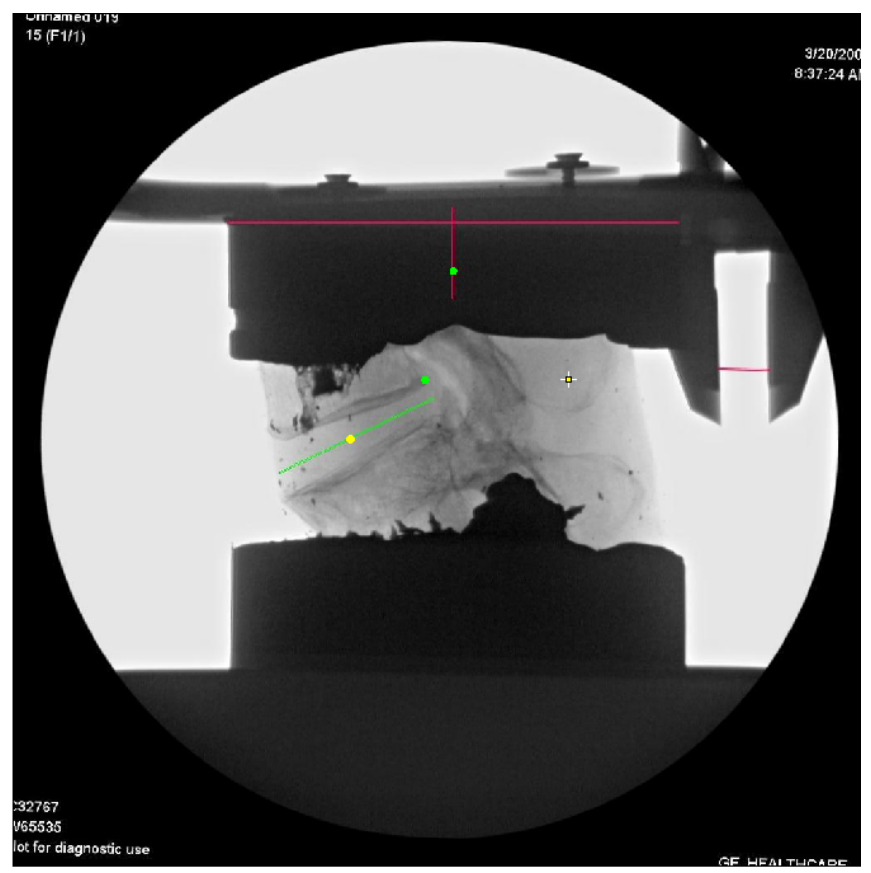

Figure B-5. Radiograph of Specimen 53103715-002-2.

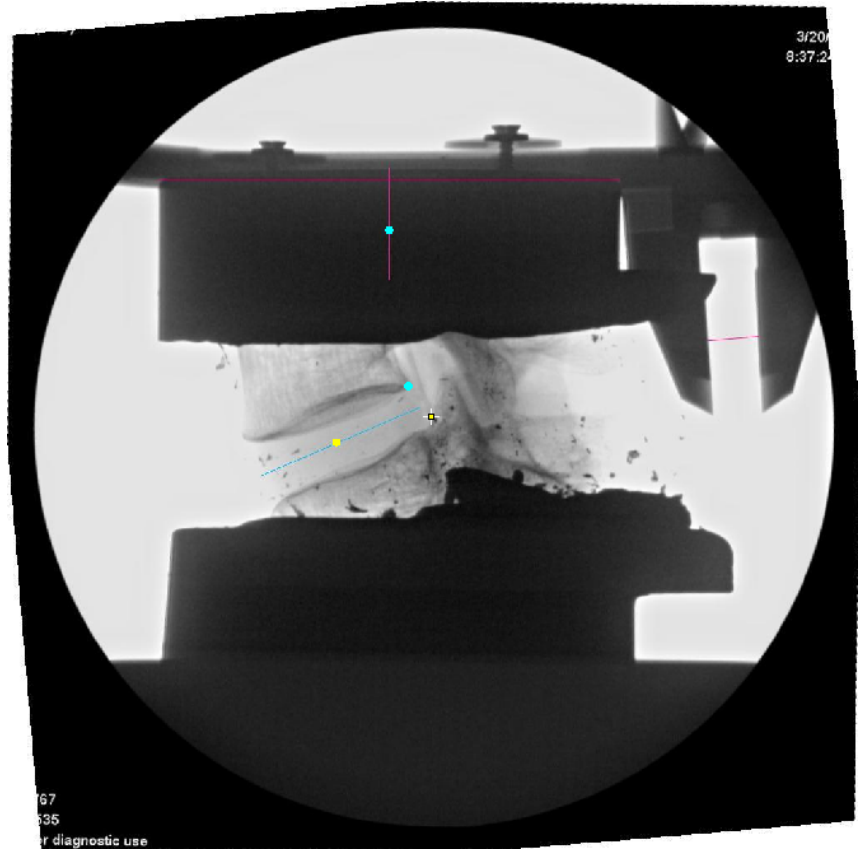

Figure B-6. Radiograph of Specimen ADS1017052. 


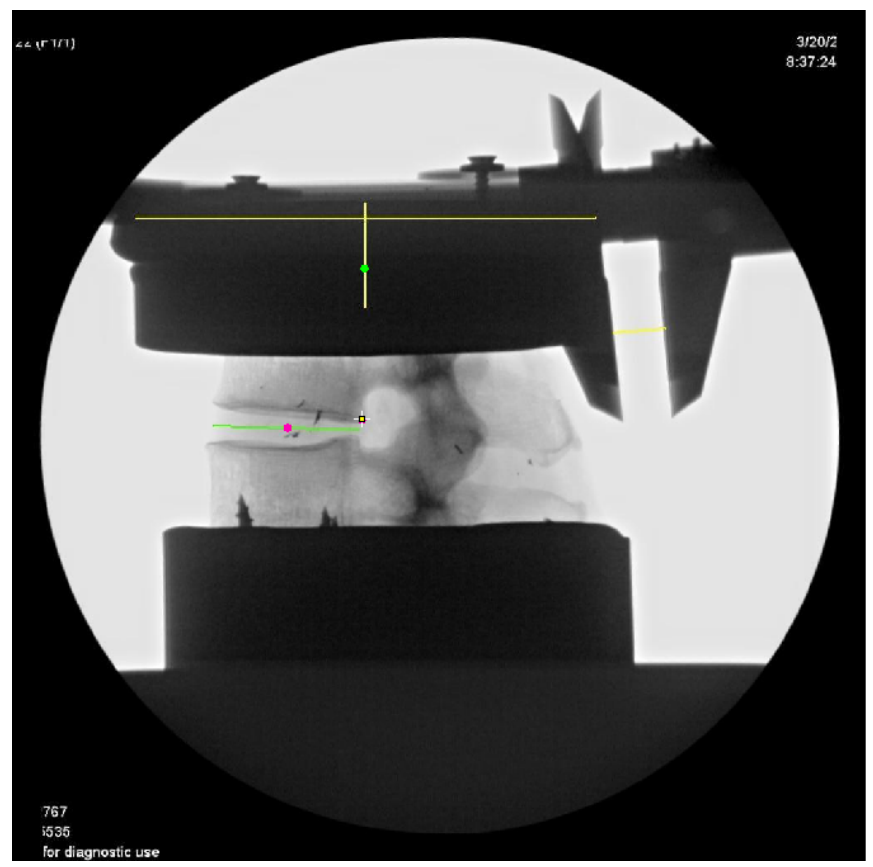

Figure B-7. Radiograph of Specimen DRT087036.

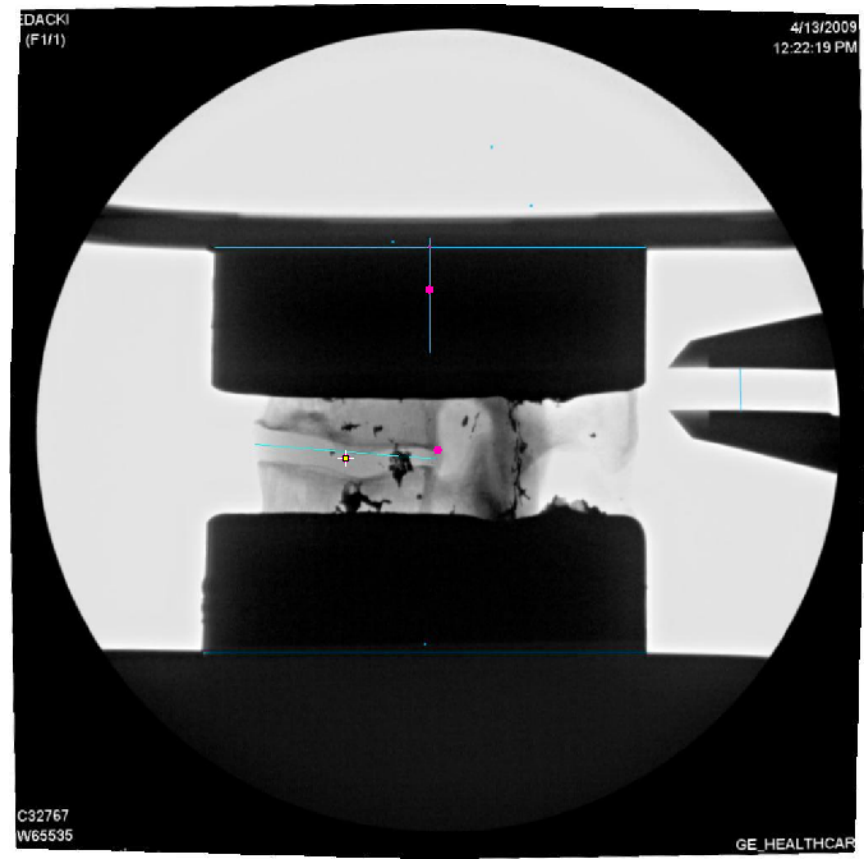

Figure B-8. Radiograph of Specimen GD-1. 
APPENDIX C: PM AND CLM TESTING PROTOCOLS TABULATED DATA 
Table C-1. Harvested Tabulated Data from PM Protocol.

\begin{tabular}{|c|c|c|c|c|c|c|c|}
\hline \multirow{3}{*}{ Spine } & \multicolumn{7}{|c|}{ Farvested: Flerion PM (Fod Limit $8 \mathrm{Nm}$ ) } \\
\hline & Patch & $\operatorname{Sheser(AP)}$ & Shas (Tat) & Axial & Mx & $\mathrm{My}$ & $\mathrm{Mz}$ \\
\hline & Degrees & $\mathrm{N}$ & $\mathrm{N}$ & $\mathrm{N}$ & $\mathrm{Nm}$ & $\mathrm{Nm}$ & $\mathrm{Nm}$ \\
\hline 105285 & 75 & 1.6 & 9.8 & 20 & -0.7 & 8.1 & -0.6 \\
\hline 105459 & 11.0 & 19 & 0.8 & 1.1 & -12 & 8.6 & -0.9 \\
\hline 701858 & 8.2 & 1.8 & 3.2 & -1.2 & -1.1 & 8.5 & -0.6 \\
\hline 7057036 & 65 & 1.8 & -15.2 & 1.4 & -1.8 & 83 & 0.3 \\
\hline $53103715-002-2$ & 6.5 & 1.7 & 4.7 & .0 .6 & -10 & 80 & 0.6 \\
\hline ADS1017052 & 8.2 & 19 & 9.0 & 0.6 & -10 & 8.0 & 0.6 \\
\hline DRT0S7036 & 5.2 & 0.9 & -20.6 & 4.5 & -19 & 8.2 & 0.3 \\
\hline GD-1 & 4.7 & 0.7 & 0.9 & 0.3 & -15 & 8.3 & 1.1 \\
\hline Mesa & 7.2 & 15 & .09 & 10 & -1.3 & 8.3 & 0.1 \\
\hline Sandard Deviation & 20 & 0.5 & 11.1 & 1.8 & 0.4 & 0.2 & 0.7 \\
\hline
\end{tabular}

\begin{tabular}{|c|c|c|c|c|c|c|c|}
\hline \multirow{3}{*}{ Spine } & \multicolumn{7}{|c|}{ Harvested: Extemion PM (Evd Limit $8 \mathrm{Nm}$ ) } \\
\hline & Paxh & $\operatorname{Shas}(A P)$ & Sheas (Lat) & Axial & Mx & My & $\mathrm{Mz}$ \\
\hline & Degrees & $\mathrm{N}$ & $\mathrm{N}$ & $\mathrm{N}$ & $\mathrm{Nm}$ & $\mathrm{Nm}$ & $\mathrm{Nm}$ \\
\hline 105285 & 65 & 1.7 & -8.1 & -22 & -1.2 & 8.1 & 0.4 \\
\hline 105459 & 5.5 & 3.0 & 15.5 & 0.7 & -0.6 & 3.8 & -0.5 \\
\hline 701858 & 6.2 & 27 & -39 & 0.6 & -1.3 & 8.5 & -0.1 \\
\hline 7057036 & 4.2 & 1.6 & -13.6 & 0.8 & -1.7 & 8.2 & .0 .2 \\
\hline $53103715-002-2$ & 65 & 19 & -30.6 & 1.4 & -24 & 8.4 & -10 \\
\hline ADS1017052 & 6.7 & 1.8 & 80 & 0.4 & -1.0 & 3.5 & 0.1 \\
\hline DRT087036 & 4.2 & 10 & -9.4 & -0.9 & -1.5 & 8.5 & -0.5 \\
\hline GD-1 & 4.5 & 3.1 & 70 & 0.4 & -1.1 & 3.5 & .0 .5 \\
\hline Masn & 5.5 & 21 & -4.4 & 0.1 & -1.3 & 3.4 & -0.3 \\
\hline Standard Deviation & 1.1 & 0.7 & 14.6 & 1.2 & 0.5 & 0.2 & 0.5 \\
\hline
\end{tabular}

\begin{tabular}{|c|c|c|c|c|c|c|c|c|}
\hline \multirow{3}{*}{ Spine } & \multicolumn{8}{|c|}{ Harrested: Left Lateral PM(Eod Limit $6 \mathrm{Nm})$} \\
\hline & Pasch & $\operatorname{Shes}(A P)$ & Sheas (Lat) & Axial & Mx & $\mathrm{My}$ & $\mathrm{Mz}$ & Passive Axial Rotatise \\
\hline & Degrees & $\mathrm{N}$ & $\mathrm{N}$ & $\mathrm{N}$ & $\mathrm{Nm}$ & $\mathrm{Nm}$ & $\mathrm{Nm}$ & Degrees \\
\hline 105285 & 45 & -13 & 8.4 & -0.2 & 1.4 & -6.4 & -0.2 & 0.8 \\
\hline 105459 & 60 & -0.1 & 227 & 1.8 & .05 & -60 & 0.0 & 10 \\
\hline 701858 & 8.2 & -19 & 63 & 1.3 & 1.8 & -6.1 & -0.1 & 09 \\
\hline 7087036 & 5.5 & -1.7 & 10.5 & -0.7 & 25 & -6.4 & -0.1 & 0.7 \\
\hline $53103715-002-2$ & 5.5 & -1.5 & -27.1 & 19 & 0.4 & -63 & 0.1 & 15 \\
\hline ADS1017052 & 5.2 & -15 & 324 & .0 .8 & 0.9 & -6.2 & 0.1 & 1.7 \\
\hline DRTOS7 036 & 3.7 & 0.9 & 124 & 28 & -3.1 & -6.7 & 0.3 & 0.5 \\
\hline GD-1 & 25 & 0.0 & -37.1 & 3.4 & .0 .5 & -6.2 & 0.1 & 0.4 \\
\hline Masa & 5.1 & .09 & 3.6 & 1.2 & 0.4 & -63 & 0.0 & 09 \\
\hline Sandard Deviatiog & 1.7 & 10 & 23.7 & 1.6 & 1.8 & 0.2 & 0.2 & 0.5 \\
\hline
\end{tabular}

\begin{tabular}{|c|c|c|c|c|c|c|c|c|}
\hline \multirow{3}{*}{ Spine } & \multicolumn{8}{|c|}{ Farrested: Right Latersl PM (Evd Limit $6 \mathrm{Nm}$ ) } \\
\hline & Pach & $\operatorname{Shes}(A P)$ & Shess (Lat) & Axial & Mx & $\mathrm{My}$ & $\mathrm{Mr}$ & Passine Axial Rotation \\
\hline & & & & & & & & \\
\hline 105285 & 4.2 & -1.1 & 11.2 & -2.1 & -1.7 & -6.3 & 0.2 & 1.2 \\
\hline 105459 & 9.5 & -1.5 & -1.7 & 10 & 0.7 & -6.0 & -0.1 & 0.7 \\
\hline 701858 & 6.7 & -1.7 & 20.1 & -0.7 & 0.5 & -63 & 0.0 & 0.7 \\
\hline 7087036 & 4.0 & .0 .5 & -6.6 & 1.0 & -24 & -6.5 & 0.2 & 0.7 \\
\hline $53103715-002-2$ & 4.5 & 0.6 & -263 & 0.8 & -0.5 & -6.4 & 0.1 & 0.6 \\
\hline ADs1017052 & 59 & -0.6 & 3.4 & -0.9 & 20 & -6.2 & -0.1 & 2.1 \\
\hline DRT0S7036 & 5.0 & -1.5 & 30.7 & -22 & 3.2 & -6.1 & -0.2 & 0.7 \\
\hline GD-1 & 3.2 & -0.6 & -9.7 & -3.3 & 12 & -6.3 & 0.0 & 0.4 \\
\hline Mesa & 5.4 & -0.9 & 26 & -0.8 & 0.4 & -63 & 0.0 & 09 \\
\hline Sandard Deviation & 20 & 0.7 & 180 & 1.7 & 19 & 0.2 & 0.2 & 0.5 \\
\hline
\end{tabular}


Table C-2. UF Tabulated Data from PM Protocol.

\begin{tabular}{|c|c|c|c|c|c|c|c|}
\hline \multirow{3}{*}{ Spine } & \multicolumn{7}{|c|}{ UF: Flexion PM (End Limit $8 \mathrm{Nm}$ ) } \\
\hline & Paxh & $\operatorname{Shear}(A P)$ & Shess (Lat) & Axial & Ma & $\mathrm{My}$ & $\mathrm{Mz}$ \\
\hline & Degrees & $\mathrm{N}$ & $\mathrm{N}$ & $\mathrm{N}$ & $\mathrm{Nm}$ & $\mathrm{Nm}$ & $\mathrm{Nm}$ \\
\hline 105285 & 7.2 & 1.2 & 15.7 & 3.1 & -0.4 & 3.1 & -0.9 \\
\hline 105459 & 100 & 1.6 & 21.7 & 1.6 & -0.7 & 8.4 & -0.6 \\
\hline 701888 & 6.2 & 3.1 & 22.5 & -0.6 & -0.2 & 8.2 & -0.5 \\
\hline 7057036 & 5.5 & 27 & -15.8 & 1.7 & -20 & 3.1 & 0.2 \\
\hline $53103715-002-2$ & 3.5 & 1.7 & 15.8 & 19 & -0.5 & 3.5 & -0.3 \\
\hline ADS1017052 & 3.0 & 25 & -209 & 2.1 & -1.7 & 8.3 & 0.7 \\
\hline DRTOS7ר36 & 3.5 & 0.6 & -13.3 & 3.7 & -1.7 & 8.4 & 0.2 \\
\hline GD-1 & 4.7 & 10 & 17.1 & 1.8 & -1.1 & 3.1 & 0.7 \\
\hline Masa & 63 & 1.8 & 5.3 & 19 & -10 & 83 & 0.0 \\
\hline Standard Deviatise & 20 & 0.9 & 18.5 & 19 & -1.0 & 0.2 & 0.6 \\
\hline
\end{tabular}

\begin{tabular}{|c|c|c|c|c|c|c|c|}
\hline \multirow{3}{*}{ Spine } & \multicolumn{7}{|c|}{ UF: Extemion PM (Evd Límit $8 \mathrm{Nm})$} \\
\hline & Pasch & $\operatorname{Shas}(A P)$ & Shear (Lat) & Axial & Mx & $\mathrm{My}$ & $\mathrm{Mx}$ \\
\hline & Degrees & $\mathrm{N}$ & $\mathrm{N}$ & $\mathrm{N}$ & $\mathrm{Nm}$ & $\mathrm{Nm}$ & $\mathrm{Nm}$ \\
\hline 105285 & 5.2 & 1.6 & .79 & 0.3 & -1.3 & 8.4 & 1.1 \\
\hline 105459 & 3.0 & 1.7 & 31.4 & -28 & -0.3 & 3.2 & 0.6 \\
\hline 701858 & 5.0 & 23 & -5.1 & 0.5 & -1.2 & 8.1 & -0.3 \\
\hline 7057036 & 4.0 & 1.7 & -12.6 & 12 & -1.8 & 3.2 & 0.2 \\
\hline $53103715-002-2$ & 5.5 & 20 & -21.5 & 1.3 & -21 & 3.6 & -0.5 \\
\hline ADS1017052 & 6.5 & 1.8 & -7.2 & 0.9 & -1.3 & 8.0 & -0.1 \\
\hline DRT0S7ר36 & 3.5 & 1.5 & -189 & 1.1 & .09 & 3.2 & -0.3 \\
\hline GD-1 & 40 & 23 & 8.4 & 10 & -1.2 & 8.2 & 0.0 \\
\hline Mesa & 4.8 & 19 & -4.2 & 0.5 & -1.3 & 8.3 & 0.1 \\
\hline Standard Deviation & 10 & 0.3 & 17.1 & 1.3 & 0.5 & 0.2 & 0.5 \\
\hline
\end{tabular}

\begin{tabular}{|c|c|c|c|c|c|c|c|c|}
\hline \multirow{3}{*}{ Spine } & \multicolumn{8}{|c|}{ UF: Left Lateral PM (Evd Limit $6 \mathrm{Nm}$ ) } \\
\hline & Paxh & $\operatorname{Shear}(A P)$ & Shear (Lat) & Axial & Mx & My & $\mathrm{M} x \mathrm{x}$ & Passive Axial Roatise \\
\hline & Degrees & $\mathrm{N}$ & $\mathrm{N}$ & $\mathrm{N}$ & $\mathrm{Nm}$ & $\mathrm{Nm}$ & $\mathrm{Nm}$ & Degrees \\
\hline 105285 & 4.7 & -20 & 26 & 15 & 3.1 & -6.2 & -0.2 & 10 \\
\hline 105459 & 5.7 & -20 & 19.7 & 3.1 & 0.7 & -6.1 & 0.0 & 1.0 \\
\hline 701898 & 6.2 & -1.6 & 3.4 & -12 & 25 & -6.3 & -0.1 & 0.6 \\
\hline 7057036 & 4.7 & 1.3 & 17.7 & -20 & -24 & 6.2 & 0.0 & 0.3 \\
\hline $53103715-002-2$ & 4.7 & -1.1 & 0.5 & -0.4 & 0.3 & -62 & 0.1 & 0.7 \\
\hline ADS1017052 & 4.2 & 2.1 & 25 & 26 & 0.1 & 6.1 & 0.0 & 1.4 \\
\hline DRT087036 & 40 & 3.4 & 9.4 & 15 & -0.1 & 6.5 & 0.0 & 0.4 \\
\hline GD-1 & 22 & -0.7 & 19.2 & 0.4 & 1.2 & -60 & 0.1 & 0.4 \\
\hline Mase & 4.6 & -0.1 & 9.4 & 0.7 & 0.7 & -15 & 00 & 0.7 \\
\hline Standard Deviation & 12 & 2.1 & 8.3 & 1.8 & 1.7 & 6.4 & 0.1 & 0.4 \\
\hline
\end{tabular}

\begin{tabular}{|c|c|c|c|c|c|c|c|c|}
\hline \multirow{3}{*}{ Spine } & \multicolumn{8}{|c|}{ UF: Right Latergl PM (Fod Limit $6 \mathrm{Nm}$ ) } \\
\hline & Path & $\operatorname{Shear}(A P)$ & Shear (Lat) & Axial & Mx & $\mathrm{My}$ & $\mathrm{M} x$ & Passive Axial Rotatiog \\
\hline & Degrees & $\mathrm{N}$ & $\mathrm{N}$ & $\mathrm{N}$ & $\mathrm{Nm}$ & $\mathrm{Nm}$ & $\mathrm{Nm}$ & Degrees \\
\hline 105285 & 5.5 & -1.3 & -10.1 & -1.4 & -1.4 & -6.3 & 0.2 & 1.0 \\
\hline 105459 & 9.7 & 23 & 4.1 & 0.7 & -1.2 & 6.1 & 0.0 & 0.7 \\
\hline 701888 & 6.7 & 1.5 & 1.0 & -1.8 & 0.8 & 62 & 0.2 & 0.7 \\
\hline 7087036 & 4.0 & -1.7 & 6.8 & 1.2 & -3.9 & -6.5 & 0.4 & 0.3 \\
\hline $53103715-002-2$ & 4.7 & 10 & 18.2 & .0 .7 & 0.7 & 6.1 & 0.2 & 0.6 \\
\hline AD\$1017052 & 6.0 & 2.1 & -16.2 & 2.1 & -1.1 & 6.4 & -0.2 & 20 \\
\hline DRTOS7036 & 5.2 & -1.6 & 3.1 & 0.9 & 1.7 & -6.0 & -0.1 & 0.5 \\
\hline GD-1 & 3.7 & 15 & 17.4 & 21 & 0.0 & 6.3 & 0.1 & 0.7 \\
\hline Mase & 5.7 & 0.5 & 3.0 & 0.4 & -0.5 & 1.5 & 0.1 & 0.8 \\
\hline Standard Deviation & 19 & 1.7 & 119 & 1.5 & 1.7 & 6.5 & 0.2 & 0.5 \\
\hline
\end{tabular}


Table C-3. BF Tabulated Data from PM Protocol.

\begin{tabular}{|c|c|c|c|c|c|c|c|}
\hline \multirow{3}{*}{ Spine } & \multicolumn{7}{|c|}{ BF: Flexion PM (End Limit $8 \mathrm{Nm}$ ) } \\
\hline & Paxh & $\operatorname{Shear}(A P)$ & Shear (Lat) & Axial & Max & My & $\mathrm{M} x$ \\
\hline & Dearees & $\mathrm{N}$ & $\mathrm{N}$ & $\mathrm{N}$ & $\mathrm{Nm}$ & $\mathrm{Nm}$ & $\mathrm{Nm}$ \\
\hline 105285 & 9.5 & 1.8 & 17.4 & 22 & 0.0 & 8.2 & -0.8 \\
\hline 105459 & 11.7 & 2.1 & 26.1 & 29 & 0.3 & 8.4 & -2.3 \\
\hline 701898 & 7.5 & 1.7 & 13.2 & 0.3 & -0.1 & 8.5 & -0.2 \\
\hline 7087036 & 6.7 & 19 & 4.4 & 1.7 & -0.3 & 8.4 & 1.3 \\
\hline $53103715-002-2$ & 6.7 & 1.8 & -3.2 & 0.3 & -10 & 8.5 & 0.8 \\
\hline ADS1017052 & 8.2 & 3.0 & .0 .8 & 12 & -0.7 & 3.2 & 0.0 \\
\hline DRTOS7036 & 5.5 & 1.2 & 0.7 & 3.4 & -0.8 & 8.7 & -0.1 \\
\hline GD-1 & 5.7 & 13 & -1.1 & 3.5 & -12 & 9.2 & 0.0 \\
\hline Mesan & 7.7 & 19 & 7.1 & 19 & -0.5 & 8.5 & -0.2 \\
\hline Sandard Deviation & 2.1 & 0.6 & 10.6 & 13 & 0.6 & 0.3 & 1.1 \\
\hline
\end{tabular}

\begin{tabular}{|c|c|c|c|c|c|c|c|}
\hline \multirow{3}{*}{ Spine } & \multicolumn{7}{|c|}{ BF: Extemion PM (End Limit $8 \mathrm{Nm}$ ) } \\
\hline & Pasch & $\operatorname{Shear}(A P)$ & Shear (Lat) & Axial & Mx & My & $\mathrm{M} z$ \\
\hline & Dearees & $\mathrm{N}$ & $\mathrm{N}$ & $\mathrm{N}$ & $\mathrm{Nm}$ & $\mathrm{Nm}$ & $\mathrm{Nm}$ \\
\hline 105285 & 7.2 & 1.6 & 26.7 & -19 & 0.3 & 8.2 & -0.4 \\
\hline 105459 & 6.5 & 25 & -24 & 0.2 & 1.8 & 8.1 & -0.1 \\
\hline 701898 & 5.5 & 23 & 3.0 & 1.6 & -0.5 & 8.1 & 0.1 \\
\hline 7057036 & 4.7 & 2.1 & -14.5 & 1.8 & -2.1 & 8.5 & 0.0 \\
\hline $53103715-002-2$ & 6.5 & is & -9.0 & -20 & -1.3 & 80 & 0.5 \\
\hline ADS1017052 & 7.5 & .0 .5 & 15.5 & 0.4 & .03 & 83 & 0.1 \\
\hline DRTOS7036 & 5.0 & 25 & 0.0 & 0.4 & .0 .8 & 8.6 & 0.0 \\
\hline GD-1 & 5.2 & 21 & -0.7 & 1.6 & 26 & 8.3 & 0.0 \\
\hline Masa & 6.0 & 1.8 & 3.0 & 0.3 & 0.0 & 83 & 0.0 \\
\hline Shandard Deviatise & 1.1 & 10 & 13.3 & 1.5 & 1.6 & 0.2 & 0.2 \\
\hline
\end{tabular}

\begin{tabular}{|c|c|c|c|c|c|c|c|c|}
\hline \multirow{3}{*}{ Spine } & \multicolumn{8}{|c|}{ BF: Left Lateral PM (End Limit $6 \mathrm{Nm}$ ) } \\
\hline & Patch & $\operatorname{Shear}(A P)$ & Shesar (Lat) & Axial & $\mathrm{Mx}$ & $\mathrm{My}$ & $\mathrm{M} x \mathrm{z}$ & Passine Axial Rotatise \\
\hline & Dearees & $\mathrm{N}$ & $\mathrm{N}$ & $\mathrm{N}$ & $\mathrm{Nm}$ & $\mathrm{Nm}$ & $\mathrm{Nm}$ & Dearees \\
\hline 105285 & 60 & -1.2 & 32.3 & -0.6 & 19 & -6.2 & .0 .2 & 1.8 \\
\hline 105459 & 7.7 & 1.7 & -163 & 1.6 & -1.1 & 6.4 & -0.2 & 1.5 \\
\hline 701858 & 65 & 25 & 260 & 24 & -0.9 & 6.5 & 0.1 & 0.8 \\
\hline 7057036 & 4.7 & -0.7 & -3.2 & -3.4 & .0 .3 & -6.4 & 0.1 & 0.5 \\
\hline $53103715-002-2$ & 5.7 & -27 & -6.6 & 20 & -0.1 & -62 & 0.1 & 1.7 \\
\hline ADs1017052 & 4.5 & 22 & 20.2 & 12 & 0.2 & 6.4 & 0.0 & 13 \\
\hline DRT087036 & 4.7 & 0.8 & -0.7 & -27 & 0.6 & 6.4 & 0.0 & 1.1 \\
\hline GD-1 & 27 & -0.4 & -22 & 0.3 & 1.5 & -6.1 & 0.0 & 0.5 \\
\hline Masa & 5.3 & 0.3 & 6.2 & 0.1 & 0.2 & 0.1 & 0.0 & 1.1 \\
\hline Sandard Deviation & 15 & 1.8 & 17.5 & 22 & 1.1 & 6.8 & 0.1 & 0,5 \\
\hline
\end{tabular}

\begin{tabular}{|c|c|c|c|c|c|c|c|c|}
\hline \multirow{3}{*}{ Spine } & \multicolumn{8}{|c|}{ BF: Right Latersl PM (Evd Limit $6 \mathrm{Nm}$ ) } \\
\hline & Paxh & $\operatorname{Shear}(A P)$ & Shear (Lat) & Axial & Max & My & $\mathrm{M} x \mathrm{x}$ & Passive Axwal Rotatiog \\
\hline & Degrees & $\mathrm{N}$ & $\mathrm{N}$ & $\mathrm{N}$ & $\mathrm{Nm}$ & $\mathrm{Nm}$ & $\mathrm{Nm}$ & Degrees \\
\hline 105285 & 7.2 & 1.3 & 31.9 & -1.6 & 1.1 & 6.3 & 0.2 & 1.8 \\
\hline 105459 & 9.5 & -2.3 & -13.8 & 0.8 & -0.3 & -6.5 & -0.1 & 1.3 \\
\hline 701858 & 6.7 & 1.1 & -0.2 & -3.0 & 15 & 6.1 & 0.2 & 1.4 \\
\hline 7057036 & 5.0 & 19 & 200 & 1.1 & 1.2 & 62 & 0.3 & 0.8 \\
\hline $53103715-002-2$ & 5.5 & 26 & 19.4 & 1.6 & 0.1 & 6.2 & 0.1 & 1.6 \\
\hline ADS1017052 & 7.2 & -25 & 4.0 & 24 & 09 & -6.2 & -0.1 & 24 \\
\hline DRTOS7036 & 5.2 & -24 & -110 & 29 & 1.5 & -6.5 & -0.1 & 0.8 \\
\hline GD-1 & 5.0 & 1.4 & -20 & 0.6 & 10 & 6.1 & 0.1 & 1.2 \\
\hline Mesa & 6.4 & 0.1 & 60 & 0.6 & 09 & 1.4 & 0.1 & 1.4 \\
\hline Standard Deviation & 1.6 & 2.1 & 162 & 20 & 0.6 & 65 & 0.2 & 0.5 \\
\hline
\end{tabular}


Table C-4. Laminectomy Tabulated Data from PM Protocol.

\begin{tabular}{|c|c|c|c|c|c|c|c|}
\hline \multirow{3}{*}{ Spine } & \multicolumn{7}{|c|}{ Lami: Flesion PM (End Limit $8 \mathrm{Nm}$ ) } \\
\hline & Paxh & $\operatorname{Shess}(A P)$ & Shases (Lat) & Axial & Mx & $\mathrm{My}$ & $\mathrm{Mx}$ \\
\hline & Dearees & $\mathrm{N}$ & $\mathrm{N}$ & $\mathrm{N}$ & $\mathrm{Nm}$ & $\mathrm{Nm}$ & $\mathrm{Nm}$ \\
\hline 105285 & 13.2 & 23 & 6.8 & 19 & 09 & 83 & 0.4 \\
\hline 105459 & 14.7 & 26 & 8.7 & 22 & 0.7 & 3.6 & -0.2 \\
\hline 701858 & 6.7 & -1.5 & 9.9 & -0.2 & -0.9 & 83 & -0.5 \\
\hline 7087036 & 5.7 & 12 & 23 & 0.4 & -0.7 & 8.2 & 0.0 \\
\hline $53103715-002-2$ & 8.7 & 1.7 & 30.8 & 24 & -0.7 & 8.1 & -1.6 \\
\hline ADs1017052 & 8.5 & 1.7 & 10.8 & -2.3 & .02 & 83 & 0.3 \\
\hline DRT0S7036 & 4.7 & .0 .2 & -1.5 & 0.8 & -12 & 30 & 0.0 \\
\hline GD-1 & 6.5 & 20 & 30 & -10 & 1.6 & 8.1 & -0.1 \\
\hline Mean & 8.6 & 12 & 9.5 & 0.5 & -0.1 & 7.6 & .02 \\
\hline Standard Deviation & 3.6 & 1.4 & 9.6 & 1.6 & 10 & 16 & 0.6 \\
\hline
\end{tabular}

\begin{tabular}{|c|c|c|c|c|c|c|c|}
\hline \multirow{3}{*}{ Spins } & \multicolumn{7}{|c|}{ Lamidectomy: Ertemion PM (Evd Limit $8 \mathrm{Nm}$ ) } \\
\hline & Patch & $\operatorname{Sinear}(A P)$ & Shear (Lat) & Axial & $\mathrm{Mx}$ & $\mathrm{My}$ & $\mathrm{M} x$ \\
\hline & Dearees & $\mathrm{N}$ & $\mathrm{N}$ & $\mathrm{N}$ & $\mathrm{Nm}$ & $\mathrm{Nm}$ & $\mathrm{Nm}$ \\
\hline 105285 & 6.7 & 0.8 & 140 & 0.7 & -0.1 & 30 & -0.1 \\
\hline 105459 & 5.7 & 1.8 & -1.3 & -19 & 18 & 8.3 & 0.0 \\
\hline 701858 & 5.5 & 1.6 & 4.6 & 0.2 & .0 .2 & 8.2 & 0.2 \\
\hline 7057036 & 60 & -1.8 & -3.4 & 0.6 & -1.5 & 8.2 & -0.1 \\
\hline $53103715-002-2$ & 30 & 1.6 & -9.1 & 0.0 & -1.3 & 8.1 & 00 \\
\hline ADs1017052 & 100 & -19 & -24 & 0.6 & -0.6 & 8.2 & 0.0 \\
\hline DRTOS7036 & 5.7 & -1.7 & 3.5 & .0 .2 & -0.4 & 8.5 & 0.0 \\
\hline GD-1 & 6.2 & 13 & 5.0 & -28 & 0.2 & 3.2 & 0.3 \\
\hline Masa & 6.7 & 0.2 & 1.4 & .03 & -0.3 & 3.2 & 0.0 \\
\hline Standard Deviation & 1.5 & 1.7 & 7.0 & 1.3 & 10 & 0.1 & 0.1 \\
\hline
\end{tabular}

\begin{tabular}{|c|c|c|c|c|c|c|c|c|}
\hline \multirow[b]{2}{*}{ Spine } & \multicolumn{8}{|c|}{ Lamivectomy: Left Lateral PM(Evd Limit $6 \mathrm{Nm}$ ) } \\
\hline & Path & Sheas(AP) & Shear (Lat) & Axial & Mx & $\mathrm{My}$ & $\mathrm{Mg}$ & Axial Rotatise \\
\hline & Dearsees & $\mathrm{N}$ & $\mathrm{N}$ & $\mathrm{N}$ & $\mathrm{Nm}$ & $\mathrm{Nm}$ & $\mathrm{Nm}$ & Dearees \\
\hline 105285 & 7.7 & 1.4 & -5.1 & -1.3 & -3.5 & 6.1 & -0.4 & 1.6 \\
\hline 105459 & 80 & 10 & -3.1 & 2.1 & 40 & 6.0 & -0.8 & 1.5 \\
\hline 701898 & 5.2 & -28 & -5.5 & -1.5 & -1.1 & 6.2 & -0.1 & 1.0 \\
\hline 7057036 & 5.7 & 19 & 6.1 & 0.2 & 0.7 & 6.4 & 0.1 & 1.1 \\
\hline $53103715-002-2$ & 5.5 & 22 & -109 & 0.7 & 0.7 & 6.5 & 0.1 & 12 \\
\hline ADS1017052 & 6.0 & -0.7 & 4.6 & 0.6 & 0.5 & 6.2 & -0.1 & 1.1 \\
\hline DRT0S7036 & 5.0 & 1.4 & 83 & 10 & -0.1 & 6.2 & -0.1 & 0.7 \\
\hline GD-1 & so & 0.2 & -19.4 & 0.7 & -1.6 & 6.1 & 0.2 & 10 \\
\hline Mean & 6.0 & 0.6 & -3.1 & 0.3 & -0.1 & 6.2 & -0.2 & 1.2 \\
\hline Sandard Devasisen & 1.2 & 1.7 & 9.3 & 1.2 & 22 & 0.2 & 0.3 & 0.3 \\
\hline
\end{tabular}

\begin{tabular}{|c|c|c|c|c|c|c|c|c|}
\hline \multirow{3}{*}{ Spise } & \multicolumn{8}{|c|}{ Laminectomy: Right Lateral PM (Evd Limit $6 \mathrm{Nm}$ ) } \\
\hline & Paxh & $\operatorname{Sanse}(A P)$ & Shear (Lat) & Axial & Ma & $\mathrm{My}$ & $\mathrm{Mz}$ & Axial Rotation \\
\hline & Dearees & $\mathrm{N}$ & $\mathrm{N}$ & $\mathrm{N}$ & $\mathrm{Nm}$ & $\mathrm{Nm}$ & $\mathrm{Nm}$ & Dearees \\
\hline 105285 & 5.0 & -20 & -0.6 & 0.9 & -3.3 & 6.4 & 0.1 & 1.7 \\
\hline 105459 & 9.7 & 1.7 & -6.0 & 0.6 & 30 & 6.1 & 0.4 & 1.2 \\
\hline 701898 & 72 & 0.6 & .0 .2 & 0.2 & 0.3 & 60 & 0.0 & 0.4 \\
\hline 7057036 & 4.2 & -1.8 & .0 .2 & 24 & -21 & 6.2 & -0.1 & 0.3 \\
\hline $53103715-002-2$ & 5.2 & -1.1 & 10.4 & 10 & -1.3 & 6.1 & 0.4 & 0.6 \\
\hline ADS1017052 & 6.0 & -1.7 & -24 & 0.0 & 0.6 & 62 & -0.3 & 1.6 \\
\hline DRT087036 & 4.2 & 10 & 5.6 & 1.2 & .03 & 6.4 & -0.1 & 0.5 \\
\hline GD-1 & 3.0 & -2.1 & 20 & 0.9 & -1.8 & 6.4 & 0.3 & 0.8 \\
\hline Mesa & 5.6 & -0.7 & 1.1 & 0.9 & -0.7 & 62 & 0.1 & 09 \\
\hline Sandard Deviasise & 2.1 & 15 & 5.0 & 0.7 & 20 & 0.1 & 0.3 & 0.5 \\
\hline
\end{tabular}


Table C-5. Harvested and UF Tabulated Data from CLM Protocol.

\begin{tabular}{|c|c|c|c|c|c|c|c|}
\hline \multirow{3}{*}{ Spine } & \multicolumn{7}{|c|}{ Harvested: Flexion CLM(End Limit $8 \mathrm{Nm}$ ) } \\
\hline & Pitch & Shear(AP) & Shear (Lat) & Axial & $\mathrm{Mx}$ & My & $\mathrm{Mz}$ \\
\hline & Degrees & $\mathrm{N}$ & $\mathrm{N}$ & $\mathrm{N}$ & $\mathrm{Nm}$ & $\mathrm{Nm}$ & $\mathrm{Nm}$ \\
\hline 105285 & 7.5 & 35.8 & 6.4 & -260.2 & -0.6 & 8.2 & -0.1 \\
\hline 105459 & 10.2 & 45.8 & 26.1 & -256.4 & -1.1 & 8.1 & -0.9 \\
\hline 701888 & 7.2 & 32.0 & 14.2 & -261.3 & -0.3 & 8.1 & -0.3 \\
\hline 7087036 & 6.2 & 31.0 & -18.0 & -260.8 & -1.6 & 8.8 & 0.1 \\
\hline $53103715-002-2$ & 5.7 & 24.7 & -21.2 & -258.3 & -1.8 & 8.1 & 0.3 \\
\hline ADS1017052 & 8.0 & 39.5 & 5.8 & -259.0 & 0.1 & 8.3 & 0.8 \\
\hline DRT087036 & 4.2 & 23.4 & -11.8 & -259.0 & -1.1 & 8.4 & 0.1 \\
\hline GD-1 & 4.7 & 22.6 & -2.2 & -260.2 & -1.7 & 8.4 & 0.1 \\
\hline Mean & 6.7 & 31.8 & -0.1 & -259.4 & -1.0 & 8.3 & 0.0 \\
\hline Standard Deviation & 1.9 & 8.3 & 16.4 & 1.6 & 0.7 & 0.2 & 0.5 \\
\hline
\end{tabular}

\begin{tabular}{|c|c|c|c|c|c|c|c|}
\hline \multirow{3}{*}{ Spine } & \multicolumn{7}{|c|}{ Harvested: Extension CLM(End Limit $8 \mathrm{Nm}$ ) } \\
\hline & Pitch & Shear(AP) & Shear (Lat) & Axial & $\mathrm{Mx}$ & $\mathrm{My}$ & $\mathrm{Mz}$ \\
\hline & Degrees & $\mathrm{N}$ & $\mathrm{N}$ & $\mathrm{N}$ & $\mathrm{Nm}$ & $\mathrm{Nm}$ & $\mathrm{Nm}$ \\
\hline 105285 & 5.0 & 23.1 & 1.9 & -262.1 & 0.1 & 8.3 & 0.7 \\
\hline 105459 & 5.5 & 27.5 & -13.1 & -264.7 & 0.1 & 8.1 & 0.1 \\
\hline 701888 & 3.8 & 20.7 & 3.1 & -261.9 & -0.4 & 8.3 & 0.0 \\
\hline 7087036 & 4.0 & 19.2 & -10.6 & -260.6 & -0.8 & 8.6 & -0.1 \\
\hline $53103715-002-2$ & 5.7 & 29.6 & -14.0 & -261.6 & -0.4 & 8.2 & -0.3 \\
\hline ADS1017052 & 5.7 & 27.5 & 8.7 & -261.5 & -0.9 & 8.1 & 0.1 \\
\hline DRT087036 & 2.7 & 14.4 & -10.1 & -263.0 & -0.5 & 8.0 & 0.0 \\
\hline GD-1 & 4.2 & 21.5 & 22.8 & -261.5 & 0.1 & 9.1 & 0.2 \\
\hline Mean & 4.6 & 22.9 & -1.4 & -262.1 & -0.3 & 8.3 & 0.1 \\
\hline Standard Deviation & 1.1 & 5.1 & 13.0 & 1.3 & 0.4 & 0.4 & 0.3 \\
\hline
\end{tabular}

\begin{tabular}{cccccccc}
\hline & \multicolumn{7}{c}{ UF: Flexion CLM(End Limit 8 Nm) } \\
\cline { 2 - 8 } Spine & Pitch & \multicolumn{1}{c}{ Shear(AP) } & Shear (Lat) & Axial & $\mathrm{Mx}$ & $\mathrm{My}$ & $\mathrm{Mz}$ \\
& Degrees & $\mathrm{N}$ & $\mathrm{N}$ & $\mathrm{N}$ & $\mathrm{Nm}$ & $\mathrm{Nm}$ & $\mathrm{Nm}$ \\
\hline 105285 & 7.4 & 35.7 & 9.5 & -259.9 & 0.0 & 8.1 & -0.2 \\
105459 & 10.2 & 48.5 & 27.9 & -258.4 & -1.2 & 8.4 & -0.4 \\
701888 & 6.2 & 27.2 & 16.4 & -259.7 & 0.3 & 8.3 & -0.4 \\
7087036 & 5.7 & 30.3 & -18.2 & -260.8 & -1.8 & 8.5 & 0.2 \\
$53103715-002-2$ & 5.4 & 26.4 & 2.7 & -260.2 & -0.6 & 8.0 & 0.0 \\
ADS1017052 & 8.7 & 40.1 & -21.0 & -259.4 & -0.4 & 8.2 & 0.7 \\
DRT087036 & 3.2 & 17.5 & -7.5 & -266.1 & -0.9 & 8.0 & 0.1 \\
GD-1 & 4.5 & 21.5 & 4.1 & -262.4 & -1.5 & 8.2 & 0.8 \\
Mean & 6.4 & 30.9 & 1.7 & -260.9 & -0.8 & 8.2 & 0.1 \\
Standard Deviation & 2.3 & 10.1 & 16.8 & 2.4 & 0.7 & 0.2 & 0.4 \\
\hline
\end{tabular}

\begin{tabular}{|c|c|c|c|c|c|c|c|}
\hline \multirow{3}{*}{ Spine } & \multicolumn{7}{|c|}{ UF: Extension CLM(End Limit $8 \mathrm{Nm}$ ) } \\
\hline & Pitch & Shear(AP) & Shear (Lat) & Axial & $\mathrm{Mx}$ & My & $\mathrm{Mz}$ \\
\hline & Degrees & $\mathrm{N}$ & $\mathrm{N}$ & $\mathrm{N}$ & $\mathrm{Nm}$ & $\mathrm{Nm}$ & $\mathrm{Nm}$ \\
\hline 105285 & 4.7 & 22.9 & 5.3 & -260.7 & -0.3 & 9.0 & 0.1 \\
\hline 105459 & 4.2 & 20.0 & 3.9 & -263.3 & 0.4 & 8.3 & -0.1 \\
\hline 701888 & 3.7 & 20.7 & 11.8 & -262.7 & -1.4 & 8.2 & 0.2 \\
\hline 7087036 & 3.7 & 19.8 & -10.0 & -264.2 & -1.1 & 8.3 & -0.1 \\
\hline $53103715-002-2$ & 4.7 & 22.7 & -11.8 & -265.3 & -0.5 & 8.0 & -0.2 \\
\hline ADS1017052 & 6.5 & 31.2 & 3.2 & -262.6 & -1.3 & 8.1 & 0.0 \\
\hline DRT087036 & 3.0 & 14.1 & 2.1 & -265.9 & -1.1 & 8.8 & 0.0 \\
\hline GD-1 & 4.5 & 21.5 & 4.1 & -262.4 & -1.5 & 8.2 & 0.8 \\
\hline Mean & 4.4 & 21.6 & 1.1 & -263.4 & -0.8 & 8.4 & 0.1 \\
\hline Standard Deviation & 1.0 & 4.7 & 8.0 & 1.7 & 0.7 & 0.3 & 0.3 \\
\hline
\end{tabular}


Table C-6. BF and Laminectomy Tabulated Data from CLM Protocol.

\begin{tabular}{cccccccc}
\hline \multirow{2}{*}{ Spine } & \multicolumn{7}{c}{ BF: Flexion CLM(End Limit 8 Nm) } \\
\cline { 2 - 8 } & Pitch & \multicolumn{2}{c}{ Shear(AP) Shear (Lat) } & Axial & $\mathrm{Mx}$ & $\mathrm{My}$ & $\mathrm{Mz}$ \\
& Degrees & $\mathrm{N}$ & $\mathrm{N}$ & $\mathrm{N}$ & $\mathrm{Nm}$ & $\mathrm{Nm}$ & $\mathrm{Nm}$ \\
\hline 105285 & 9.4 & 46.2 & 24.2 & -261.0 & 0.1 & 8.5 & -0.5 \\
105459 & 11.9 & 56.3 & 40.4 & -255.5 & 0.1 & 8.2 & -1.4 \\
701888 & 6.7 & 31.4 & 18.9 & -259.8 & 0.5 & 8.3 & -0.1 \\
7087036 & 7.2 & 36.2 & 10.8 & -260.8 & -0.3 & 8.6 & 1.6 \\
$53103715-002-2$ & 7.0 & 34.4 & -9.7 & -261.4 & -1.6 & 8.1 & 0.6 \\
ADS1017052 & 8.7 & 43.1 & -8.4 & -260.9 & -0.1 & 8.3 & 0.0 \\
DRT087036 & 4.7 & 19.9 & 10.8 & -260.8 & -0.1 & 8.1 & -0.1 \\
GD-1 & 5.2 & 26.6 & 3.6 & -259.4 & -1.9 & 8.5 & -0.1 \\
Mean & 7.6 & 36.8 & 11.3 & -259.9 & -0.4 & 8.3 & 0.0 \\
Standard Deviation & 2.4 & 11.5 & 16.7 & 1.9 & 0.9 & 0.2 & 0.8 \\
\hline
\end{tabular}

\begin{tabular}{cccccccc}
\hline \multirow{2}{*}{ Spine } & \multicolumn{7}{c}{ BF: Extension CLM(End Limit 8 Nm) } \\
\cline { 2 - 8 } & Pitch & \multicolumn{2}{c}{ Shear(AP) Shear (Lat) } & Axial & $\mathrm{Mx}$ & $\mathrm{My}$ & $\mathrm{Mz}$ \\
& Degrees & $\mathrm{N}$ & $\mathrm{N}$ & $\mathrm{N}$ & $\mathrm{Nm}$ & $\mathrm{Nm}$ & $\mathrm{Nm}$ \\
\hline 105285 & 5.5 & 27.4 & 38.5 & -262.8 & 0.7 & 8.4 & 0.0 \\
105459 & 6.3 & 29.4 & -23.5 & -264.4 & 2.9 & 8.4 & -0.6 \\
701888 & 5.0 & 24.9 & 15.9 & -265.2 & -0.7 & 8.7 & 0.2 \\
7087036 & 4.5 & 21.7 & -4.2 & -263.0 & -1.6 & 8.4 & 0.0 \\
$53103715-002-2$ & 6.2 & 30.4 & -4.2 & -262.1 & -0.4 & 8.6 & 0.7 \\
ADS1017052 & 6.5 & 31.7 & 30.3 & -263.0 & 0.3 & 8.3 & 0.1 \\
DRT087036 & 4.0 & 22.4 & -5.3 & -261.9 & -0.9 & 8.4 & -0.1 \\
GD-1 & 4.5 & 22.2 & 2.7 & -260.6 & 4.3 & 8.1 & 0.0 \\
Mean & 5.3 & 26.3 & 6.3 & -262.9 & 0.6 & 8.4 & 0.1 \\
Standard Deviation & 0.9 & 4.0 & 20.6 & 1.4 & 2.1 & 0.2 & 0.4 \\
\hline
\end{tabular}

\begin{tabular}{|c|c|c|c|c|c|c|c|}
\hline \multirow{3}{*}{ Spine } & \multicolumn{7}{|c|}{ Lami: Flexion CLM(End Limit $8 \mathrm{Nm}$ ) } \\
\hline & Pitch & Shear(AP) & Shear (Lat) & Axial & $\mathrm{Mx}$ & My & $\mathrm{Mz}$ \\
\hline & Degrees & $\mathrm{N}$ & $\mathrm{N}$ & $\mathrm{N}$ & $\mathrm{Nm}$ & $\mathrm{Nm}$ & $\mathrm{Nm}$ \\
\hline 105285 & 13.0 & 61.4 & 8.1 & -254.4 & 0.8 & 8.0 & 0.4 \\
\hline 105459 & 14.5 & 65.6 & 4.5 & -253.1 & 0.6 & 8.0 & -0.3 \\
\hline 701888 & 6.7 & 31.6 & 11.4 & -256.5 & -0.1 & 8.1 & -0.6 \\
\hline 7087036 & 5.7 & 29.5 & -0.1 & -262.2 & -0.4 & 8.5 & 0.0 \\
\hline $53103715-002-2$ & 8.2 & 38.6 & 16.1 & -258.3 & -1.3 & 8.0 & -1.0 \\
\hline ADS1017052 & 8.0 & 38.5 & 4.5 & -260.1 & 0.7 & 8.2 & 0.4 \\
\hline DRT087036 & 5.0 & 24.7 & -0.6 & -258.7 & -0.5 & 8.1 & -0.1 \\
\hline GD-1 & 8.7 & 42.4 & 19.1 & -257.9 & 0.8 & 8.1 & -0.5 \\
\hline Mean & 8.7 & 41.6 & 7.9 & -257.7 & 0.1 & 8.1 & -0.2 \\
\hline Standard Deviation & 3.4 & 14.7 & 7.2 & 2.9 & 0.8 & 0.2 & 0.5 \\
\hline
\end{tabular}

\begin{tabular}{|c|c|c|c|c|c|c|c|}
\hline \multirow{3}{*}{ Spine } & \multicolumn{7}{|c|}{ Laminectomy: Extension CLM(End Limit $8 \mathrm{Nm}$ ) } \\
\hline & \multirow{2}{*}{$\begin{array}{c}\text { Pitch } \\
\text { Degrees }\end{array}$} & \multicolumn{2}{|c|}{ Shear(AP) Shear (Lat) } & \multirow{2}{*}{$\begin{array}{c}\text { Axial } \\
\mathrm{N}\end{array}$} & \multirow{2}{*}{$\begin{array}{l}\mathrm{Mx} \\
\mathrm{Nm}\end{array}$} & \multirow{2}{*}{$\begin{array}{l}\mathrm{My} \\
\mathrm{Nm}\end{array}$} & \multirow{2}{*}{$\begin{array}{l}\mathrm{Mz} \\
\mathrm{Nm}\end{array}$} \\
\hline & & $\mathrm{N}$ & $\mathrm{N}$ & & & & \\
\hline 105285 & 6.0 & 28.6 & 10.4 & -263.9 & 1.2 & 8.1 & -0.1 \\
\hline 105459 & 5.0 & 26.1 & 0.4 & -262.0 & 4.1 & 8.7 & 0.3 \\
\hline 701888 & 4.7 & 23.9 & 3.1 & -263.9 & -0.5 & 8.4 & 0.2 \\
\hline 7087036 & 5.5 & 23.8 & 1.6 & -260.7 & -1.1 & 8.6 & -0.3 \\
\hline $53103715-002-2$ & 6.5 & 32.4 & -13.5 & -261.4 & -0.4 & 8.3 & 0.2 \\
\hline ADS1017052 & 9.0 & 40.4 & -6.2 & -260.9 & -0.7 & 8.1 & -0.1 \\
\hline DRT087036 & 4.5 & 23.4 & -2.7 & -261.4 & -1.3 & 8.2 & 0.0 \\
\hline GD-1 & 5.5 & 28.4 & 7.2 & -262.8 & 2.2 & 9.0 & 0.5 \\
\hline Mean & 5.8 & 28.4 & 0.0 & -262.1 & 0.4 & 8.4 & 0.1 \\
\hline Standard Deviation & 1.4 & 5.7 & 7.5 & 1.3 & 1.9 & 0.3 & 0.3 \\
\hline
\end{tabular}




\section{APPENDIX D: TABULATED SIMULATION DATA FROM PM AND CLM PROTOCOLS}

Table D-1. Simulation Tabulated Data from PM and CLM Protocols.

\begin{tabular}{|c|c|c|c|c|c|c|c|c|}
\hline \multirow[b]{2}{*}{ Spine } & \multicolumn{8}{|c|}{ Translation along Disc Plane (mm) } \\
\hline & Harvested PM & Harvested CLM & UF PM & UF CLM & BF PM & BF CLM & Lami PM & Lami CLM \\
\hline 105285 & 0.414 & 0.481 & 0.571 & 0.237 & 0.360 & 0.416 & 0.368 & 0.610 \\
\hline 105459 & 1.471 & 1.982 & 1.304 & 1.664 & 1.075 & 1.645 & 1.595 & 3.768 \\
\hline 701888 & 1.694 & 2.437 & 1.148 & 1.597 & 0.687 & 1.744 & 0.999 & 1.973 \\
\hline 7087036 & 0.691 & 0.890 & 0.324 & 0.707 & 0.626 & 0.531 & 0.214 & 0.875 \\
\hline $53103715-002-2$ & 0.642 & 1.507 & 0.554 & 1.001 & 0.414 & 1.253 & 1.637 & 2.376 \\
\hline ADS1017052 & 0.529 & 1.654 & 1.331 & 1.772 & 0.753 & 1.335 & 0.688 & 1.599 \\
\hline DRT087036 & 0.660 & 0.562 & 0.238 & 0.129 & 0.471 & 0.413 & 0.534 & 1.046 \\
\hline GD-1 & 1.137 & 0.236 & 0.359 & 0.151 & 1.075 & 0.558 & 0.251 & 1.238 \\
\hline Mean & 0.905 & 1.219 & 0.729 & 0.907 & 0.683 & 0.987 & 0.786 & 1.686 \\
\hline Standard Deviation & 0.471 & 0.792 & 0.458 & 0.704 & 0.277 & 0.566 & 0.571 & 1.023 \\
\hline Mean Minus 0701888 & 0.745 & 0.974 & 0.669 & 0.809 & 0.682 & 0.879 & 0.755 & 1.645 \\
\hline Standard Deviation & 0.375 & 0.670 & 0.459 & 0.699 & 0.299 & 0.515 & 0.610 & 1.098 \\
\hline
\end{tabular}


Table D-2. Translation Data of PM and CLM, Excluding Specimen 0701888.

\begin{tabular}{|c|c|c|c|c|}
\hline \multirow[b]{2}{*}{ Spine Condition } & \multicolumn{4}{|c|}{ Translations for Individual MSU Levels (mm) } \\
\hline & Value & Level & PM & CLM \\
\hline \multirow[t]{7}{*}{ Harvested } & Mean & L1-2 & 0.388 & 0.918 \\
\hline & & L2-3 & 0.414 & 0.481 \\
\hline & & L4-5 & 0.586 & 1.581 \\
\hline & Standard & & & \\
\hline & Deviation & L1-2 & 0.629 & 0.403 \\
\hline & & L2-3 & - & - \\
\hline & & L4-5 & 0.080 & 0.104 \\
\hline \multirow{7}{*}{$\begin{array}{l}\text { Unilateral } \\
\text { Facetectomy }\end{array}$} & Mean & L1-2 & 0.501 & 0.663 \\
\hline & & L2-3 & 0.571 & 0.237 \\
\hline & & L4-5 & 0.943 & 1.387 \\
\hline & Standard & & & \\
\hline & Deviation & L1-2 & 0.480 & 0.375 \\
\hline & & $\mathrm{L} 2-3$ & - & - \\
\hline & & L4-5 & 0.549 & 0.545 \\
\hline \multirow[t]{7}{*}{ Bilateral Facetectomy } & Mean & $\mathrm{L} 1-2$ & 0.310 & 0.787 \\
\hline & & L2-3 & 0.360 & 0.416 \\
\hline & & L4-5 & 0.584 & 1.294 \\
\hline & Standard & & & \\
\hline & Deviation & L1-2 & 0.461 & 0.371 \\
\hline & & $\mathrm{L} 2-3$ & - & - \\
\hline & & L4-5 & 0.240 & 0.058 \\
\hline \multirow[t]{7}{*}{ Laminectomy } & Mean & $\mathrm{L} 1-2$ & 0.647 & 1.732 \\
\hline & & L2-3 & 0.368 & 0.610 \\
\hline & & L4-5 & 1.163 & 1.988 \\
\hline & Standard & & & \\
\hline & Deviation & L1-2 & 0.874 & 0.638 \\
\hline & & L2-3 & - & - \\
\hline & & L4-5 & 0.671 & 0.549 \\
\hline
\end{tabular}


APPENDIX E: TABULATED DATA FROM CEL PROTOCOL 
Table E-1. Harvested Tabulated CEL Data.

\begin{tabular}{|c|c|c|c|c|c|c|c|c|c|}
\hline \multirow{3}{*}{ Spine } & \multicolumn{9}{|c|}{ Harvested: Flevion (+Left Avial) } \\
\hline & $\mathrm{Fx}$ & Fy & $\mathrm{F} z$ & Mx & $\mathrm{My}$ & $\mathrm{Mx}$ & Resulast & Paxh & Roll \\
\hline & $\mathrm{N}$ & $\mathrm{N}$ & $\mathrm{N}$ & $\mathrm{Nm}$ & $\mathrm{Nm}$ & $\mathrm{Nm}$ & $\mathrm{Nm}$ & Dexrees & Dezrees \\
\hline 105285 & -28 & -0.8 & -43.3 & 0.0 & -6.6 & 5.1 & 83 & 4.7 & 29 \\
\hline 105459 & -4.2 & -21.7 & -77.6 & -1.1 & -6.7 & 4.2 & 79 & 5.6 & 4.1 \\
\hline 701858 & -5.2 & -80 & -383 & -0.6 & -59 & 5.7 & 83 & 3.8 & 22 \\
\hline 7087036 & -3.6 & -13.0 & -38.7 & .0 .8 & -6.2 & 5.6 & 83 & 3.3 & 0.8 \\
\hline $53103715-002-2$ & -3.7 & -28 & -35.8 & 0.2 & .60 & 5.4 & 8.1 & 27 & 1.5 \\
\hline ADS1017052 & -5.3 & -1.7 & -37.5 & 0.5 & -5.7 & s.5 & 79 & 5.2 & 1.7 \\
\hline DRT087036 & -29 & -18.8 & -31.4 & -1.1 & -5.2 & 6.1 & 3.1 & 1.5 & 0.8 \\
\hline$G D-1$ & 1.2 & -121 & -41.4 & 0.2 & -5.6 & 5.5 & 7.8 & 2.1 & 2.1 \\
\hline Mase & -3.3 & -99 & -43.0 & .0 .3 & -6.0 & 5.4 & 8.1 & 3.6 & 20 \\
\hline Sandard Deviation & 20 & 79 & 14.4 & 0.6 & 0.5 & 0.6 & 0.2 & 1.5 & 1.1 \\
\hline
\end{tabular}

\begin{tabular}{|c|c|c|c|c|c|c|c|c|c|}
\hline \multirow{3}{*}{ Spine } & \multicolumn{9}{|c|}{ Harrested: Flerion (+Right Arial) } \\
\hline & $\mathrm{Fx}$ & Fy & $\overline{F z}$ & Ma & $\mathrm{My}$ & $\mathrm{Mr}$ & Remoltant & Pasch & Roill \\
\hline & $\mathrm{N}$ & $\mathrm{N}$ & $\mathrm{N}$ & $\mathrm{Nm}$ & $\mathrm{Nm}$ & $\mathrm{Nm}$ & $\mathrm{Nm}$ & Deneses & Dearees \\
\hline 105285 & -2.8 & 10.1 & .40 .5 & 1.6 & -5.3 & -5.8 & 80 & 4.6 & 3.2 \\
\hline 105459 & -3.0 & 19.1 & -76.0 & 3.1 & -6.3 & -4.2 & 3.2 & 6.1 & 4.7 \\
\hline 701858 & -6.3 & 70 & -425 & 0.3 & -6.3 & -5.5 & 8.4 & 39 & 2.1 \\
\hline 7087036 & -3.3 & 7.7 & -349 & 0.0 & -5.2 & -5.7 & 7.7 & 3.5 & 1.4 \\
\hline $53103715-002-2$ & -4.2 & 1.8 & -36.1 & -0.5 & -59 & -5.8 & 8.2 & 28 & 2.1 \\
\hline ADS1017052 & -5.5 & -6.8 & -38.8 & -1.3 & -5.7 & -5.5 & 8.0 & 5.3 & 1.7 \\
\hline DRT0S7036 & -24 & 20.6 & -34.6 & 09 & -5.4 & -6.1 & 3.1 & 1.8 & 1.4 \\
\hline GD-1 & -0.4 & 14.7 & -36.0 & 1.3 & -50 & -6.2 & 8.1 & 2.1 & 19 \\
\hline Mesn & -3.5 & 9.3 & -424 & 0.7 & -5.6 & -5.6 & 8.1 & 3.8 & 23 \\
\hline Shandard Deviation & 1.8 & 9.1 & 13.8 & 1.4 & 0.5 & 0.6 & 0.2 & 1.5 & 1.1 \\
\hline
\end{tabular}

\begin{tabular}{|c|c|c|c|c|c|c|c|c|c|}
\hline \multirow{3}{*}{ Spine } & \multicolumn{9}{|c|}{ Harrested: Extemion (+Left Arial) } \\
\hline & $\mathrm{Fx}$ & Fy & $\mathrm{Fz}$ & Mx & $\mathrm{My}$ & $\mathrm{Mx}$ & Resulast & Paxch & Roll \\
\hline & $\mathrm{N}$ & $\mathrm{N}$ & $\mathrm{N}$ & $\mathrm{Nm}$ & $\mathrm{Nm}$ & $\mathrm{Nm}$ & $\mathrm{Nm}$ & Dearees & Dearees \\
\hline 105285 & -4.1 & 7.6 & -51.1 & 0.3 & -5.3 & -6.0 & 80 & 3.5 & 25 \\
\hline 105459 & -1.2 & 11.2 & -529 & 15 & -6.7 & -4.4 & 3.1 & 3.8 & 1.2 \\
\hline 701858 & -5.1 & 17.3 & -46.0 & -0.1 & -5.4 & -59 & 80 & 28 & 19 \\
\hline 7087036 & -4.0 & 3.4 & -440 & 0.5 & -5.5 & -6.1 & 8.3 & 22 & 1.1 \\
\hline $53103715-002-2$ & -4.8 & 109 & .46 .3 & 0.6 & -5.5 & -5.8 & 80 & 4.0 & 1.4 \\
\hline ADS1017052 & -4.3 & 24.2 & -39.7 & 22. & -5.0 & -6.2 & 8.2 & 4.7 & 1.7 \\
\hline DRTOS7036 & -3.8 & 15.7 & -47.4 & 0.6 & -5.5 & -60 & 8.1 & 1.7 & 1.3 \\
\hline GD-1 & -23 & 14.8 & -53.6 & 1.4 & -5.5 & -5.6 & 80 & 23 & 19 \\
\hline Mesa & -3.7 & 13.8 & -47.6 & 09 & .5 .5 & -5.7 & 8.1 & 3.1 & 1.6 \\
\hline Shandard Deviation & 1.3 & 53 & 4.7 & 0.7 & 0.5 & 0.6 & 0.1 & 10 & 0.5 \\
\hline
\end{tabular}

\begin{tabular}{|c|c|c|c|c|c|c|c|c|c|}
\hline \multirow[b]{2}{*}{ Spine } & \multicolumn{9}{|c|}{ Harrested. Frtemion (+Right Avial) } \\
\hline & $\mathrm{Fx}$ & $\overline{F y}$ & $\mathrm{Fz}$ & Mx & $\mathrm{My}$ & $\mathrm{M} x$ & Resultast & Paxh & Roll \\
\hline & $\mathrm{N}$ & $\mathrm{N}$ & $\mathrm{N}$ & $\mathrm{Nm}$ & $\mathrm{Nm}$ & $\mathrm{Nm}$ & $\mathrm{Nm}$ & Dearees: & Dearees \\
\hline 105285 & -19 & -1.0 & -540 & 0.0 & -6.3 & 5.2 & 3.1 & 3.6 & 23 \\
\hline 105459 & -1.5 & -226 & -43.4 & 0.6 & -5.5 & 5.8 & 3.1 & 4.1 & 6.5 \\
\hline 701888 & -3.8 & -15.1 & -46.2 & 0.2 & -59 & 5.2 & 79 & 24 & 1.4 \\
\hline 7057036 & -3.6 & -20.8 & -425 & -10 & -5.8 & 5.8 & 8.3 & 1.8 & 09 \\
\hline $53103715-002-2$ & -3.6 & -26.8 & -40.7 & -25 & -5.3 & 5.2 & 79 & 3.7 & 15 \\
\hline ADs1017052 & -4.4 & -19.0 & -39.9 & -1.6 & -5.5 & 5.7 & 8.0 & 4.0 & 0.9 \\
\hline DRT0S7036 & -4.2 & -17.8 & -44.1 & -0.1 & -5.5 & 6.2 & 8.3 & 1.5 & 1.2 \\
\hline GD-1 & -22 & -7.7 & -983 & -0.2 & -5.3 & 6.0 & 8.0 & 25 & 24 \\
\hline Masa & -3.2 & -16.3 & -46.1 & -0.6 & -5.6 & 5.7 & 8.1 & 29 & 2.1 \\
\hline Sandard Deviation & 1.1 & 8.4 & 6.6 & 10 & 0.3 & 0.4 & 0.1 & 10 & 19 \\
\hline
\end{tabular}

\begin{tabular}{|c|c|c|c|c|c|c|c|c|c|}
\hline \multirow{3}{*}{ Spine } & \multicolumn{9}{|c|}{ Harvested: Left Lateral (+Left Arial) } \\
\hline & $\mathrm{Fx}$ & $\mathrm{Fy}$ & $\mathrm{Fz}$ & Max & My & $\mathrm{Mx}$ & Remaltast & Patch & Roll \\
\hline & $\mathrm{N}$ & $\mathrm{N}$ & $\mathrm{N}$ & $\mathrm{Nm}$ & $\mathrm{Nm}$ & $\mathrm{Nm}$ & $\mathrm{Nm}$ & Degrees & Degrees \\
\hline 105285 & -0.4 & -3.0 & -329 & -0.9 & -5.1 & 3.0 & 6.0 & 2.1 & 1.4 \\
\hline 105459 & -1.0 & -9.3 & -34.1 & -0.4 & -4.5 & 4.4 & 63 & 3.0 & 3.5 \\
\hline 701858 & -4.3 & -10.4 & -31.3 & -0.7 & -4.4 & 4.4 & 6.3 & 4.7 & 1.2 \\
\hline 7087036 & -3.0 & -4.8 & -29.6 & 0.0 & -4.2 & 4.7 & 63 & 23 & 0.7 \\
\hline $53103715-002-2$ & -3.0 & -100 & -250 & 0.0 & -3.6 & 5.3 & 6.4 & 3.3 & 23 \\
\hline ADS1017052 & -1.5 & -11.3 & -59 & -0.4 & -0.9 & 6.1 & 6.1 & 1.8 & 19 \\
\hline DRTOSר 036 & -1.8 & -8.2 & -29.7 & -0.3 & -4.5 & 4.7 & 6.5 & 20 & 0.6 \\
\hline GD-1 & .0 .9 & -11.1 & -349 & -0.5 & -3.6 & 4.5 & 5.8 & 1.6 & 1.1 \\
\hline Mesen & -20 & -9.1 & -279 & -0.4 & -3.8 & 4.6 & 6.2 & 26 & 1.6 \\
\hline Standard Deviation & 1.3 & 21 & 9.4 & 0.3 & 1.3 & 09 & 0.2 & 10 & 0.9 \\
\hline
\end{tabular}

\begin{tabular}{|c|c|c|c|c|c|c|c|c|c|}
\hline \multirow{3}{*}{ Spine } & \multicolumn{9}{|c|}{ Harrested: Right Lateral (+Right Arial) } \\
\hline & $\mathrm{Fx}$ & Fy & $\mathrm{Fz}$ & Mx & My & $\mathrm{Mz}$ & Resulast & Paxh & Roll \\
\hline & $\mathrm{N}$ & $\mathrm{N}$ & $\mathrm{N}$ & $\mathrm{Nm}$ & $\mathrm{Nm}$ & $\mathrm{Nm}$ & $\mathrm{Nm}$ & Degrees: & Degrees \\
\hline 105285 & -1.7 & 1.4 & -33.0 & 0.5 & -40 & 4.5 & 6.0 & 3.5 & 3.3 \\
\hline 105459 & -49 & 1.7 & -359 & 0.8 & -4.5 & 3.8 & 59 & 7.8 & 28 \\
\hline 701888 & -5.2 & -1.4 & -29.3 & 0.2 & -3.9 & 4.5 & 6.0 & 5.2 & 19 \\
\hline 70057036 & -27 & -1.4 & -27.4 & 0.3 & -39 & 4.5 & 59 & 3.0 & 1.1 \\
\hline $53103715-002-2$ & -3.0 & -21 & -28.3 & 0.3 & -40 & 4.1 & 5.7 & 25 & 0.6 \\
\hline ADs1017052 & -1.8 & -11.1 & -24.9 & -0.2 & -3.6 & 49 & 6.1 & 29 & 0.1 \\
\hline DRT0S7036 & -3.7 & -11.3 & -26.4 & -10 & -3.8 & 4.6 & 6.1 & 20 & 10 \\
\hline GD-1 & 0.1 & -6.2 & -321 & -0.4 & -3.3 & 5.2 & 6.1 & 20 & 20 \\
\hline Masa & -29 & -3.8 & -29.7 & 0.1 & -39 & 4.5 & 6.0 & 3.6 & 1.6 \\
\hline Standard Deviatise & 1.8 & 5.1 & 3.7 & 0.6 & 0.3 & 0.4 & 0.1 & 20 & 1.1 \\
\hline
\end{tabular}


Table E-2. Tabulated UF Data from CEL Protocol.

\begin{tabular}{|c|c|c|c|c|c|c|c|c|c|}
\hline \multirow{3}{*}{ Spine } & \multicolumn{9}{|c|}{ Unilateral Facetectonr: Flevion (+Left.Arial) } \\
\hline & $\mathrm{Fx}$ & $\overline{F y}$ & $\bar{F} z$ & Mx & $\mathrm{My}$ & $\mathrm{N} x$ & Resolast & Pasth & Roll \\
\hline & $\mathrm{N}$ & $\mathrm{N}$ & $\mathrm{N}$ & $\mathrm{Nm}$ & $\mathrm{Nm}$ & $\mathrm{Nm}$ & $\mathrm{Nm}$ & Dearees & Dearees \\
\hline 105285 & -69 & -14.0 & -37.2 & 0.2 & -59 & 5.5 & 8.1 & 5.0 & 28 \\
\hline 105459 & -10.1 & -9.4 &.-43.5 & 0.0 & -69 & 43 & 82 & 7.4 & 3.7 \\
\hline 701988 & -4.4 & -10.4 & -37.4 & -0.6 & -59 & 5.6 & 8.2 & 3.4 & 21 \\
\hline 7087036 & -3.8 & -13.3 & .409 & -0.8 & -63 & 5.4 & 83 & 3.2 & 0.9 \\
\hline$\$ 3103715-002-2$ & -3.8 & -13.3 & -34.1 & 0.2 & -5.8 & 5.5 & 8.0 & 3.6 & 1.7 \\
\hline ADs1017052 & -3.6 & -19.1 & -36.6 & 0.2 & -5.6 & 5.5 & 79 & 4.3 & 1.1 \\
\hline DRTOS7036 & -3.5 & -7.3 & -359 & -0.1 & -59 & 5.3 & 79 & 1.4 & 0.8 \\
\hline GD-1 & -21 & -13.3 & -34.5 & -0.4 & -5.6 & 5.2 & 7.6 & 23 & 13 \\
\hline Masa & -4.8 & -125 & -37.5 & -0.2 & -60 & 5.3 & 80 & 3.8 & 1.8 \\
\hline Sandard Deviatisen & 25 & 3.6 & 3.2 & 0.4 & 0.4 & 0.4 & 0.2 & 1.8 & 10 \\
\hline
\end{tabular}

\begin{tabular}{|c|c|c|c|c|c|c|c|c|c|}
\hline \multirow{3}{*}{ Spine } & \multicolumn{9}{|c|}{ Uniateral Facetectonv: Flevion (+Right Axial) } \\
\hline & $\mathrm{Fx}$ & Fy & $\mathrm{Fz}$ & Mx & My & $\mathrm{M} x$ & Reswahast & Paxh & Roll \\
\hline & $\mathrm{N}$ & $\mathrm{N}$ & $\mathrm{N}$ & $\mathrm{Nm}$ & $\mathrm{Nm}$ & $\mathrm{Nm}$ & $\mathrm{Nm}$ & Dexrees & Dearees \\
\hline 105285 & -3.6 & 179 & -31.7 & 0.3 & -5.7 & -5.7 & 80 & 49 & 28 \\
\hline 105459 & -6.6 & 0.3 & -40.2 & .0 .5 & -6.7 & .43 & 30 & 7.2 & 2.1 \\
\hline 701858 & -3.5 & 79 & -38.0 & 0.0 & -6.1 & -5.5 & 8.3 & 3.2 & 19 \\
\hline 7057036 & -3.6 & 5.1 & -36.3 & -0.2 & -5.7 & -5.6 & 80 & 3.4 & 1.3 \\
\hline $53103715-002-2$ & -3.2 & 127 & -29.6 & -1.2 & -5.5 & -5.5 & 79 & 3.6 & 1.7 \\
\hline ADS1017052 & -5.1 & -2.5 & .40 .0 & -25 & -5.7 & -5.3 & 8.2 & 4.2 & 1.4 \\
\hline DRTOSר 036 & .0 .8 & 23.4 & -310 & 1.5 & -5.7 & -59 & 83 & 1.5 & 1.4 \\
\hline$G D-1$ & -3.7 & 8.5 & -34.6 & 0.5 & -5.6 & -5.4 & 7.8 & 23 & 1.4 \\
\hline Mesa & -3.8 & 8.7 & -35.2 & -0.3 & -5.8 & -5.4 & 8.1 & 3.8 & 1.8 \\
\hline Standard Deviatisa & 1.7 & 9.3 & 4.2 & 1.2 & 0.4 & 0.5 & 0.2 & 1.8 & 0.5 \\
\hline
\end{tabular}

\begin{tabular}{|c|c|c|c|c|c|c|c|c|c|}
\hline \multirow{3}{*}{ Spins } & \multicolumn{9}{|c|}{ Unlateral Facetectony: Extewion (+Left Arial) } \\
\hline & $\mathrm{Fx}$ & Fy & $\overline{F z}$ & Max & Ny & $\mathrm{Mx}$ & Resolitast & Paxh & Roll \\
\hline & $\mathrm{N}$ & $\mathrm{N}$ & $\mathrm{N}$ & $\mathrm{Nm}$ & $\mathrm{Nm}$ & $\mathrm{Nm}$ & $\mathrm{Nm}$ & Degrees & Degrees \\
\hline 105285 & -6.7 & 9.4 & -43.3 & -2.2 & -5.7 & -5.5 & 8.2 & 4.0 & 1.8 \\
\hline 105459 & -4.8 & 220 & -54.1 & 1.5 & -6.8 & -4.2 & 3.1 & 3.6 & 22 \\
\hline 701858 & -3.5 & 3.4 & -429 & 0.2 & -5.7 & -5.8 & 8.1 & 23 & 1.4 \\
\hline 7057036 & -3.8 & .0 .7 & -421 & -0.4 & -5.5 & -5.5 & 7.8 & 1.6 & 10 \\
\hline $53103715-002-2$ & -3.8 & 120 & -45.2 & 0.5 & -5.7 & -5.7 & 8.1 & 3.3 & 1.4 \\
\hline ADS1017052 & -3.3 & 20.2 & -34.3 & 20 & -49 & -6.0 & 80 & 4.4 & 1.3 \\
\hline DRTOS7036 & -20 & 17.8 & .440 & -0.2 & -5.8 & -5.7 & 8.1 & 19 & 0.9 \\
\hline GD-1 & -3.3 & 23.7 & -400 & 20 & -5.4 & -4.9 & 7.6 & 21 & 0.9 \\
\hline Mase & -4.0 & 14.1 & .43 .2 & 0.4 & -5.7 & -5.4 & 80 & 29 & 1.4 \\
\hline Sandard Deviatise & 1.3 & 8.3 & 3.5 & 1.4 & os & 0.6 & 0.2 & 10 & 0.5 \\
\hline
\end{tabular}

\begin{tabular}{|c|c|c|c|c|c|c|c|c|c|}
\hline \multirow[b]{2}{*}{ Spins } & \multicolumn{9}{|c|}{ Unilateral Facetectony: Exteucion ( + Right Avial) } \\
\hline & $\begin{array}{l}\mathrm{Fx} \\
\mathrm{N}\end{array}$ & $\begin{array}{l}\mathrm{Fy} \\
\mathrm{N}\end{array}$ & $\begin{array}{l}\mathrm{F}_{2} \\
\mathrm{~N}\end{array}$ & $\begin{array}{l}\mathrm{Mx} \\
\mathrm{Nm}\end{array}$ & $\begin{array}{l}\mathrm{My} \\
\mathrm{Nm}\end{array}$ & $\begin{array}{l}\mathrm{M} / \mathrm{x} \\
\mathrm{Nm}\end{array}$ & $\begin{array}{c}\text { Resulast } \\
\mathrm{Nm}\end{array}$ & $\begin{array}{c}\text { Path } \\
\text { Deareses }\end{array}$ & $\begin{array}{c}\text { Roll } \\
\text { Dexers }\end{array}$ \\
\hline 105285 & -60 & -18.1 & -48.1 & -1.1 & -6.1 & 5.1 & 3.0 & 3.7 & 1.6 \\
\hline 105459 & -7.0 & 24 & -47.6 & 0.8 & -5.5 & 5.6 & 79 & 4.1 & 4.5 \\
\hline 701858 & -39 & -5.3 & -45.3 & 0.1 & -6.0 & 5.7. & 8.3 & 25 & 1.4 \\
\hline 7057036 & -20 & -22.6 & -42.1 & -1.6 & -5.6 & 4.8 & 7.6 & 1.8 & 0.9 \\
\hline $53103715-002-2$ & -4.3 & -27.2 & -49.1 & -23 & -5.8 & 5.1 & 8.1 & 3.2 & 1.2 \\
\hline ADs1017052 & -5.8 & -253 & .45 .3 & -1.3 & -5.5 & 5.8 & 8.1 & 4.0 & 0.7 \\
\hline DRTOS7036 & -4.1 & -20.6 & -48.8 & 0.3 & -5.7 & 5.7 & 8.1 & 2.1 & 0.9 \\
\hline GD-1 & .49 & 3.2 & -45.1 & 1.6 & -5.5 & 5.3 & 79 & 22 & 1.3 \\
\hline Masa & -4.8 & -14.2 & -46.4 & -0.4 & -5.7 & 5.4 & 30 & 3.0 & 1.6 \\
\hline Sandard Deviation & 1.5 & 124 & 24 & 1.3 & 0.2 & 0.3 & 0.2 & 0.9 & 1.2 \\
\hline
\end{tabular}

\begin{tabular}{|c|c|c|c|c|c|c|c|c|c|}
\hline \multirow{3}{*}{ Spine } & \multicolumn{9}{|c|}{ Unlateral Facetectonry: Left Lateral (+Left Arial) } \\
\hline & $\mathrm{Fx}$ & Fy & $\mathrm{Fr}$ & Mx & My & $\mathrm{Mx}$ & Resulast & Path & Roll \\
\hline & $\mathrm{N}$ & $\mathrm{N}$ & $\mathrm{N}$ & $\mathrm{Nm}$ & $\mathrm{Nm}$ & $\mathrm{Nm}$ & $\mathrm{Nm}$ & Degrees & Degrees \\
\hline 105285 & -3.0 & -15.4 & -34.3 & .09 & -5.0 & 3.6 & 6.2 & 29 & 1.6 \\
\hline 105459 & 0.1 & -3.1 & -319 & -0.3 & -4.5 & 39 & 60 & 4.4 & 40 \\
\hline 701858 & -28 & -9.6 & -289 & -0.4 & -4.2 & 4.3 & 60 & 4.7 & 1.1 \\
\hline 7087036 & -3.0 & -8.4 & -30.8 & -0.2 & -4.4 & 4.2 & 60 & 2.7 & 0.7 \\
\hline $53103715-002-2$ & .4 .6 & -7.5 & -31.4 & -0.1 &.-4.3 & 4.5 & 63 & 3.3 & 21 \\
\hline ADS1017052 & -3.5 & -7.6 & -20.3 & 0.0 & -26 & 5.3 & 59 & 19 & 15 \\
\hline DRT087036 & -4.4 & -7.7 & -324 & 0.7 & -4.3 & 4.5 & 63 & 1.8 & 0.7 \\
\hline$G D-1$ & -1.6 & -11.6 & -32.1 & -0.3 & -4.6 & 4.4 & 6.4 & 1.4 & 09 \\
\hline Mase & -28 & -89 & -30.3 & .0 .2 & -4.2 & 4.3 & 6.1 & 29 & 1.6 \\
\hline Standard Deviation & 1.5 & 3.6 & 4.3 & 0.4 & 0.7 & 0.5 & 0.2 & 12 & 1.1 \\
\hline
\end{tabular}

\begin{tabular}{|c|c|c|c|c|c|c|c|c|c|}
\hline \multirow{3}{*}{ Spine } & \multicolumn{9}{|c|}{ Unilateral Facetectonry: Right Lateral (+Right Arial) } \\
\hline & $\mathrm{Fx}$ & Fy & $\mathrm{Fz}$ & Max & My & $\mathrm{Mr}$ & Resulast & Paxh & Roll \\
\hline & $\mathrm{N}$ & $\mathrm{N}$ & $\mathrm{N}$ & $\mathrm{Nm}$ & $\mathrm{Nm}$ & $\mathrm{Nm}$ & $\mathrm{Nm}$ & Degrees & Degrees \\
\hline 105285 & -4.8 & -15.0 & -31.5 & 0.2 & -4.4 & 4.3 & 6.2 & 4.3 & 3.0 \\
\hline 105459 & -4.4 & -16.4 & -29.2 & -0.7 & -4.2 & 3.7 & 5.6 & 7.3 & 3.3 \\
\hline 701858 & -28 & -8.2 & -289 & -0.1 & -4.1 & 4.4 & 6.0 & 4.6 & 1.7 \\
\hline 7057036 & -3.3 & 27 & -29.1 & 0.7 & -4.0 & 4.2 & 59 & 23 & 0.8 \\
\hline $53103715-002-2$ & -39 & -9.5 & -320 & 0.5 & -4.4 & 3.5 & 5.7 & 25 & 0.4 \\
\hline ADS1017052 & -29 & -6.3 & -23.8 & 0.1 & -3.3 & 4.8 & 5.8 & 23 & 0.2 \\
\hline DRT0s7036 & -3.0 & -124 & -28.8 & -0.7 & -39 & 4.3 & 5.3 & 22 & 09 \\
\hline GD-1 & -1.7 & -7.4 & -27.4 & 0.2 & -4.1 & 4.4 & 60 & 22 & 1.3 \\
\hline Mesa & -3.4 & -9.1 & -28.8 & 0.0 & -4.1 & 4.2 & 59 & 3.5 & 1.4 \\
\hline Sandard Deviation & 10 & 6.0 & 25 & 0,5 & 0.4 & 0.4 & 0.2 & 1.8 & 1.1 \\
\hline
\end{tabular}


Table E-3. Tabulated BF Data from CEL Protocol.

\begin{tabular}{|c|c|c|c|c|c|c|c|c|c|}
\hline \multirow{3}{*}{ Spine } & \multicolumn{9}{|c|}{ Bilateral Facetectomv: Flerion (+Left,Avial) } \\
\hline & $\mathrm{Fx}$ & Fy & $\mathrm{Fz}$ & Mx & My & $\mathrm{M} x$ & Reswhast & Patsh & Roll \\
\hline & & $\mathrm{N}$ & $\mathrm{N}$ & $\mathrm{Nm}$ & $\mathrm{Nm}$ & $\mathrm{Nm}$ & $\mathrm{Nm}$ & Dearees & Dearess \\
\hline 105285 & -7.8 & -23.5 & -41.0 & 0.3 & -6.4 & 5.3 & 83 & 59 & 39 \\
\hline 105459 & -10.8 & -15.7 & -39.2 & -0.1 & -6.4 & 5.0 & 8.1 & 79 & 6.0 \\
\hline 701858 & -3.5 & -15.4 & -35.4 & 0.1 & -5.8 & 5.6 & 8.1 & 3.4 & 23 \\
\hline 7057036 & -3.5 & -127 & -40.1 & -0.9 & -6.2 & 5.1 & 30 & 29 & 0.8 \\
\hline $53103715-002-2$ & -4.1 & -18.2 & -36.2 & 0.0 & -5.7 & 5.1 & 7.6 & 3.1 & 1.8 \\
\hline ADS1017052 & -4.8 & -219 & -36.7 & -0.2 & -6.1 & 5.3 & 8.1 & 4.5 & 1.6 \\
\hline DRT087036 & .4 .4 & -12.6 & -35.5 & -10 & -59 & 5.0 & 7.8 & 1.5 & 0.9 \\
\hline GD-1 & -29 & -14.6 & -39.1 & -0.1 & -6.4 & 5.1 & 8.1 & 26 & 1.3 \\
\hline Masa & -5.2 & -16.8 & -379 & -0.2 & -6.1 & 5.2 & 30 & 40 & 23 \\
\hline Standard Deviatise & 27 & 4.1 & 22 & 0.4 & 0.3 & 0.2 & 0.2 & 21 & 1.8 \\
\hline
\end{tabular}

\begin{tabular}{|c|c|c|c|c|c|c|c|c|c|}
\hline \multirow{3}{*}{ Spine } & \multicolumn{9}{|c|}{ Bilateral Facetectomv: Flerion (+Right Arial) } \\
\hline & $\mathrm{Fx}$ & $\mathrm{Fy}$ & $\bar{F} \mathbf{z}$ & Mx & My & $\mathrm{M} x$ & Resulast & Paxh & Roll \\
\hline & $\mathrm{N}$ & $\mathrm{N}$ & $\mathrm{N}$ & $\mathrm{Nm}$ & $\mathrm{Nm}$ & $\mathrm{Nm}$ & $\mathrm{Nm}$ & Dearees & Dearest \\
\hline 105285 & -5.3 & 16.5 & -38.7 & 0.7 & -5.7 & -5.8 & 8.1 & 6.1 & 3.2 \\
\hline 105459 & -8.7 & 25.2 & -38.1 & 0.1 & -59 & -5.8 & 8.2 & 8.5 & 3.0 \\
\hline 701858 & -24 & 24.1 & -37.3 & 1.0 & -5.5 & -5.4 & 7.8 & 3.7 & 26 \\
\hline 7057036 & -26 & 27.8 & -359 & 0.1 & -5.4 & -59 & 8.0 & 3.6 & 1.4 \\
\hline $53103715-002-2$ & -3.3 & 26.2 & -34.6 & -0.8 & -5.4 & -5.6 & 7.8 & 3.3 & 1.7 \\
\hline ADS10170s2 & -6.2 & 69 & -35.0 & -19 & -5.5 & -5.5 & 8.0 & 4.7 & 1.8 \\
\hline DRT0S7ר36 & -10 & 33.2 & -37.1 & 1.5 & -5.3 & -59 & 8.1 & 19 & 1.1 \\
\hline GD-1 & -3.5 & 13.0 & -35.7 & 1.2 & -5.5 & -5.8 & 8.1 & 29 & 1.4 \\
\hline Masn & -4.1 & 21.6 & -36.6 & 0.2 & -5.5 & -5.7 & 8.0 & 4.3 & 20 \\
\hline Standard Deviatise & 25 & 3.7 & 15 & 1.1 & 0.2 & 0.2 & 0.2 & 21 & 0.8 \\
\hline
\end{tabular}

\begin{tabular}{|c|c|c|c|c|c|c|c|c|c|}
\hline \multirow{3}{*}{ Spine } & \multicolumn{9}{|c|}{ Bilateral Facetectomy: Exteuion (+Left Arial) } \\
\hline & $\mathrm{Fx}$ & $\mathrm{Fy}$ & $\mathrm{Fz}$ & Mx & My & $\mathrm{M} x$ & Resulatast & Patsh & Roll \\
\hline & $\mathrm{N}$ & $\mathrm{N}$ & $\mathrm{N}$ & $\mathrm{Nm}$ & $\mathrm{Nm}$ & $\mathrm{Nm}$ & $\mathrm{Nm}$ & Degrees & Dezrees \\
\hline 105285 & -5.6 & 33.4 & -528 & 0.5 & -5.6 & -5.5 & 79 & 49 & 24 \\
\hline 105459 & -7.8 & 359 & -560 & 29 & -5.1 & -5.5 & 80 & 69 & 3.9 \\
\hline 701858 & -50 & 14.3 & .47 .5 & 0.2 & -5.8 & -5.7 & 8.1 & 26 & 1.8 \\
\hline 7057036 & -5.5 & 210 & -410 & -0.2 & -49 & -6.3 & 30 & 20 & 1.0 \\
\hline $53103715-002-2$ & -4.8 & 39.3 & -521 & 0.7 & -5.4 & -5.8 & 80 & 4.4 & 20 \\
\hline ADS1017052 & -62 & 220 & -46.4 & 23 & -49 & -6.0 & 8.1 & 53 & 1.8 \\
\hline DRT087036 & .4 .2 & 31.6 & -509 & 0.4 & -5.6 & -59 & 8.1 & 3.2 & 1.3 \\
\hline GD-1 & -4.4 & 30.7 & -45.7 & 28 & -49 & -5.4 & 7.8 & 3.3 & 1.7 \\
\hline Masa & -5.4 & 28.5 & -49.1 & 12 & -5.3 & -5.8 & 80 & 4.1 & 20 \\
\hline Standard Deviation & 1.2 & 8.5 & 4.8 & 13 & 0.4 & 0.3 & 0.1 & 1.6 & 0.9 \\
\hline
\end{tabular}

\begin{tabular}{|c|c|c|c|c|c|c|c|c|c|}
\hline \multirow{3}{*}{ Spiose } & \multicolumn{9}{|c|}{ Biateral Facetectomy: Extemcion (+Right Arial) } \\
\hline & $\mathrm{Fx}$ & Fy & $\mathrm{F} z$ & Mx & $\mathrm{My}$ & $\mathrm{M} x$ & Resolast & Patch & Roll \\
\hline & $\mathrm{N}$ & $\mathrm{N}$ & $\mathrm{N}$ & $\mathrm{Nm}$ & $\mathrm{Nm}$ & $\mathrm{Nm}$ & $\mathrm{Nm}$ & Degrees & Degrese \\
\hline 105285 & -9.1 & -5.5 & -61.7 & 1.3 & -6.3 & 4.8 & 3.0 & 4.4 & 29 \\
\hline 105439 & -9.3 & -22.7 & -48.6 & 0.8 & -5.6 & 5.5 & 79 & 6.6 & 5.6 \\
\hline 701988 & -5.1 & -24.7 & -45.4 & 0.1 & -6.1 & 4.8 & 7.8 & 23 & 1.7 \\
\hline 7087036 & -4.4 & -26.5 & -44.2 & -1.8 & -6.3 & 4.8 & 3.1 & 1.4 & 10 \\
\hline $53103715-002-2$ & -7.2 & -20.1 & -54.1 & -2.3 & -6.3 & 4.8 & 83 & 3.7 & 1.4 \\
\hline ADS1017052 & -6.1 & -269 & -39.4 & -1.2 & -5.6 & 5.5 & 80 & 4.1 & 09 \\
\hline DRT0S7036 & -6.4 & -20.5 & -48.5 & -0.4 & -62 & 49 & 79 & 26 & 1.3 \\
\hline GD-1 & -8.4 & -224 & -50.4 & 15 & -59 & 5.4 & 3.1 & 3.0 & 1.7 \\
\hline Masa & -7.0 & -21.1 & -49.0 & -0.2 & -60 & 5.1 & 80 & 3.5 & 2.1 \\
\hline Standard Deviatise & 1.8 & 6.8 & 6.8 & 1.4 & 0.3 & 0.4 & 0.2 & 1.6 & 1.6 \\
\hline
\end{tabular}

\begin{tabular}{|c|c|c|c|c|c|c|c|c|c|}
\hline \multirow{3}{*}{ Spine } & \multicolumn{9}{|c|}{ Biateral Facetectomy: Leff Lateral (+Left Awial) } \\
\hline & $\mathrm{Fx}$ & Fy & $\mathrm{Fz}$ & Mx & My & $\mathrm{Mx}$ & Reswihast & Paxh & Roill \\
\hline & $\mathrm{N}$ & $\mathrm{N}$ & $\mathrm{N}$ & $\mathrm{Nm}$ & $\mathrm{Nm}$ & $\mathrm{Nm}$ & $\mathrm{Nm}$ & Degrees & Degrees \\
\hline 105285 & -4.0 & -11.9 & -35.0 & -1.1 & -5.0 & 3.3 & 6.1 & 4.1 & 1.6 \\
\hline 105459 &.-4.2 & -6.2 & -29.6 & -0.8 & -4.1 & 4.4 & 6.1 & 5.0 & 6.5 \\
\hline 701858 & .4 .5 & -18.5 & -300 & -0.9 & -4.6 & 40 & 62 & 4.1 & 1.6 \\
\hline 7057036 & -26 & -9.5 & -34.1 & -0.2 & -4.7 & 3.8 & 6.1 & 26 & 0.6 \\
\hline $53103715-002-2$ & -3.4 & -3.8 & -827 & 0.1 & -4.4 & 4.2 & 6.1 & 3.7 & 23 \\
\hline ADS1017052 & -28 & -11.1 & -18.6 & 0.1 & -2.7 & 5.3 & 60 & 3.0 & 28 \\
\hline DRT0S7ר36 & -28 & -9.1 & -328 & 0.0 & -4.8 & 4.1 & 63 & 2.1 & 0.8 \\
\hline$G D-1$ & -21 & -18.1 & -31.4 & -0.7 & -5.0 & 3.2 & 59 & 1.2 & 0.9 \\
\hline Masa & -3.3 & -11.6 & -36.8 & -0.4 & -4.4 & 40 & 6.1 & 3.2 & 2.1 \\
\hline Standard Dexvation & 0.9 & 4.4 & 19.2 & 0.5 & 0.7 & 0.7 & 0.1 & 12 & 19 \\
\hline
\end{tabular}

\begin{tabular}{|c|c|c|c|c|c|c|c|c|c|}
\hline \multirow{3}{*}{ Spine } & \multicolumn{9}{|c|}{ Bilateral Facetectonry: Right Lateral (+Right Avial) } \\
\hline & $\mathrm{Fx}$ & Fy & $\mathrm{F} z$ & Mx & $\mathrm{My}$ & $\mathrm{Nax}$ & Remitast & Patsh & Roll \\
\hline & $\mathrm{N}$ & $\mathrm{N}$ & $\mathrm{N}$ & $\mathrm{Nm}$ & $\mathrm{Nm}$ & $\mathrm{Nm}$ & $\mathrm{Nm}$ & Degrees & Degrees \\
\hline 105285 & -5.7 & -219 & -31.7 & -0.3 & -4.3 & 4.2 & 6.0 & 4.5 & 4.3 \\
\hline 105459 & -5.8 & -200 & -29.4 & .02 & -4.6 & 3.4 & 5.7 & 85 & 3.2 \\
\hline 701888 & -8.4 & -125 & -34.4 & .03 & .4 .5 & 4.1 & 6.1 & 4.0 & 21 \\
\hline 7087036 & -28 & .43 & -35.6 & 1.1 & .43 & 4.0 & 6.0 & 26 & 0.7 \\
\hline $53103715-002-2$ & -3.4 & -13.2 & -35.4 & 0.0 & -49 & 3.4 & 6.0 & 3.3 & 0.5 \\
\hline ADS1017052 & -28 & -3.4 & -27.6 & -0.1 & -3.8 & 4.5 & 59 & 28 & 0.4 \\
\hline DRT0S7036 & -3.5 & -16.8 & -26.6 & -1.6 & -4.3 & 3.4 & 5.7 & 1.7 & 10 \\
\hline GD-1 & -22 & -18.2 & -29.1 & -0.6 & .4 .6 & 39 & 6.1 & 26 & 1.6 \\
\hline Masa & .43 & -13.8 & -31.2 & .0 .2 & -4.4 & 39 & 39 & 3.7 & 1.7 \\
\hline Sandard Deviation & 21 & 69 & 3.6 & 0.3 & 0.3 & 0.4 & 0.2 & 21 & 1.4 \\
\hline
\end{tabular}


Table E-4. Tabulated Laminectomy Data from CEL Protocol.

\begin{tabular}{|c|c|c|c|c|c|c|c|c|c|}
\hline \multirow{3}{*}{ Spine } & \multicolumn{9}{|c|}{ Lamivectomv: Flerion (+Left Axial) } \\
\hline & $\mathrm{Fx}$ & $\overline{F y}$ & $\bar{F} z$ & $\mathrm{Mx}$ & $\mathrm{My}$ & $\mathrm{Mx}$ & Resoltast & $\overline{\text { Path }}$ & Roll \\
\hline & $\mathrm{N}$ & $\mathrm{N}$ & $\mathrm{N}$ & $\mathrm{Nm}$ & $\mathrm{Nm}$ & $\mathrm{Nm}$ & $\mathrm{Nm}$ & Dearees: & Dearees \\
\hline 105285 & -4.3 & -6.8 & -36.7 & -0.2 & -59 & 5.3 & 79 & 11.2 & 6.1 \\
\hline 105459 & -3.4 & -120 & -37.4 & -0.7 & -6.0 & 4.4 & 7.5 & 13.5 & 3.6 \\
\hline 701858 & -59 & -109 & -369 & -0.9 & -5.7 & 5.3 & 79 & 3.4 & 3.4 \\
\hline 7057036 & -24 & -140 & -34.7 & -1.2 & -5.8 & 5.0 & 7.7 & 3.7 & 1.2 \\
\hline $53103715-002-2$ & -2.1 & -5.8 & -33.8 & -0.2 & -5.8 & 5.7 & 8.1 & 4.7 & 25 \\
\hline ADS1017052 & -5.4 & -6.1 & -35.4 & -0.1 & -5.8 & 5.7 & 8.1 & 4.4 & 1.8 \\
\hline DRTOS7036 & -2.8 & -20.1 & -33.5 & -10 & -5.7 & 5.7 & 8.1 & 20 & 1.4 \\
\hline$G D-1$ & -25 & -60 & -37.7 & 0.2 & -6.2 & 5.1 & 8.1 & 4.1 & 21 \\
\hline Masn & -4.2 & -10.2 & -35.7 & .0 .5 & -5.8 & 5.3 & 79 & 59 & 3.4 \\
\hline Standard Dexiatise & 22 & 3.1 & 1.6 & 0.5 & 0.2 & 0.4 & 02 & 4.1 & 26 \\
\hline
\end{tabular}

\begin{tabular}{|c|c|c|c|c|c|c|c|c|c|}
\hline \multirow{3}{*}{ Spins } & \multicolumn{9}{|c|}{ Laminectomy: Flevion (+Right Avial) } \\
\hline & $\mathrm{Fx}$ & Fy & $\bar{F} \mathbf{z}$ & Mx & My & $\mathrm{Mx}$ & Resulast & Patch & Roll \\
\hline & $\mathrm{N}$ & $\mathrm{N}$ & $\mathrm{N}$ & $\mathrm{Nm}$ & $\mathrm{Nm}$ & $\mathrm{Nm}$ & $\mathrm{Nm}$ & Dearest & Deareas \\
\hline 105285 & -4.2 & 12.1 & -37.1 & 0.8 & -5.8 & -5.8 & 8.2 & 11.2 & 5.5 \\
\hline 105459 & -8.5 & 126 & -369 & 1.3 & -5.7 & -5.7 & 8.2 & 13.5 & 4.1 \\
\hline 701958 & -5.8 & 103 & -359 & 0.0 & -5.6 & -6.1 & 8.2 & 3.7 & 27 \\
\hline 7087036 & -3.8 & 4.8 & -35.5 & -0.4 & -5.6 & -5.8 & 8.1 & 4.4 & 1.4 \\
\hline $53103715-002-2$ & -27 & -4.7 & -34.1 & .09 & -59 & -5.2 & 79 & 4.7 & 25 \\
\hline ADS1017052 & -69 & 0.7 & -364 & -0.5 & -5.8 & -5.6 & 8.1 & 4.4 & 20 \\
\hline DRTOS7036 & -1.7 & 15.3 & -32.7 & 0.8 & -5.5 & -5.7 & 3.0 & 20 & 1.2 \\
\hline GD-1 & -3.7 & 14.7 & -35.8 & 1.7 & -5.6 & -5.7 & 8.2 & 4.1 & 1.7 \\
\hline Masa & -4.7 & 8.2 & -35.5 & 0.4 & -5.7 & -5.7 & 8.1 & 6.0 & 26 \\
\hline Shandard Deváaiso & 23 & 7.2 & 15 & 09 & 0.1 & 0.2 & 0.1 & 4.0 & 15 \\
\hline
\end{tabular}

\begin{tabular}{|c|c|c|c|c|c|c|c|c|c|}
\hline \multirow{3}{*}{ Spine } & \multicolumn{9}{|c|}{ Lamivectomy: Entemion (+Left Arial) } \\
\hline & $\overline{F x}$ & Fy & $\mathrm{F} z$ & Mx & My & $\mathrm{M} x$ & Resulast & Paxh & Roll \\
\hline & $\mathrm{N}$ & $\mathrm{N}$ & $\mathrm{N}$ & $\mathrm{Nm}$ & $\mathrm{Nm}$ & $\mathrm{Nm}$ & $\mathrm{Nm}$ & Dearees: & Dearees \\
\hline 105285 & -9.0 & -17.3 & -47.1 & -22 & -5.4 & 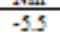 & $\frac{3.1}{8.1}$ & 6.8 & 3.1 \\
\hline 105459 & -10.4 & 28.7 & -51.3 & 28 & -6.0 & .4 .8 & 32 & 9.1 & 40 \\
\hline 701898 & -5.3 & 3.8 & .47 .8 & -0.1 & -59 & -5.7 & 8.2 & 24 & 27 \\
\hline 7057036 & -4.8 & 59 & -44.3 & 0.8 & -3.5 & -5.6 & 79 & 27 & 1.2 \\
\hline $53103715-002-2$ & -5.1 & 9.6 & -47.1 & 0.8 & -5.6 & -5.7 & 8.0 & 4.4 & 19 \\
\hline ADS1017052 & -23 & 18.6 & -38.4 & 21 & -50 & -59 & 30 & 6.4 & 27 \\
\hline DRTOS7036 & -11.5 & 14.5 & .47 .5 & 0.5 & -5.5 & -5.8 & 8.0 & 3.4 & 13 \\
\hline GD -1 & -4.7 & -6.3 & -45.5 & .0 .5 & -5.6 & -5.7 & 3.0 & 4.1 & 19 \\
\hline Mean & -6.6 & 7.2 & .46 .1 & 0.5 & -3.6 & -5.6 & 8.1 & 49 & 24 \\
\hline Shandard Deviatise & 3.2 & 14.4 & 3.7 & 1.6 & 0.3 & 0.3 & 0.1 & 23 & 10 \\
\hline
\end{tabular}

\begin{tabular}{|c|c|c|c|c|c|c|c|c|c|}
\hline \multirow{3}{*}{ Spine } & \multicolumn{9}{|c|}{ Laminectomy: Extemion (+Right Arial) } \\
\hline & $\overline{F x}$ & Fy & $\mathrm{Fz}$ & Mx & $\mathrm{My}$ & $\mathrm{Mx}$ & Resolast & Paxh & Roll \\
\hline & $\mathrm{N}$ & $\mathrm{N}$ & $\mathrm{N}$ & $\mathrm{Nm}$ & $\mathrm{Nm}$ & $\mathrm{Nm}$ & $\mathrm{Nm}$ & Dearees & Dearees \\
\hline 105285 & -8.3 & -5.6 & -50.7 & -0.6 & -6.1 & 5.3 & 3.1 & 6.4 & 49 \\
\hline 105459 & -10.7 & -9.9 & -49.9 & -1.2 & -59 & 5.5 & 3.1 & 5.4 & 70 \\
\hline 701858 & -5.3 & -8.1 & -30.7 & 0.2 & -3.5 & 7.5 & 8.2 & 24 & 24 \\
\hline 7087036 & -3.4 & -14.8 & -45.0 & -1.3 & -5.9 & 5.4 & 8.1 & 24 & 1.3 \\
\hline $53103715-002-2$ & .99 & -23.5 & -526 & -24 & -5.8 & 49 & 8.0 & 4.1 & 1.6 \\
\hline ADs1017052 & -1.7 & -149 & -363 & -1.7 & -5.0 & 59 & 7.8 & 5.7 & 13 \\
\hline DRT087036 & -6.5 & -16.6 & -500 & -0.3 & -5.7 & 5.5 & 79 & 3.4 & 1.7 \\
\hline GD-1 & -25 & -20.6 & -43.6 & -1.7 & -5.7 & 5.2 & 79 & 3.7 & 21 \\
\hline Mean & -60 & -14.2 & .44 .8 & -1.1 & -5.5 & 5.6 & 30 & 4.2 & 28 \\
\hline Standard Deviation & 3.4 & 6.1 & 7.8 & 0.8 & 09 & 0.8 & 0.1 & 15 & 21 \\
\hline
\end{tabular}

\begin{tabular}{|c|c|c|c|c|c|c|c|c|c|}
\hline \multirow{3}{*}{ Spine } & \multicolumn{9}{|c|}{ Laminectomv: Left Lateral(tLeft,Arial) } \\
\hline & $\mathrm{Fx}$ & $\mathrm{Fy}$ & $\mathrm{Fz}$ & $\mathrm{Mx}$ & $\mathrm{Ny}$ & $\mathrm{Mr}$ & Resolast & Pinch & Roll \\
\hline & $\mathrm{N}$ & $\mathrm{N}$ & $\mathrm{N}$ & $\mathrm{Nm}$ & $\mathrm{Nm}$ & $\mathrm{Nm}$ & $\mathrm{Nm}$ & Degrees & Degrees \\
\hline 105285 & -3.8 & -16.1 & -35.8 & -2.1 & -5.0 & 3.0 & 6.2 & 3.0 & 25 \\
\hline 105459 & -3.1 & -14.4 & -31.3 & -2.3 & -4.1 & 39 & 6.1 & 8.5 & 6.2 \\
\hline 701858 & -3.6 & -3.6 & -29.7 & -0.3 & -4.2 & 4.3 & 60 & 4.1 & 2.1 \\
\hline 70057036 & -19 & -4.0 & -28.4 & -0.1 & -4.2 & 4.0 & 5.8 & 3.0 & 1.2 \\
\hline $53103715-002-2$ & -3.6 & -11.5 & -29.8 & .09 & -4.2 & 4.3 & 6.1 & 3.4 & 22 \\
\hline AD\$1017052 & -24 & -4.7 & -18.2 & -0.2 & -2.6 & 5.3 & 59 & 3.4 & 3.0 \\
\hline DRTUS7036 & -24 & -10.8 & -29.6 & -0.2 & -4.4 & 4.2 & 6.1 & 27 & 1.2 \\
\hline GD-1 & -1.1 & -12.8 & -29.8 & -1.1 & -4.5 & 3.4 & 5.3 & 24 & 1.4 \\
\hline Masen & -2.7 & -10.4 & -29.1 & -0.9 & -4.2 & 4.1 & 60 & 3.8 & 25 \\
\hline Standard Deviation & 0.9 & 4.4 & 49 & 0.9 & 0.7 & 0.7 & 0.2 & 20 & 1.6 \\
\hline
\end{tabular}

\begin{tabular}{|c|c|c|c|c|c|c|c|c|c|}
\hline \multirow{3}{*}{ Spiose } & \multicolumn{9}{|c|}{ Laminectomy: Right Lateral (+Kight Arial) } \\
\hline & $\mathrm{Fx}$ & Fy & $\mathrm{Fz}$ & Mx & $\mathrm{My}$ & $\mathrm{Mr}$ & Resulast & Pasth & Roll \\
\hline & $\mathrm{N}$ & $\mathrm{N}$ & $\mathrm{N}$ & $\mathrm{Nm}$ & $\mathrm{Nm}$ & $\mathrm{Nm}$ & $\mathrm{Nm}$ & Degrees: & Degrees \\
\hline 105285 & -4.5 & 9.3 & -31.2 & 1.3 & -4.1 & 4.2 & 6.0 & 4.4 & 5.8 \\
\hline 105459 & -3.9 & -0.6 & -30.4 & 0.7 & -4.6 & 3.6 & 59 & 6.4 & 59 \\
\hline 701858 & -3.5 & -7.7 & -29.2 & .0 .5 & .4 .2 & 4.3 & 6.0 & 4.1 & 23 \\
\hline 7087036 & .0 .2 & -4.4 & -29.8 & 0.0 & -4.3 & 4.2 & 6.0 & 4.1 & 1.2 \\
\hline $53103715-002-2$ & -6.7 & -3.8 & -35.0 & 0.2 & -4.6 & 3.6 & 5.8 & 3.0 & 0.5 \\
\hline ADS1017052 & -29 & -5.0 & -29.5 & -0.2 & -4.1 & 4.7 & 6.2 & 27 & 0.7 \\
\hline DRTOS7036 & .0 .8 & -16.3 & -26.5 & -19 & -4.1 & 39 & 60 & 27 & 1.7 \\
\hline GD-1 & -3.1 & -8.2 & -28.6 & 0.2 & -4.2 & 4.2 & 60 & 24 & 20 \\
\hline Mean & -3.2 & -4.6 & -300 & 0.0 & -4.3 & 4.1 & 6.0 & 3.7 & 25 \\
\hline Shandard Deviatiso & 20 & 73 & 25 & 10 & 0.2 & 0.4 & 0.1 & 13 & 22 \\
\hline
\end{tabular}


APPENDIX F: FACET ANGLE OBSERVATIONS 

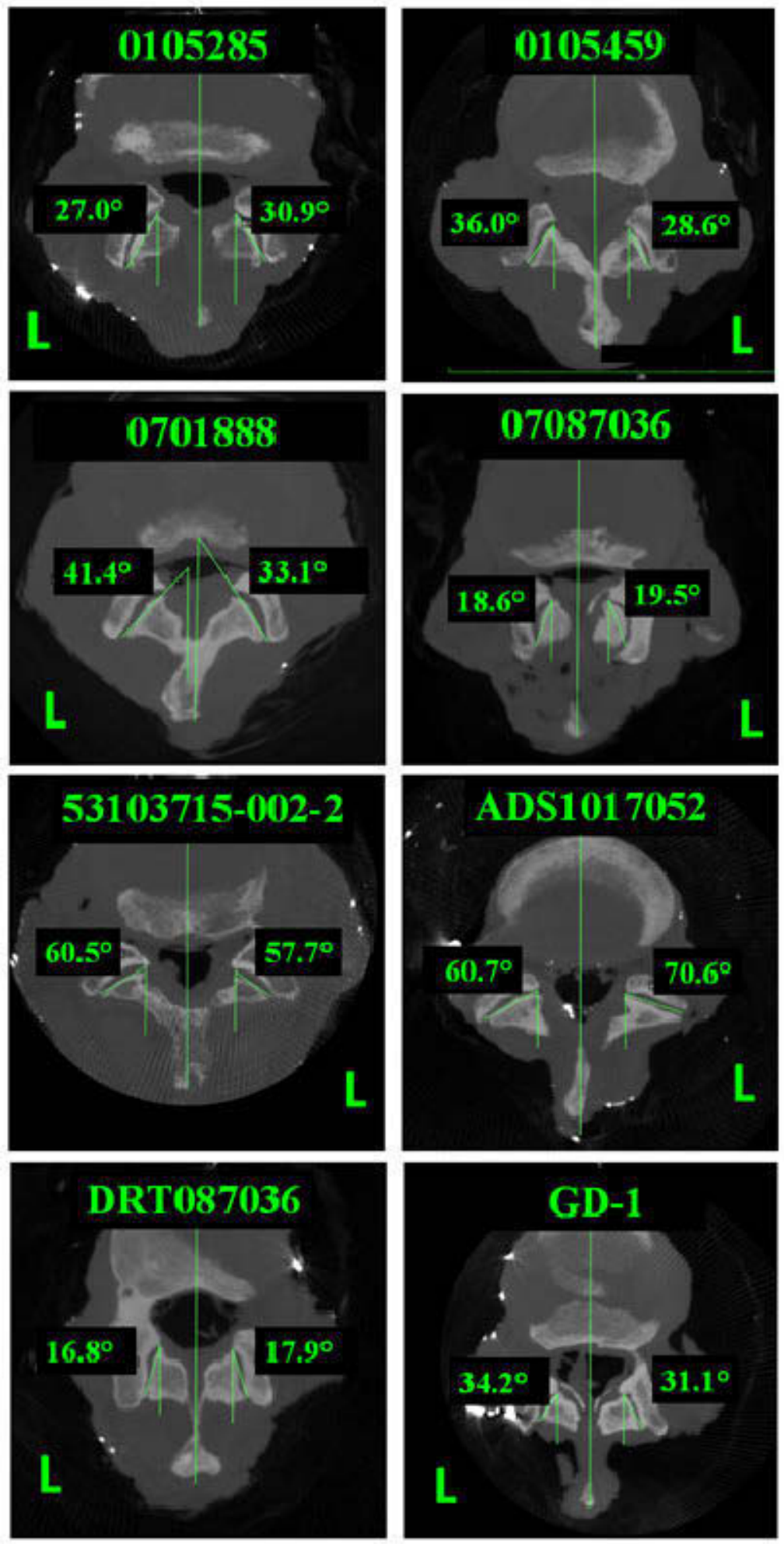

Figure F-1. Harvested Facet Angle Measurements (KS). Note: Observations made by Karen Sedacki. 

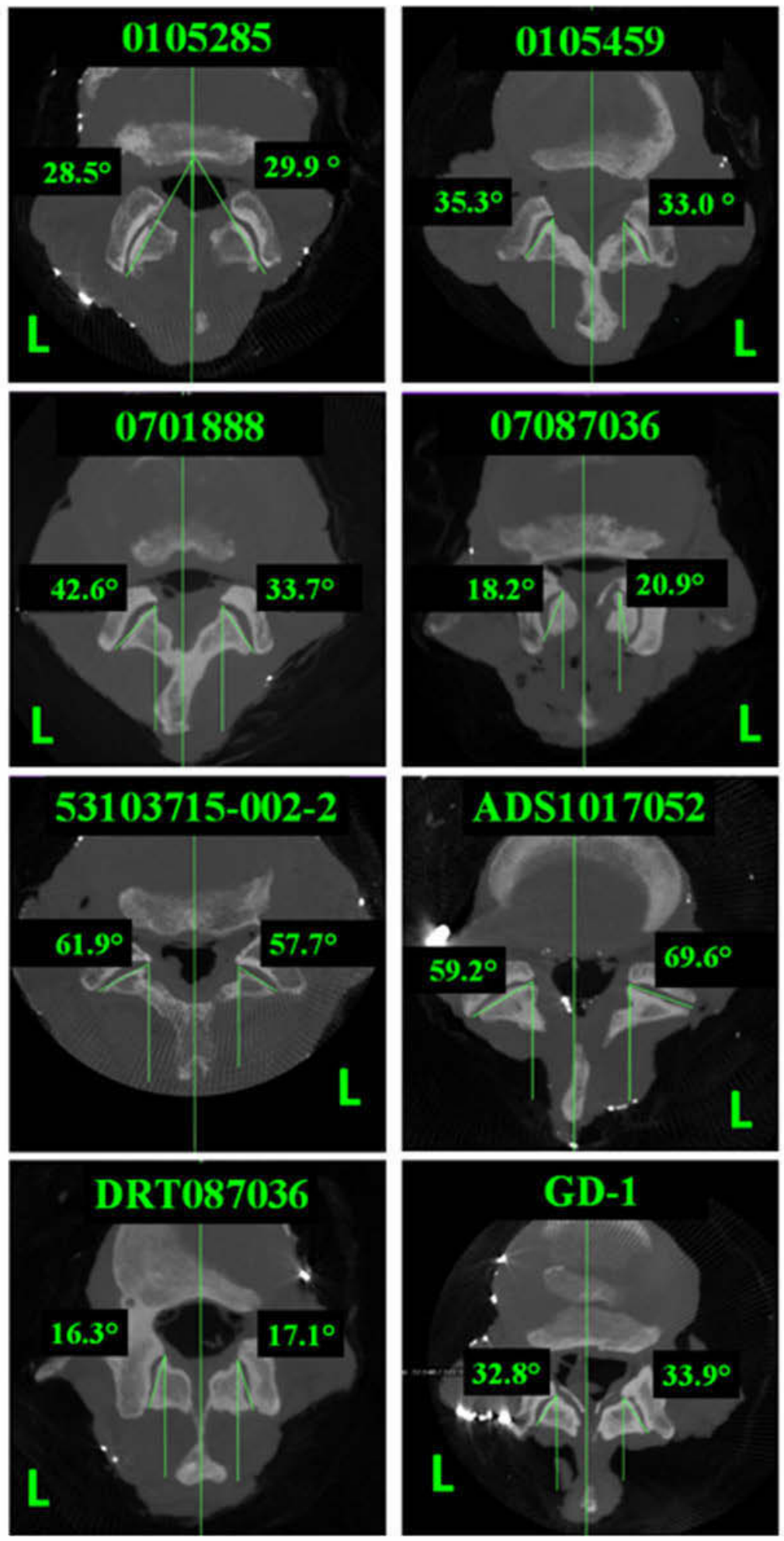

Figure F-2. Harvested Facet Angle Measurements (MC). Note: Observations made by Dr. Mauricio Campos. 

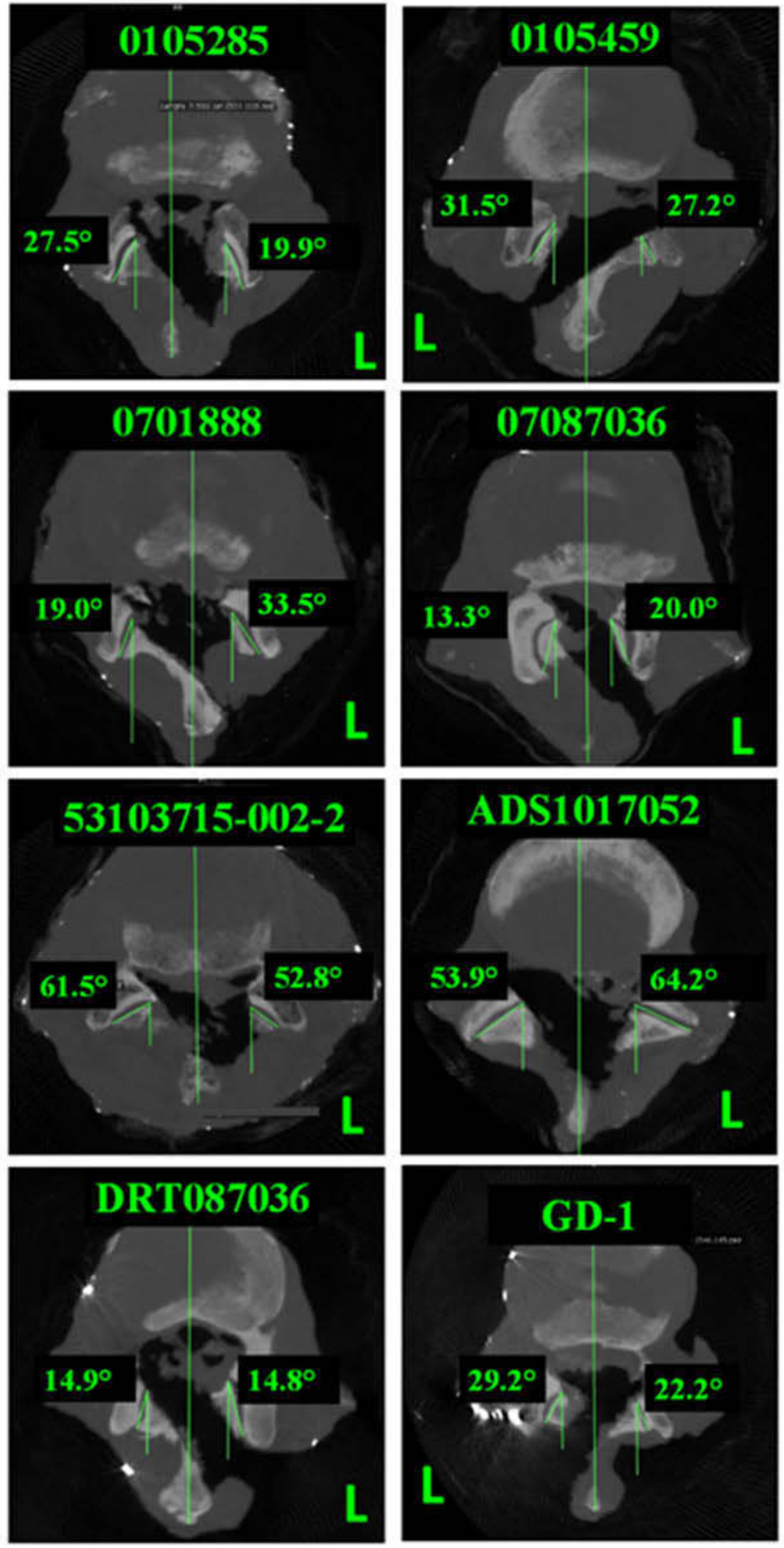

Figure F-3. BF Facet Angle Measurements (KS). Note: Observations made by Karen Sedacki. 

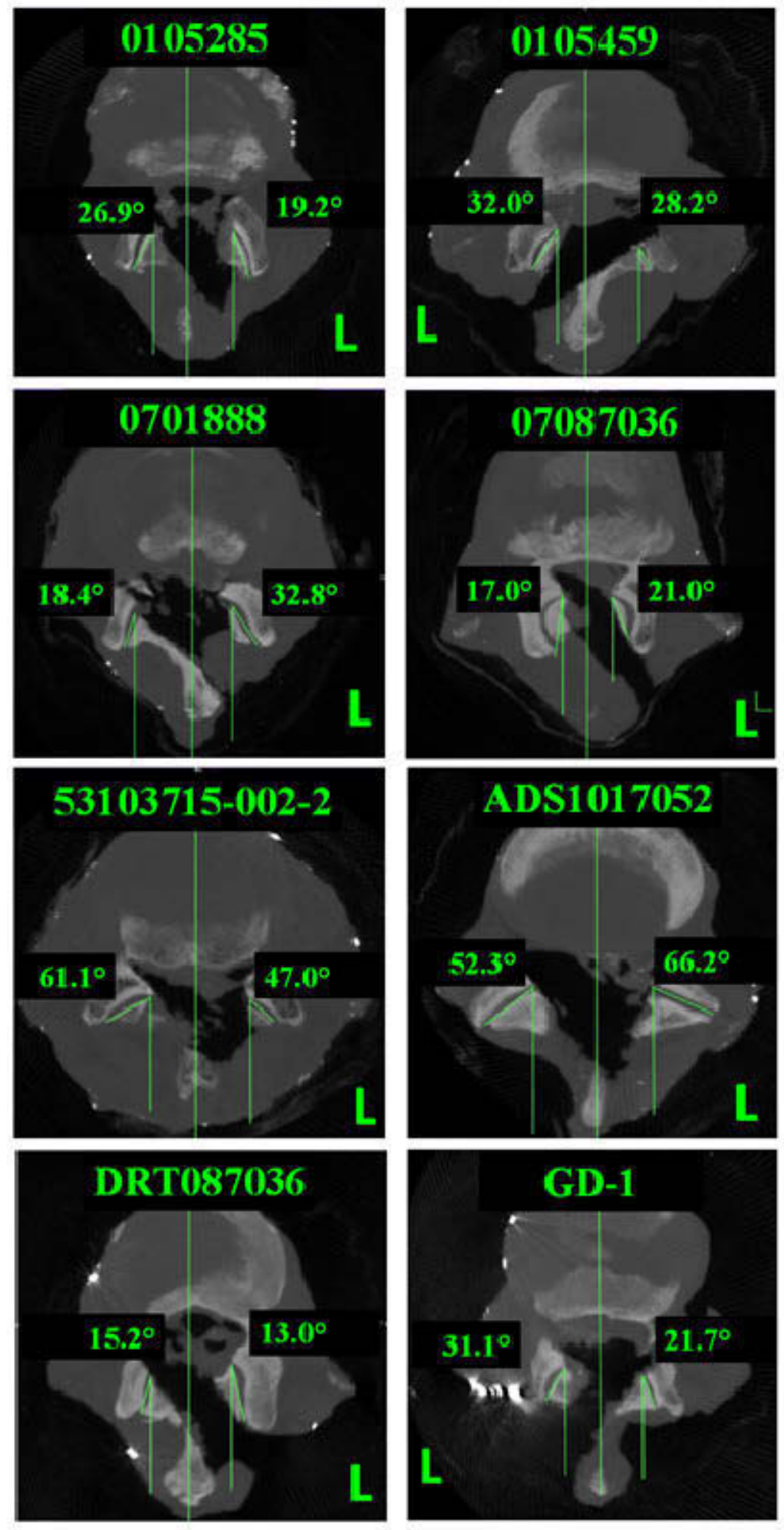

Figure F-4. BF Facet Angle Measurements (MC). Note: Observations made by Dr. Mauricio Campos. 
APPENDIX G: TABULATED CT DATA 
Table G-1. Tabulated CT Angle Observations.*

\begin{tabular}{|c|c|c|c|c|}
\hline \multirow[b]{2}{*}{ Specimen } & \multicolumn{4}{|c|}{ Harressted CT Asgle Observations: Right Facet } \\
\hline & Level & $\begin{array}{l}\text { K-Asgle } \\
\text { Degrees }\end{array}$ & $\begin{array}{l}\text { M-Axgle } \\
\text { Degrees }\end{array}$ & $\begin{array}{c}\text { Aversge Asgle } \\
\text { Degrees }\end{array}$ \\
\hline 105235 & L2-3 & 309 & 299 & 30.4 \\
\hline 105459 & L1-2 & 360 & 35.3 & 35.7 \\
\hline 701858 & L2-3 & 33.1 & 33.7 & 33.4 \\
\hline 7087036 & $\mathrm{~L} 1-2$ & 18.6 & 18.2 & 18.4 \\
\hline $53103715-002-2$ & L4-5 & 60.5 & 619 & 61.2 \\
\hline GD-1 & L1-2 & 31.1 & 33.9 & 32.5 \\
\hline ADS1017052 & L4-5 & 60.7 & 59.2 & 600 \\
\hline \multirow[t]{9}{*}{ DRTOS7036 } & L1-2 & 179 & 17.1 & 17.5 \\
\hline & \multirow{3}{*}{\multicolumn{2}{|c|}{ Mese }} & $\mathrm{L} 1-2$ & 260 \\
\hline & & & L2-3 & 319 \\
\hline & & & L4.5 & 60.6 \\
\hline & \multirow{3}{*}{\multicolumn{2}{|c|}{ Standard Deviation }} & L1-2 & 9.4 \\
\hline & & & L2-3 & 2.1 \\
\hline & & & L4-5 & 309 \\
\hline & \multirow{2}{*}{\multicolumn{3}{|c|}{$\begin{array}{r}\text { Mese of All } \\
\text { Standard Detiation }\end{array}$}} & 36.13125 \\
\hline & & & & 1651920452 \\
\hline \multirow{3}{*}{ Specimen } & \multicolumn{4}{|c|}{ Harrested CT Asgle Observations: Left Facet } \\
\hline & \multirow[t]{2}{*}{ Level } & K-Asgle & M-Asgle & Averago Asgle \\
\hline & & Degrees & Degrees & Degrees \\
\hline 105285 & L2-3 & 270 & 28.5 & 27.8 \\
\hline 105459 & $\mathrm{~L} 1-2$ & 28.6 & 330 & 30.8 \\
\hline 701858 & $L 2-3$ & 41.4 & 42.6 & 420 \\
\hline 7087036 & L1-2 & 19.5 & 209 & 20.2 \\
\hline $53103715-002-2$ & $14-5$ & 57.7 & 57.7 & 57.7 \\
\hline GD-1 & L1-2 & 34.2 & 328 & 33.5 \\
\hline ADS1017052 & $14-5$ & 70.6 & 69.6 & 70.1 \\
\hline \multirow{9}{*}{ DRTOS7036 } & L1-2 & 16.8 & 16.3 & 16.5 \\
\hline & & Mess & & 25.3 \\
\hline & & & L2:-3 & 349 \\
\hline & & & L4.5 & 639 \\
\hline & \multirow{3}{*}{\multicolumn{2}{|c|}{ Standard Deviation }} & $\mathrm{L} 1-2$ & \\
\hline & & & L2-3 & 100 \\
\hline & & & L4-5 & 3.8 \\
\hline & \multirow{2}{*}{\multicolumn{2}{|c|}{$\begin{array}{r}\text { Mess of All } \\
\text { Stavdard Detianion }\end{array}$}} & & 37.3 \\
\hline & & & & 18.5 \\
\hline
\end{tabular}

\begin{tabular}{|c|c|c|c|c|}
\hline \multirow[b]{2}{*}{ Specimes } & \multicolumn{4}{|c|}{ BF CT Asglo Observations: Right Facet } \\
\hline & Level & K-Asgle & M-Asgle & Average Asgle \\
\hline 105285 & L2-3 & $\frac{27.5}{27.5}$ & 26.9 & 27.2 \\
\hline 105459 & $\mathrm{~L} 1-2$ & 272 & 28.2 & 27.7 \\
\hline 701585 & L2-3 & 19.0 & 18.4 & 18.7 \\
\hline 7087036 & L1-2 & 13.3 & 17.0 & 15.1 \\
\hline$\$ 3103715-002-2$ & L 4.5 & 61.5 & 61.1 & 61.3 \\
\hline GD-1 & L1-2 & 222 & 21.7 & 219 \\
\hline \multirow{10}{*}{ DRTOS7036 } & L4-5 & 53.9 & 523 & 53.1 \\
\hline & L1-2 & 149 & 15.2 & 15.1 \\
\hline & \multirow{3}{*}{\multicolumn{2}{|c|}{ Mess }} & L1-2 & 200 \\
\hline & & & L2-3 & 229 \\
\hline & & & L4-5 & 572 \\
\hline & \multirow{3}{*}{\multicolumn{2}{|c|}{ Stavdard Deviation }} & L1-2 & 6.1 \\
\hline & & & L2-3 & 60 \\
\hline & & & L4-5 & 32.7 \\
\hline & \multirow{2}{*}{\multicolumn{3}{|c|}{$\begin{array}{r}\text { Mese of All } \\
\text { Stavdard Detiation }\end{array}$}} & 300 \\
\hline & & & & 17.6 \\
\hline \multirow{3}{*}{ Specimes } & \multicolumn{4}{|c|}{ BF CT Anglo Obserrations: Left Facet } \\
\hline & Level & K-Asglo & M-Axgle & Average Angle \\
\hline & & Degrees & Degrees & Degrees \\
\hline 105285 & L2-3 & 19.9 & 19.2 & 19.6 \\
\hline 105459 & $\mathrm{~L} 1-2$ & 31.5 & 320 & 31.8 \\
\hline 701898 & $\mathrm{~L} 2-3$ & 33.5 & 328 & 33.1 \\
\hline 7087036 & $\mathrm{~L} 1-2$ & 20.1 & 210 & 20.5 \\
\hline $53103715-002-2$ & L4-5 & 528 & 47.0 & 499 \\
\hline GD-1 & $\mathrm{L} 1-2$ & 29.2 & 31.1 & 302 \\
\hline ADS1017052 & $\mathrm{L} 4.5$ & 64.2 & 66.2 & 65.2 \\
\hline \multirow[t]{9}{*}{ DRT087036 } & $\mathrm{L} 1-2$ & 14.8 & 13.0 & 139 \\
\hline & \multirow{3}{*}{\multicolumn{2}{|c|}{ Mess }} & L1-2 & 24.1 \\
\hline & & & L2-3 & 26.4 \\
\hline & & & L $4-5$ & 57.6 \\
\hline & \multirow{3}{*}{\multicolumn{2}{|c|}{ Standard Deviation }} & L1-2 & 8.4 \\
\hline & & & L2-3 & 9.6 \\
\hline & & & L4-5 & 10.8 \\
\hline & \multirow{2}{*}{\multicolumn{2}{|c|}{$\begin{array}{l}\text { Mens of All } \\
\text { Standard Deviation }\end{array}$}} & & 330 \\
\hline & & & & 170 \\
\hline
\end{tabular}

Note: *Observations made by Dr. Mauricio Campos and Karen Sedacki. 
Table G-2. Tabulated CT Area Data.*

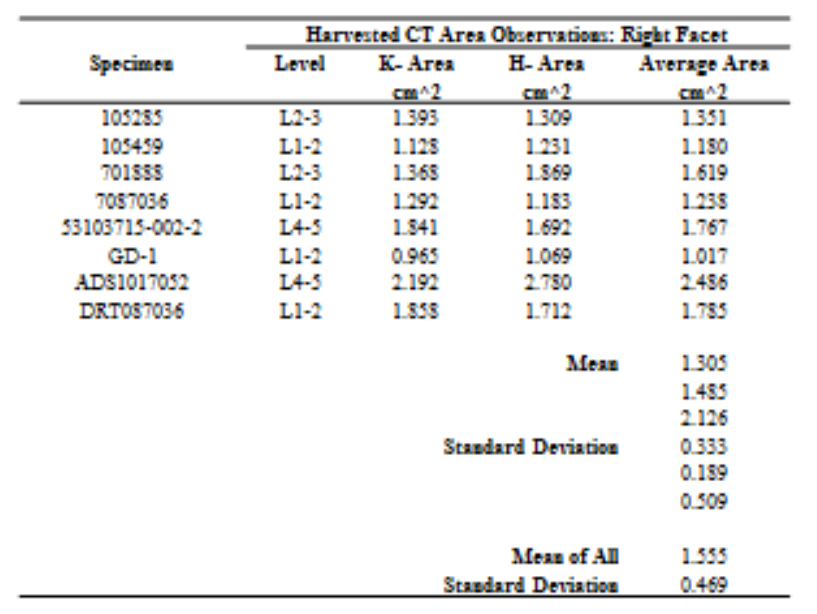

\begin{tabular}{|c|c|c|c|c|}
\hline \multirow{3}{*}{ Specimen } & \multicolumn{4}{|c|}{ BF CT Ares Observations: Right Facet } \\
\hline & Level & K-Ares & H-Ares & Average Ares \\
\hline & & $\mathrm{cm} \wedge 2$ & $\mathrm{~cm} \wedge 2$ & \\
\hline 105285 & L2-3 & 1.167 & 1.212 & 1.190 \\
\hline 105459 & L1-2 & 0.594 & 1066 & 0.950 \\
\hline 701888 & L $2-3$ & 1.134 & 0.819 & 0.977 \\
\hline 7057036 & $\mathrm{~L}_{1-2}$ & 1.105 & 1.112 & 1.109 \\
\hline $53103715-002-2$ & L4-5 & 1.729 & 1.708 & 1.719 \\
\hline GD-1 & $\mathrm{L} 1-2$ & 0.790 & 0.859 & 0.340 \\
\hline ADS1017052 & L4-5 & 1.735 & 1.647 & 1.691 \\
\hline \multirow[t]{9}{*}{ DRTOS7036 } & $\mathrm{L} 1-2$ & 1.145 & 1.183 & 1.164 \\
\hline & & & Mesn & 1.023 \\
\hline & & & & 1.083 \\
\hline & & & & 1.705 \\
\hline & & \multirow{3}{*}{\multicolumn{2}{|c|}{ Stavdard Deviation }} & 0.145 \\
\hline & & & & 0.151 \\
\hline & & & & 0.392 \\
\hline & & \multirow{2}{*}{\multicolumn{2}{|c|}{$\begin{array}{r}\text { Mene of All } \\
\text { Standard Deriation }\end{array}$}} & 1.208 \\
\hline & & & & 0.327 \\
\hline
\end{tabular}

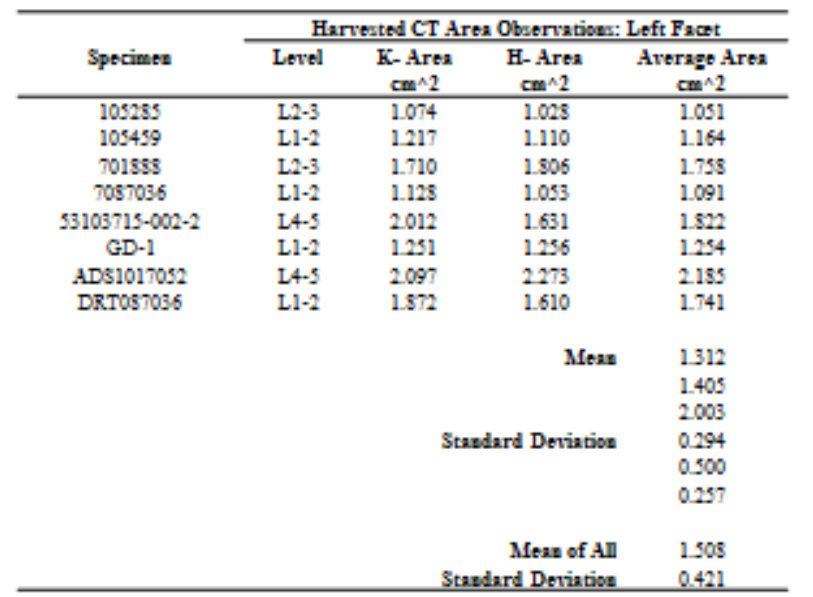

\begin{tabular}{|c|c|c|c|c|}
\hline \multirow[b]{2}{*}{ Specimes } & \multicolumn{4}{|c|}{ BF CT Area Observations: Left Facer } \\
\hline & Level & $\begin{array}{c}\text { K-Ares } \\
\mathrm{cm}^{\wedge} 2\end{array}$ & $\begin{array}{c}\text { H-Ares } \\
\cos ^{\wedge} 2\end{array}$ & $\begin{array}{c}\text { Average Ares } \\
\operatorname{csin} \wedge 2\end{array}$ \\
\hline 105285 & L:2-3 & 1.045 & 0.960 & 1.003 \\
\hline 105459 & $\mathrm{~L} 1-2$ & 0.952 & 0.927 & 0.940 \\
\hline 701898 & $L 2 \cdot 3$ & 1.227 & 1.626 & 1.427 \\
\hline 7087036 & $\mathrm{~L} 1-2$ & 1.116 & 1.057 & 1057 \\
\hline $53103715-002-2$ & L4-5 & 1316 & 1.493 & 1.405 \\
\hline GD-1 & $\mathrm{L} 1-2$ & 0.834 & 1.104 & 0.969 \\
\hline \multirow{10}{*}{ DRTOS7036 } & L4-5 & 1.783 & 1.824 & 1.504 \\
\hline & L1-2 & 1.809 & 1.854 & 1.832 \\
\hline & & & Mesn & 1.207 \\
\hline & & & & 1.215 \\
\hline & & & & 1.604 \\
\hline & & \multirow{3}{*}{\multicolumn{2}{|c|}{ Standard Deriation }} & 0.421 \\
\hline & & & & 0.300 \\
\hline & & & & 0.282 \\
\hline & & & Menu of All & 1308 \\
\hline & & & rd Deriation & 0.366 \\
\hline
\end{tabular}

Note: *Observations made by Dr. Hamid Shah and Karen Sedacki. 
Table G-3. Tabulated CT Length Data.*

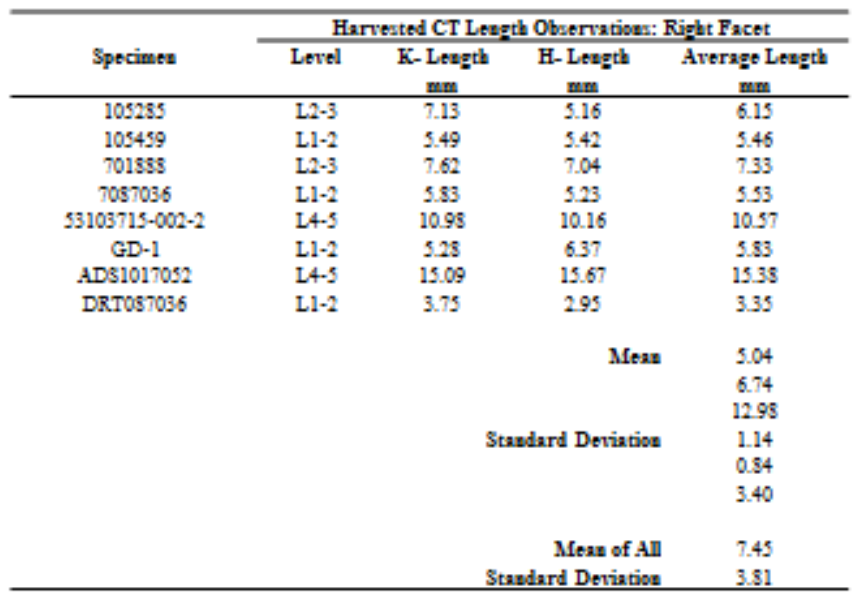

\begin{tabular}{|c|c|c|c|c|}
\hline \multirow[b]{2}{*}{ Specimes } & \multicolumn{4}{|c|}{ BF CT Lesgth Observations: Right Facet } \\
\hline & Level & K-Lesgth & H- Lesgth & Average Lexgth \\
\hline 105285 & L2:-3 & $\frac{\mathrm{mm}}{6.28}$ & $\frac{\mathrm{mm}}{6.05}$ & \\
\hline 105459 & $\mathrm{~L} 1-2$ & 1.58 & 1.47 & 1.53 \\
\hline 701898 & $\mathrm{~L} 2-3$ & 1.68 & 1.54 & 1.76 \\
\hline 7057036 & L1-2 & 3.28 & 3.07 & 3.18 \\
\hline $53103715-002-2$ & L4-5 & 10.35 & 10.42 & 10.39 \\
\hline GD-1 & $\mathrm{L} 1-2$ & 3.86 & 4.04 & 3.95 \\
\hline ADS1017052 & L4-5 & 10.01 & 9.39 & 9.70 \\
\hline \multirow[t]{8}{*}{ DRTOS7036 } & L1-2 & 1.13 & 1.01 & 107 \\
\hline & & & Mese & 243 \\
\hline & & & & $\begin{array}{l}3.96 \\
1004\end{array}$ \\
\hline & & & Standard Deviation & 136 \\
\hline & & & & 3.11 \\
\hline & & & & 0.48 \\
\hline & & & Mens of All & 4.72 \\
\hline & & & Standard Deriation & 3.67 \\
\hline
\end{tabular}

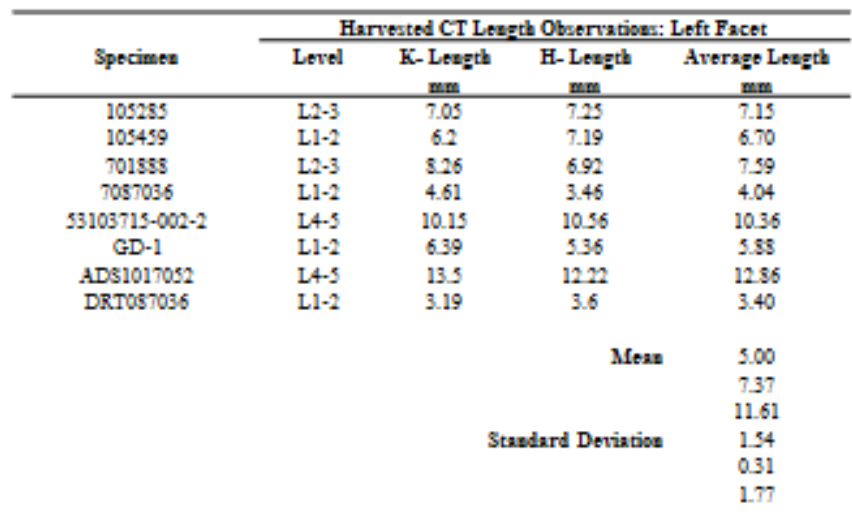

Mess of AII

7.24
3.13

Note: *Observations made by Dr. Hamid Shah and Karen Sedacki.

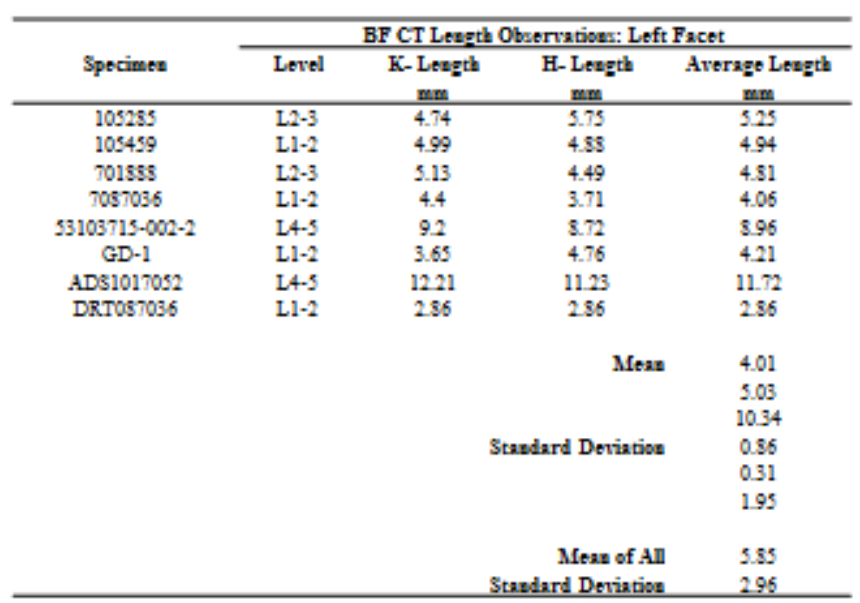


Table G-4. Calculated Preservation Percentages.

\begin{tabular}{cccc}
\hline & & \multicolumn{2}{c}{ Percentage of Preservation (\%) } \\
\cline { 3 - 4 } Specimen & Level & Left Facet & Right Facet \\
\hline 105285 & L2-3 & 73.4 & 100.3 \\
105459 & L1-2 & 73.7 & 28.0 \\
701888 & L2-3 & 63.4 & 24.0 \\
7087036 & L1-2 & 100.5 & 57.4 \\
$53103715-002-2$ & L4-5 & 86.5 & 98.2 \\
GD-1 & L1-2 & 71.6 & 67.8 \\
ADS1017052 & L4-5 & 91.1 & 63.1 \\
DRT087036 & L1-2 & 84.2 & 31.9 \\
Mean & & 80.6 & 58.8 \\
Standard Deviation & 12.2 & 29.9 \\
\hline
\end{tabular}




\section{VITA}

Karen Sedacki was born in Joliet, IL in 1985. She graduated from Lockport Township High School in 2003. She attended Illinois Institute of Technology, in Chicago, from which she received a Bachelor's of Science degree of Biomedical Engineering in May 2007. She enrolled in the University of Tennessee-University of Memphis Joint Program in Biomedical Engineering in the Fall of 2007, and joined the Biomechanics Laboratory in Spring of 2008. 